\title{
Circadian variability of the cardiovascular system in hypertension : therapeutic implications
}

Citation for published version (APA):

Oosting, J. (1998). Circadian variability of the cardiovascular system in hypertension : therapeutic implications. [Doctoral Thesis, Maastricht University]. Universiteit Maastricht. https://doi.org/10.26481/dis.19981127jo

Document status and date:

Published: 01/01/1998

DOI:

10.26481/dis.19981127jo

Document Version:

Publisher's PDF, also known as Version of record

\section{Please check the document version of this publication:}

- A submitted manuscript is the version of the article upon submission and before peer-review. There can be important differences between the submitted version and the official published version of record. People interested in the research are advised to contact the author for the final version of the publication, or visit the DOI to the publisher's website.

- The final author version and the galley proof are versions of the publication after peer review.

- The final published version features the final layout of the paper including the volume, issue and page numbers.

Link to publication

\footnotetext{
General rights rights.

- You may freely distribute the URL identifying the publication in the public portal. please follow below link for the End User Agreement:

www.umlib.nl/taverne-license

Take down policy

If you believe that this document breaches copyright please contact us at:

repository@maastrichtuniversity.nl

providing details and we will investigate your claim.
}

Copyright and moral rights for the publications made accessible in the public portal are retained by the authors and/or other copyright owners and it is a condition of accessing publications that users recognise and abide by the legal requirements associated with these

- Users may download and print one copy of any publication from the public portal for the purpose of private study or research.

- You may not further distribute the material or use it for any profit-making activity or commercial gain

If the publication is distributed under the terms of Article $25 \mathrm{fa}$ of the Dutch Copyright Act, indicated by the "Taverne" license above, 


\section{Circadian variability of}

the cardiovascular system in hypertension:

Therapeutic implications 


\section{CIP-DATA KONINKLIJKE BIBLIOTHEEK DEN HAAG}

Oosting, Jan

Circadian variability of the cardiovascular system in hypertension." Therapeutic implications / Jan Oosting.

Thesis Maastricht. - With ret.- With summary in Dutch.

ISBN $90-9012201-\mathrm{X}$

NUGI 743

Subject headings: chronopharmacology / autonomic nervous system regulation 


\section{Circadian variability of}

\section{the cardiovascular system}

\section{in hypertension:}

\section{Therapeutic implications PROEFSCHRIFT}

ter werkrijging van de graad van doctor aan de Universiteit Maastricht,

op gezag van Rector Magnificus, Prof. dr. A.C. Nieuwenhuizen Kruseman, volgens het besluit van het College van Decanen, in het openbaar te verdedigen, op vrijdag 27 November 1998 op 12.00 uur

door

\section{Jan Oosting}

geboren te Zutphen in 1963 
Promotor:

Prof. dr. H.A.J. Struijker Boudier

Co-promotor:

Dr. B.J.A. Janssen

Beoordelingscommisie: Prof. dr. P. de Leeuw (voorzitter)

Prof. dr. B. Lemmer (Heidelberg, Duitsland)

Prof. dr. J-L Elghozi (Parijs, Frankrijk)

Prof. dr. D.W. Slaaf

D. L.L.H. Peeters

Het onderzoek beschreven in dit proefschrift is mede mogelijk gemaakt door financiele bijdragen van de Nederlands Hart Stichting (NHS 90.258) en ALZA Corporation, Palo Alto, California, USA.en ALZA

Ook wil ik graag de Dr. Saal van Zwanenberg Stichting bedanken voor de bijdrage aan het uitgeven van dit proefschrift. 


\section{Contents}

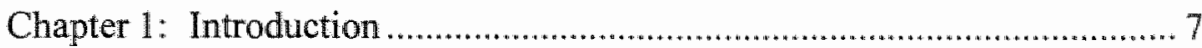

Chapter 2: Hemodynamic basis of oscillations in systemic arterial pressure in conscious rats

Chapter 3: Validation of a continuous baroreceptor reflex sensitivity index calculated from spontaneous fluctuations of blood pressure and pulse interval in rats

Chapter 4: Autonomic control of ultradian and circadian rhythms of blood pressure, heart rate, and baroreflex sensitivity in SHR

Chapter 5: Circadian and ultradian control of cardiac output in spontaneous hypertension in rats

Chapter 6: Time-Dependent Efficacy of Antihypertensive Agents in Spontaneously Hypertensive Rats

Chapter 7: Circadian-phase dependent pharmacodynamics of angiotensin converting enzyme inhibitors in spontaneously hypertensive rats

Chapter 8: General discussion.

Chapter 9: Nederlandse samenvatting

Dankwoord

Curriculum Vitae 



\section{Chapter 1 Introduction}

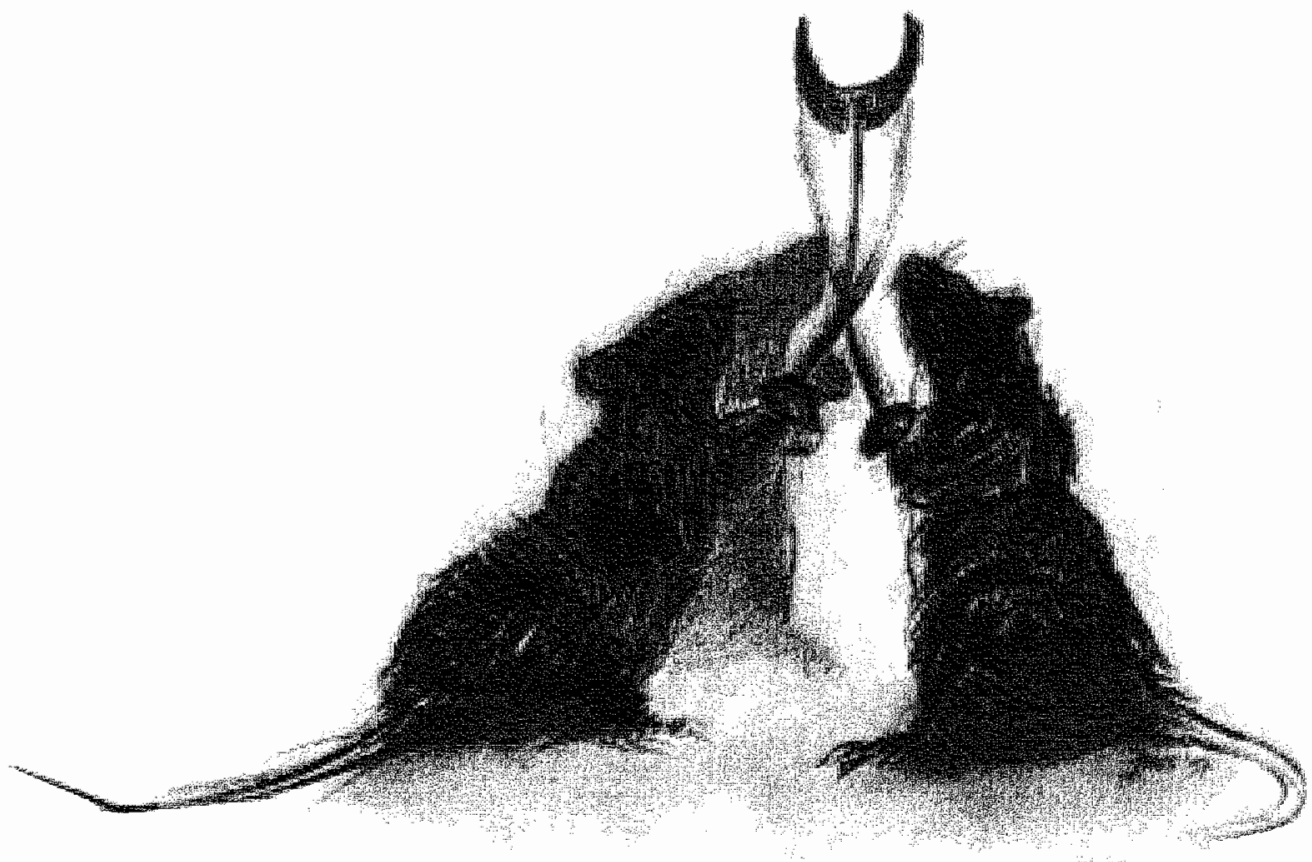


Chapter I 


\section{Introduction}

In all life forms most biological variables show different values depending on the time of day'. The explanation for these circadian, or about 24 hour, differences must be sought in the adaptation to changing external stimuli throughout the day ${ }^{2}$. The differences between darkness and light are possibly the strongest amongst these stimuli. Many organisms relate their level of activity to the level of light intensity. Therefore, most organisms are entrained to the 24-hour light/dark cycle.

In the course of evolution several mechanisms have developed which show endogenous circadian rhythmicity in the absence of external time clues. Molecular mechanisms have been identified that influence the circadian clock in the fungus Nerrospora crassa ${ }^{3}$ and the fruit fly drosophila melanogaster ${ }^{4}$. In Neurospora crassa the expression of the gene 'frequency' shows a circadian rhythm. When mutations in this gene appear the circadian behaviour is changed (see Figure 1.1). Both shortening and extending of the period is possible ${ }^{3}$. In drosophila melanogaster a pair of proteins, timeless and per, has been shown to cause circadian behavioural rhythms which disappear when mutations in the genes of these proteins occurs. These proteins are entrained to the light dark cycle because the timeless protein degrades in the presence of light.

In mammals a small part of the hypothalamus in the brain, the supra chiasmatic nucleus ( $\mathrm{SCN}$ ), has been shown to be involved in many circadian rhythms ${ }^{6.7}$. In the

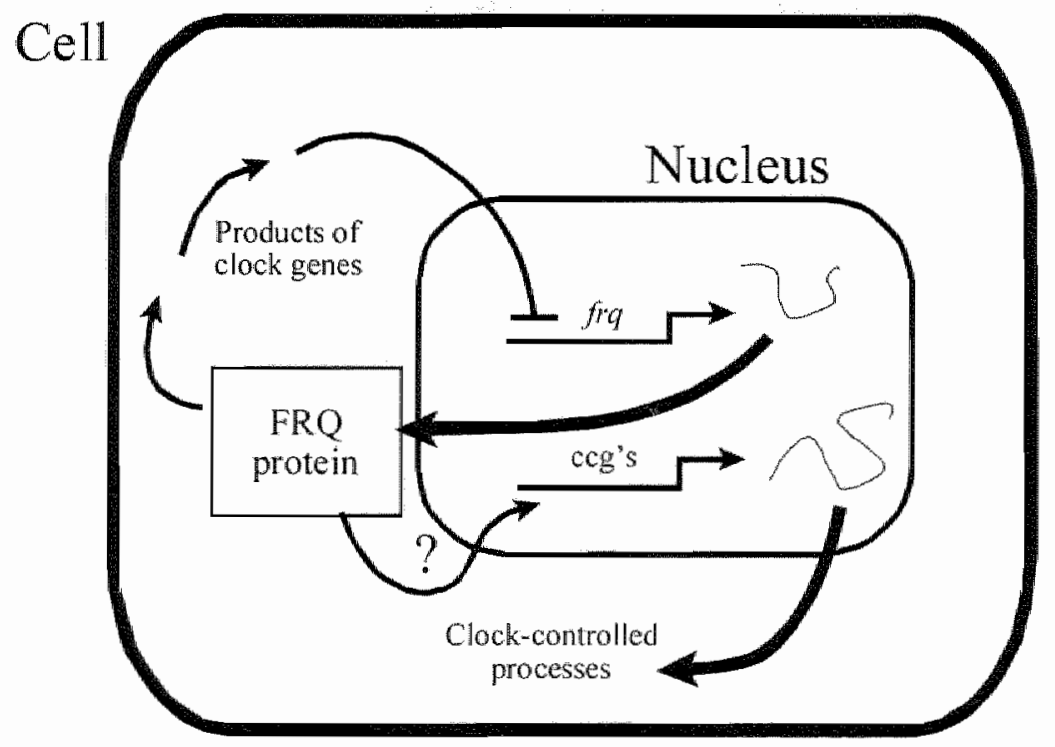

Figure 1.1 A schematic diagram of a cell expressing a circadian wy hm. The fro gene encodes the FRO protein that has multiple roles, of which the best established is to regulate the amount of frq mRNA as a part of a negative feedback loop that constitutes the circadian oscillator. The or her is to activate clock-cowrolled genes (ccg s) (adapted from Aronson') 
absence of external clues the SCN is able to maintain a circadian pattern. The supra chiasmatic nucleus is symchronized or entrained by the actual dark/light pattern via nervous comections from the retmal cells in the eye. Light therapy is already used to cause phase-shift in disorders lke jet lag and shift work sleep disturbance. Extraocular light-sensitive sites capable of phase shifing circadian patterns have recently been showin where light pulses on the knee were able both to phase advance, and phase delay the crrcadian pattern of body temperature. This method could be used to give light exposute during the night, when people are usually asleep. Other processes are able to thtrain the SCN too, like feeding behaviour and physical activity. Melatonin, a hormone produced in the pineal gland, plays a key role in the genesis of several circadian rhythms. The SCN has binding sites for melatonin", and melatonin may be used to manipulate the circadian clock, for instance to decrease to effects of jet-lag ${ }^{10}$. The presence of endogenous circadian rhythms is important for the anticipation of daily recurring activities. For instance, the organism can prepare itself for an increase in physical activity when the day starts, even when it is still dark"1, in stead of only reacting to clanging conditions.

The time of day has been shown to be important in several pathophysiological states. For instance, asthmatic episodes are more frequent in the night, the susceptibility of cancer cells for chemotherapy shows day-night differences. Hypertension-related events such as myocardial infarction show a peak incidence in the early moming $^{3 .}$. In the case of asthma and cancer this has lead to changes in therapeutic regimens in order to improve pharmacological therapy ${ }^{13}$. The timing of anti-hypertensive drugs is not yet part of the World Heall Organization guidelines for the management of hypertension ${ }^{\text {it }}$, although recently drug formulations have been introduced which are designed for the timed delivery of anti-hypertensive agents 15.16 .

\subsection{Cardiovascular function}

The cardiovascular system is responsible for the supply of nutrients and oxygen to different parts of the body and the discharge of waste products. The heart is the punp which provides the anergy to distribute blood to all parts of the body. Blood is distributed to all organs through arteries. In capillaries nutrients and waste products aro exchanged between blood and the organ, and through veins the blood is carried back to the heart.

There are number of parameters to describe the function of the cardiovascular system. Cardiac output and total peripheral resistance determine mean arterial pressure. Cardac output is the total blood flow from the heart and is detemined by heart rate and stroke volume. The number, caliber, and geometry of small arteries and arterioles mainly determine total peripheral resistance.

In orcle to provide a steady flow of blood to the body blood pressure must be tightly regulated ${ }^{17}$. There are several mechanisms that control blood pressure. On the short term, in the order of seconds to minutes, the autonomic nervous system, by means of the baroreflex ${ }^{48-30}$, plays a major role in regulating arterial blood pressure. Pressure sensors in the carotid sinus and the arch of the aorta detect changes in blood pressure. Brain centres in the medulla oblongata correct these blood pressure changes 
by changing heart rate and the resistance in small arteries. More recent studies suggest that nitric oxide plays a role in short-term blood pressure control as well. When blood pressure increases, shear stress in the arterial wall increases too ${ }^{2123}$. This in turn leads to release of nitric oxide, a potent vasodilator, thereby reducing blood pressure. On a longer time frame, of minutes to hours, humoral factors and hormones like the renin angiotensin system, vasopressin, bradykinin, and atrial natrituretic peptide play an inportant role 24.25 . On the long term, in the order of days to weeks, blood pressure is controlled by the kidney, which keeps the amount of body fluid input and output balanced ${ }^{262 x}$. On a timescale beyond that for thud volume control, structural changes in the heart and in the vascular architecture play an important role in cardiovascular control $29+32$.

Besides mechanisms to control blood pressure, the body also has mechanisms to control blood flow to separate organs. First there are auto-regulatory mechanisms that keep flow through organs relatively constant when pressure changes, by increasing the resistance when blood pressure rises and vice versa ${ }^{33}$. On the other hand flow to an organ must increase when that organ has an increased metabolic demand, for instance flow to muscles may increase several times during physical exercise. 34 . The exact mechanisms that control local organ flow are a topic of on-going research, but the myogenic response and endothelium derived vaso-active substances like nitric oxide, endothelin and prostacyclin seem to play an important role ${ }^{35}$.

The mechanisms described here interact on several levels ${ }^{33.35 .3 *}$. Therefore it can be difficult to differentiate between the effects of different mechanisms, especially in whole animal preparations or human subjects. Blockade, or stimulation, of one mechanism is bound to be followed by reactions of another regulatory mechanism. The redundancy of control mechanisms for blood pressure is a sign for the importance of blood pressure control for the organism.

\subsection{Variability in cardiovascular parameters}

A considerable variability exists in the core parameters of cardiovascular functhon " Nariability can be caused by internal sources, like the control mechanisms regulating cardiowascular function, or circadian riythms, or by external sources, like positional changes or cardiovascular active drugs. A part of the variability can be attributed to regular oscillations. These oscillations are divided into categories, de pendent upon their period. Ultadian thythms have a period shorter than a day. Circadian rhythms have a period of about one full day, and infradian rhythms have periods of more than one day.

\subsubsection{Ultradian rhythmicity in cardiovascular function}

When the frequency content of cardiovascular parameters is examined by spectral analysis, a few frequencies are predominantly present ${ }^{35,41}$. If the spectral power in a frequency band is caused exclusively by a certain regulatory mechanism, the technique of spectral decomposition of time signals can be used to study that mechanism without having to isolate a part of an organism. Therefore a lot of studies have been devoted to 
assign physiological mechanisms to certain frequencies. The peaks most commonly studied with spectral analysis are those that ara related to actions of the autonomic nervous system ${ }^{35}$. These are normally divided in a high frequency range and a low frequency range. The parasympathetic nervous system can react fast enough on pressure fluctuations caused by respiration and is usually responsible for the fastest or high frequency oscillations in heart rate (around 0.25-0.3 Hz in humans, and about 1.2 Hz in rats). There is still debate on the origin of low frequency oscillations in blood pressure ( $0.1 \mathrm{~Hz}$ in humans, about $0.4 \mathrm{~Hz}$ in rats). These could be caused by the sympathetic nervous system, or by a combination of parasympathetic and sympathetic influences. Local regulatory systems, and mechanical factors like breathing, may interact with arterial pressure fluctuations in this frequency range ${ }^{21.42,43}$

Sometimes also even slower oscillations of blood pressure are identified of 20 minutes ${ }^{4,4}$ or with periods between 1 and 2 hours ${ }^{45.46}$ but in general, an inverse linear relationship can be found between the logarithm of the frequency and logarithm of spectral power of blood pressure and heart rate ${ }^{47-49}$ in this lower frequency range. This so called 1/f characteristic indicates the absence of a single dominant regulatory mechanism and is suggestive of non-linear system characteristics with multiple regulatory processes acting on overlapping time scales ${ }^{50}$

\subsubsection{Circadian rhythmicity in cardiovascular function}

All hemodynamic variables show differences between day and night. For heart rate and blood pressure, which are relatively easily measured, it has long been known that they are higher during the light period in diurnal animals (and humans) ${ }^{51.52}$, and that they are higher during the dark period in nocturnal animals. The circadian rhythm of blood pressure or heart rate has not yet been shown to persist under constant light conditions in humans, but rats show a circadian period of blood pressure and heart rate of longer than 24 hours in constant darkness ${ }^{5.3}$. The daily variations in heart rate and blood pressure are determined by physical activity mostly ${ }^{54.55}$. In shift-workers the circadian pattern of blood pressure is adapted to the working pattern ${ }^{56,57}$. However, subjects that are kept supine continuously, still exhibit circadian variations of these parameters ${ }^{5 *}$, showing the prevalence of an endogenous rhythm. During 6 weeks of $6^{\circ}$ head-down tilt the circadian variation of diastolic blood pressure disappears almost completely within a few days, the circadian variation of systolic blood pressure is halved, while the circadian variation of heart rate is not affected ${ }^{60}$. Cardiac output and stroke volume also exhibit a circadian rhythm with higher values during the active period ${ }^{61-63}$. Because catdiac ontput decreases relatively more at night than blood pressure, total peripheral resistance is higher during the resting period ${ }^{62.64}$. The circadian variation in vascular resistance of individual organs may differ between organs because the relative flow distribution varies throughout the day ${ }^{65}$. For instance in normotensive lumans, forearm peripheral resistance is higher during the active phase of the $\mathrm{day}^{66}$, whereas total peripheral resistance is estimated to be lower at that time $\mathrm{e}^{63}$. These differential distributions can be explained by the sympathetic control of musclle vascular beds ${ }^{67}$

Regulatory mechanisms important for cardiovascular function show oscillatory behaviour too. In humans renin is thy thmically released during sleep ${ }^{68}$. Circadian vari- 
ations are also seen. The balance between the sympathetic and the parasympathetic part of the autonomic nervous system is shifted to the sympathetic part during the active period of the day when blood pressure and heart rate are high, whereas the parasympathetic part is dominant during the resting period of the day ${ }^{60}$. Circadian patterns of plasma noradrenaline are synchronous to the blood pressure pattern in humans and rats ${ }^{70-72}$. The gain of the baroreflex is higher during the resting period ${ }^{73}$. The hormones with cardiovascular pressor effects show a circadian thythm that is opposite to the blood pressure profile. In humans the renin angiotensin system, vasopressin, and cortisol all have their highest activity during the night and early momingt. 74.77. In renin transgenic rats (TGR) even an inverted circadian blood pressure pattem has been observed ${ }^{78}$. The high levels of these hormones during inactivity could be especially important in order to retain fluid during the resting period, and keep diuresis at a low level. Endocrine mechanisms that lower blood pressure are generally more active during the resting phase, and these mechanisms are therefore synchronized to the circadian thythm of blood pressure. Atrial natriuretic peptide shows circadian rhythns with higher values during the resting phase ${ }^{64.74}$. Nitric oxide-guanylyl cyclase expresses higher activity in the aorta, and administration of L-NAME produces larger increases in blood pressure during the resting period in rats ${ }^{80}$, showing that the blood pressure lowering effect of nitric oxide is synchronized to the blood pressure pattern.

The excretion of fluid and minerals by the kidney shows a strong circadian rhythm. The excretion of water and sodium, and the ingestion of water is highest in the active period, and lower during sleep ${ }^{81-84}$. In addition to blood pressure, the excretion of fluid by the kidney is intluenced by a large number of factors, like the sympathetic nervous system ${ }^{3: 5}$, the renin-angiotensin system, aldosterone, and vasopressin. These systems all have their own circadian thythm as well ${ }^{86}$. It is therefore difficult to obtain information on the circadian variability of the direct influence of pressure on renal fluid excretion. In rats it has been shown that urinary excretion of water, sodium and potassium show a circadian rhythm both in blind rats and in rats under constant illumination ${ }^{8 \%,}$ furthermore it lasts about a week before the circadian pattern of excretion is synchronized to a phase-shift of 12 hours of the light-dark pattern..

\subsubsection{Infradian rhythmicity}

A number of rhythms have periods longer than a day. The most important of these are weekly, about monthly, and yearly rhythms. Weekly or circaseptan rhythms can be attributed to the human inclination to have one-s sleep oul, a tendency to delay" bedtime in the weekend, and a weekly working schedule. This causes a phase delay of the circadian system of about half an hour ${ }^{8 \%}$. On the other hand, circaseptan rhythms in sodium excretion have been found in laboratory animals that were on a daily paitern without changes in the weekend ${ }^{\%}$. The risk of myocardial infarction is also unevenly distributed throughout the week. The incidence is highest on Monday morning, especially in the working population". Monthly rhythms in cardiovascular function can be observed predominantly in women. Within the menstrual cycle large variations of oestrogen occur, a hormone with important cardiovascular properties. A yearly cycla has been found in the occurrence of angina pectoris. This effect is stronger in regions with clear climatic differences between the seasons, since this phenomenon seems to be 
mainly caused by differences in tempetature between the seasons ${ }^{92-44}$.

\subsection{Hypertension}

Among the human population a considerable variation exists in the level of arterial blood pressure. Only at relatvely high levels blood pressure in itself causes symptoms like head ache and retinal bleeding. Prospective epidemiological research has shown that blood pressure is positvely related to the occurrence of cardiovascular disease ${ }^{93.65}$, and it is therefore that high blood pressure is treated, even at levels at which no acute symptoms occur.

Hypertension, defined as a resting diastolic blood pressure of more than $95 \mathrm{mmHg}$ and/or a systolic blood pressure above $160 \mathrm{mmHg}^{1 / 4}$, is very common in westernised countries, and cardiovascular disease is the most common cause of death. Through an increased mechanical load on the heart and the arterial side of the vascular system hypertension causes left wentricular and arterial hypertrophy, and is a main factor in the pathogenesis of atherosclerosis. Coronary atherosclerosis again is the main cause of myocardial infarction. High blood pressure itself is the main risk factor for stroke and renal failute ${ }^{\text {n? }}$.

A cause for hypertension can be found in about $10 \%$ of cases. Common causes for these secondary forms of hypertension are adrenal, renal, or renovascular disease, or drug related causes. This means that in about $90 \%$ of cases the aetiology of hypertension is unknown. This most common form of hypertension is called primary or essential hypertension. Although the actual cause of essential hypertension is whknown, a number of risk factors have been identified. Genetic predisposition, environmental factors (i.e. high salt intake and high alcohol consumption), and psychological stress have all been shown to increase the risk for hypertension ${ }^{27}$.

From a hemodynamic point of view hypertension is characterized by high blood pressure, high total peripheral resistance but normal cardiac output, heart rate and stroke volume" There are several theories on the primary defect to explain the increase of total peripheral resistance in hypertension.

The first theory was formulated by Borst $\&$ Borst-de Geus and Guyton and puts emphasis on the kidney ${ }^{26}, 27$. Improper handling of volume and/or sodium leads to overfilling of the vascular system. This high intravascular volume leads to an increase in cardiac output. Autoregulatory mechanisms in the organs prevent over perfusion by increasing their resistance resulting in increased blood pressure. Because the kidney excretes more water and sodium when blood pressure is high, the balance between fluid input and output is restored at the expense of a higher blood pressure.

The second theory proposes increased sensitivity of the vascular system to vasoconstricting agents with associated structural changes of the resistance arteries as the primary defect $2 \%, 40 \%$. Hypertrophied vessels are hypersensitive to vasoconstricting agents and this leads to a form of positive feedback whereever less pressure increasing influence is capable of increasing blood pressure more.

More recently a third theory has been postulated that attributes the increase in total peripheral resistance to a decreased number of vessels in the microcirculation. Both regression of existing vessels, and insufficient growth of vessels during develop- 
ment ${ }^{10100}$ can contribute to this phenomenon of rarefaction. Also it has been shown that babies with low birth weight have an increased risk for hypertension later in life ins

\subsection{Circadian aspects of hypertension and cardiovascular risk}

The development of devices to automate blood pressure measurements has made it possible to study circadian aspects of hypertension ${ }^{\text {to }}$. The use of these dovices has identified a form of hypertension that is characterized by an increase of blood pressure by psychologically stressful events ${ }^{107}$. The blood pressure pattern during normal every day activities is comparable to normotensive subjects, but for instance during the interview, and examination by a doctor blood pressure rises. This somalled 'white coat hypertension" turns out to be rather benign in nature ${ }^{\text {los }}$.

In essential hypertension the circadian variability of hemodynamic parameters is Jargely preserved. However there is a subset of the hypertensive population in which blood pressure does not fall during sleep, the so-called non-dippets. Also in secondary forms of hypertension the difference between day and night blood pressure is usually small 109-112. Non-dippers have an increased morbidity of cardiovascular disease and end organ damage, like left ventricular hypertrophy and retinopathy, compared to hypertensive subjects that do show a fall in blood pressure during sleep ${ }^{113.115}$. It is not yet clear what the causal relation is in this observation. It can be either that the non-dipping phenomenon is hamful, or that end-organ damage leads to non-dipping. Extreme dipping may predispose to brain damage in elderly hypertensive patients ${ }^{16}$, and thus nondipping may be a protective reaction of the body to preserve perfusion pressure to the brain. Alternatively non-dipping may be caused by the increased importance of the renin-angiotensin system in some forms of hypertension with its higher pressor actiwity during sleep. The circadian variability of heart rate and cardiac output is hardly affected by hypertension ${ }^{117.11 \%}$.

The incidence of cardiovascullar events like myocardial infarction, stroke, and sudden death shows a circadian variation too. These events occur most often in the early morning 12.1\%-124. A number of physiological processes have a circadian rhylhm that can contribute to the increased incidence of cardiovascular events in this period. Blood pressure and heart rate rise in this period of the day ${ }^{25}$. Together with an increase in blood pressure variability ${ }^{\sharp 26}$ through a decrease in baroreflex function this imposes an increase in mechanical stress to the wascular wall, and makes atherosclerotic plaques more susceptible to rupture. Platelet aggregability peaks in this period loo ${ }^{127}$. A concur"rent decrease in the counteracting activity of plasminogen activator 28,129 , makes the formation of a blood clot more easy. Cortisol shows peak levels during the early morning too ${ }^{13 t_{13}}$, increasing the sensitivity of the coronary arteries for the vasoconstrictive properties of the catecholamines, which show an increase in plasma levels at this period $100^{127}$.

Although most evidence supports the fact that the patterns of these physiological processes are caused by the increase in physical activity during the early morning, it can not be ruled out that these rhythms are partly endogenous ${ }^{1 \%} .1 \%$. The uncertanly 
about the origin of circadian patterns is one of the fundamental topics in chronobiologic research. Most circadian patterns are composed of an endogenous component, driven by an internal oscillator, and so called masking effects, direct reactions to changes in the environment ${ }^{3}$. The combination of these effects is probably beneficial to the individual. The endogenous thythm can adapt the organism to predictable changes in the enwironment, while the masking effects react to unpredictable changes.

\subsection{Treatment of hypertension: risk reduction}

Metawanalysis of several interventional trials has shown that treatment of moderate hypertension decreases the incidence of both stroke and coronary heart disease ${ }^{34}$. The reduction in stroke is much more pronounced than the reduction in coronary heart disease $^{13 *}$, and the morbidity of cardiovascular disease is still higher in treated hypertensive subjects, than it is in normotensive subjects ${ }^{135139}$. Explanations for the partial failure of anti-hypertensive treatment to reduce cardiovascular morbidity are 1) Blood pressure is still higher in treated hypertensive subjects, than in the normotensive population $^{136}$. This can be caused by non-compliance to therapy ${ }^{139}$. 2) The anti-hypertensive agents used in these studies were mainly diuretics and beta blocking drugs which can have adverse effects on lipid and glucose metabolism ${ }^{\text {tho }}$. More modern drugs like calcium antagonists or ACE-inhibitors do nol have this adverse effect, or even improve glucose and lipid metabolism. Data of prospective studies of these drugs on mortality is not yet available ${ }^{\text {14t }}$. 3) Structural damage or changes like left ventricular hypertrophy and arterial stiffening by hypertrophy or atheroscletosis in the period before treatment may be irreversible. 4) Other risk factors contributing to (the development of) hypertension or the risk for cardiovascular morbidity, like smoking, high salt intake, and high cholesterol level, may still be present during pharmacological treatment.

It appears important that hypertensive subjects should be treated so that diastolic blood pressure is between 85 and $90 \mathrm{mmHg}$. It is reported that reduction of blood pressure below this walue increases cardiovascular morbidity again, the so-called Jshaped phenomenon ${ }^{136}$. It seems that in the untreated population this J-shaped phenotnenon does not occur and the morbidity from cardiovascular disease levels out below $90 \mathrm{mmHg}^{142}$, while in treated hypertension morbidity increases when blood pressure is lowered below $85 \mathrm{mmHg} \mathrm{g}^{136,137.143}$. The explanation for the J-shape could be that perfusion of vital organs is compromised by low pressure, because of atherosclerosis or hypertrophy of the arterial system. The term essential hypertension is appropriate in these cases, because high blood pressure is a life saving adaptation of the body'st.

In recent years some hypertension management strategies have been developed which are focussed more toward the individual patient. Therapy is initiated and evaluated dependent on absolute risk for cardiovascular morbidity, by the presence of risk factors and established end-organ damage ${ }^{145,146}$.

\subsection{Treatment of hypertension in relation to time of day}

The realization that cardiovascular incidents are most prominent in the early 
moming has generated interest in the amount of protection that anti-hypertensive drugs give at this period of the day ${ }^{147}$. 148.

Using ambulatory blood pressure devices many studies have been carried ont with various classes of anti-hypertensive drugs lo assess the effects on the 24-hour blood pressure pattern. The general conclusion of these studies is that anti-hypertensive drugs with a sufficient long half-life all lower blood pressure throughout the day and night. The circadian pattern of blood pressure during treatment resembles the pattern during placebo, although at a lower level. A meta-analysis to compare reduction of blood pressure during the day and night-time showed no difference for beta blockers and ACE-inhibitors, and with calcium antagonists blood pressure was $2 \%$ more decreased during the day-time ${ }^{\text {ly }}$ (Table 1.1).

Table 1.1 Compilation of the studies in meta-analysis of Vooget et al w . Day and night blood pressure reduction after antihypertensive treatment.

\begin{tabular}{|c|c|c|c|c|c|c|}
\hline \multirow[t]{2}{*}{ Class of drug } & \multirow[b]{2}{*}{ Studies } & \multirow[b]{2}{*}{$\mathrm{N}$} & \multicolumn{2}{|c|}{$\mathrm{SBP}_{\mathrm{knd}}(\mathrm{m}$ m) $\mathrm{HI})$} & \multicolumn{2}{|c|}{ DBP $P_{n: a}(\mathrm{~mm} / \mathrm{g})$} \\
\hline & & & Day & Nigint & Day & Nigh \\
\hline Beta-blockers, (Once) & 9 & 153 & 9.8 & 8.6 & 130 & 10.7 \\
\hline Beta-blockers $(2-3 x)$ & 5 & 67 & 13.1 & 10.6 & 15.8 & 13.8 \\
\hline Calcium antagonists (once) & 14 & $2 \| 3$ & 10.6 & 8.2 & 10.8 & 9.3 \\
\hline Calcum antagonists $(2-3 \times)$ & is & 164 & 11.5 & 11.1 & 12.7 & 10.1 \\
\hline ACE inhibitors (once) & 8 & 164 & 8.9 & 7.8 & 11.1 & 8.7 \\
\hline ACE inhibitors $(2-3 x)$ & 4 & 54 & 11.1 & 10.1 & 12,0 & 11.7 \\
\hline
\end{tabular}

Once: Once daily dosing: 2-3x: 2-3 times daily dosing; Studies: number of studies in this class; $N$ : total number of subjects. Values are weighted averages.

The United States Food and Drug Administration has introduced guidelines for the registration of new anti-hypertensive drugs which require a minimum trough-topeak ratio 150 152. The trough-to-peak ratio is calculated by dividing the remainder of the blood pressure lowering effect just before a new dose by the maximum blood pressure lowering effect of a drug (Figure 1.2). The trough-to-peak ratio was designed to ensure efficacy at the end of the dosing interval, without having to resort to inappropriately high doses. Trough-to-peak ratio is dependent on factors like ellimination half-time, type of elimination, pharmacokinetic-dynamic properties, dose, and dosing interval ${ }^{153}$. There has been considerable discussion on the implementation and value of the troughto-peak ratio ${ }^{154}$.155, also because it proves difficult to determine the peak effect of drugs in relation to the dosing time and plasma concentrations of drugs ${ }^{156}$. The frequency of blood pressure measurements must be high enough to detect the peak effect reliably ${ }^{153}$.

The fact that blood pressure and heart rate pattern are comparable in treated and non-treated subjects is rather surprising since there are numerous factors which can produce differences in the efficacy of these drugs throughout the day. Pharmacokinetics may vary throughout the day by variations in absorption, distribution, or clear- 


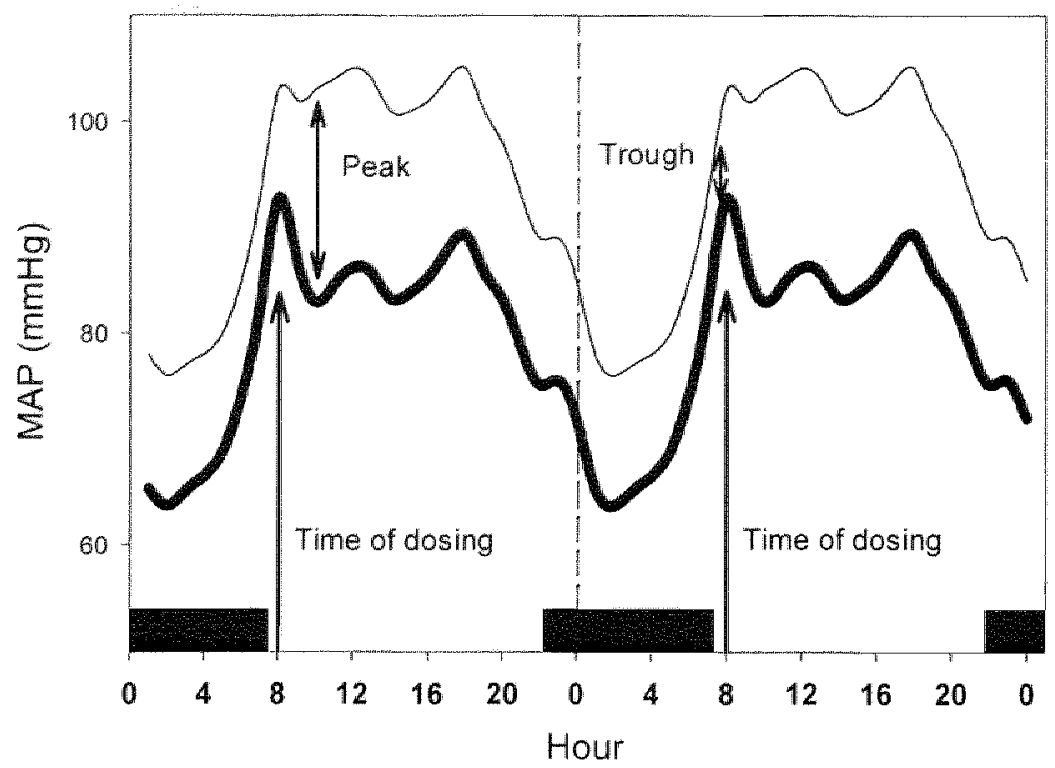

Figure 1.2 Trough peak ratio for the calculation of trough-toweak ratio treament effect is important. The trough walue is the lowest difference between control blood pressure and blood pressure during treatment, which is wswally in the period just before the new dose is taken. The peak value is taken at the time of the maximum blood pressure lowering effect. This time point is dependent on the ding and formulation used. The measurenent of blood pressure must be sufficienly often in order to ensure that the maximum blood pressure lowering effect is really found

ance ${ }^{15 \%}$. 15:8 Furthermore, the responsiveness of effector organs or receptor sensitivity to drugs may differ during the day ${ }^{5 \%}$. Lastly, the physiological response to the changes induced by the drugs may show day-night differences ${ }^{160-162}$.

The development of the trough-to-peak ratio has focussed attention on a flat anti-hypertensive profile of drugs, but questions remain about the desirability of such a profile 163.164 . It could be advantageous to specifically target treatment to the high-risk period of the early morning besides being effective for 24 hours"s

Current objectives for pharmacological anti-hypertensive therapy include $\|$ ) 24 hour control of blood pressure, also during the early moming rise in blood pressure. 2) A once daily dosing regimen to improve compliance to therapy. 3) Absence of drug related side effects; since hypertension is not a disease itself, it merely increases the risk for cardiovascular morbidity in the future. There is still room for improvement of anti-hypertensive therapy. The uneven daily distribution of cardiovascular events related to hypertension makes this a target in therapy that has not been explored fully.

\section{Use of animal models to study circadian rhythms in essential hypertension}

Animal research has a number of advantages over research in human subjects in the study of hypertension. Small size and a short life span make it easier to study the 
natural history and pathophysiological alterations of disease. Furthermore in is possible to use interventions and experimental deteminations that are not possible in humans. The genetic homogeneity and expermental control over the enviromment wake it possible to obtain high-grade results.

In order to translate findings from animal research to the human situation, care must be taken that the studied conditions or disease have comparable effects in the animal and the human population.

A number of animal models have been designed to study hypertension. These models involve a range of experimental procedures, such as (in)breeding, surgical interventions, genetic alterations, drug or hormone administration or exposure to noxious stimuli ${ }^{165}$. The spontaneously hypertensive rat (SHR) has been extensively used as a model for essential hypertension. The SHR was originally developed by inbreeding in 1963. Hemodynamics, vascular reactivity, sympathetic nerve activity, and levels of cardiovascular active hormones have all been shown to show a comparable effect in human essential hypertension and SHR ${ }^{\text {in6 }}$. Goldblatt first introduced the 2-kidney 1-clip mode ${ }^{16}$. During surgery the lumen of one renal artery is narrowed. This causes a lower pressure in the affected kidney, which secretes more renin in order to nomalize pressure in that kidney. The model refects hypertension as seen during renal artery stenosis in humans. In 1990 a new model of secondary hypertension was developed by the introduction of the mouse Ren-2 salivary gland renin gene into the genome of the rat ${ }^{\text {th: }}$. In these rats very high levels of renin are secreted, resulting in markedly elevated blood pressure levels.

Recent advances in genetic engineering in mice have also produced models of hypertension, especially with transgenic animals with human renin or angiotensingenes ${ }^{169}$. However because of the size of these animals long-term blood pressure measurements are not feasible yet.

In SHR and $2 \mathrm{~K}-1 \mathrm{C}$ circadian variability of blood pressure been shown to exhibit blood pressure patterns which are comparable with those in human hypertension 22.170. 171, although with a phase difference of about 12 hours because of the nocturnal nature of these animals, while Ren-2 TGR show an inverted circadian blood pressure pattern ${ }^{73}$.

In the present thesis SHR are used because it serves as a model of human hypertension in aspects under investigation in the studies. The neurohumoral status, the circadian variability of hemodynamic variables, and the response to anti hypertensive drugs is comparable to the effects seen in essential hypertension in humans.

\section{Aim of this thesis}

From the introduction it can be concluded that ant-hypertensive therapy can be improved. The uneven distribution of incidence of cardiovascular disease over the day makes this a target in therapy which has not been explored fully. In order to make fundamental changes in therapeutic strategies it is important to acquire knowledge of the basic mechanisms that are responsible for blood pressure control throughout the day. The autonomic nervous system seems to play a key part in the circadian variability of hemodynamic parameters. Levels of sympathetic activity and plasma levels of noradrenaline are synchronous to the blood pressure, and heart rate pattern. The chapters 
2-5 of the thesis are aimed at understanding the role of the autonomic nervous system in the regulation of short-, and long-term rhythms of blood pressure, heart rate, and cardiac output in hypertension. The second part of the thesis is devoted to timedependent treatment of hypertension (chapters 6 and 7 ).

The short-term variability of blood pressure has already been well established. In chapter 2 we have studied the short-term rhythms of regional and systemic blood flow, and the interaction between regional and systemic flow and blood pressure on this time scale.

Baroreflex function is one of the regulatory mechanisms of the autonomic nervous system. In humans and cats methods have been developed to measure baroreflex gain continuously from spontaneously occurring fluctuations in blood pressure and heart rate ${ }^{172.074}$. In chapter 3 we have developed a method in rats to determine baroreflex sensitivity from spontaneous changes in blood pressure and heart rate, in order to obtain this measure contimuously over 24 hours.

In hypertension the gain of the baroreflex is generally decreased ${ }^{175}$. In order to evaluate the effects of hypertension on 24-hour baroreflex control, baroreflex function was measured for 24 hours in normotensive and spontaneously hypertensive rats in chapter 4.

In chapter 5 , the relationship between cardiac output, blood pressure, heart rate, and total peripheral resistance was investigated over ultradian and 24-hour periods. Normotensive and hypertensive animals were compared under control conditions as well as during autonomic blockade.

A number of physiological processes have a circadian rhythm that increases the risk for cardiovascular events like myocardial infarction or stroke in the early morning. The accumulation of these risks at this period of the day may be synergistic. We hypothesize that it could be beneficial to desynchronize the circadian patterns of these processes. The study in chapter 6 was aimed at providing an insight into the timedependent effects of different classes of anti-hypertensive drugs. Chapter 7 presents the effects on circadian patterns of blood pressure in hypertensive rats by repeated, timed infusion of anti-hypertensive drugs affecting the renin angiotensin system during the transition from the sleeping to the active period.

Finally, chapter 8 is aimed at an integrative discussion of all studies presented in this thesis, with the implications towards anti-hypertensive treatment.

\section{References}

1. Rusak B, Zucker I: Neural regulation of circadian rythms. Am J Physiol 1979; 59:449526.

2. Halberg F, Good RA, Levine H: Some aspects of the cardiovascular and renal circadian systems. Circulation 1966; 34: 715-717.

3. Aronson BD, Johnson KA, Loros JJ, Dunlap JC: Negative feedback defining a circadian clock: autoregulation of the clock gene frequency. Sci 1994;263(5153): 15781584 .

4. Hardin PE, Hall JC, Rosbash M: Feedback of the Drosophila period gene product on circadian cycling of its messenger RNA levels. Noure 1990; 343(6258): 536-540.

5. Sehgal A, Price JL, Man B, Young MW: Loss of circadian behavioral rhythms and per RNA oscillations in the Drosophila mutant timeless. Sci 1994; 263: 1603-1606. 
6. Turek FW: Circadian neural rhythms in mammals. Am Rev phys ol 1985; 47:49-64.

7. Meijer JH, Rietveld: WJ: Neurophysiology of the suprachiasmatic circadian pacemaker in rodents. Phys Rev 1991; 69: 671-707.

8. Campbell SS, Murphy PJ: Extraocular circadian phototransduction in humans. Sci 1998: 279: 396-399.

9. Webb SM, Puig-Domingo M: Role of melatonin in health and disease. Chin Endocrin $1995 ; 42: 221-234$.

10. Dawson D, Encel N: Melatonin and sleep in humans. I Pinteal Res 1993; 15: $1-12$.

11. Moore-Ede MC: Physiology of the circadian timing system: predictive versus neactive homeostasis. Am f Physiol 1986; 250: R735-R752.

12. Muller JE, Ludmer PL. Willich SN, et al: Circadian variation in the frequency of sudden cardiac death. Circulation 1987; 75: 131-138.

13. Bruguerolle B, Lemmer B: Recent advances in chronopharmacokinetics: methodological problems. Life Sciences 1993; 52: 1809-1824.

14. Guidelines Subcommittee of the WHO/ISH Mild Hypertension Liaison Committee: 1993 Guidelines for the management of mild hypertension. Hypertension $1993 ; 22$ : 392-403.

15. Neutel JM, Alderman M, Anders RJ, Wever MA: Novel delivery system for verapamil designed to achieve maximal blood pressure control during the early morning period. Am Heart $J$ 1997; 132: 1202-1206.

16. White WB, Mehrotra DV, Black HR, Fakouhi TD, COER-Verapanil Study Group: Effects of controlled-onset extended-release verapamil on nocturnal blood pressure (dippers versus nondippers). Am I Cardiol \997; 80:469-474.

17. Cowley Jr AW: Long-term control of arterial blood pressure. Phys Rev 1992; 72: 231 300.

18. Wennergren $\mathrm{G}$ : Aspects of central integrative and efferent mechamisms in cardiovascular reflex control. Acta Physiol Scand 1975(Suppl. 428): 1-53.

19. Abboud FM: The sympathetic system in hypertension. Hypertersion 1982; 4(Suppl. 2): ] II-208-II-225.

20. Fritsch JM, Eckberg DL, Graves LD, Wallin BG: Arterial pressure ramps provoke linear increases of heart period in humans. Am I Physiol 1986;251: R 1086-R 1090.

21. Just $A$, Witmann $U, N a f z B$, et al: The blood pressure buffering capacity of nitric oxide by comparison to the baroreceptor reflex. Am J Physiol 1994; 267: H52 I-HS27.

22. Nafz B, Just A, Stauss HM, et al: Blood-pressure variability is buffered by nitric oxide. J Auton Nerv Syst 1996; 57:181-183.

23. Persson PB, Baumann JE, Nafz B, Wittman U, Kirchheim HR: Phasic and 24 h blood pressure control by endothelium-derived relaxing factor in conscious dogs. Am I Plysiol 1992; 262: H1395-H/400.

24. Brunner HR: Rolle of vasoactive peptides in blood pressure control. I Hum Hypertens $1993 ; 7: 375-381$.

25. Saavedra JM: Brain and Pituatary angiotensin. Endocrine Rew $1992 ; 18: 329-380$.

26. Borst JGG, Borst-De Geus A: Hypertension explained by Starling's theory of circulatory homeostasis. Lancet 1963; 1:677-682.

27. Guyton A: The surprising kidney-fluid mechanism for pressure control-Its infinite gain! Hypertension 1990; 16: 725-730.

28. Hamlyn JM, Blaustein MP: Sodium chloride, extracellular fluid wolume, and blood pressure regulation. Am J Physiol 1986; $20: 1563-\mathrm{f5} 75$.

29. Folkow B: "Structural factor" in primary and secondary hypertension. Hypertension 1990; 16:89-101.

30. Struijker-Boudier HAJ, Smits JFM, De Mey JGR: Pharmacology of cardiac and vascular remodeling. Annu Rev Pharmacol Toxicol 1995; 35:509-539. 
31. Mulvany MJ, Aalloer C: Stucture and function of small arteries. Phys Rev 1990; 70: 921.961 .

32. Hoagerty AM: Structural changes in resistance arteries in hypertension. In Zanchett: A, Mancia $G$ (eds): Handbook of hyperiension, w. 17: Pathophysiology of hypertension, Elsevier Science B. V. Ansterdam, 1997: 426-437.

33. Cowley Jr. AW, Hinojosja-Laborde C, Barber BJ, Harder DR, Lombard JH, Greene AS: Short-tem autoregulation of systemic blood flow and cardiac output. Nips 1989; 4:21. 19225 .

34. Rowell LB, Defry $\mathbb{I}-\mathrm{M}$, Blackmon $\mathbb{R}$, Wyss $\mathrm{C}$ : Importance of the splanchnic vaseular bed in human blood pressure regulation. J Appl Physiol 1972; 32: 213-220.

35. Persson PB: Modulation of cardiovascular control mechanisms and their interaction. Phos Rev 1996; 76:193-244.

36. Rowell LB, O'Leary DS: Reflex control of the circulation during exercise: chemorellexes and mechanoreflexes. I Appl Physiol 1990; 69:407-418.

37. Brooks WL, Osbon JW: Homonal-sympethetic interactions in long-term regulatin of arterial pressure: an hypothesis. Am J Physiol 1995; 268: R1343-R1358.

38. Chaouloff : Physiopharmacological interactions between stress homones and central serotonergic systems. Brain Res Rev 1993; 18:1-32.

39. Conway I: Blood pressure and heart rate varability. J Hypertens 1986; 4: 261-263.

40. Littler WA, Wesi MJ, Honout AJ, Sleight P: The variability of blood pressure. Am Heart 1978; 95: 180-186.

41. Mancia G, Parati G, Di Rienzo M, Zanchetti A: Blood pressure variability. In Zanchetti A, Mancia G (eds): Hondbook of Hypertension. Vol 17: Pathophysiology of Jypertension, v. 17, Elsevier Science B.V., 1997: 117-169.

42. Janssen BJA, Oosting J, Slaaf DW, Persson PB, Struyker-Boudier HAJ: Hemodynamic basis of oscillations in systemic anterial pressure in conscious rats. $\mathrm{Am}$ J Plysiol 1995; 269: H62-H71.

43. Brown TE, Beightol LA, Koh J, Eckberg DL: Important influence of respiration on human R.R interval power spectra is largely ignored. $J$ Appl Physiol 1993; 75:23102317.

44. Persson PB, Ehnke H, Köhler WW, Kirchheim HR: Identification of major slow blood pressure oscillations in conscious dogs. Am / Physol 1990; 259: H1050-H1055.

45. Broten TP, Zehr JE: Autonomic modulation of ultradian blood pressure and heart rate oscullations in dogs. Am J Physiol 1989;256: R\|127-R1137.

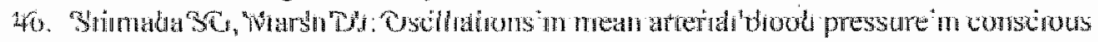
dogs. Circ Res 1979; 44:692-700.

47. Wngner $C D$, Persson $\mathrm{PB}$ : Two ranges in blood pressure spectrum with different $1 / \mathrm{f}$ characteristics. An of Physiol 1994; 267 : H449-H454.

48. Marsh DJ, Osborn JL, Cowley Jr AW: V/ Auctuations in arterial pressure and regulation of renal blood flow in dogs. Am of Physiol 1990; 258: F1394-F1400.

49. Di Rienzo $M$, Castiglion $P$, Parat $G$. Mancia $G$, Pedoti A: Effects of sino-aontic denervation on spectral characteristics of blood pressure and pulse interval variability: a wide band approach. Med Biol Eng Comput 1996; 34: 133-141.

50. Goldberger AL, West BJ: Fractals in physiology and medicine. Yale J Biol Med 1987 ; 60: $421-435$.

51. Lemmer B: Circadian rlythms in the cardiovascular system. In Arende J, Waterhouse J, Minors D (eds): Bological whthms in the cardiovascular system John Wright, Bristol, England, $1990: 51-70$.

52. Millar-Craig MW, Bishop CN, Raferty EB: Circadian variation of blood pressure. Lance 1978; 1: 795-797.

53. Witte $K$, Lemmer $B$ : Free-running rhythms in blood pressure and heart rate in normotensive and transgenic hypertensive rats. Chronobiol hm 1995; 12: 237-247. 
54. Pickering TG: The influence of daily activity on ambulatory blood pressure. An Hear J1988; 116:1141-1145.

55. Khoury AF, Sunderajan P, Kaplan NM: The early morning rise in blood pressure is related mainly to ambulation [see comments]. Am J Hypertens 1992; $5(6 \mathrm{Pt}$ 1):339. 344.

56. Chau NP, Mallion IM, De Gaudenaris R, et al: Twenty-four hour ambulatory blood pressure in shift workers. Cinculation 1989;80:34 I-347.

57. Baumgart $P$, Walger $P$, Fuchs $G$, Dorst $K G$, Vetter $H$, Ralun $K H$ : Twenty-four-hour blood pressure is not dependent on endogenous circadian thythm. J Hpertens 1989 ; $7: 331-334$.

58. Van-de-Borne P, Nguyen H, Biston P, Linkowski P, Degaute JP: Effects of wake and sleep stages on the 24-h autonomic control of blood pressure and heart rate in recumbent men. Am J Physiol 1994; $266(2 \mathrm{Pt} 2$ ): H548-H554.

59. Pickering TG: The ninth Sir George Pickering memorial lecture. Ambulatory monitoring and the definition of hypertension. J Hyperfens 1992; 10:401-409.

60. Voogel A., Stok WJ, Pretorius PI, Van Montfrans GA, Langewouters G., Karemaker JM: Circadian blood pressure and systemic hamonodynamics during 42 days of 6 degrees head-down tilt. Acta Physiol Scand 1997;161:71-80.

61. Smolensky MH, Tatar SE, Bergman SA, et al: Circadian rhythmic aspects of human cardiovascular function: a review by chronobiologic statistical methods. Chronobiologia 1976; 3:337-371.

62. Smith TL, Coleman TG, Stanek KA, Murphy WR: Hemodynamic monitoring for 24$\mathrm{h}$ in unanesthetized rats. Am If Physial 1987; 253: H1335-H1341.

63. Veeman DP, Imholz BPM, Wieling $W$, Wesseling KH, Van Montfrans GA: Circadian profile of systemic hemodynamics. Hypertension 1995; 26:55-59.

64. Kool MJ, Wijnen JA, Derkx FH, Struijker-Boudier HA, Van-BortelLM: Diumal variation in prorenin in relation to other humoral factors and hemodynamics. $A m \mathrm{~J}$ Hypertens 1994; 7: 723-730.

65. Delp MD, Manning RO, Bruckner JV, Amstrong RB: Distribution of cardiac output during diurnal changes of activity in rats. Am J Physiol $1991 ; 261$ : H1 487-1-1 493.

66. Casiglia $E$, Palatini $\mathbb{P}$, Colangeli $G$, et al: 24 h rhythm of blood pressure and forearm peripheral resistance in normotensive and hypertensive subjects confined to bed. $J$ Hypertens 1996; 14:47-52.

67. Puvi-Rajasingham S, Smith GDP, Akinol A, Mathias CJ: Abnormal regional bllod flow responses during and after exercise in human sympathetic denervation. J Physiol 1997; $505: 841-849$.

68. Brandenberger $G$, Follenius $M$, Simon $C$, Ehrhart $J$, Libert JP. Nocturnal oscillations in plasma renin activity and REM-NREM sleep cycles in humans: a common regulatory mechanism? Sleep 1989; 11:242-250.

69. Hartikainen J, Tarkiainen I, Tahvanainen $K$, Mantysaari $M$, Lansimies $E$, Pyorala K: Cincadian variation of cardiac autonomic regulation during $24-\mathrm{h}$ bed rest. Clin Physiod $1993 ; 13: 1854196$.

70. De Boer SF, van der Gugten J: Daily wariations in plasma noradrenaline, adrenaline and corticosterone concentrations in rats. Physiol and Behav 1987; 40:323-328.

71. Linsell CR, Lightman SL, Mullen PE, Brown MJ, Causon RC: Circadian rhythms of epinephrine and norepinephrine in man. J Clim Endocrinol Metab 1985; 60: 1210 1215.

72. Tuck ML, Stern N, Sowers IR: Enhanced 24-Hour Norepinephrine and Renin Secretion in Young Patients with Essential Hypertension: Relation wilh the Circadian Pattem of Arterial Blood Pressure. Am J Cardiol 1985; 55: 112-115.

73. Parati G, Frattola A, Di Rienzo M, Castiglioni P, Pedotti A, Mancia G: Effects of 
aging on 24 h dynamic baroreceptor control of heart rate in ambulant subjects. $A$ m $J$ Physlol 1995; 268 , H1606-41612.

74. George CPL, Messerli FH, Genest $₫$, et al: Diumal variation of plasma vasopressin in Man. J Clin Endocrinol Metab 1975; $41: 332-338$.

75. Modlinger RS, Scharif-Zadeh K, Ertel NH, et al: The cireadian thythm of renin. $J \mathrm{Clm}$ Endocrinol Metab 1976; 43:1276, 1282.

76. Gordon $\mathrm{RD}$, Wolfe $L K$, Island DP, Liddle $\mathrm{OW}$ : A diurnal rhythm in plasma renin activity in man. J Clin Jwest 1966; 10: 1587-1592.

77. Cugini $\mathrm{P}$, Letzia $\mathrm{C}$, Cerci $\mathrm{S}$, et al: $\mathrm{A}$ chronobiological approach to circulating levels of renin, angiotensin-converting enzyme, aldosterone, $\mathrm{ACTH}$, and cortisol in Addison's disease. Chronobiol in 1993; 10: 119-122.

78. Lemmer $B$, Mattes $A$, Bohm $M$, Ganten $D$ : Circadian blood pressure variation in transgenic hypertensive rats. Hypertension 1993; 22: 97-101.

79. Portaluppi $F$, Vergnani $L_{s}$ Uberti degli EC: Atrial natriuretic peptide and circiadian blood pressure regulation: clues from a chronobiological approach. Chronobiol int 1993; 10: 176-189.

80. Witte $K$, Schnecko A, Zuther $P, L$ emmer $B$ : Contribution of the nitric oxide-guanylyl cyclase system to circadian regulation of blood pressure in normotensive wistar-kyoto rats. Cardiovasc Res 1995; 30: 682-688.

81. Roelfsema F, van der Heide D, Smeenk. D: Circadian thythms of urinary electrolyte excretion in freely mowing rats. Life Sciences 1980; 27: 2203-2309.

82. Koopman MG, Koomen GCM, Krediet RT, de Moor EAM, Hoek FJ, Arisz L: Circadian rhythm of glomerular filtration rate in normal individuals. Clin Sci 1989; 77: 105-111.

83. Johnson RE, Johnson AK: Light-dark cycle modulates drinking to homeostatic challenges. Am J Physiol 1990; 259: R1035-R 1042.

84. Manchester RC: The diurnal rhythm in water and mineral exchange. 1933: 995-1008.

85. Birkenhager WH, Statius van Esp LW, de Vries LA. Reversal of rhythmic water and sodium excretion patterns during ganglionic or adrenergic block. Acta Med Scand 1962; 172:105-115.

86. Hilfenhaus $\mathrm{M}$ : Circadian thythm of the renin-angiotensin-aldosterone system in the rat. Arch Toxicol 1976; 36: 305-316.

87. Kawasaki $T$, Ueno $M$, Uezono $K$, et al: The renin-angiotensin-aldosterone system and circadain rhythm of urine variables in normotensive and hypertensive subjects. Jap Circ.J 1984; $48: 168-172$.

88. Poulis I, Roelfsema F, van der Heide D, Smeenk D: Resynchronization patterns for urinary thythms in rats after light-dark shifts. Am J Physiol 1985; 249: R402-R409.

89. Valdez P, Ramirez C, Garcia A: Delaying and extending sleep during weekends: sleep recovery or circadian effect? Chronobiol Int 1996; 13:191-198.

90. Uezono K, Sacket-Lundeen LL, Kawasaki T, Omae T, Haus E: Circaseptan rhythm in sodium and potassium excretion in salt-sensitive and salt-resistant Dahl rats. In Liss AR (ed): Advances in chronobiology, v. Part $\mathrm{A}_{, y}, 1987$ : 297-307.

91. Willich SN, Lowel H, Lewis M, Hörmann A, Arntz HR, Keil U: Weekly variation of acute myocardial infarction. Increased monday risk in the working population.

Cinculation 1994; 90: $87-93$.

92. Marchant B, Ranjadayalan $K$, Stevenson $R$, Wilkinson $P$, Timmis AD: Circadian and seasonal factors in the pathogenesis of acute myocardial infarction: the influence of environmental temperature. Br Heart J 1993; 69: 385-387.

93. Al-Yusuf AR, Kolar J, Bhatnagar SK, Hudak A, Smid J: Seasonal variation in the incidence of unstable angina and myocardial infarction: effect of dry hot climate on the occurence of complications following acute myocardial infarction. $j$ trop med hyg $1986 ; 89: 157-161$. 
94. Woodhouse PR, Khaw K-T, Plummer M: Seasonal variation of blood pressure and its relationship to ambient temperature in an elderly population. $J$ Hyperens $1993_{3}: 11$ : 1267-1274.

95. Kannel WB, Wolf PA, Verter J, McNamara PM: Epidemiologic assessment of the role of blood pressure in stroke. JAMA 1970;214:301-310.

96. Kannel WB, Schwartz MJ, McNamara PM: Blood pressure and risk of coronary heart disease: the Framingham study. Dis Chest 1969;56:43-52.

97. MacMahon S: Blood pressure and the risks of cardiovascular disease. In Swales ID (ed): Textbook of hperrension Blackwell Scientific Publications, Oxford, 1994: 46-57.

98. Lund-Johansen P: Haemodynamics of essential hypertension. In Swales JD (ed): Textbook of hypertension Blackwell Scientific Publications, Oxford, 1994: 61-76.

99. Korner Pl: The pathogenesis of hypertension: the baker concerto. Clin Exp Hypert 1984; a6: 565-586.

100. Folkow B: Physiological aspects of primary hypertension. Phys Rev 1982;62: 347504.

101. Struijker Boudier HAJ: Vascular growth and hypertension. In Swales JD (ed): TExibook of hypertension B lackwell Scientific Publications, Oxford, 1994: 200-213.

102. Hutchins PM, Darnell AE; Observation of a decreased number of small arteriolesin spontaneously hypertensive rats. Circ Res 1974; 34\&35(Suppl 1): 161-165.

103. Evenwel RT, Kasbergen CM, Struyker Boudier HAJ: Central and regional hemodynamics and plasma volume distribution during the development of spontaneous hypertension in rats. Clin Exp Hypert 1983; A5: $1511-1536$.

104. Barker DJP, Bull AR, Osmond C, Simmonds, SJ: Fetal and placental size and risk of hypertension later in life. Br Med J 1990;301:259-262.

105. Law CM, Barker DJP, Bull AR, Osmond C: Maternal and fetal influences on blood pressure. Arch Dis Child 1991; 66: 1291-1295.

106. Drayer HIM, Weber MA, DeYoung JL, Brewer DD: Long-term BP monitoring in the evaluation of antihypertensive therapy. Arch Intern Med 1983; 143: 898-901.

107. Hoegholm A, Kristensen KS, Madsen H, Svendsen TL: White coat hypertension diagnosed by 24 -h ambulatory monitoring. Am J Hypertens $1992 ; 5 ; 64-70$.

108. Pickering TG, James GD: Ambulatory blood pressure and prognosis. J Hypertens $1994 ; 12 ; 529-\mathrm{s} 33$.

109. Doll G, Mycinski C, Cosnay P, Alison D, Raynaud R, Brochier M: Comparison of circadian blood pressure variations in hypertensive patients with renal artery stenosis and essential thypertension. J Hum Hypertens $1990 ; 4: 390-392$.

1 10. Baumgart $\mathrm{P}$, Walger $\mathrm{P}$, Dorst $\mathrm{KG}$, Von Eiff $\mathrm{M}$, Rahn $\mathrm{KH}$, Vetter $\mathrm{H}$ : Can secondary hypertension be identified by twenty-four hour ambulatory pressure monitoring? I Hypertens 1989; 7(suppl 3): 25-28.

111. Touyz RM, Milne FJ, Reinach SG: Twenty-four hour ambulatory blood pressure in therapeutically resistant hypertensive patients. I Ham Hyperens 1990; 4: 393-396.

112. Dabrowska B, Fellynowski T, Wocial B, Szpak W, Januszewicz W: Effect of removal of phaeochromocytoma on diurnal variability of blood pressure, heart rlythm and excretion of catecholamines. J Hum Hypertens 1990; 4: 397-399.

113. Myers MG: Twenty-four-hour blood pressure control: a brief review of aspects of target-organ portection. J Hypertens 1996; 14: Supp S7-S10.

114. Frattola $A$, Parati $G$, Cuspidi $C$, Albini $F$, Mancia $G$ : Prognostic value of 24-hour blood pressure variability. I Hypertens 1993; 11:1133-1157.

115. Parati $G$, Pomidossi G, Albini F, Malaspina D, Mancia G: Relationship of 24 hour blood pressure mean and variability to severity of target-organ damage in hypertension. J Hyperters $1987 ; 5: 93-98$.

116. Kario K, Matsuo T, Kobayashi $H$, Imiya M, Matsuo M, Shimada K: Noctumal fall of 


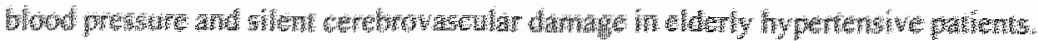

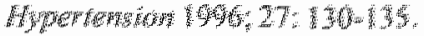

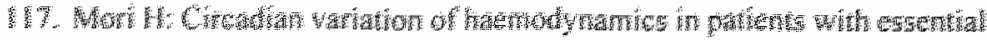

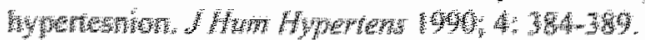

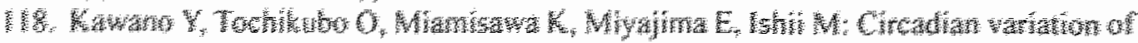

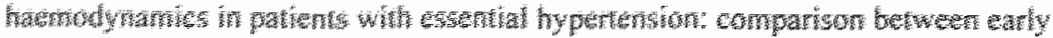

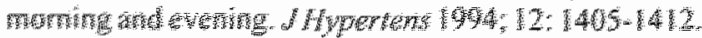

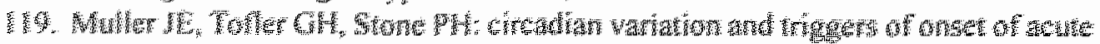

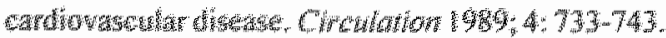

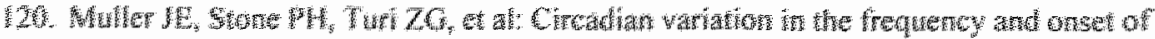

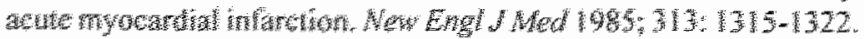

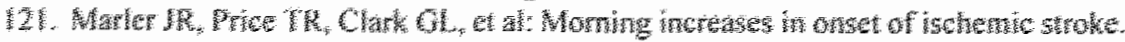

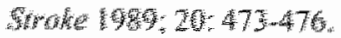

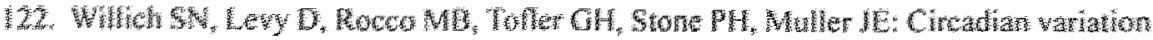

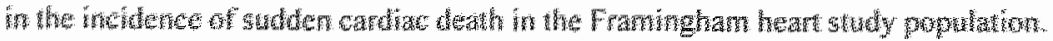

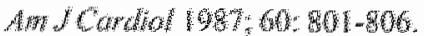

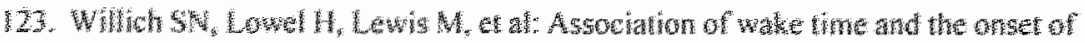

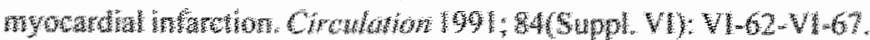

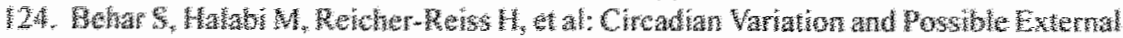

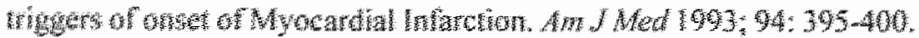

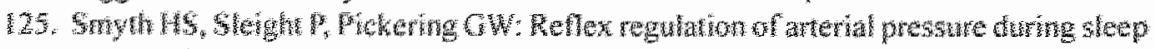

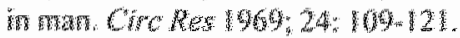

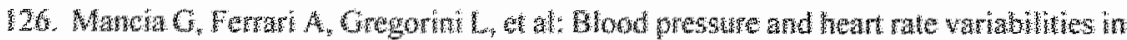

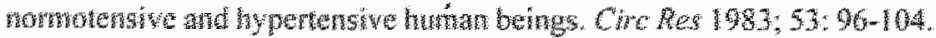

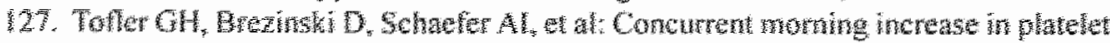

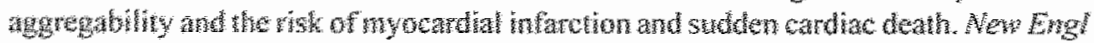
Mod $1997,36 \% 154-1519$

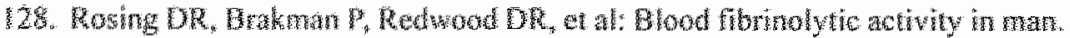

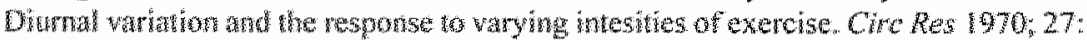
$171-194$

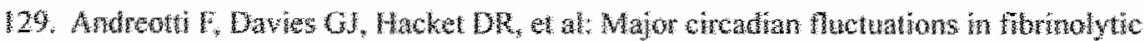

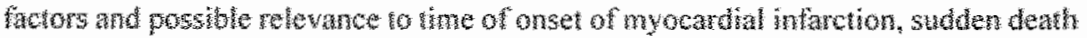
wh stroke. Am J Cardiol 198\%;62:635-637.

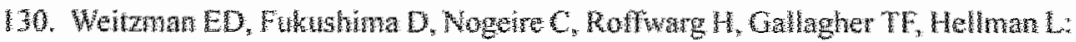
Twenty-four hour pattern of the episodic secretion of cortisol in human subjects. $J$ Chin Endocy" 1971; 33: 14-22.

131. Akersedt T, Levi L: Cincadian rhythms in the secretion of contisol, adrenaline and noradrenaline. Eur J Clin Invest 1978; 8:57-58.

132. Portaluppi $F$, Bagni $B$, degli Uberti $E$, et al: Circadian rhythms of atrial natriuretic pepticle, renin, aldosterone, cortisol, blood pressure and heart rate in normal and hypertensive subjects. J Hypertens 1990; 8: 85-95.

133. Rielveld WI, Minors DS, Waterhouse JM: Circadian Rhythms and Masking: An Overview. Chronobiol Int 1993; 10:306-312.

134. MacMahon SW, Cutler J A, Furberg CD, Payne GH: The effects of drug treatment for hypertension on morbidity and mortality from cardiovascular disease: a review of randomized trials. Prog Cardiovasc Dis 1986; 29(suppl 1): 99-118.

135. Hansson L: Shortcomings of current antihypertensive therapy. Am J Hypertens 1991; $4: 845-87 \mathrm{~s}$.

136. Cruickshank JM. Thorp JM, Zacharias FJ: Benefits and potenstial harm of lowering blood pressure. Lancet 1987 ; i: $581 \cdot 584$.

137. Lindholm L, Ejlertsson $G$, Schersten $B$ : High risk of cerebromcardiovascular morbidity in well treated mate hypertension. Acta Med Scand 1984; $216: 251-259$. 
138. Isles CG, Walker LM, Beevers GD, et al: Mortality in pathents of the Glasgow blood pressure clinic. J Hypertens $1986 ; 4: 141-156$.

139. Urquhart $\mathbb{I}$ : Role of patient compliance in clinical phamacokinetics. A review of recent research. Chin Pharmacokinet 1994; $27: 202-215$.

140. Grimm Ji RH: The drug treatment of mild hypertension in the multiple risk factor intervention trial. A review. Drugs 1986;31(Suppl. 1): 13-21.

141. Hansson L: The benefits of lowering elevated blood pressure: a critical review of studtes of cardiovascualr morbidity and mortality in hypertnesion. J Hypertens 1996 ; $14: 537-544$.

142. Anderson TW: Re-examination of some of the framingham blood pressure data. Lancet $1978 ; 2(8100): 1139-1141$.

143. Samuelsson OG, Wilhelmsen LW, Pernert KM, Wedel H, Berglund GL: The J-shaped relationship between coronary heart disease and achieved blood pressure level in treated hypertension: further analyses of 12 years of follow-up of treated hypertensives in the Primary Prewention Triat in Gothenburg, Sweden. J Hyertens 1990; 8: 547-555.

144. Zanchetti $A$, Amery $A$, Berglund $G$, et al: How much should blood pressure be lowered? The problem of the J-shaped curve. J Hypertens' $1989 ; 7$ (suppl 6): 338-348.

145. Simpson FO: Guidelines for antihypertensive therapy: problems with a strategy on absolute cardiowascular risk. J Hypertens 1996; 14:683-689.

146. Swales JD: Treating hypertension. J Hypentens 1996; 14:813-814.

147. Sirgo MA, Mills RJ, DeQuattro W: Effects of antihypertensive agents on circadian blood pressure and heart rate patterns. Arch Intern Med 1988; 148: 2547-2552.

148. Materson BJ, Preston RA: Classic therapeutic trials in hypertension. Am $J$ Hypentens $1991 ; 4: 449 \mathrm{~S}-453 \mathrm{~S}$.

149. Voogel AJ, Van Der Meulen JHP, Van Montrans GA: effects of antihypertensive drugs on the circadian blood pressure profile. J Cardiovasc Pharmacol 1996; $28: 463$ 469.

150. Rose M, McMahon FG: Some problems with antihypertensive drug studies in the context of the new guidelines. Ann J Hypertens 1990; 3: 151-155.

151. Lipicky $\mathrm{RJ}$ : Trough : peak ratio: the rationale behind the united states food and drug administration recommendations. J Hypertens 1994; 12: s17-S19.

152. Meredith PA, Elliott HL: FDA guidelines on trough : peak ratios in the evaluation of antihypertensive agents. $J$ Cardowasc Pharmacol 1994; 23: $526-\$ 30$.

153. Elliott HL, Meredith PA: Troughrpeak ratio: clinically useful or practically irrelevant? JHypertens 1995; 13:279-283.

154. Myers MG: Trough-to-peak ratio and 24-hour blood pressure control. Methodologic issues. Am J Hyperters 1995; 8: 214-219.

155. Meredith PA, Elliott HL: Antihypertensive treatment and trough : peak rato: general considerations. JHyertens 1994; 12:\$79-\$83.

156. Witte $K$. Weisser $K$, Neubeck $M$, et al: Cardiovascular effects, pharmacokinetics, and converting enzyne inhibition of enalapril after morning versus evening adninistration. Clin Phamacol Ther 1993; 54: 177-186.

157. Levy G: Pharmacokinetic constraints and opportunities. Ann NY Acad Sci 1991; 618 : $116-122$.

158. Tateishi $T_{*}$ Fujimura $A_{*}$ Miura T, Ebihara A: Chronopharmacological study of furosemide in human subjects. In J Clin Pham Res 1988; 8: 401-407.

159. Langner B, Lemmer B: Circadian changes in the pharmacokinetics and cardiovascuar effects of oral propranolol in healthy subjects. Eur J Clin Pharmacol 1988; 33:619. 624.

160. Reinberg A: New concepts in chronopharmacology. Nips 1988; 3: 84-88. 
161. Hossmann $\mathrm{V}$, pherald GA, Dollery CT: Circadian rhythm of baroreflex reactivity and adrenergic vascular response. Cardlovasc Res 1980; 14: 125-129.

162. Pollmann L: Chronobiological considerations of aspirin and indomethacin. 1984:349352.

163. Raftery EB: Circadian variation in blood pressure: considerations for therapy. Postgrad Med in 1991;67:\$9-\$14.

164. Meredith PA, Perloff D, Mancia $G$, Pickering $T$ : Blood pressure variability and its implications for antihypertensive therapy. Blood Pressure 1995; $4: 5-11$.

165. Struijker-Boudier: Hemodynamics of experimental hypertension. In Zanchetti $\mathbb{A}$, Mancia G (eds): Handbook of hypertension Elsevier Science B. V., Ansterdam, 1997 : $170-212$.

166. Trippodo NC, Frohlich ED: Similarities of Genetic (Spontaneous) Hypertension. Circ Res 1981; 48: $309-319$.

167. Goldblat H, Haas $\mathrm{E}_{3}$ Klick RL, Lewis LV: The effect of main artery occlusion of one kidney on bllood pressure of dogs. Proc Natl Acad Sci USA 1976; 73: 1722-1724.

168. Mullins JJ, Peter's J, Ganten D: Fulminant hypertension in transgenic rats harbouring the mouse Ren-2 gene. Nature 1990; $334: 541-544$.

169. Fukamizu A, Takimoto E, Sugimura $K$, et al: Dependence of angiotensin production in transgenic mice carrying either the human renin or human angiotensinogen genes on species-specific kinetics of the renin-angiotensin system. Arzneirn-Forsch/Drug Res $1993 ; 43(2 a): 222-225$.

170. Holstein-Rathlou N-H, He J, Wagner AJ, Marsh DJ: Patterns of blood pressiure variability in normotensive and hypertensive rats. Am J Physiol 1995; 269: R1230R1239.

171. Friberg P, Karlsson B, Nordlander M: Autonomic control of the diumal variation in arterial blood pressure and heart rate in spontaneously hypertensive and WistarKyoto rats. J Hypertens 1989; $7: 799-807$.

172. Parati $G$, Di Rienzo $M$, Bertinieri $G$, et al: Evaluation of the baroreceptor-heart rate reflex by 24-hour intra-arterial blood pressure monitoring in humans. Hypertension $1988 ; 12: 2 \rrbracket 4-222$.

173. Bertinieri G, Di Rienzo $M$, Cavallazzi A, Ferrari AU, Pedotti A, Mancia G: Evaluation of baroreceptor reflex by blood pressure monitoring in unanesthetized cats. Am $J$ Physiol 1988; 254: H377-H383.

174. Robbe HWJ, Mulder LJM, Ruddel H, Langewitz WA, Veldman JBP, Mulder G: Assessment of baroreceptor reflex sensitivity by means of spectral analysis. HyperJension 1987; 10:538-543.

175. Struyker-Boudier HAJ, Evenwel RT, Smits JFM, Van Essen H: Baroreflex sensitivity during the development of spontaneous hypertension in rats. Clin Sci 1982; 56: 163. 167 . 


\section{Chapter 2 \\ Hemodynamic basis of oscillations in systemic arterial pressure in conscious rats}

Ben J.A. Janssen

Jan Oosting

Dick W. Slaaf, Department of Biophysics, University of Maastricht

Pontus B. Persson, Department of Physiology2, Humboldt University (Charité), Berlin, Germany.

Harry A.J. Struijker-Boudier

Published in American Journal of Physiology (Heart Circulation Physiology 38) 1995; 269, H62-H71

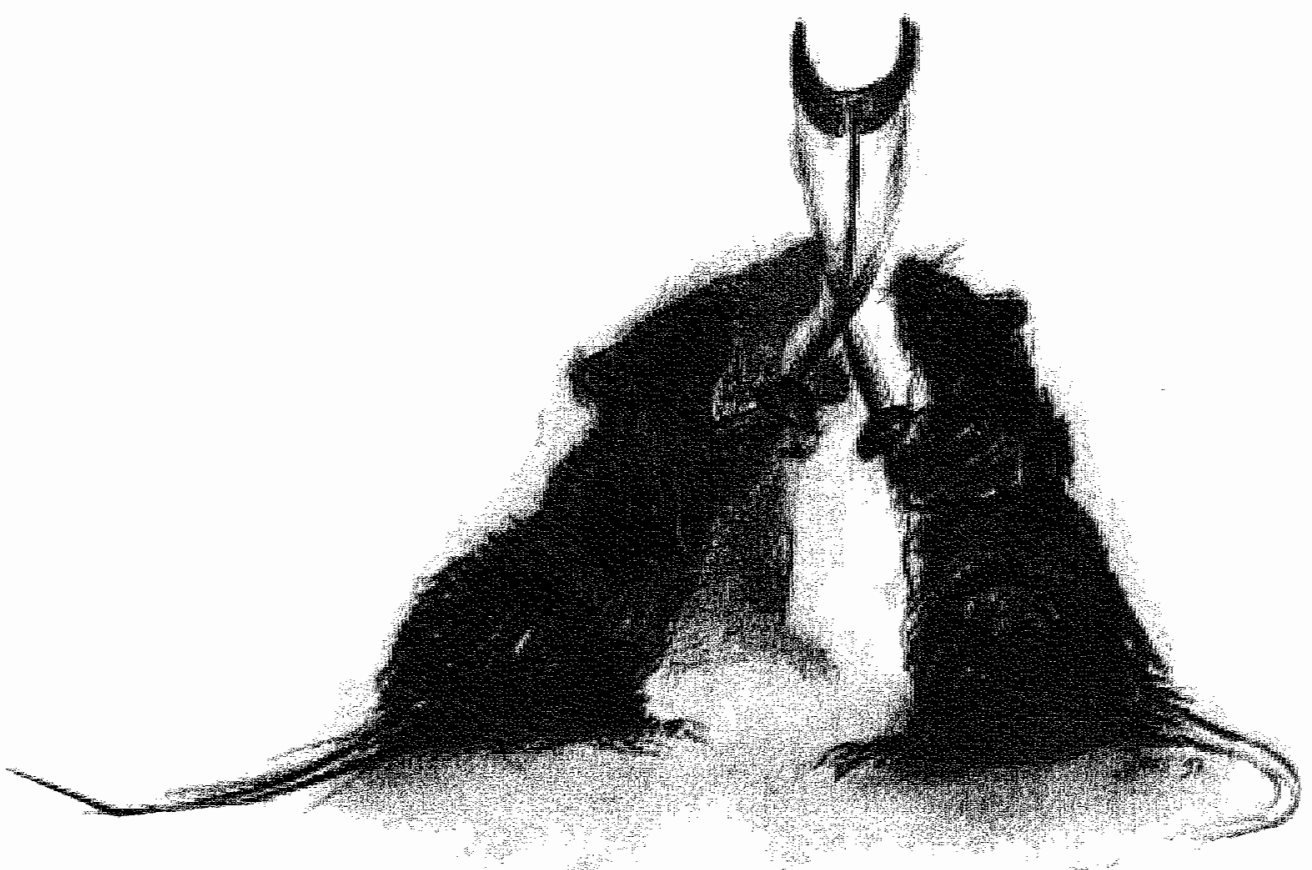




\section{Abstract}

In conscious resting rats, beat-to-beat fluctuations in systemic mean arterial pressure (MAP) were compared with those in cardiac output and those in blood flow in the renal, mesenteric, and hindquarter vascular beds. Spontaneous oscillations (lability) in MAP were observed in frequency bands centered about $1.6 \mathrm{~Hz}$ (high: $\mathrm{HF}$ ), $0.4 \mathrm{~Hz}$ (mid: MF), and $0.13 \mathrm{~Hz}$ (low: LF). Lability of MAP was confined within the LF ( $8 \mathrm{~s}$ ) band. Lability of cardiac output, on the other hand, showed primary HF oscillations. LF oscillations in regional blood flow were most prominent in the mesenteric and renal vascular beds. In these beds, LF oscillations in blood flow showed negative phase angles with MAP, whereas those between MAP and hindquarter blood flow were positive. Cross correlation analysis indicated that $\sim 2 \mathrm{~s}$ following a LF change in MAP, LF changes in mesenteric and renal blood flow occurred opposite to those of MAP. Changes in hindquarter flow were negatively correlated with those in MAP about zero time delay. Admittance gains were 1 across all frequencies for all vascular beds, indicating the absence of autoregulation. This hemodynamic pattern suggests that myogenic mechanisms predominantly control mesenteric and renal blood flow in a nonautoregulatory but rather superregulatory manner, while autonomic mechanisms regulate hindquarter blood flow. Thus, in conscious resting rats, spontaneous fluctuations in systemic arterial pressure predominantly exhibit slow $(\sim 8 \mathrm{~s})$ oscillations, which do not arise from fluctuations in cardiac output, but originate from regionally specific myogenic oscillatory mechanisms contributing to resistance to flow. 


\section{Introduction}

Indexes of blood pressure and heart rate variability are increasingly explored as prognostic tools in various circulatory pathophysiological states ${ }^{1-4}$. However, the hemodynamic mechanisms underlying fluctuations in blood pressure and heart rate, especially those that are slower than the cardiac and respiratory cycle (Traube-Hering waves), have not been fully characterized. These so-cailed Mayer waves or third-order waves were first described more than a century ago". They are centered about $0.1 \mathrm{~Hz}$ in lhumans ${ }^{2-4.6}$, dogs $^{7}$, and cats $^{8}$, and about $0.4 \mathrm{~Hz}$ in rats ${ }^{9.14}$. After comparison between patient groups ${ }^{15}$ and after using various experimental interventions ${ }^{9.11-44}$, oscillations in these frequency bands were shown to depend largely on the integrity of the autonomic nervous system. They are possibly caused by modulation of vascular tone or heart rate either directly by a central oscillator ${ }^{16}$, or by resonance of the baroreflex or respiratory mediated changes in autonomic nervous activity ${ }^{4.6 .14}$.

The relevance of the Mayer waves is not clear. Changes in their amplitude have been used to estimate changes in autonomic circulatory control in various diseases.1.2. In addition, open-heart patients who showed vasomotor waves during cardiopulmonary bypass, needed less perioperative and postoperative inotropic support ${ }^{17}$. A considerable amount of variability in spontaneous blood pressure fluctuations may be found in frequencies below those of Mayer waves ${ }^{1.18}$. The origin of such blood pressure fluctuations, with periods between $10 \mathrm{~s}$ and $24 \mathrm{~h}$, has not been studied in detail for several reasons. First, most studies restricted their interest to the respiratory and Mayer waves, since the resolution of data sampling or processing was too low to clearly identify oscillations at lower frequencies. Second, in conscious animal experiments, the stationarity of the blood pressure signal may be disturbed by large fluctuations due to movement ${ }^{19}$. Third, because linear logistic relations were found between spectral power and frequency ${ }^{20,21}$, deterministic nonlinear processes may underlie these blood pressure fluctuations. Consequently, independent low-frequency oscillations are not required. Nevertheless slow nonbehavioral endogenous rhythmic processes influencing arterial pressure cannot be excluded because low-frequency spectral power of blood pressure often changes after pharmacological or surgical manipulation of circulatorycontrolling mechanisms ${ }^{8.13 .14 .18}$.

In pilot studies we tested for the presence of oscillations in arterial blood pres. sure in conscious rats with frequencies lower than those of Mayer waves $(0.4 \mathrm{~Hz})$. We were able to identify major oscillations in arterial pressure with a period of roughly $8 \mathrm{~s}$, especially when rats were asleep or resting. The present study describes the hemodynamic characterization of these blood pressure rhythms. In two groups of rats we compared beat-to-beat variations in cardiac output with those occurring in blood flow in three major peripheral vascular beds. The results indicate that in resting rats the $8 \mathrm{~s}$ rliythm in blood pressure is not dependent of fluctuations in cardiac output but primarily caused by myogenic oscillations in renal and especially in mesenteric blood flow. 


\section{Methods}

\section{Animal Preparation}

Experiments were performed in male adulit Wistar rats purchased from Winkelmann (Borchen, Germany). Rats were kept on $12: 12 \mathrm{~h}$ light-dark cycle and had free access to water and standard food pellets (type RMM-TM, Hope Farms, Woerden. The Netherlands). The experimental protocol was approved by the Institutional Animal Care and Use Committee of the University of Limburg, Maastricht.

Instrumentation of flow probes was performed under pentobarbital sodium anesthesia $(60 \mathrm{mg} / \mathrm{kg}$ ). For recording of central hemodynamics, electromagnetic flow probes (2.7 min diam; Skalar, Delft, The Netherlands) were implanted on the ascending aorta. For recording of regional hemodynamics, miniaturized $20-\mathrm{MHz}$ pulsed Doppler flow probes (Crystal Biotech, Holliston, MA) were implanted on the left renal artery and superior mesenteric artery and the abdominal aorta to measure renal (RBF), mesenteric (MBF), and hindquarter blood flow (HBF), respectively. Both surgical procedures have previously been described by us in detail ${ }^{22,23}$. Rats were allowed to recover for $4-5$ days to regain their preoperative body weight. Two days before the actual experiments, under ether anesthesia, a catheter (PE-10 heat sealed to PE-50) was inserted into the abdominal aorta via the left femoral artery for blood pressure recordings. The catheter was tunneled subcutaneously to the neck, where it was exteriorized, filled with saline, and closed with a metal plug. Experiments were completed in nine rats instrumented for recording of central hemodynamics [group l, avg body wt $290 \pm 13$ (SD) g] and in eight rats prepared for the regional blood flow measurements (group II, avg body wt $288 \pm 11$ g).

\section{Protocol}

On the day of the experiment rats were placed in experimental cages $(22 \times 13 \times 13$ $\mathrm{cm}$ ) in a quiet illuminated room. The rats were connected to the equipment and allowed to become accustomed to the environment for $1-1.5 \mathrm{~h}$. In group I, arterial pressure and ascending aortic flow was measured. In group II, arterial pressure and RBF, MBF, and HBF were measured. Recordings were made for 30 min during the resting or sleeping state to minimize locomotor-induced changes in hemodynamics. During the recording period behavioral activity of the rats was scored every $15 \mathrm{~s}$ using a scalle of $1-5$ corresponding to the following states: 1) sleeping; 2) awake but not moving; 3) small movements such as making a turn before lying down again; 4) vigorous movements associated with grooming or exploring; and 5) standing against the wall of the cage. The average behavioral activity in groups I and II was $\mathbb{1} .2 \pm 0.2$ (SD) and $1.3 \pm 0.2$, respectively. In both groups, the time span in which the average index was $>2$ was $<5 \%$ of the whole recording period. For this reason we did not exclude periods with higher behavioral activity from the analyses. Breathing rhythm was assessed by watching the abdominal movements every $10 \mathrm{~min}$. Respiratory frequencies were not different between groups [group 1 1.72 \pm 0.33 (SD), group II: $1.58 \pm 0.19$ ].

\section{Data acquisition}

The arterial catheter was connected to a low-volume pressure transducer (Micro Switch 156PC15GWL, Honeywell, Amsterdam, The Netherlands) for the measurement 
of arterial blood pressure. Cardiac output was measured as ascending aortic flow by using a sine-wave electromagnetic flowmeter (model 1401, Skalar). Late diastolic flow was taken to be zero. Regional blood flow velocities were measured as Doppler shift (in $\mathrm{kHz}$ ) with a three-channel 20-MHz pulsed ultrasound Doppler flowmeter (Bioengineering Department, University of Iowa, lowa City, IA). Zero flows were obtained electronically. Arterial pressure and flow signals were recorded on a beat-to-beat basis with the aid of a data-acquisition program developed by the Engineering Department of the University of Limburg, Maastricht, The Netherlands. All signals were sampled continuously with a minimum frequency of $500 \mathrm{~Hz}$ using a DT 2814 A/D converter board (Data Translation, CN Rood, Rijswijk, The Netherlands) housed in a 486 IBM-compatible computer. The time lag between the beginning of the ascending aortic flow and the abdominal aortic pressure wave was $\sim 20 \mathrm{~ms}$. The time lag between the beginning of the regional flow waves and the abdominal pressure wave was $\sim 6 \mathrm{~ms}$. Beat-to-beat values of mean arterial pressure (MAP), pulse interval (PI), stroke volume (SV), and cardiac output $(\mathrm{CO})$ were calculated on-line using an algorithm that used the end-diastolic value of the aortic (group I) and HBF signal (group II) to determine the interbeat interval. Total peripheral resistance (TPR) was estimated by dividing MAP by CO. All beatto-beat variables were stored on disk for off-line analysis. Because of technical problems, the MBF of one rat could not be recorded.

\section{Data processing}

The beat-to-beat signals of arterial pressure and central or peripheral hemodynamics were replayed on screen for visual inspection. Data segments with artifacts due to obstruction of the arterial catheter or electrical noise were eliminated $(<0.2 \%$ of all beats). For all variables means $\pm \mathrm{SD}$ and coefficient of variation were determined. Furthermore, as an index for short-term lability, the average relative (as percentage of mean) beat-to-beat differences of all signals were calculated.

The dynamic interactions of arterial pressure and blood flow fluctuations were investigated in the frequency domain using a fast Fourier transform computer program developed at the Department of Physiology, University of Heidelberg, Germany ${ }^{10}$ ). For this analysis technique equidistantly sampled data are required. Therefore the beat-tobeat data points were converted into equidistant time series using an algorithm that extracted from sequential 230 -ms time windows the maximum value of each parameter. Because the interbeat interval was never lower than $226 \mathrm{~ms}$ during the recordings, the width of the window was set at $230 \mathrm{~ms}$ to avoid aliasing. The resulting $(4.35 \mathrm{~Hz})$ time series were divided into half-overlapping sequential sets of 512 data points (each $\sim 100$ s). Before calculation of spectral density power, each segment was subjected to linear trend removal and cosine tapering of the first and last 60 data points. Spectral density power was expressed relative to total power obtained by integrating all values from 0 to $2.175 \mathrm{~Hz}$ (Nyquist frequency).

In addition to the spectral density power, the transfer function was calculated, assuming MAP as input and blood flow as output, as previously described in detai $2^{24}$ ${ }^{25}$. For each segment of 512 data points, the magnitude and phase of the transfer function was calculated as the quotient of the input and cross spectrum. Variance was reduced by averaging the resulting sequential data sets. The admittance gain was calculated by normalizing the magnitude of the transfer function by the average con- 
Figure 2.1

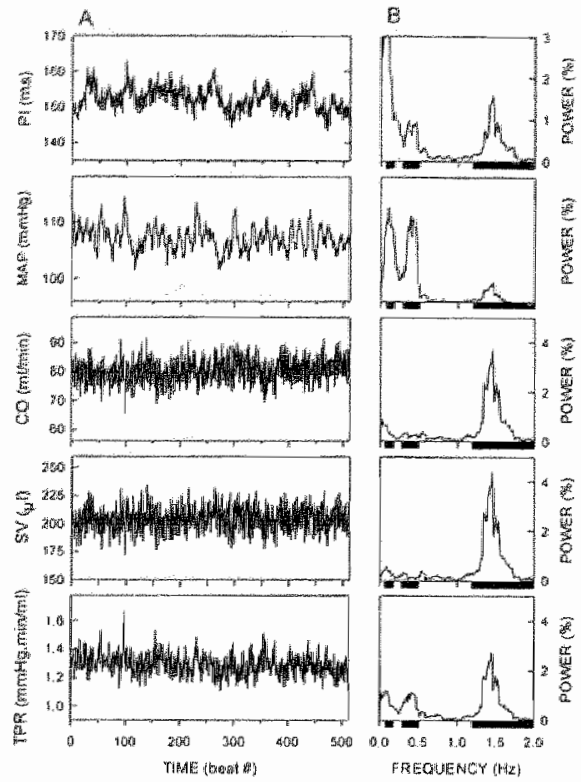

Figure 2.2

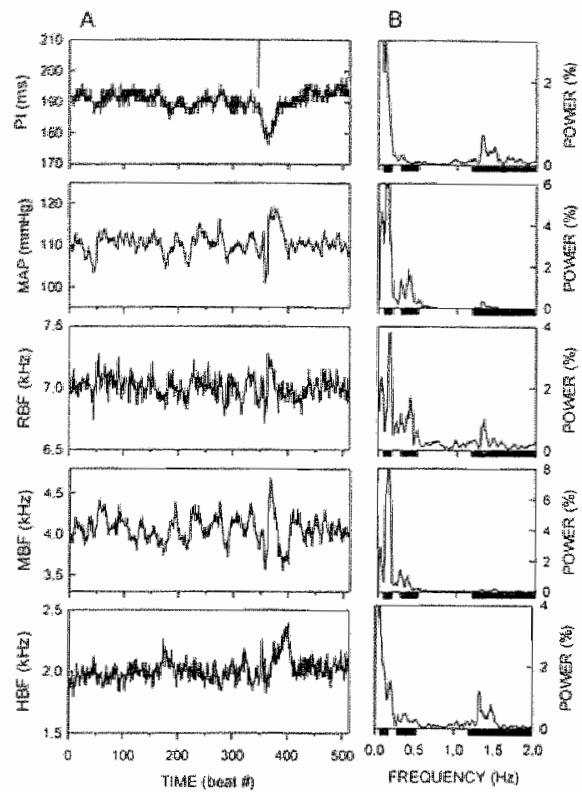

Figure 2.1. A: racings from rat 1 showing example of 512 beats recordings of pulse interval (PI), mean arterial pressure (MAP), cardiac output (CO), stroke volume $(S V)$, and total peripheral resistance (TPR), respectively, in a conscious resting rat (Group 1). B: Spectral power plots of corresponding rracings. Low (LF: 0.09-0.19 $\mathrm{Hz}_{\mathrm{z}}$-, nrid (MF: 0.30-0.50 Hz)-, and high ( $\mathrm{HF}: 1.20-2.00 \mathrm{~Hz}$-frequency bands are indicated by black bars.

Figure 2.2. A: tracings from rat 5 showing example of 512 beals recordings of $P I$, MAP, and renal (RBF), mesemeric (MBF), and hindquarter ( $M B F)$ blood flow in a conscious resing rat (Group ID). B. Spectral power plots of conresponding tracings. The LF, MF, and HF bands are indicared by black bars.

ductance calculated as the ratio of the average blood flow and pressure in the whole 30 min time series. The admittance gain is the ratio of the fractional variation in flow and pressure. A value of I for the gain indicates that when the input (MAP) fluctuates by some fraction of the mean value, the output (flow) undergoes the same fractional variation, as would be the case in a rigid vascular bed. A value of $<\mathbb{l}$ signifies that the fractional variation in blood low was smaller than in blood pressure. This would indicate autoregulatory behavior. When the admittance gain is $>\mathbb{\|}$, the pressure oscillations are then amplified in the hear or peripheral organs. Alternatively, these admittance values may indicate that the elevated fractional variations in blood flow are caused by autonomous fuctuations originating in the heart or vascular bed and are reflected in the blood pressure signal. The phase indicates the temporal relationship between the blood pressure and blood flow signals in the frequency domain, whereas the cross-cornelation coefficient indicates their correlation in the time domain. In addi- 
Figure 2.3

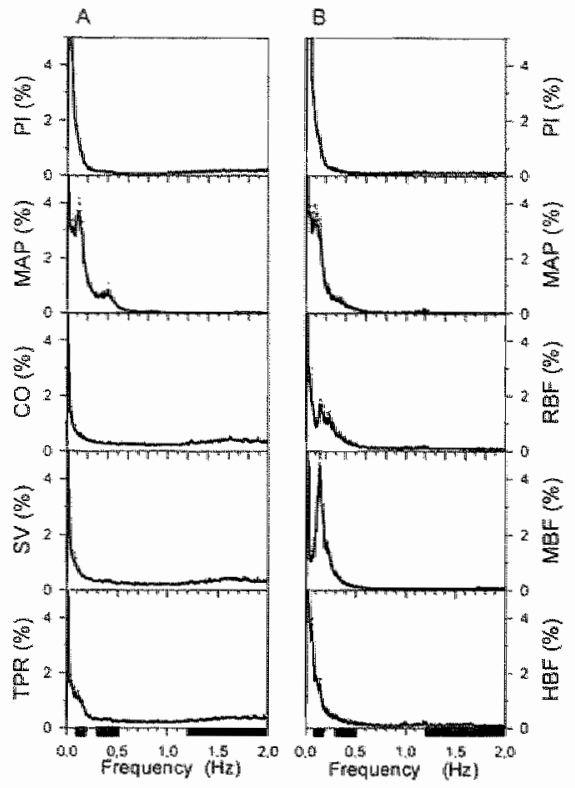

Figure 2.4

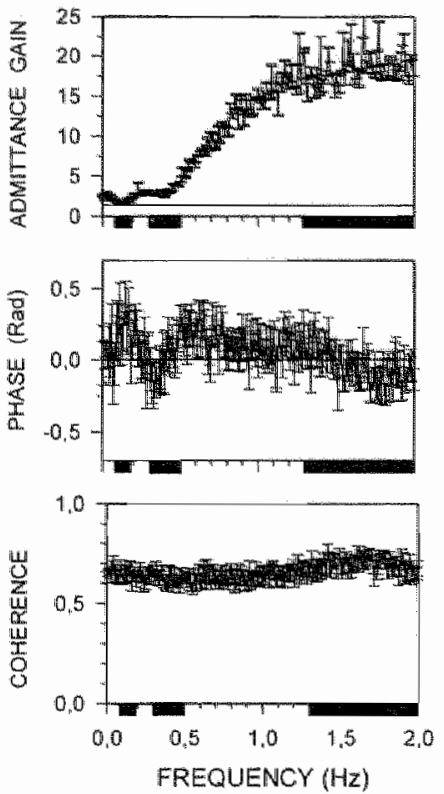

Figure 2.3. Comparison of average spectral power density (solid line) $+S E$ (dotted) line) in groups I (PI, MAP, CO, SV, and TPR, A, n=9) and II (PI, MAP, RBF, MBF, $H B F, B, n=7-8)$. For each rat data were averaged over $\sim 32$ overlapping sequential 100-s periods. LF, MF, and HF frequency bands are indicated by black bars.

Figure 2.4. Average admittance gain, phase delay, and coherence (significant when $>0.4, p<0.05)$ of MAP ws. CO. Data are means \pm SE of 9 rats. For each rat data were averaged over $\sim 32$ overlapping sequential 100-s periods. $L F, M F$ and $H F$ bands are indicated by black bars.

tion to these calculations, the coherence function was also computed. Coherence can have a value between 0 and $\mathbb{1}$ and is a frequency domain estimate of the degree that the flow variance can be explained by a linear operation of the blood pressure variance. The coherence is I if no other variables than blood pressure affect the flow oscillations. Finally, for each rat, the results obtained from these analysis techniques were averaged over the sequential data segments to reduce the variance.

The spectra were divided into four different frequency domains: 1) a high-frequency range (HF: 1.2-1.8 Hz) containing oscillations that are linked to respiration; 2) a midfrequency range (MF: 0.3-0.6 Hz) containing oscillations that may stem from sympathetic and parasympathetic influences ${ }^{211.26} ; 3$ ) a low frequency range (LF: 0.08-0.18 Hz) representing oscillations that are thought to result from vascular nyogenic responses ${ }^{24}$. 25.27; and 4) a very low frequency range (VLF:0.03-0.08 Hz) that comprises all undefined lower frequency oscillations but may include a tubuloglomerular feedback induced oscillation as has been described for $\mathrm{RBF}^{\text {in }}$ anesthetized rats ${ }^{24}, 25.27$. Note that the 
Table 2.1. Average values of hemodymamic parameters in groups I (centwal hemodynamics) and II (regional hemodynamics)

\begin{tabular}{|c|c|c|c|c|}
\hline & $\mathrm{H}$ & Mean & $C V, \%$ & $A D, \%$ \\
\hline \multicolumn{5}{|c|}{ Group 1} \\
\hline MAP, nmilg & 9 & $107 \pm 3$ & $4.1 \pm 0.5$ & $0.8 \div 0.1$ \\
\hline Pl, nins & 9 & $162 \pm 3$ & $3.7 \pm 0.5$ & $1.6 \pm 0.4 *$ \\
\hline $\mathrm{CO}_{3} \mathrm{~m} / \mathrm{m}$ in & 9 & $76 \pm 2$ & $7.2 \pm 0.7 *$ & $6.2 \pm 0.6^{*}$ \\
\hline$S V_{*} \mu$ & 9 & $203 \pm 5$ & $7.0 \pm 0.5$ & $6.0 \pm 0.6 *$ \\
\hline TPR, mmHg m: $\left.\right|^{-\frac{1}{4}}$, min & 9 & $1.4 \pm 0.1$ & $7.9 \pm 0.7^{3}$ & $6.0 \pm 0.5$ \\
\hline \multicolumn{5}{|c|}{ Giroup II } \\
\hline MAP, ImwHg & 8 & $111 \pm 5$ & $5.3 \pm 0.7$ & $0.9 \pm 0.1$ \\
\hline $\mathrm{Pl}_{1} \mathrm{mss}$ & 8 & $182 \pm 6+$ & $5.9 \pm 1.2$ & $1.6 \pm 1.6^{*}$ \\
\hline $\mathrm{RBF}, \mathrm{kH}$ & 8 & $4.4=0.4$ & $5.8 \pm 0.8$ & $11.8 \pm 1.8 *$ \\
\hline $\mathrm{MBF}^{\circ}, \mathrm{kHz}$ & 7 & $5.1 \pm 0,4$ & $7.7 \pm 0.7$ & $2.4 \pm 2.4 *$ \\
\hline HBF, $\mathrm{KH}$ & 8 & $2.5: 0.3$ & $11.8 \pm 3.7^{*}$ & $3.5 \pm 3.5^{*}$ \\
\hline
\end{tabular}

Values are means $\pm S E$. Coefficients of variation $(C V)$ and average beat-10-beat differences (AD) are shown as indexes of long-and short-term lability, respectively. MAP mean arrerial pressure; PI, pulse interval; $C O$, cardiac outpur; SW, stroke volume; TPR, total peripheral nesistance; $R B F$, renal blood flow; $M B F$, mesenteric blood flow; HBF, hindquarter blood flow. $\mathrm{P}<0.05$, significanly different from values of MAP in each group. if $\mathrm{P}<0.05$, sigmincantly different berween groups I and Il.

frequency bands are not complementary, and therefore spectral density power does not add to $1.00 \%$.

To achieve a better resolution in the LF range, we also calculated spectra over 2,048 data points $(\sim 400 \mathrm{~s})$. In some of these time series, power spectra of RBF showed a clear peak in the VLF band. No such VLF peaks were found in the power spectra of $\mathrm{MBF}$ or HBF. In general, the stationarity of these 400-5 series was too low. Therefore the present frequency analysis was performed on time series of 512 data points $(\sim 100 \mathrm{~s})$.

\section{Statistical analysis}

Data are presented as means \pm SE except where noted. Statistical differences between coefficients of variation and average beat-to-beat differences of the hemodynamic parameters were assessed by a Wilcoxon nonparametric rank test. Analysis of variance was used to compare the results obtained by the spectral analyses for arterial pressure with those obtained for blood flows in the four defined frequency bands. In case of significance, a Bonferroni post hoc t-test was applied to identify the individual differences. Statistical significance was accepted at $\mathrm{P}<0.05$. 


\section{Results}

Table 2.1 summarizes the 30 -min average values and lability indexes of both the central and regional hemodynamic parameters. The steady-state values of arterial pressure were not different between groups I and II. However, average PI was slightly but significantly $(-11 \%)$ lower in the group equipped for recording of ascending aortic flow. The reason for this discrepancy is not clear. Because we excluded fever, enhanced behavioral activity, or differences in respiration frequency as a possible cause (see METHODS, Protocol), the difference in heart rate is possibly related to the presence of the electromagnetic flow probe in the thoracic cavity. However, this difference in steady state between groups is of minor importance, since the lability indexes in Table 2.1 and dynamic fluctuations in PI (Table 2.2) were very similar. The long-term lability index of $\mathrm{CO}$ and the three regional blood flows exceeded those calculated for arterial pressure ( $P$ $<0.05$ only for $\mathrm{HBF}$ and $\mathrm{CO}$ ). Also the short-term lability indexes of regional blood flow, and of $\mathrm{CO}$ in particular, were significantly $(\mathrm{P}<0.05)$ elevated above those obtained for arterial pressure.

Series of 512 beats of central and regional hemodynamic recordings as well as their respective power spectra are depicted in Figs. 2.1 and 2.2. These tracings demonstrate the different oscillatory patterns in the various hemodynamic signals. Although the rats were not moving, other events (like deep breaths) cause nonstationarities as indicated by the arrow in Fig. 2.2. Despite the increment in LF power caused by such an

Table 2.2. Comparison of relative spectral powers in VLF, LF, MF, and HF bands for hemodynamic parameters in groups I and II

\begin{tabular}{|c|c|c|c|c|c|}
\hline & \multirow[b]{2}{*}{$\mathrm{n}$} & \multicolumn{4}{|c|}{ Spectral power, \% } \\
\hline & & $\begin{array}{c}\text { VLF } \\
(0.035-0.076 \mathrm{~Hz})\end{array}$ & $\begin{array}{c}\text { LF" } \\
(0.085-0.178 \mathrm{~Hz})\end{array}$ & $\begin{array}{c}\mathrm{MF} \\
(0.297-0.50 \| \mathrm{Hz})\end{array}$ & $\begin{array}{c}H F \\
(1.2-2.0 \mathrm{~Hz})\end{array}$ \\
\hline & \multicolumn{5}{|c|}{ Group I } \\
\hline MAP & 9 & $21+2$ & $35 \pm 3$ & $13 \pm 3$ & $2 \pm 1$ \\
\hline PI & 9 & $31 \pm 3^{\text {* }}$ & $12 \pm 2$ & $3 \pm 1 *$ & $15 \pm 15^{*}$ \\
\hline $\mathrm{CO}$ & 9 & $7 \pm 1 *$ & $7 \pm 1^{*}$ & $7 \pm 1 *$ & $36 \pm 36^{\mathrm{m}}$ \\
\hline$S \mathrm{~V}$ & 9 & $10 \pm *$ & $8 \pm 1 *$ & $8 \pm 1 \%$ & 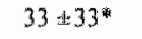 \\
\hline \multirow[t]{2}{*}{ TPR } & 9 & $11 \pm 2^{*}$ & $12 \pm 1 *$ & $7 \pm 1 *$ & $32=32^{4}$ \\
\hline & \multicolumn{5}{|c|}{ Group II } \\
\hline MAP & 8 & $24 \pm 1$ & $32 \pm 3$ & $7 \pm 11$ & $2 \pm 1$ \\
\hline PI & 8 & $33 \pm 3$ & $16 \pm 2 *$ & $y=1$ & $10 \pm 1$ \\
\hline RBF & 8 & $16 \pm 1^{\#}$ & $16 \pm 2^{\%}$ & $10 \pm 1$ & 10 背 \\
\hline MBF & 7 & $10 \pm 1 *$ & $37 \pm 4$ & $7 \pm 1$ & $7 \pm 1$ \\
\hline $\mathrm{HBF}$ & 8 & $26 \pm 3$ & $18 \div 1^{*}$ & $6 \pm 1$ & $9 \pm 2 *$ \\
\hline
\end{tabular}

Values are means $\pm S E$. Frequency bands: VLF, very low; $L F$, low; $M F$, mid; $H F$, high. * $P<0.05$, significantly different from values of $M A P$ within a single frequency band within each group. $+P<0.05$, significantly different between groups I and II. 


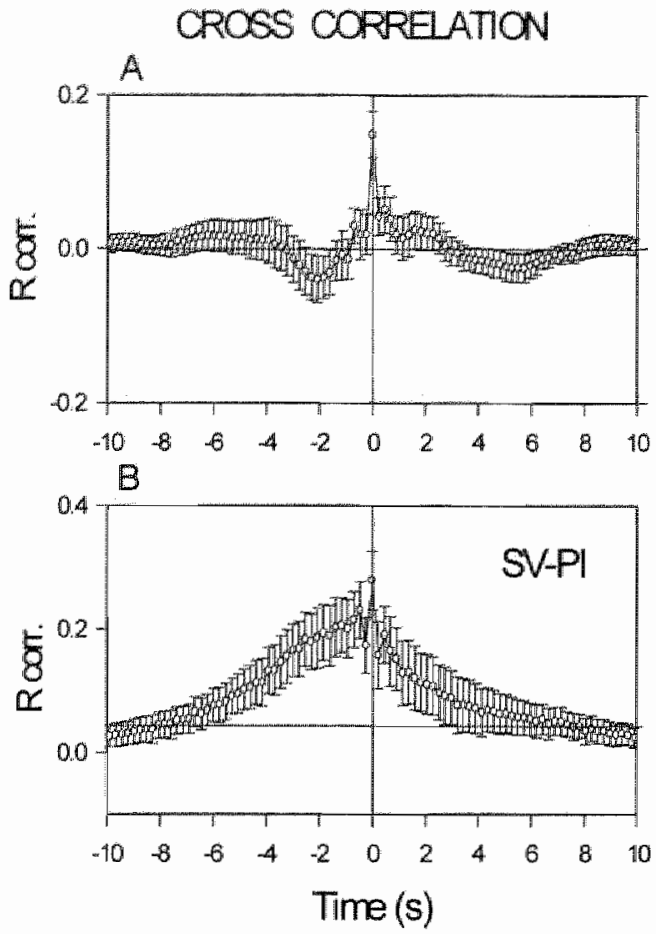

Figure 2.5. A: Average crosscorrelation function between MAP and $C O$. $B$ : Average cross correlation function between $S V$ and $P I$. Data are means $\pm S E$ of 9 rats. For each rat data were calculated from $\sim 32$ overlapping sequential $100-s$ periods. The correlation coefficient $\left(R_{c a r r}\right)$ reaches significance $(P<0.05)$ at values above 0.09 and under -0.09 .

event, most characteristic fluctuations were preserved. For each rat, mean power spectra were calculated by averaging the set of sequential spectra of the recording session. The resultant spectra were again averaged for all rats and are presented in Fig. 2.3. Figures 2.1 and 2.3 demonstrate the prevalence of LF and MF oscillations in the MAP signal and the absence of those oscillations in SV and in CO. Figures 2.2 and 2.3 illustrate the predominance of the LF fluctuations in MBF and to a lesser extent in RBF but not HBF. The average data for the different frequency bands are quantified in Table 2.2. The distribution of MAP and PI over the four different frequency bands was, except for MF of MAP, not different in both groups of rats, suggesting reproducible and comparable hemodynamic stability in the two sets of experiments. The magnitude of the respiratory (HF) fluctuations in CO was comparable to those in SV and made up approximately one-third of all variability in these signals. The HF oscillations in the peripheral flow signals were considerably smaller $(\sim 9 \%)$ and contributed little $(\sim 2 \%)$ to total MAP variability. MF variations were lowest for $\mathrm{PI}(\sim 3 \%)$, and values ranging from 6 to $13 \%$ were found for the MF fluctuations in other parameters. LF fluctuations comprised $\sim 35 \%$ of all wariability in MAP. Because $\mathrm{SV}$ and $\mathrm{CO}$ displayed little LF spectral density power $(\sim 7 \%)$, the LF oscillations must have arisen from resistance to flow. LF oscillations were most pronounced in $\mathrm{MBF}(\sim 35 \%)$, smaller in RBF and HBF ( $17 \%)$, and lowest in SV and CO $(\sim 7 \%)$. VLF power was most abundant in the PI signal. High VLF values were also found for HBF but not for RBF, MBF, CO, and SV.

The vascular admittance gain of MAP and $\mathrm{CO}$ is presented in Fig. 2.4. In the HF band, the admittance gain of MAP vs. CO reached values up to 20 , corroborating the impact of the respiratory fluctuations in $\mathrm{CO}$ on MAP in this frequency range. The 
A
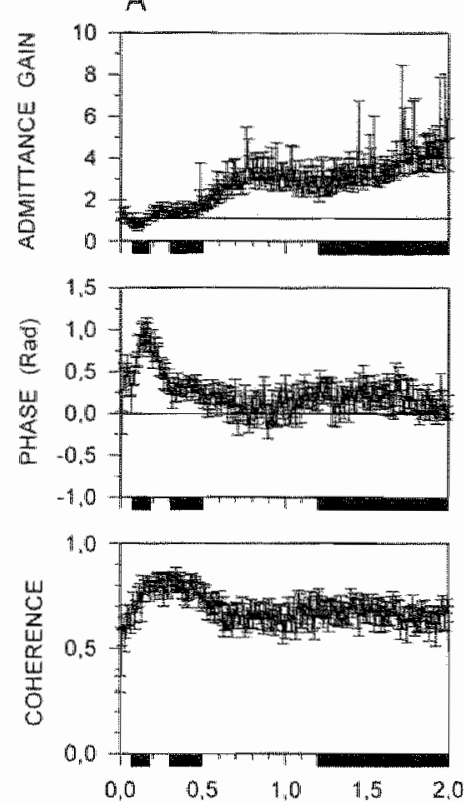

B
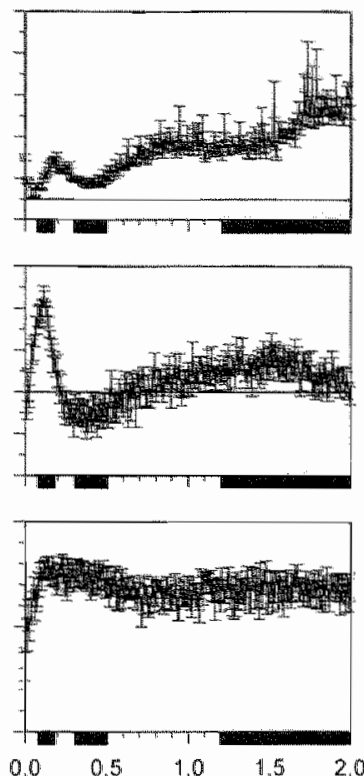

FREQUENCY $(\mathrm{Hz})$
C
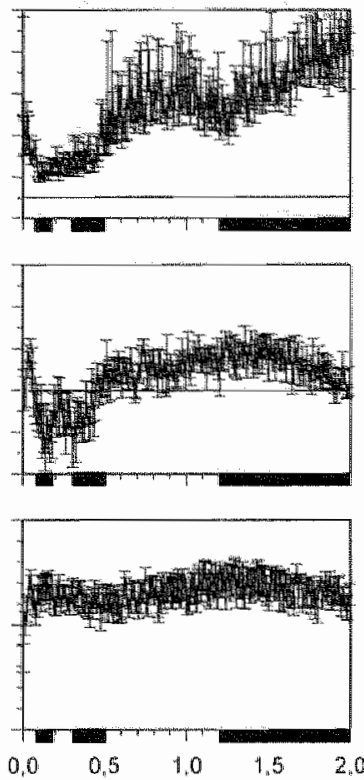

Figure 2.6. Average admittance gain, phase delay, and coherence (significant when $>0.4, p<0.05)$ of MAP vs. RBF (A), MBF (B), and HBF (C), respectively. Dara are means $\pm S E$ of $7-8$ rats. For each rat data were averaged over $\sim 32$ overlapping sequential 100-s periods.LF, MF, and HF bands are indicated by black bars.

cross-correlation function between MAP and CO is presented in Fig. 2.5. Remarkably, fluctuations in MAP and $\mathrm{CO}$ behave independently and were only significantly correlated at zero delay, demonstrating the direct increase in arterial pressure as $\mathrm{CO}$ rises. The cross-correlation function between SV and $\mathrm{Pl}$ is also depicted in Fig. 2.5. The positive correlation values about zero illustrate the lengthening of PJ when SV increases and, vice versa, the increase of SV as PI gets larger. In the peripheral vascular beds the influence of the respiratory cycle on blood flow variations gradually declined, as indicated by the decreasing values of the admittance gain at this frequency (Table 2.3).

The admittance gain of regional blood flow and MAP interactions is presented in Fig. 2.6. In most regional vascular beds, the fractional variations in blood flow in the MF and LF band exceeded those in arterial pressure (admittance gain $>1$ ). Only for the LF band of the MAP-RBF interactions was the admittance gain smaller, but not significantly different from 1. Notably, the phase lag between arterial pressure and RBF and MBF in the LF band on the one hand was opposite to the phase shift between arterial pressure and HBF on the other (Table 2.3). This divergent behavior of the regional flow signals is further demonstrated in Fig. 2.7, showing the cross correlation with MAP. Both RBF and MBF are positively correlated at a time delay near zero, indicating that 

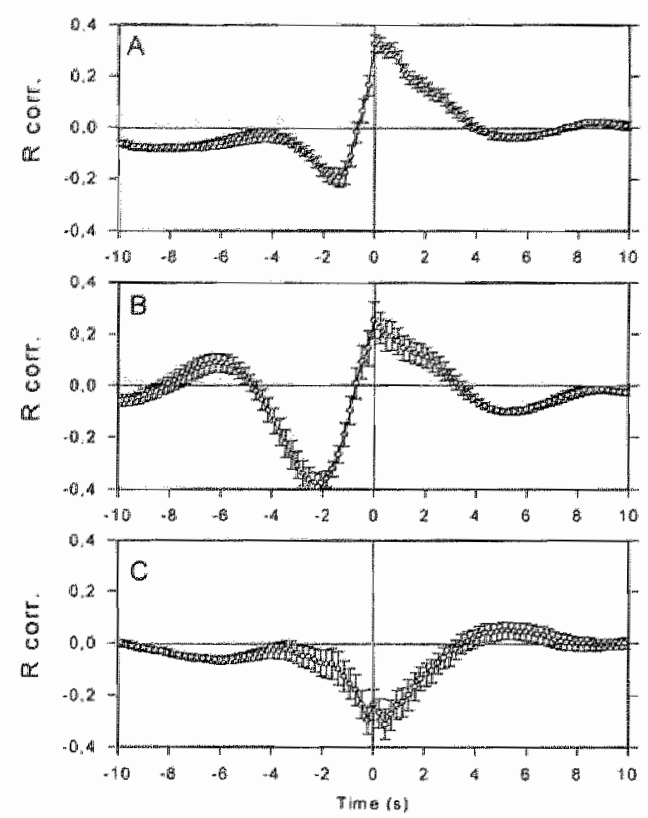

Figure 2.7. Average cross correlation functions between $M A P$ and $R B F(A), M B F(B)$, and $H B F(C)$, respectively. Dala are means $\pm S E$ of $7-8$ rats. For each rat dara were calculated from $\sim 32$ overlapping sequential 100-s periods. $R_{\text {curr }}$ reaches significance $(P<0.05)$ at values above 0.09 and under -0.09 .

changes in pressure are paralleled by similar changes in blood flow. In addition, significant negative correlations were found at approximately $-2 \mathrm{~s}$, meaning that $2 \mathrm{~s}$ after a pressure change, flow changes occurred in the opposite direction. In contrast, the average correlation with $\mathrm{HBF}$ at zero delay was negative, showing that in this vascular bed concurrent changes in pressure and flow occur in opposite directions.

\section{Discussion}

Beat-to-beat changes in arterial pressure, $\mathrm{CO}$, and regional blood flows were analyzed by spectral analysis techniques to characterize the hemodynamics underlying systemic cardiovascular oscillations. The two main findings of this study are that 1) in conscious resting rats the principal oscillations in systemic arterial pressure are centered about $0.13 \mathrm{~Hz}$ and do not arise from fluctuations in $\mathrm{CO}$ but, rather, from those in the renal and mesenteric vascular bed and 2) there is no evidence for autoregulation across all frequencies in any of the peripheral vascular beds studied.

In the present study in conscious rats, we used spontaneous variations of blood pressure as input for calculation of the transfer function to both $\mathrm{CO}$ as well as blood flow in three different vascular beds. Because coherence reached statistical significance for all frequencies in all vascular beds, it appeared that the naturally occurring fluctuations in blood pressure are adequate perturbations to study the transfer properties to the peripheral organs. In most previous related studies, interest was restricted to the analysis of pressure-flow interactions in the renal vascular bed ${ }^{20,21,24,25,28-31}$, whereas transfer properties of arterial blood pressure to RBF were assessed in anesthetized 
Table 2.3. Average coherence, admithance gain, and phase shiffor MAP. CO. RBF, MBF, and $H B F$

\begin{tabular}{|c|c|c|c|c|}
\hline & $\begin{array}{l}\text { Freq } \\
\text { Band }\end{array}$ & Coherence & Admitance Gain, $\%$ & Phase, \\
\hline$\overline{\mathrm{MAP}-\mathrm{CO}}$ & $V L F$ & $0.65=0.02$ & $2.29 \pm 0.41$ & $+0.03 \pm 0.48^{\circ}$ \\
\hline \multirow[t]{3}{*}{$(n=9)$} & $L F$ & $0.65 \pm 0.02$ & $1.84 \pm 0.30$ & $+0.28 \pm 0.15^{\text {b.e.d }}$ \\
\hline & $\mathrm{M} \mathbb{F}$ & $0.63 \pm 0.02^{b}$ & $3.13+0.27^{b}$ & $\pm 0.003 \pm 0.03$ \\
\hline & $\mathrm{HF}$ & $0.69 \pm 0.03$ & $18.4 \pm 4.3$ boud & $-0.002 \pm 0.003^{0 . d}$ \\
\hline MAP-RBF & $\mathrm{VLF}$ & $0.64 \pm 0.04$ & $1.06 \pm 0.17$ & $+1.20 \pm 0.22$ \\
\hline \multirow[t]{3}{*}{$(n=8)$} & LF & $0.76 \pm 0.04$ & $0.91 \pm 0.10^{\mathrm{c} .4 \mathrm{~s}}$ & $40.96 \pm 0.11^{\mathrm{a} d}$ \\
\hline & $\mathrm{MF}$ & $0.79 \pm 0.03^{\mathrm{add}}$ & $1.53 \pm 0.22^{.40}$ & $+0.12 \pm 0.02^{\mathrm{e} i}$ \\
\hline & HF & $0.67 \pm 0.03$ & $3.73 \pm 0.42^{a}$ & $+0.019 \pm 0.005$ \\
\hline $\mathrm{MAP}-\mathrm{MBF}$ & $V \mathbb{L F}$ & $0.61 \pm 0.05$ & $1.37 \pm 0.12$ & $+1.67 \pm 0.22^{8}$ \\
\hline \multirow[t]{3}{*}{$(n=7)$} & LF & $0.76 \pm 0.04^{b}$ & $2.20 \pm 0.24^{b}$ & $+0.90 \pm 0.10^{\mathrm{add}}$ \\
\hline & $\mathrm{MF}$ & $0.74 \pm 0.04^{b}$ & $1.84 \pm 0.14$ & $-0.10 \pm 0.04^{b}$ \\
\hline & $\mathrm{HF}$ & $0.68 \pm 0.05$ & $4.46 \pm 0.57^{a}$ & $+0.025 \pm 0.006^{i}$ \\
\hline MAP-HBF & VLF & $0.63 \pm 0.05$ & $3.44 \pm 0.56$ & $+0.61 \pm 0.39$ \\
\hline \multirow[t]{3}{*}{$(n=8)$} & LF & $0.66 \pm 0.06$ & $2.30 \pm 0.26^{b}$ & $-0.50 \pm 0.16^{2 . b x}$ \\
\hline & $\mathrm{MF}$ & $0.62 \pm 0.05$ & $3.15 \pm 0.52^{b}$ & $-0.09 \pm 0.03^{h}$ \\
\hline & HF & $0.67 \geq 0.05$ & $6.87 \pm 0.58^{\mathrm{a}}$ & $+0.037 \pm 0.007^{\mathrm{a}}$ \\
\hline
\end{tabular}

Values are means $\pm S E$. "h.hed Significantly different from values within the same frequency band of MAP-CO, MAP-RBF, MAP-MBF, and MAP-HBF, respectively

animals during forcing of the arterial pressure signa [24.25.30.

As indicated by the individual tracings in Figs. 2.1 and 2.2, three distinct oscillations in MAP can be identified under resting conditions in rats. The hemodynamic characterization of these HF, MF, and LF oscillations in MAP is discussed in detail below. For reasons explained in METHODS VLF fluctuations are not discussed.

\section{Respiratory (HF) oscillations in MAP}

The amount of the respiratory-related HF power to overall MAP variability was low and generally not higher than $5 \%$, which is roughly similar to values found in other rat studies 9.11 .12 .14 . Particularly when longer time tracings were analyzed, the contribution of HF power to total MAP variability declined because in resting rats the breathing rhythm was regularly interrupted, about every minute, by a deep breath, causing nonstationarities in the hemodynamic recordings as indicated in Fig. 2.2. The present data clearly indicate that changes in $\mathrm{CO}$ were the primary source of HF fluctuations in MAP. Comparison of the vascular admittance values in the HF band indicated to what degree these respiratory fluctuations in $\mathrm{CO}$ were dampened along the vascular tree. The HF fluctuations in HBF, MBF, and RBF were respectively $2.7,4.1$, and 4.9 times smaller than those in the ascending aortic flow. Regarding the similarity in the tracings of SV and $\mathrm{CO}$ (Fig. 2.1) and the difference in HF spectral power between SV and PI, it can 
be concluded that, at least in resting conditions, the HF fuctuations in CO were mainly caused by respiration-synchonous oscillations in $S V$ and not in PI. Because neither sinoartic denervation nor chronic sympathectomy reduced the magnitude of the HF oscillations in MAP in rats ${ }^{2}$ is , it seems that in this species the respiratory-related fluctuations in $\mathrm{CO}$ are devoid of neural imfluences and are purely mechanical in origin. In fact, as indicated by the positive cross-correlation function, the lengthening of the interbeat interwal may have a stabilizing influence on the variability in CO when SV rises ${ }^{4}$. In dogs, however, heart rate oscillations seem to dominate the lability in $\mathrm{CO}^{*}$; whereas in humans, as in rats, fuctuations in $\mathrm{SV}$ are the main source of respiratoryrelated wariability in $\mathrm{CO}^{32}$.

\section{Autonomic (MF) oscillations in MAP}

In rats, MF oscillations have been shown to be largely dependent on the antegrity of the autonomic nervous system ${ }^{92-14}$. In the present study spectral density power and vascular admittance of the MF band were roughly similar for ascending aortic and regional blood flows. This suggests that both $\mathrm{MF}$ fluctuations in $\mathrm{CO}$ as well as resistance to flow contribute to these $-2.5-5$ oscillations in MAP. The extent that MF power contributed to total MAP varialility was $\sim 10 \%$. This seems rather small compared with other rat studies. 11.12 . 14 but can be explained by the differences in the definition of the width of this frequency band in these studies as well as the arousal level of the animals". In sympathectomized rats, MF oscillations in MAP were absent ", suggesting that these MF oscillations depend highly on the integrity of the sympathetic nerves. However, in direct recordings of sympathetic nerve activity in rats, no explicit peaks at $0.4 \mathrm{~Hz}$ were found ${ }^{\text {}}$. Further experiments are needed to clarify whether this discrepancy could be explained by transfer properties of the nerve signal to vascular smooth muscle or to cardiac muscle. Vascular $\mathrm{MF}$ admittance gain was higher in the hindquarter than renal or mesenteric vascullar beds, which may be indicative of a greater autonomic influence on this vascular bed in the resting state ${ }^{33}$. This hypothesis is supported by the present findings. As indicated by the cross-correlation function, HBF and MAP were significantly negatively correlated about zero time delay. A physiological interpretation of this relationship is that the HBF changes are responsible for the MAP changes, which may be govemed by the autonomic nervous system. In contrast, RBF and MBF showed significant positive contelations with MAP about zero. This probably reflects the elastic behavior of these vascular beds when pressure rises. The above-mentioned differential pattern of pressure-flow interactions in the three vascular beds only applies to the resting state and may be different when bethavior changes. We found that the occasional movements of the rats increased blood low through this region by $>40 \%$, whereas RBF and MBF fell only by $\sim 3$ and $9 \%$, respectively. This may explain the significantly higher long - term lability index for HBF. Furthemore, it should be noted that blood flow through the abdominal aorta is the result of now through the bindlimb muscles, tail, and parts of the skin.

\section{Myogenic (LF) oscillations in MAP}

This is the first study in rats showing that a substantial part of LF power in MAP was due to clear oscillations centered about $0.13 \mathrm{~Hz}$. Spectral analysis of the hemodymamic recordings indicated that the LF oscillations in MAP resulted from resistance to flow and were especially prominent in the mesenteric vascular bed. Because 
this vascular bed receives a relatively high proportion of $\mathrm{CO}$ in resting rats is is not surprising that these LF oscilations in MBF were transmitted into the MAP signal. LF fluctuations in RBF may have also contributed, since the time lags of the LF oscillations in RBF and MBF with MAP were wery similar. The time shift between MAP and the regional low signals identified by the cross-correlation function were somewhat difer ent, because this calculation necessarily includes all frequency components. Nonetheless, we found that the fluctuations in MAP were leading those in MBF and RBF by $=$ $2 s$ and that they were negatively correlated. This correlation pattern was repeated every $8 \mathrm{~s}$, as could be expected from the predominance of the LF fluctuations in these signals. The physiological interpretation of such a pressure-flow relationship is that when pressure increases, significant reductions in blood flow occur at the indicated delay. The present characteristics are suggestive of active myogenic control of blood flow. In fact, in this conscious preparation, the myogenic response of the mesenterio arteries seems so robust that the LF fluctuations in MBF were proportionally about twice the MAP huctuations. Thus rather than autoregulation, this owershooting reaction points to superregulation ${ }^{35}$. The pressure-flow interactions seem less vigorous in the renal vascular bed, since here the admittance gain was smaller but not statistically significantly different from 1. In anesthetized rats, with the wse of forced pressure fuctuations, similar interactions between arterial pressure and RBF have been identified in the $0.1-$ to $0.2-\mathrm{Hz}$ band with a response time of $\sim 1 \mathrm{~s}^{24,25.22}$. In addition, in various experimental and clinical microcimculatory preparations (muscle, cerebral, and skin), blood flow shows spontaneous fluctuations in frequency ranges similar to LF oscillations seen here ${ }^{36}$. Interestingly, these fuctuations increased in frequency and amplitude under conditions of low blood pressure or hy poperfusion, suggesting a myogenic reaction 35 .

The LF oscillations in regional blood flow are not necessarily pressure dependent but may also arise from an endogenous oscillator located in the peripheral vessell. Resistance arteries isolated from various organs, in particular from the mesentery, are known to exhibit spontaneous LF oscillatory contractions, especially when stimulated with agonists ${ }^{3 \% 39}$. In addition, in a modeling study, Ursino and colleagues ${ }^{40}$ showed that self-sustamed oscillations can develop when the dymamic component of the myogenic response of terminal arterioles is greater than that of more proximal arterioles in a vascular bed.

Because the present LF oscillations originate from resistance vessels, their activity must be somewhat synchronized or otherwise no rhythmicity would have been found in whole organ blood flow. Thus the absence of peaks in this frequency band may not decisively exclude myogenic activity, because the contractile activity of the smooth muscle cells may be out of phase. However, from microcircullatory work it is known that periodic vasomotion may spread upstream over the arteriolar network". This property may synchronize and increase the amplitude of the oscillation, so that it can be detected in whole organ blood flow. Similarly, related oscillations in tubula. pressure in adjacent nephrons are known to entrain and thereby enlarge their impact on autoregulation of $\mathrm{RBF}^{42}$.

The superregulatory behavior of the LF oscillations does not exclude its serwing a homeostatic function in the control of organ blood flow. Although its characteristics are that of a vicious cycle, causing further rise in resistance in response to a pressure 
increase, this mechanism is probably often overruled by the baroteflex when systemic pressure increases its threshold value. On the other hand, in the case of a pressure decrease, a further pressure fall is probably also prevented by the baroreflex. Support for the stabitizing function of the autonomic nervous system comes from a study in sympathectomized rats ${ }^{13}$. Arterial pressure lability in these rats is characterized by many spontaneous hypotensive episodes. The regional flow pattem accompanying such a hypotensive cwent showed that vasodilation in the mesenteric vascular bed followed the pressure fall amplifying the fall in pressure'.

The amplitude of the LF oscillations may also be influenced by other oscillatory mechanisms ${ }^{234}$. Ye and colleagues ${ }^{28}$ reported that during inhibition of slow $(-0.03 \mathrm{~Hz})$ tubuloglomerular feedback (TGF) related oscillations in single-nephron blood flow fluctuations in the LF myogenic band increased, whereas they fell at saturation of TGF. On the basis of such an inverse relationship, it is tempting to speculate that the abundance of $L E$ power in the mesenteric vascular bed may be partly due to the absence of a slow regulatory mechanism in this organ.

In humans, the so-called 10-s rhythm in blood pressure and heart rate has been thought to depend primarily on the autonomic nervous system activity ${ }^{2}{ }^{3}$. Changes in the amplitude of these LF oscillations are increasingly used as markers to estimate clinical autonomic disturbances ${ }^{2-4}$. The clinical implication of this study is that if the elements of the arterial tree in humans behave similarly as those in rats, myogenic fluctuations may also contribute to the so-called 10 -s rhythm in blood pressure in humans.

In summary, in conscious resting rats, spontaneous fluctuations in systemic arterial pressure predominantly exhibit slow $(\sim 8 \mathrm{~s})$ oscillations, which do not arise from fluctuations in CO but originate from regionally specific oscillatory mechanisms contributing to resistance to flow. These blood flow fluctuations were most pronounced in the mesenteric and renal vascular beds and displayed flow-conserving myogenic-like superregulatory character. In contrast, blood flow oscillations in the hindquarter vascular bed were typified as being caused by mechanisms that serve systemic pressure control.

\section{References}

I. Appel ML, Berger RD, Saul P, Smith $M_{M}$, Cohen RI: Beat-to-beat variability in cardiovascular variables, Noise or music? J Am Coll Cardiol 1989;14: $1139-1148$.

2. Malliani A, Pagani $M$, Lombardi F, Cerutti S: Cardiovascular Neural Regulation Explored in the Frequency Domain. Circulation 1991; 84: 482-492.

3. Elghozi $\mathrm{Jl}$, Laude D, Girard A: Effects of respiration on blood pressure and heart rate variability in humans. Clin Exp Pharmacol P/hysiol 1991; 18: 735-742.

4. Brown TE, Beightol LA, Koh J, Eckberg DL: Important influence of respiration on human R-R interval power spectra is largely ignored. I Appl Physiol 1993; 75: 2310231.7

5. Peñáz J: Mayel waves: history and methodology. Awomedica 1977; 2; 135-141.

6. DeBoer RW, Karemaker JM, Strackee J: Hemodynamic huctuations and baroreflex sensitivity in humans: a beat-to-beat model. Am J Physiol $1987 ; 253$ : H680-H689. 
7. Rimoldi O, Pierini S, Ferrari A, Ceruti S, Pagani M, Malliani A: Analysis of shortterm oscillations of R-R and arterial pressure in conscious dogs. Am J Plysiol 1900 258: $4967-H 976$.

8. Di Rienzo M, Parati $G$, Castiglioni $P_{0}$ et al: Role of sinoaontic afferents in modulating $\mathrm{BP}$ and pulse-interval spectral characteristics in unanesthetized cats. Am J Plysiol $1991 ; 261$ : H181 I-H1818.

9. Japundzic $N$, Grichois $M-L$, Zitoun $P, \mathbb{L}$ aude D, Elghozi J-L: Spectral analysis of blood pressure and heart rate in conscious rats: effects of autonomic blockers. I Awon Nerv Syst 1990; 30: 91-100.

10. Persson $P B$, Stauss $H$, Chung $O$, Wittmann $U$, Unger T: Spectrum analysis of sympathetic nerve activity and blood pressure in conscious rats. Am J Physiol 1992; 263: H1348-H1355.

11. Blane J, Grichois ML, Vincent M, EIghozi JL: Spectral analysis of blood pressure and heart rate variability in response to stress fron air-jet in the Lyon rat. $J$ Auton Pharmacol 1994; 14: 37-48.

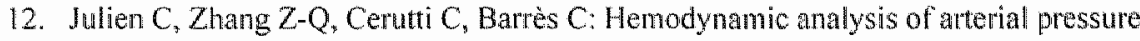
oscillations in conscious rats. J Awon Nerv Syst 1995; 50: 239-252.

13. Zhang ZQ, Julien $C$, Gustin MP, Cerutti $C$, Barres $C$ : Hemodynamic analysis of arterial pressure lability in sympathectomized rat. Am J Physiol 1994; 267(1 Pt 2): H48-H56.

14. Cerutti $C$, Barres $C$, Paultre $C$ : Barorefex modulation of blood pressure and heart rate variabilities in rats: assessment by spectral analysis. Am J Physiol 1994; 266: H1993$\mathrm{H} 2000$.

15. Inoue K, Miyake S, Kumashiro M, Ogata H, Ueta T, Akatsu T: Power spectral analysis of blood pressure variability in tramatic quadriplegic humans. Am J Physol 1991; 260: 1 8842-H847.

16. Haxhiu MA, VanLunteren $\mathbb{E}_{\text {, Deal }} \mathrm{EC}$, Cherniack NS: Role of the ventral surface of medulla in the generation of Mayer waves. Am J Physiol 1989 257: R804-R809.

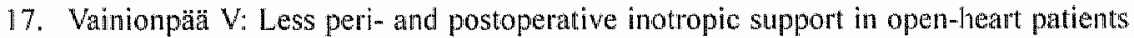
with vasomotor waves during cardiopulmonary bypass? Basic Res Cordiol 1989;84: 653-660.

18. Persson PB, Ehmke H, Köhler WW, Kirchheim HR: Identification of major slow blood pressure oscillations in conscious dogs. Am J Physiol 1990; 259: H 1050-H 1055.

19. Grady $\mathrm{HC}$, Bulliwant $\mathrm{MA}$ : Renal blood flow varies during normal activity in conscious unrestrained rats. Am J Physiol 1992; 262: R926-R932.

20. Marsh DJ, Osborn JL, Cowley Ir AW: $1 / f$ fluctuations in arterial pressure and regulation of renal blood flow in dogs. Am J Physhol $1990 ; 258$ : F $1394-\mathrm{F} \| 400$.

21. Persson $\mathrm{PB}$, Ehmke H, Kurcheim HR, et al: Autoregulation and non-homeostatic behaviour of renal blood flow in conscious rats. J Physiol 1993; 462:261-273.

22. Janssen BJA, Struyker Boudier HAJ, Smits JFM: Acute arteriolar vasoconstriction following furosemide in conscious spontaneously hypertensiwe rats. Eur.J Phormacol $1989 ; 170: 1-9$.

23. Janssen BJA, Van Essen H, Struyker Boudier HAJ, Smits IFM: Hemodynamic effects of activation of renal and mesenteric sensory nerves in rats. Am J Physiol 1989;257: R29-R36.

24. Daniels FH, Arendshorst WJ, Roberds RO: Tubuloglomerular feedback and autoregtlation in spontaneously hypertensive rats. Am J Physiol 1990; 258: F1479-F1489.

25. Holstein-Rathlou N-H, Wagner AJ, Marsh DJ: Tubuloglomenular feedback dynamics and renal blood flow autoregulation in rats. Am J Physiol 1991; 260: F53-F68.

26. Cerutti $C$, Gustin MP, Paultre $C Z$, et al: Autonomic nervous system and cardiovascu. lar variability in rats: a spectral analysis approach. Am J Physiol $1991 ; 261$ : H1292H1299. 
27. Chen $Y-M$, Holsten-Rathou $N$-H: Differences in dynamic autoregulation of renal blood tlow beween SHR and WKY rats. An I Physiol 1993; 264: F166-F174.

28. Yip K-P, Holstein-Rathlou N-H, Marsh DJ: Mechanisms of temporal variation in single-nephron blood flow in rats. Am J Physiol 1993; 264: F427-F434.

29. Skatatos S, DiPaola W, Frankel RA, al: Spontaneous pressure-flow relationships in renall circulation of conscious dogs Am J Physiol 1993;264: H1517-H1527.

30. Chon KH, Chen $Y$-M, Marmarelis VZ, Marsh DJ, Holstein-Rathlou NH: Detection of interactions between myogenic and TGF mechanisms using non-linear analysis. Am J Physial 1994:267: F160-F173.

31. Skarlatos S, Metting PJ, Britton SL: Spontaneous pressure-flow pattems in the kidney of conscious rats. Am I Physiol 1993; 265: H2151-H2159.

32. Toska K, Eriksen M: Respiration-synchronous fuctuations in stroke volume, heart rate and arterial pressure in humans. I Physiol Lond 1993; 472: 501-512.

33. Machado BH, Bonagamba LGH, Castania JA, Menani JV: Aortic baroreceptors play a dominant role in the regulation of hind imb vascular resistance in rats. A $f$ Physiol 1994; 267: R467-R480.

34. Delp MD, Manning $Q_{4}$ Bruckner JV, Armstrong RB: Distribution of cardiac output during diumal changes of activity in rats. Am J Plysiol 1991; 261: H1487-H1493.

35. Ping $\mathrm{P}$, Johnson $\mathrm{PC}$ : Role of myogenic response in enhancing autoregulation of flow during sympathetic nerve stimulation. Am f Physiol 1992; 263: H1177-H1184.

36. Intaglietta M: Arteriolar vasomotion: implications for tissue ischemia. Blood Vessels $1991: 28: 1.7$.

37. Myers JH, Lamb FS, Clinton-Webb R: Norepinephrine-induced phasic activity in tail arteries from genetically hypertensive rats. Am I Physiol 1985; 248: $\mathrm{H} 419-\mathrm{H} 423$.

38. Van Bavel E, Giezeman MJJM, Mooij T, Spaan JAE: Influence of pressure alterations on tone and vasomotion of isolated mesenteric small arteries of the rat. J P/ysiol 1991 ; $436: 371.383$.

39. Gustafsson H, Mulvany MJ, Nilsson H: Rhythmic contractions of isolated small arteries from rat: influence of endothelium. Acta Phwsiol Scand 1993; 148: 153-163.

40. Ursino M, Fabbri $\mathrm{G}$, Belardinelli $\mathrm{E}$ : A mathematical analysis of vasomotion in the peripheral vascular bed. Cardioscience 1992; 3; 13-25.

41. Segal SS, Duling BR: Propagation of wasodilation in resistance vessels of the hamster: development and review of a working hypothesis. Circ Res 1987; 61:20-25.

42. Kalliskog $\mathrm{O}$, Marsh DI: TGF-induced vascular interactions between adjacent nephrons in the rat kidney. Am \& Physial 1990; 259: F60-F64. 


\section{Chapter 3 \\ Validation of a continuous}

baroreceptor reflex sensitivity

index calculated from

spontaneous fluctuations of

blood pressure and pulse interval

in rats

Jan Oosting

Harry A.J. Struijker-Boudier

Ben J.A. Janssen

Published in : Journal of Hypertension 1997, 15:391-399

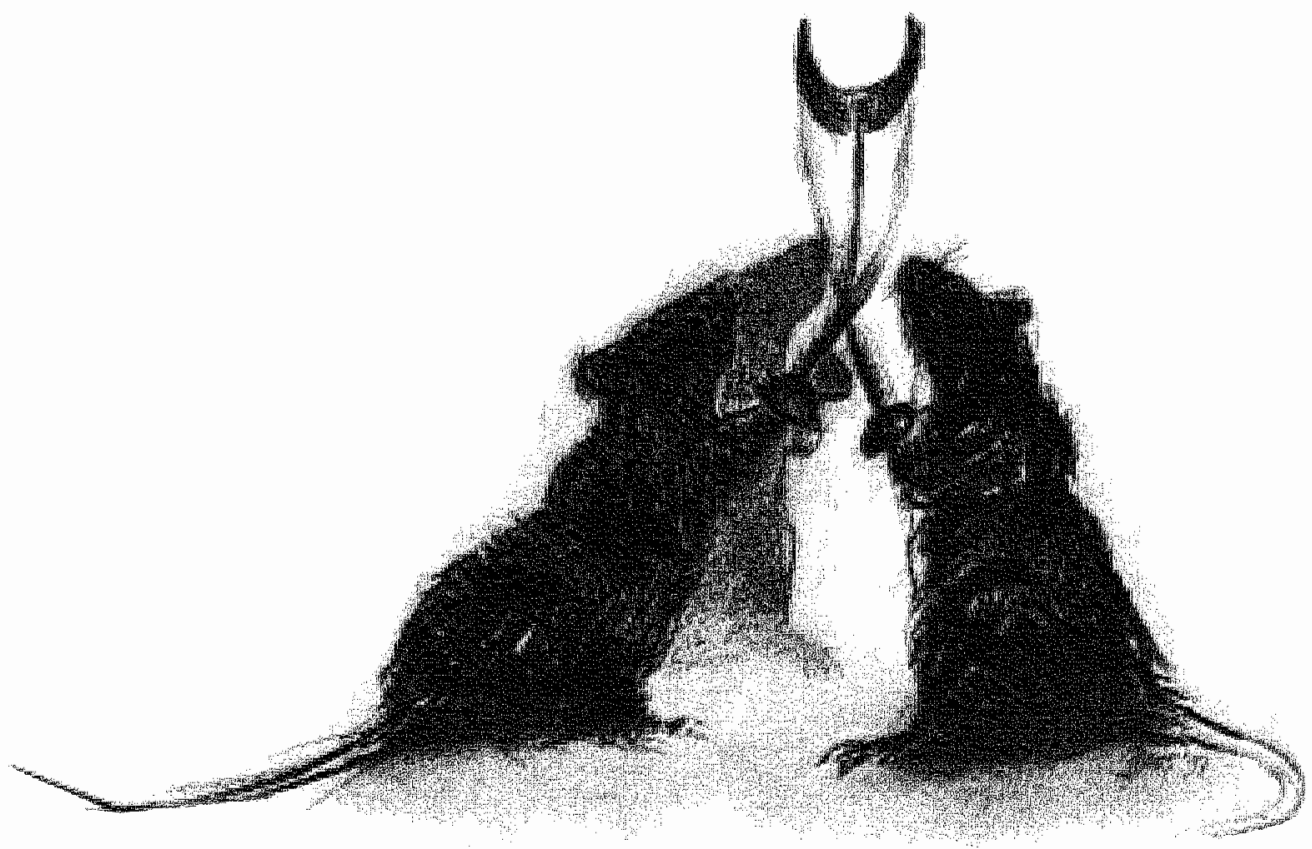




\section{Abstract}

Objective To develop and validate a technique for the continuous computerized calculation of the baroreceptor reflex sensitivity (BRS) of the heart rate in rats.

Design The BRS was calculated from spontaneous changes in blood pressure and pulse interval using spectral analysis as well as time-series techniques. The BRS values obtained with these techniques were compared with those obtained by standard pharmacological methods.

Methods The blood pressure and pulse interval in adult Wistar-Kyoto (WKY) rats were recorded on a beat-to-beat basis for two consecutive $30 \mathrm{~min}$ periods. During one of these periods the BRS was determined pharmacologically by injections of nitroprusside and phenylephrine. Measurements were performed after administration of saline as vehicle or during manipulation of the autonomic nervous system by infusion of metoprolol, methyl-atropine and hexamethonium. Sequential time-series methods for continuous BRS calculation were tested for $24 \mathrm{~h}$ periods in intact WKY rats as well as in WKY rats that had been subjected to sino-aortic denervation or to electrical lesioning of the nucleus tractus solitarius.

Results The correlation coefficient between BRS values in intact WKY rats derived from the pharmacological method and those from spectral analysis techniques was low $\left(R^{2}=0.16\right)$. The correlation coefficient between $B R S$ values from the pharmacological method and those from the developed time-series method was higher $\left(R^{2}=0.64\right)$. The BRS measured using the latter method was found to vary over $24 \mathrm{~h}$ with the highest values during the sleeping period. After surgical elimination of the baroreflex, the algotithm returned BRS values close to zero throughout the $24 \mathrm{~h}$ period. The BRS estimate was found to be a measure of the parasympathetic rather than of the sympathetic component of the baroreceptor reflex.

Conclusion The developed time-series method calculates an index of the gain of the cardiac baroreflex in rats faithfully. This method can be implemented in data acquisition software, allowing continuous on-line monitoring of the cardiac baroreflex gain. 


\section{Introduction}

The baroreceptor reflex is the most important regulatory mechanism in the shortterm control of the heart rate and blood pressure and operates through the autonomic nervous system. In the past, the gain of the cardiac baroreflex, further referred to as the baroreflex sensitivity (BRS), has usually been obtained by comparing changes in heart rate as a consequence of imposed blood pressure changes induced by pharmacological or mechanical methods ${ }^{1-5}$. Measuring the BRS from spontaneous variations in blood pressure and heart rate has, in principle, several advantages over methods that provoke changes in blood pressure. There is no need to administer vasoactive compounds or external appliances that could influence the baroreceptor reflex by a direct action on receptor or effector sites. Second, the BRS is measured within physiological blood pressure ranges, allowing the computation of the gain at the operating point of the blood pressure with minimal non-specific effects from other afferent nerves. Furthermore, these methods do not arouse subjects or animals, thereby reducing stress-induced effects. Finally, in contrast to the pharmacological or mechanical methods, they are suitable to assess the BRS over prolonged periods of time.

Published methods that evaluate the BRS from spontaneous changes in blood pressure and heart rate make use of spectral analysis techniques ${ }^{6.7}$, of spontaneously occurring ramps in blood pressure ${ }^{8-10}$ or of statistical relationships between blood pressure and pulse interval changes ${ }^{11}$. With advancing computer technology, it should now be possible to implement such methods in data-acquisition software, making continuous BRS recordings possible. However, before such a method can be applied, not only technical but also physiological testing is required. Here we describe such physiological validation studies. Experiments were performed in rats. This species was chosen to allow extensive surgical and pharmacological interventions to manipulate the gain of the baroreflex. We compared spectral analysis techniques ${ }^{6}$ and modified time-series methods ${ }^{8}$ with standard pharmacological methods 1.5 in terms of their applicability for the on-line determination of the cardiac baroreflex gain. In addition we evaluated the effect of low-pass filtering the spontaneous fluctuations of the blood pressure and heart rate data. There is increasing evidence that the baroreflex is especially capable of buffering lowfrequency variations in pressure. After sino-aortic denervation (SAD) the spectral density power of the blood pressure increased, especially at low frequencies (below $0.1 \mathrm{~Hz}$ ), whereas it decreased at high frequencies ${ }^{12.14}$.

The BRS calculated from spontaneous fluctuations should show a high correlation to pharmacological methods, detect contrasts in animals with known differences in BRS and return a zero value in cases without baroreflex activity. For these reasons the methods were tested on data obtained in rats that had been treated with agents that block part or all of the autonomic nervous system as well as in rats that had been subjected to sino-aortic denervation or to bilateral lesioning of the nucleus tractus solitarius. With regard to these criteria we developed an algorithm that calculated faithfully and continuously a minute-to-minute BRS index from spontaneous ramps in blood pressure and pulse interval in 16 rats simultaneously using an IBM-compatible $50 \mathrm{MHz}$ 486 computer. 


\section{Methods}

\section{Animats}

Adult WKY rats weighing $280-300$ g each were used. The rats were obtaned from the central Animal Facilities of the Universiteit Maastricht. Expeniments were performed according to the Universiteit Mastricht guidelines. After they had undergone surgery, the animals were housed individually in cages. Rats were kept on a $12 \mathrm{~h} / \mathrm{l} 2 \mathrm{~h}$ light/dark cycle and were allowed normal rat chow and drinking water ad libitum.

\section{Surgery}

All rats were instrumented with an arterial catheter for measuring their blood pressure and two venous catheters for administering drugs, as described in detail previously "In short, the catheters were implanted with the rats under pentobarbital anaesthesia ( $60 \mathrm{mg} / \mathrm{kg}$ intraperitoneally) via the femoral vessels and then tumelled to the lower back of the animal. The catheters were exteriorized through a $40 \mathrm{~cm}$ long steel spring that was fixed to the back muscles using silicone rubber artached to a piece of mersilene gauze. The venous catheters were filled with $5 \mathrm{U} / \mathrm{ml}$ heparinized saline solution. The steel spring was led to the outside of the cage, where the arterial catheter was connected via a hydraulic swivel (model 375/20; Instech Labs, Plymouth Meeting, Pennsylvania, USA) to a low-volume displacement pressure transducer (microswitch, model 156PC 156W/ Honey well, Inc., Amsterdam, The Netherlands). The arterial canula was kept patent by continuous arterial infusion of $30 \mathrm{U} / \mathrm{ml}$ heparinized saline solution at a rate of $2.4 \mathrm{ml} / \mathrm{day}$. This set-up allowed us to measure blood pressures continuously and to administer drugs without disturbing the rats.

\section{Data acquisition}

After at least 3 days of recovery the measurements were performed in the home cage of the animal. The arterial pressure transducer was connected to an amplifier that delivered a high-voltage signal to an analogue-to-digital converter board (model 2814 ; Data Translation, CN Rood, Rijswijk, The Netherlands) connected to an IBM-compatible computer. The blood pressure signal was sampled with two computerized units, one operating at $500 \mathrm{~Hz}$, the other at $1000 \mathrm{~Hz}$. The detection limit of blood pressure changes was smaller than $0,1 \mathrm{~mm} / \mathrm{Hg}$. Beat-to-beat pulse interval, heart rate and mean arterial pressure values were calculated on-line and stored on hard disc. We recorded the mean arterial pressure instead of the systolic blood pressure, because, especially during long-term recordings, the mean arterial pressure is more reliable than is the systolic blood pressure. The pulse pressure in unobserved catheterized rats sometimes decreases due to movement artefacts and catheter position problems. The mean arterial blood pressure is less affected by this than is the systolic blood pressure.

\section{Protocols}

To validate the methods which calculate an index of the gain of the cardiac baroreftex from spontaneous blood pressure fluctuations, a set of beat-to-beat blood pressure and pulse interval sequences was obtained for rats in which the baroreflex sensitivity was also measured by the pharmacological "Oxford method" 5 . In onder to obtain a wide range in the cardiac baroreflex gain, recordings were performed under the 
following conditions: the cardiac sympathetic system was blocked by $1.5 \mathrm{mg} / \mathrm{kg}$ metoprolol ( $\mathrm{n}=10$ ); the cardiac parasympathetic system was blocked by $0.5 \mathrm{mg} / \mathrm{kg}$ methyl-atropine $(n=7)$; both cardiac nervous systems were blocked by combining metoprolol and methyl-atropine ( $\mathrm{n}=11)$; ganghionic transmission was blocked by hexamethonium $(n=14)$; and saline was administered as vehicle $(n=26)$. Metoprolol and methyl-atropine were dissolved in saline and injected as an intravenous bolus $(<350 \mu \mathrm{l})$. To avoid great falls in blood pressure, which are ewoked when hexamethonium is adninistered as a bolus injection, we infused this agent at a rate of $25 \mathrm{mg} / \mathrm{kg}$ per $\mathrm{h}$, starting 1 $\mathrm{h}$ before the recordings. When rats were used for multiple recordings, the recordings of the separate autonomic conditions were performed at intervals of at least 2 days.

Under each condition two consecutive recordings each of duration $30 \mathrm{~min}$ were performed in random order. During one period the blood pressure and heart rate were allowed to vary spontaneously. During the other the blood pressure was changed by bolus injections of $0.1 \mathrm{mg} / \mathrm{ml}$ sodium nitroprusside and $0.03 \mathrm{mg} / \mathrm{ml}$ phenylephrine. These agents were injected alternately in volumes ranging from 2 to $30 \mu 1$, administered within $2-5 \mathrm{~s}$ to obtain changes in blood pressure ranging from -40 to $+40 \mathrm{mmHg}$. At least six injections of each drug were administered. The injection volumes were allocated in random order.

In an additional experiment surgical disruption of the baroreflex was performed in six WKY rats $\mathbb{1}$ week before the catheters were implanted. Three rats were subjected to SAD using the method described by Krieger ${ }^{16}$. A bilateral electrical lesion of the nucleus tractus solitarius (NTS) was made in 3 other rats according to the method of Buchholz and Nathan ${ }^{17}$. That denervation had been achieved in these rats was confirmed by the absence of heart rate changes greater than 15 beats/min after a reduction by about $40 \mathrm{mmHg}$ in blood pressure had been induced by injections of sodium nitroprusside. In addition, the presence of NTS lesions was confirmed by histology. In these rats as well as in intact WKY rats $24 \mathrm{~h}$ beat-to-beat recordings of blood pressure and heart rate were performed.

\section{Calculations of the BRS of the heart rate}

\section{Pharmacologically induced blood pressure changes}

From each change in pressure evoked by bolus injections of phenylephrine or sodium nitroprusside, the BRS was calculated as the slope of the linear regression function between the beat-to-beat changes in mean arterial pressure and the related beat-to-beat changes in pulse interval at a delay that scored the highest correlation coefficient 5 . The average BRS estimate was calculated as the mean value of $8 \pm 1$ increasing and $11 \pm 1$ decreasing ramps. In intact rats, the gains of the increasing and decreasing ramps did not differ (phenylephrine $0.94 \pm 0.11$, sodium nitroprusside $0.95 \pm$ 0.09 ). The delay of the pulse-interval response was in the range 2.14 beats, tachycardic responses generally being two or three beats later than bradycardic responses. Because methods triggering on spontaneous fluctuations provide only a value of the gain of the baroreflex, we did not construct a complete sigmoidal baroreflex curve to assess the full range of the heart-rate response ${ }^{18}$. 


\section{Spontaneous blood pressure changes}

Initially the BRS was calculated from the spontaneous fluctuations in blood pressure by two methods. First we tested the spectral analysis technique described by Robbe et al. ", in which the transfer function between variations in blood pressure and in heart rate in the midfrequency band was calculated as an index of the BRS. We divided the time series into consecutve parts of 256 beats. These segments were subjected to cosine-tapering of 30 data points. Then the transfer function was calculated using the blood pressure as the input and the pulse interval as the output signal. The average pulse interval during the recording was taken as the sample frequency. Results were averaged over all consecutive data blocks and the mean value of the gain in the frequency range 0.35-0.65 $\mathrm{Hz}$ was used as an index of the BRS. In rats the variability in this frequency range is generally attributed to the baroreflex ${ }^{14,19.21}$.

The first time-series method we tested was a direct translation of the original method described by Bertinieri et al. ". Their algorithm searches for periods of three or more consecutive beats in the blood pressure and pulse interval signal within which the blood pressure changes by at least $1 \mathrm{mmH}$ per beat, while the pulse interval changes in the same direction during the following beat by at least $4 \mathrm{~ms}$. The slope of the linear correlation function of the two parameters in such a ramp is taken as an index of the BRS. This method has been applied successfully to data obtained from humans ${ }^{6}$ and cats ${ }^{8}$. Our analysis on data obtained from rats, however, revealed that, with the original threshold pressure ( $1 \mathrm{mmHg}$ ) and pulse interval (4 ms) settings, it was impossible to find a reasonable number of ramps to allow continuous registration of the BRS and a reliable comparison with pharmacological BRS estimates. There are several physiological reasons for this. First of all, the average heart rate and respiration rate are much higher in rats than those in cats and humans. Thus, the algorithm of the time-series method should be adapted using appropriate delays between changes in pressure and in pulse interval. Using the beat-to-beat tracings during injections of phenylephrine and nitroprusside, we found that batoreflex-related changes in pulse interval became apparent $3-5$ beats after a pressure change. This delay corresponds to a time shift roughly in the range 0.6-1.2 s. Second, because of the higher cardiac frequency, the beat-10-beat differences in blood pressure and heart rate are smaller than those in species with lower heart rates. We tried several threshold settings for the pressure and pulse interval changes to trigger a BRS calculation in combination with the $3-5$ beats delay. However, it appeared that the height of the thresholds did not lead to the detection of longer ramps in these unfiltered data sets. Rather, we observed that the fast respiratory-related variations in blood pressure and pulse interval hampered the detection of ramps longer than five beats during which the blood pressure or pulse interval increased or decreased continuously (see Fig. 3.1). This was one of the reasons to apply a filtering procedure to the rat data set. The physiological validity of this filtering procedure has been supported by several recent observations. First, evidence is accumulating that the baroreflex buffers predominantly low-frequency $(<0.1 \mathrm{~Hz})$ fluctuations in blood pressure. Following $\mathrm{SAD}$ in cats, rats and dogs, the spectral density power of low-rather than of high-frequency oscillations in arterial pressure increased ${ }^{12}$ 14. In rats, but not in cats ${ }^{12}$, also the spectral power density of the highfrequency pulseinterval oscillations increased after $\mathrm{SAD}$ and the coherence between respiratory-related fluctuations in pressure and in pulse interval did not alter ${ }^{14}$. This suggests that 


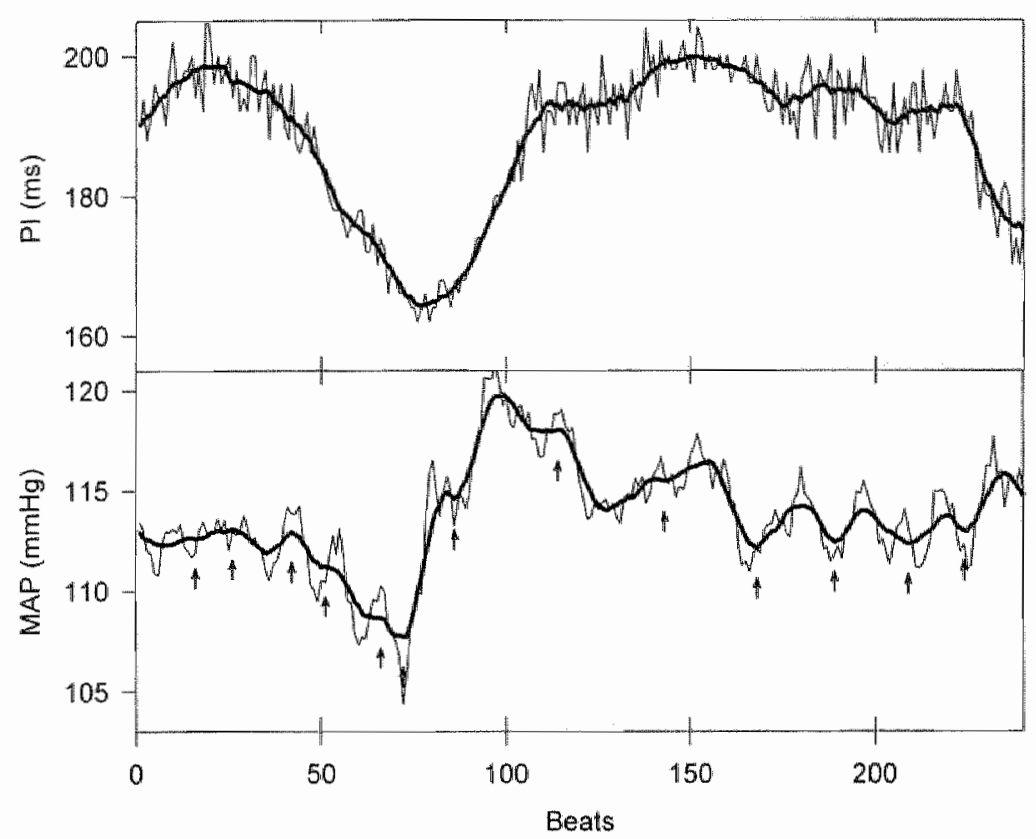

Figure 3.1. Beat-to beat pulse interval (PD) and mean arterial pressure (MAP) values shown as they were recorded originally (thin line) and after the application of a la-beat moving average function (thick line). The arrows indicate the first beat for which the algorithm found a ramp that was included into the calculation of the baroreflex sensitivity estimate.

baroreflex buffering of the heart rate in the rat is not the major determinant of the highfrequency oscillations in heart rate. In support of this view, we found recently that respiratory-related fluctuations in pressure and cardiac output in rats were caused. mainly by oscillations in stroke volume rather than by baroreflex-mediated changes in pulse interval ${ }^{20}$. Also in humans, it has now been demonstrated ${ }^{22}$ that respiratory sinus arrhythmia contributes to such arterial pressure fluctuations, rather than that it represents baroreflex buffering. Thus, in the rat, the fluctuations in blood pressure and heart rate related to the respiratory cycle are probably due more to mechanical than to nervous mechanisms. On the basis of these arguments we chose to eliminate the relatively fast fluctuations from the blood pressure and pulse interval signal by low-pass filtering of the pressure and pulse interval signal using a 10-beat moving average function. Thus, we restricted the focus of our analysis to the low-frequency part of the spectrum in rats. The efficacy of this procedure is visualized in Figure 3.1. The tesult is that the blood pressure and pulse interval signals show 'longer lasting' transients, allowing the algorithm to find triggers.

As a last point, an intrinsic property of the available rimeseries methods is that they introduce bias in the sense that ramps in blood pressure and pulse interval are 
included in the calculation of the BRS only when they have a certain magnitude and direction. The magnitude of bias introduced by this is not known. We chose to circumvent this problem by including in the calculation all ramps in the pressure signal, neglecting the direction and magnitude of the change in pulse interval. The idea behind this approach is that, if baroreflex-mediated changes in pulse interval are present, then they should appear as such when the blood pressure changes. In all other cases the blood pressure and heart rate fluctuations were assumed to occur randomly, thus only adding noise to the detection system. The same assumption also applies when spectral analysis techniques are employed.

On the basis of the aforementioned criteria, we chose to implement the following algorithm. Apply a moving average of 1.0 beats both to the blood pressure signal and to the pulse interval signal. Search for ramps of decreasing or increasing blood pressure of four beats or more. When a ramp has been found, determine the slopes between the blood pressure ramp and pulse interval changes with three, four and five beats delay. Calculate the BRS as the average value of these three slopes.

By using this algorithm we found that the average ramp length in intact WKY rats was $9.7 \pm 1.6$ beats (mean \pm SD), whereas the average blood pressure change was $3.4 \pm$ $0.9 \mathrm{mmHg}$ for ramps during which the blood pressure increased and $3.8 \pm 0.8 \mathrm{mmHg}$ for ramps during which the blood pressure decreased. On the average an increase in blood pressure was associated with a higher BRS estimate $(0.32 \pm 0.03 \mathrm{~ms} / \mathrm{mmHg})$ than was a decrease in blood pressure (BRS $0.17 \pm 0.03 \mathrm{~ms} / \mathrm{mmHg}$ ). Of all beats, $49.8 \pm 4.1 \%$ were included in the calculations. Because the BRS is calculated as the regression coefficient of the pulse interval and pressure changes over several beats in a ramp, the BRS estimate can be lower than $1 \mathrm{~ms} / \mathrm{mmHg}$, despite the $2 \mathrm{~ms}$ sampling rate.

One of the technical considerations for adapting the timeseries method rather than the spectral analysis method was that we wanted to calculate the BRS on-line. The calculations of the BRS index can be performed as soon as a blood pressure ramp has been found, imposing only a small time penalty. Frequency analysis requires stationary signals with a certain minimum length to detect the frequencies of interest. Therefore, these latter methods can be applied only to certain time periods and take relatively more time. In general, the algorithm detected about 20 ramps per minute in the blood pressure time series.

\section{Drugs}

Sodium pentobarbital was obtained from Sanofi Sante BV (Maassluis, The Netherlands). Metoprolol tartrate (metoprolol), atropine methyl nitrate (methyl-atropine), hexamethonium bromide (hexamethonium) and phenylephrine hydrochloride (phenylephrine) were obtained from Sigma Chemical Co. (St Louis, Missouri, USA). Sodium nitroprusside (nitroprusside) was obtained from Janssen Chimica (Beerse, Belgium).

\section{Statistics}

Differences between baseline blood pressure and heart rate values obtained during the two consecutive 20 min periods were compared using a paired Student's t-test. BRS values obtained from the methods using spontaneous fluctuations in blood pressure and pulse interval were compared with those from the pharmacological method by Pearson correlation. The correlation, slope and intercept were computed. The magnitudes 
Table 3.1. Baseline haemodynamic values in groups of ras treated with autonomic blocking agemis

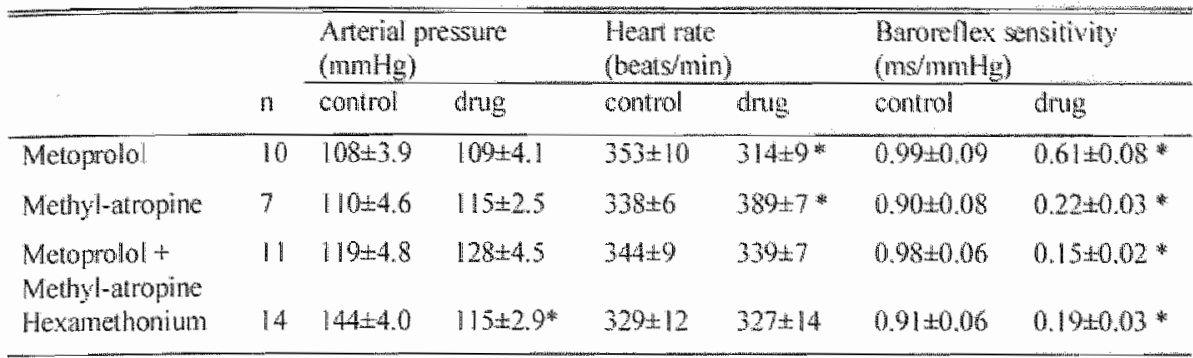

Baroreflex sensitivity was assessed by a pharmacological mehod (see text) Vahes are expressed as means $\pm S E M * \mathrm{P}<0.05$, versus control by paired Student st t-text

of the differences between groups were compared using analysis of variance. $P<0.05$ was considered statistically significant.

\section{Results}

Under all treatments baseline blood pressure and heart rate values did not differ between the two $30 \mathrm{~min}$ recording periods $(\mathrm{P}>0.6)$. Therefore pooled data are presented in Table 3.1. In addition the average BRS values calculated by the pharmacological method are shown. The baseline mean arterial pressure values varied between the groups of rats. However, under control conditions, average heart rates and average BRS values were similar in the groups. As expected, hexamethonium administration reduced the arterial pressure, whereas metoprolol decreased and methyl-atropine increased the heart rate. The $\mathrm{BRS}$ fell slightly during metoprolol administration, but was suppressed severely during administration of methyl-atropine, of the combination of methyl-atropine and metoprolol and of hexamethonium.

The linear correlation between BRS values calculated by pharmacological means and by the spectral analysis method is presented in Figure 3.2. Figure 3.2 shows that the spectral method yielded variable gains, even under conditions in which the baroreflex was blocked. The correlation coefficient was low $\left(R^{2}=0.16\right)$ and the intercept was at $0.66 \mathrm{~ms} / \mathrm{mmHg}$ (Table 3.2, experiment 1). The linear correlation between BRS values calculated by pharmacological means and the time-series method using nonfiltered blood pressure and heart rate signals was not much better than that obtained with the spectral method. As indicated (Table 3.2, experiments 2 and 3 ), the correlation coefficient between the BRS estimates increased from $R^{2}=0.0910 R^{2}=0.41$ when, instead of a one-beat delay, the average of the BRS estimates calculated with three, four and five beats delay between the mean arterial pressure and the pulse interval was used. The correlation coefficient was not further increased by setting specific thresholds for the mean arterial pressure and pulse interval (data not shown).

Using the arguments indicated in the methods section, we applied moving-average filters to the mean arterial pressure and pulse interval signals and examined whether this would improve the correlation with the pharmacological BRS estimate. We found 

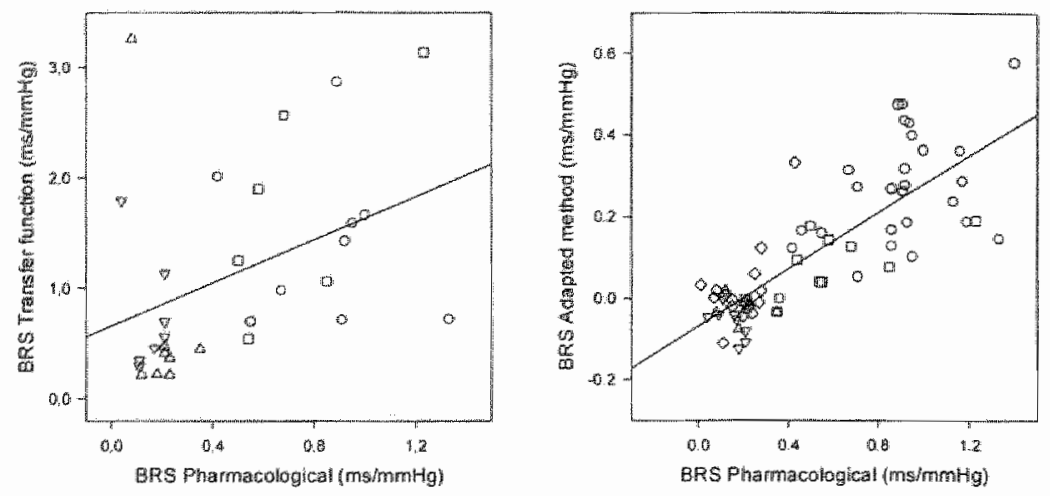

Figure 3.2. Comparison between baroreflex sensitivity of the heart rate (BRS) values calculated by phamacological merhods and by spectral analysis techniques (using a transfer function). The methods were compared during control (Circle) and treatment with metoprolol (Square), methylatropine (Cpward triangle), and a combination of metopralol and methylatropine (Downward triangle). The drawn line represents the regression function (correlation $R^{2}=0.16$, constant $0.66 \pm 0.84$, slope $0.98 \pm 0.42$ )

Figure 3.3. Comparison between baroreflex sensitivity of the heart rate (BRS) walues calculated by phamacological methods and the adapted time-series method (method 7. Table 2). Symbols represent the same conditions as in figure 3.2. The drawn line represents the regression function (correlation $R^{2}=0.64$, constant -0.06 \pm 0.19 slope $0.35 \pm 0.03$ j

that, with a 10-beat moving-average procedure, the correlation between the BRS estimates rose to $\mathrm{R}^{2}=0.64$ (Table 3.2, experiment 7). We tested also different lengths of the moving average procedune $(5$ or 12 beats, instead of 1.0 beats, see Table 3.2 , experiments 5 and 6 ). Sucly differences in smoothing thad only minor effects on the correlation between the BRS estimates. To investigate whether the algorithm could be further improved, several other settings of variables in it were tested. When the delay was made variable in the range $3-5$ beats and the linear relation between the blood pressure and the pulse interval was calculated at the delay with the thighest correlation, the comelation to the pharmacological method fell slightly to $\mathrm{R}^{2}=0.46$ (Table 3.2, experiment 7d). However, in this case also SAD and NTS-lesioned animals exhibited a positive BRS $(0.37 \pm 0.06 \mathrm{~ms} / \mathrm{mm} / \mathrm{gg})$. When ramps were used in which the blood pressure change was greater than $2 \mathrm{mmHg}$, then the correlation coefficient was lowered slightly to $\mathrm{R}^{2}=0.55$ (Table 3.2, experiment $7 \mathrm{a}$ ) and the number of detected ramps fell from $17.7 \pm 3.2$ to $8.9 \pm$ $2.4 /$ min (mean $t \mathrm{SD}$ ). When the pulse interval was set to change by more than 1 ms in the same direction as the blood pressure ramp, not only did the correlation decrease but also the intercept increased (Table 3.2, experiment $7 \mathrm{~b}$ ). Finally, we selected ramps in which the correlation function between the blood pressure and the pulse interval ramp 
Talble 3.2. Comparison of the pharmacological method and technigues calculating the baroreflex sensitivity of the heart rate from spontaneous changes in ariturial pressure and pulse interval.

\begin{tabular}{|c|c|c|c|c|}
\hline Exp & Description & $\mathrm{R}^{2}$ & Constant & Slope \\
\hline 1 & Transfer function analysis [6] & 0.16 & $0.66 \pm 0.84$ & $0.98 \pm 0.42$ \\
\hline 2 & No smoothing one beat delay & 0.1 & $0.00 \pm 0.23$ & $0.18 \pm 0.05$ \\
\hline 3 & No smoothing $3-5$ beats delay & 0.41 & $-0.04 \pm 0.10$ & $0.24=0.03$ \\
\hline 4 & Moving average 10 beats, one beat delay & 0.14 & $-0.05+0.17$ & $0.18 \pm 0.05$ \\
\hline 5 & Moving average 5 beats, $3-5$ beats delay & 0.61 & $-0.08 \pm 0.14$ & $0.34 \pm 0.03$ \\
\hline 6 & Moving average 12 beats, 3.5 beats delay & 0.52 & $-0.05 \pm 0.11$ & $0.31+0.03$ \\
\hline 7 & Moving average 10 beats, $3-5$ beats delay & 0.64 & $-0.06 \pm 0.10$ & $0.35 \pm 0.03$ \\
\hline $7 a$ & Change in blood pressure within ramp $>2$ mollg & 0.55 & $-0.08 \pm 0.12$ & $0.33 \pm 0.03$ \\
\hline $7 b$ & Change in pulse interval within ramp $>\| \mathrm{ms}$ & 0.48 & $0.38 \pm 0.30$ & $0.74 \pm 0.09$ \\
\hline $7 c$ & $\begin{array}{l}\text { Comelation between pulse interval and blood pressure } \\
\text { within ramp }>0.5\end{array}$ & 0.39 & $0.42 \pm 0.35$ & 0.7240 .11 \\
\hline $7 d$ & Best linear fit between 3 and 5 beats delay & 0.46 & $0.45 \pm 0.06$ & $0.10 \pm 0.19$ \\
\hline
\end{tabular}

was higher than $\mathrm{R}^{2}=0.25$. This method also gave a lower correlation to the pharmacological method and a high constant of the correlation function (Table 3.2, experiment $7 \mathrm{c}$ ). For these reasons we finally chose to implement the algorithm of experiment 7 (Table 3.2, Fig. 3.3).

To illustrate the efficacy of this algorithm and its on-line implementation, we compared the $24 \mathrm{~h}$ BRS values for WKY rats, SAD and NTS-lesioned rats (Fig. 3.4). Figure 3.4 shows that the BRS in intact WKY rats was higher during the light period than it was during the dark period and that the BRS in SAD and NTS-lesioned animals was close to zero throughout the $24 \mathrm{~h}$.

\section{Discussion}

In this study we have validated a sequence method that can be used for the continuous calculation of an index of the baroreceptor reflex activity from spontaneous fluctuations in blood pressure and pulse interval in rats. The method yields predominantly estimates of the gain of the parasympathetic component of the cardiac baroreflex which correlate well with those obtained by pharmacological means. The algorithm can be implemented online in data-acquisition software.

Our study indicates that, in rats, in contrast to in humans:, BRS values obtained by calculation of the transfer function between blood pressure and pulse interval oscil. lations in the mid-frequency bands were correlated poorly to those acquired by pharmacological techniques. This could be a species-specific problem and might depend on the frequency range within which the baroreceptor reflex in rats is active. Cerutti et al." have shown that approximately $50 \%$ of the oscillations in the range $0.27-0.74 \mathrm{~Hz}$ can be attributed to the baroreflex. Our data indicated that, although the absolute values of the reflex gains in intact rats were comparable between the pharmacological and spectral methods, the correlation was poor. This might partly be because in this species the 


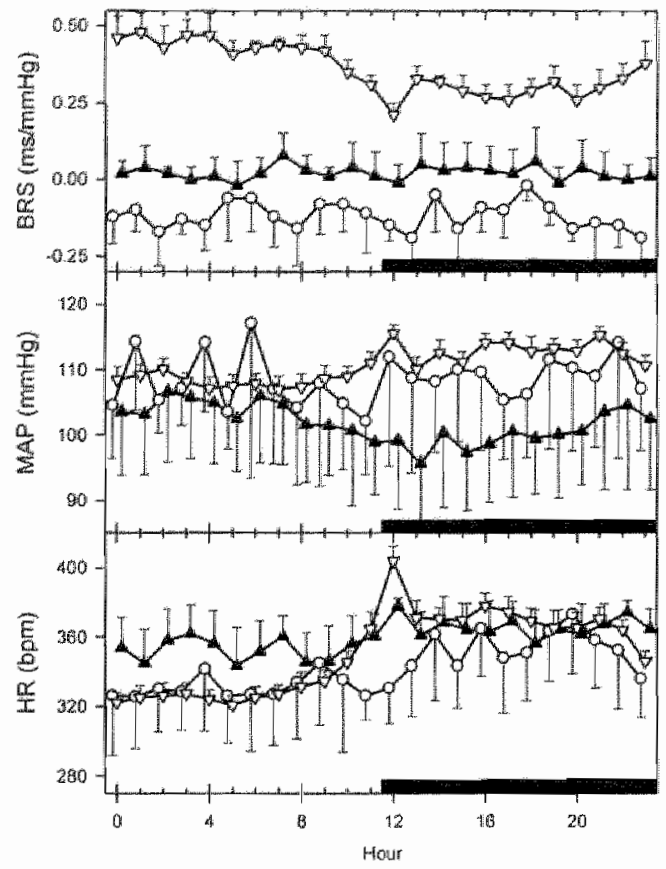

Figure 3.4. Parterns of baroreflex sensitivity of heart rate (BRS). mean arrerial pressure (MAP) and heart rate (HR) during a $24 \mathrm{~h}$ period. Hourly averages $\pm S E M$ are plotted for three sino-aoritic devervated (Cincles), three mucless tractus solitari-lesioned (Filled triangles), and eight control WKY rats (Open triangles). The black bar on the right-hand side indicates the dark (active) period.

baroreflex probably operates also at frequencies below the midfrequency band ${ }^{14}$. In addition, the pharmacological interventions could have changed the relative influence of non-baroreflex components in the mid-frequency range and consequently changed the phase relation between the blood pressure and the pulse interval in this band. For these reasons, we conclude that the calculation of the transfer gain between the blood pressure and the pulse interval in the mid-frequency band is not suited to measure the BRS in rats. We therefore chose to develop and implement a time-series method. While seeking the best sequential method, we found that the respiratoryrelated fluctuations seriously hindered the detection of blood pressure ramps lasting longer than five beats in rats. Because the origin of these rapid oscillations is of mechanical rather than of nervous origin in rat ${ }^{20.22}$, we applied a 10-beat moving-average function to filter out such fast oscillations. In addition this would also facilitate the detection of slower transients in blood pressure and in pulse interval that may be baroreflex-related ${ }^{12.14}$. Therefore, the focus of our analysis of the spontaneous BRS is restricted to the lowfrequency region of the blood pressure and pulse interval fluctuations. Another adaptation of the algorithm was concerned with the shift in beats between the pressure and pulse interval signals. As expected, a one-beat delay between the blood pressure and the heart and pulse interval signals, assuming a latency of the baroreflex of about 200 $\mathrm{ms}$, was inappropriate. To correct this error, we looked for a more appropriate delay of the order of $800 \mathrm{~ms}^{2.182 .23}$. However, because the pulse interval is variable, a fixed delay could not be chosen. As a compromise we calculated the BRS at three different delays, three, four and five beats. Averaging these three slopes instead of taking the best fitted 
slope at delays of three, four or five beats gave the best results. When the delay was not fixed, but rather the BRS was calculated at a variable delay (range 1-12) with the highest correlation coefficient, then, also in SAD and NTS-lesioned tats, a delay could be found at which ramps in blood pressure and pulse interval correlated well. We therefore excluded use of this method because the selection process creates bias towards high BRS estimates in all situations.

It should be noted that the delay of 3-5 beats is probably too short to take account of full sympathetic reactions ${ }^{\text {: }}$. Therefore our BRS index is mainly a measure of the parasympathetic reaction. As shown in Figure 3.3 and Table 3.I, the BRS is reduced less by $\beta$-blockade than it is by administration of methyl-atropine, indicating the predominance of vagal effects in this measure of the baroreflex sensitivity. We sought to detect possible effects of the sympathetic nervous system by using much longer delays between pressure and pulse interval changes. However, in all cases the results were negative. One of the reasons for this might have been that vagal reactions on the heart may occur superimposed upon slow sympathetically induced changes in heart rate.

In contrast to previously published time-series methods, our algorithm does not select blood-pressure and pulse interval ramps of a certain magnitude. In our method all blood-pressure ramps of four or more beats are included, regardless of the direction and magnitude of the pulse interval change. In cases in which the baroreflex was active, as in intact WKY rats, the average BRS value was always positive. In cases in which the baroreflex had been blocked by pharmacological means or eliminated surgically, a value close to zero was found. These results strengthen our view that baroreflex-mediated variations in pulse interval can be detected on top of all other possible relations between blood pressure and pulse interval changes. These other variations occur in a more random fashion and add only noise to the system. In all circumstances under which the BRS was absent, the detection algorithm returned a gain of zero for the average non-baromodulated triggers. However, in cases in which the baroreflex was active, positive values for the gain were found always. This non-selective method has the advantage that it can be applied also to cases in which it is expected that the baroreflex activity will be absent or very low. When ramps would have been selected on the basis of their magnitude and direction, then only the number of triggers and not so much the slope of the correlation function would fall considerably in cases of low BRS. This introduces the choice of a cut-off point to decide whether the number of triggers is high enough to calculate a value for the BRS. Thus, the present approach differs from previous related methods ${ }^{8-10}$, in that it does not include a specific gating mechanism that selects only baroreflex blood pressure and pulse interval sequences. Instead of the baroreflex sensitivity in the classical sense, the present method returns estimates about the prevalence of baroreceptor function and indicates the extent to which the baroreceptor functions over time. To track the dynamic baroreceptor function over time it is, however, mandatory to average the individual ramps over time. In our rats, the present algorithm returned about 20 estimates of the baroreflex function each minute. We estimate that a resolution of $1 \mathrm{~min}$ is adequate to track the baroreflex function over time. We have used this approach to investigate ultradian variations in BRS in spontaneously hypertensive rats and in WKY rats ${ }^{24}$.

One limitation of our algorithm might be that the absolute BRS values were about 
a factor of three lower than those obtained by the pharmacological method. Several reasons account for this. First, the algorithm calculates the slope as the average of three individual slopes, including slopes with low walues. Second, the beat-to-beat fluctuations in pulse interval are relatively higher than those in blood pressure. Therefore, lowpass filtering by the movingaverage function will affect the pulse interval more and will therefore reduce the slope between these signals, too. Finally, when the algorithm has found a ramp in blood pressure, then all changes in pulse interval are included, regardless of their direction or magnitude. This causes a reduction in the average BRS value, because also nonbaroreflex sequences are included. The reduction in absolute BRS values, however, does not mean that the sensitivity of the method has declined. The BRS index calculated with this on-line method discriminates between WKY rats and spontaneously hypertensive rats and responds to drug treatments ${ }^{24}$.

It should be borne in mind that the development of the present estimate for the cardiac baroreflex gain from spontaneous fluctuations in blood pressure was done by correlating the performance of the computerized method to the gain derived from pharmacological methods. However, there may be, a priori, limitations to this approach. In the present study the central nervous system was regarded as a system reacting in a linear fashion to changes in input regardless of the magnitude of the input. Although baroreceptor afferents may increase their firing pattern in a linear way within a wide range of pressures, this does not mean that the reaction of the brain to small and large deviations in pressure is simillar. With pharmacological methods, the induced changes in blood pressure were much greater than those occurring spontaneously. In the conscious state, the pattern of response to greater input signals could lead to a different or more complete activation-deactivation pattern of brain structures involved in the reflex than when input signals are small. Therefore, the resulting reflex changes in heart rate are not necessarily linear in response to both input levels. This implies that it cannot be decided which approach is superior to the other. We chose to circumvent this problem by matching the pharmacological and spontaneous BRS estimates.

In conclusion, the developed time-series method calculates the gain of the baroreceptor reflex faithfully from spontaneously occurring changes in blood pressure and pulse interval in rats. Furthermore, this method can be implemented on-line in dataacquisition software, making it suitable for long-term continuous measurements of this important physiological control mechanism.

\section{Acknowledgments}

We would like to thank Tony Verberne (Department of Pharmacology, Austin Hospital, Heidelberg, Australia) for performing the electrical lesions of the NTS, and Caroline Eerdmans-Tyssen for expert technical assistance.

\section{References}

1. Snyth HS, Sleight P, Pickering GW: Reflex regulation of arterial pressure during sleep in man. Circ Res 1969; $24: 109-121$.

2. Coleman TG: Arterial batoreflex control of heart rate in the conscious rat. $A m J$ Physiol 1980; $238: \mathrm{H} 515-\mathrm{H} 520$.

3. Korner PI, West MJ, Shaw J, Uther JB: Steady-state properties of the baroreceptor- 
heart rate reflex in essential hypertension in man. Chn Exp Pharmac Phasio/ 1974; 1 : 65-76.

4. Cowie MR, Rawles JM: A modified method of quantifying the carotid baroreceptorheart rate reflex in man: the effect of age and blood pressure. Clin So1 1989; 77,223 . 228.

5. Struyker-Bondier HAJ, Evenwel RT, Smits JFM, Van Essen H: Baroteflex sensitivity during the development of spontaneous hypertension in rats. Clin Sci 1982; 56:163167.

6. Robbe HWJ, Mulder LMM, Ruddel H, Langewitz WA, Veldman IBP, Mulder $G$; Assessment of baroreceptor reflex sensitivity by means of spectral analysis. Hypertension 1987; 10: 538-543.

7. Saul JP, Berger RD, Albrecht P, Stein SP, Chen MH, Cohen RJ: Transfer function analysis of the cinculation: unique insights into cardiovascular regulation. Am I Phosiol 1991; 261: H1231-H1245.

8. Bertinieri G, Di Rienzo M, Cavallazzi A, Ferrari AU, Pedotti A, Mancia G: Evaluation of barareceptor reflex by blood pressure monitoring in unanesthetized cats. Aw $J$ Physiol 1988; 254: H377-H383.

9. Parati $G, D$ Rienzo $M$, Bertinieri $G$, et al: Evaluation of the baroreceptor-heart rate reflex by 24 -hour intra-arterial blood pressure monitoring in humans. Hypertension $1988 ; 12: 214-222$.

10. Fritsch JM, Eckberg DL, Graves LD, Wallin BG: Arterial pressure ramps provoke linear increases of heart period in humans. Am J Physial 1986; 251: R 1086-R 1090.

11. Cerutti $C$, Ducher M, Lantelme P, Gustin M-P, Paultre C: Assessment of spontaneous barorellex sensitivity in rats: a new method using the concept of statistical diependence. Am J Physiol 1995; 268: R382-R388.

12. Di Rienzo M, Parati G, Castiglioni $P$, et al: Role of sinoaortic afferents in modulating BP and pulse-interval spectral characteristics in unanesthetized cats. $A \mathrm{~m} J \mathrm{Physiol}$ 1991; 261: H1811-H1818.

13. Just $A$, Witmann $U, N a f z B$, et al: The blood pressure buffering capacity of nitric oxide by comparison to the baroreceptor reflex. AnJ Physiol 1994; 267: H52 1-H527.

14. Cerutti $C$, Barrès C, Paultre $C$ : Baroreflex modulation of blood pressure and heart rate variabilities in rats: assessment by spectral analysis. Am J Physiol 1994; 266: H1993$\mathrm{H} 2000$.

15. Janssen BJA, Tyssen CM, Struijker Boudier HAJ, Hutchins PM: 24-Hour homeodynanic states of arterial blood pressure and pulse interval in conscious rats. $J$ Appl Physiol 1992; 73: 754-761.

16. Krieger EM: Neurogenic hypertension in the rat. Circ Res: 1964; 15:511-521.

17. Buchholz RA, Nathan MA: Chronic lability of the arterial blood pressure produced by electrolytic lesions of the nucleus tractus solitarii in the rat. Circ Res 1984;54: $227-238$.

18. Head GA, McCarthy $\mathbb{R}$ : Vagal and sympathetic components of the heart rate range and gain of the baroreceptor-heart rate reflex in conscious rats. I A uton Nerv Syst $1987 ; 21: 203-213$.

19. Japundzic N, Grichois M-L, Zitoun P, Laude D, Elghozi J-L: Spectral analysis of blood pressure and heart rate in conscious rats: effects of autonomic blockers. $J$ Auton Nerv Syst 1990; 30: 91-100.

20. Janssen BIA, Oosting J, Slaaf DW, Persson PB, Struyker-Boudier HAJ: Hemodymamic basis of oscillations in systemic arterial pressure in conscious rats. Am JPhysiol 1995; 269: H62-H71.

21. Jacob HJ, Rananathan $A$, Pan $\mathrm{SG}$, Brody MJ, Myers GA: Spectral analysis of arterial pressure lability in tats with sinoaortic deafferentiation. An J Plywiol 1995; 269: R1481-R1488. 
22. Taylor JA, Eckberg DL: Fundamental relations between short-term RR unterval and arterial pressure oscillations in humans. Cinchlotion 1996; 93: 1527-1532.

23. Smith SA, Stallard T., Litter WA: Estimation of sinoaortic baroreceptor heart rate sensitivity and latency in man: a new microcomputer assisted method of analysis. Cardiovase Res 1986, 20:877-882.

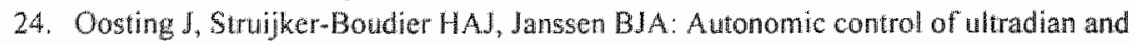
circadian rhythms of blood pressure, heart rate, and baroreflex sensitivity in spontaneously hypertensive rats. I Hypertens 1997; 15: $401-410$ 


\section{Chapter 4}

\section{Autonomic control of ultradian and circadian rhythms of blood pressure, heart rate, and baroreflex sensitivity in SHR}

Jan Oosting

Harry A.J. Struijker-Boudier

Ben J.A. Janssen

Published in : Joumal of Hypertension, 1997, 15:401 41:0

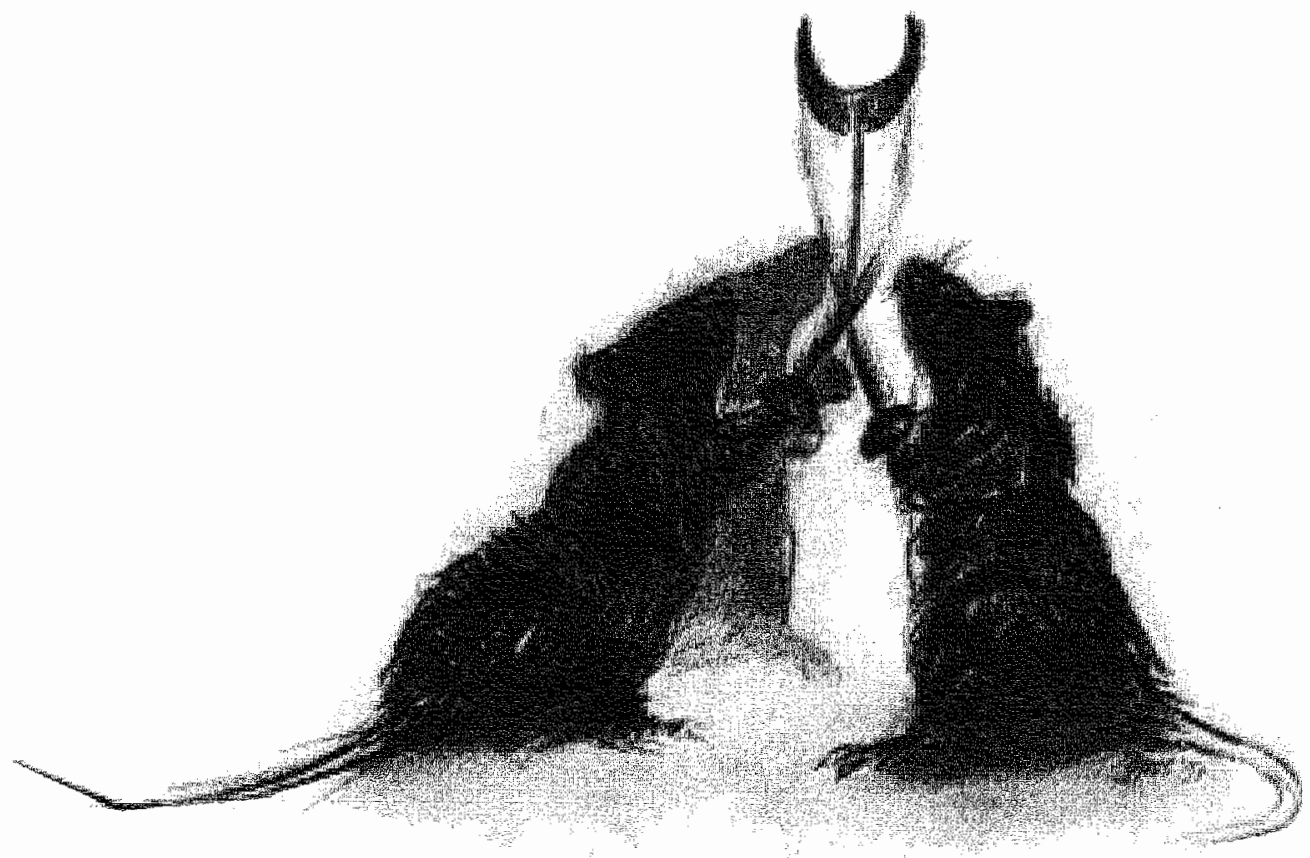




\section{Abstract}

Objective To examine the intuence of the autonomic nervous system on ultradian and circadian thythms of blood pressure, heart rate and baroreflex sensitivity of heart rate (BRS) in spontancously hypertensive rats (SHR).

Methods Spontaneous fluctuations in blood pressure, heart rate and BRS in SHR were recorded continuously for $24 \mathrm{~h}$ using a computerized system and compared wit those in Wistar-Kyoto (WKY) rats. Furthermore, $24 \mathrm{~h}$ recordings were performed in SHR during cardiac autonomic blockade by metoprolol and methyl-atropine, vascular autonomic blockade by prazosin, ganglionic blockade by hexamethonium and vagal stimulation by a low dose of scopolamine. The magnitudes of the ultradian fluctuations in blood pressure, heart rate and BRS were assessed by wide-band spectral analysis techniques.

Results The BRS was lower in SHR than it was in WKY rats throughout the $24 \mathrm{~h}$ cycle. In both strains high value were found during the light, resting period, whereas low values were found during the first hours of the dark, active period. The circadian thythmicity of the blood pressure in SHR was abolished completely during the infusions of prazosin and hexamethonium. In contrast, the circadian rhythmicities of the blood pressure and heart rate were not altered by infusions of metoprolol, methylatropine and the low dose of scopolamine. Power spectra of the blood pressure and heart rate lacked predominant peaks at ultradian frequencies and showed I/f characteristics. In the absence of autonomic tone, the ultradian fluctuations in heart rate, but not in blood pressure, were decreased. The ultradian BRS spectra had no 1/f shape, but showed a major peak at . 20 min for $71 \%$ of the WKY rats and $42 \%$ of the SHR.

Conclusions The influence of the autonomic nervous system on the blood pressure and heart rate in SHR is frequency-dependent. The circadian, but not ultradian, blood pressure rhythmicity is controlled by vascular autonomic activity. Conversely, the circadian, but not ultradian, heart rate rhythmicity is independent of autonomic tone. In rats, just as in humans, the trough in baroreflex sensitivity occurred after the sleeping period, when locomotor activity is resumed. 


\section{Introduction}

Many studies have examined the role of the sympathetic and parasympathetic nervous systems in the high-frequency oscillations of the blood pressure and heart rate which are related to respiration ${ }^{1.2}$ and cardiovascular reflex mechanisms or Mayer waves ${ }^{3-7}$. Typically, on these second-to-second time scales, blood pressure and heart rate variabilities show a reciprocal relationship, which is possibly baroreceptor reflexmediated ${ }^{8}$. However, less is known about the extent to which the autonomic nervous system contributes to much slower, ultradian fluctuations. Studies in dogs have indicated that the sympathetic nervous system might be involved in blood pressure and heart rate cycles of about $20 \mathrm{~min}^{9}$ or of $1-2 \mathrm{~h}^{10.11}$. The exact origin of these cycles is, however, not known. Other studies have found an inverse linear relationship between the logarithm of the frequency and the logarithm of the spectral power of the blood pressure and heart rate ${ }^{12-14}$. The $1 / f$ characteristic indicates the absence of a single dominant regulatory mechanism and is suggestive of non-linear system characteristics with multiple processes acting on overlapping time scales ${ }^{15}$

The $24 \mathrm{~h}$ diurnal variations in blood pressure and heart rate are thought to be related mainly to behavioural changes, with elevated levels of sympathetic activity during the active period and the dominance of parasympathetic influences during sleep ${ }^{\text {it }}$ ${ }^{18}$. Now, on this time scale, changes in blood pressure and heart rate occur in parallel. Most evidence for effects of the autonomic nervous system on the $24 \mathrm{~h}$ blood pressure and heart rate variability has been derived from studies on essential hypertension ${ }^{16}$. In humans as well as in experimental animals, differences between daytime and night-time blood pressure and heart rate values are usually more pronounced in hypertensive individuals than they are in normotensive controls ${ }^{17-20}$. The increased long-term variability generally is explained in terms of elevated sympathetic tone in hypertension or progressively waning control mechanisms ${ }^{2 !}$. Treatment with sympatholytic agents can normalize such differences between hypertensive and normotensive states. However, in general, the circadian rhythm in blood pressure and heart rate is preserved ${ }^{20.22}$. This is not surprising since the doses of those sympatholytic drugs administered usualiy suppressed the autonomic nervous system only partly. Thus, the extent to which the autonomic nervous system controls the circadian rhythmicity of the blood pressure and heart rate remains unknown

The present study was designed to evaluate the role played by the autonomic nervous system both in circadian and in ultradian fluctuations in blood pressure and heart rate. Experiments were performed in spontaneously hypertensive rats (SHR) because of the enhanced circadian thythmicity of their blood pressure and the presumed

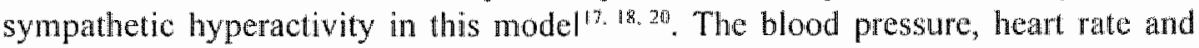
baroreflex sensitivity of the heart rate (BRS) were recorded for 24 h periods during continuous infusions of agents that blocked parts of the autonomic nervous system. In these studies, the BRS was measured continuously by using an algorithm that calculates the gain of the cardiac baroreflex from spontaneous beat-to-beat fluctuations in blood pressure and pulse intervat ${ }^{23}$. 


\section{Methods}

\section{Animals}

Adul Wistar-Kyoto (WKY) rats and SHR weighing 280 -300 g each were used. The rats were obtained from the central Animal Facilites of the Universiteit of Maastricht. Experiments were performed according to the Universiteit Maastricht guidelines. The animals were kept on a $12 \mathrm{~h}$ light $12 \mathrm{~h}$ dark cycle. After they had undergone surgery, the animals were housed individually in cages and were allowed nomal rat chow and drinking water ad libinm.

\section{Surgery}

All rats were instrumented with an arterial catheter for measuring their blood pressure and a venous catheter for administration of drugs, as described in detail previouslly ${ }^{20}$. In short, the catheters were implanted via the femoral vessels and then tunnelled through to the lower back of the animal with the animal under pentobarbital anaesthesia. The catheters were exteriorized through a $40 \mathrm{~cm}$ long steel spring which was fixed to the back muscles with silicone rubber attached to a piece of mersilene gauze. The venous catheter was filled with a heparinized salline solution $(5 \mathrm{U} / \mathrm{ml})$. The steel spring was led to the outside of the cage, where the arterial catheter was connected via a hydraulic swivel (model 375120 ; Instech Labs, Plymouth Meeting, Pennsy vania, USA) to a low-volume displacement pressure transducer (micro-switch model 156PC 156WL; Honeywell, Inc., Amsterdam, the Netherlands). The arterial canula was kept patent by continuous arterial infusion of heparinized saline solution $(30 \mathrm{U} / \mathrm{ml}$ ) at a rate of $2.4 \mathrm{~mL} / \mathrm{day}$. This set-up allowed us to measure blood pressures continuously and to administer drugs without disturbing the rats, for periods lasting usually 4 weeks.

\section{Data acquisition}

After the rat had been allowed at least 3 days for recovery the measurements were performed in the home cage of the animal. The arterial pressure transducer was connected to an amplifier that delivered a high-voltage signal to an analogue-to-digital converter board (model 2814; Data Translation, CN Rood, Rijswijk, the Netherlands) connected to an IBM-compatible computer. The blood pressure signal was sampled at 500-1000 Hz. Beat-10-beat pulse interval and mean arterial pressure values were calculated on line and stoted on a hard dise.

\section{Protocols}

All experiments were performed in SHR using the following standard protocol. Beat-10-beat recordings were made during intravenous infusions of drugs or saline. The infusions were started $1-4$ h before the start of the actual recording. This was done to obtain steady-state phamacokinetics as well as to avoid acute drug effects within the study period. The infusions were stated within the second hour of the dark period. Paired controls were used in these drug studies with at least 2 days between the reconding during the saline infusion and that during the drug infusion. The order of the saline infusion and drug infusion was randomized for each animal. The infusion rate in the experiments was $0.2 \mathrm{~m} / / \mathrm{h}$.

The following studies were conducted. First, SHR $(n=15)$ and WKY rats $(n=10)$ 
were compared to study the effect of hypertension. Second, to study the effects of cardiac autonomic blockade, SHR ( $\mathrm{n}=9)$ were infused with the $\mathrm{\beta}$-adrenoceptor antagonist metoprolol (40 mg/kg per $24 \mathrm{~h}$ ) and the muscarinergio antagonist methylatropine $(40 \mathrm{mg} / \mathrm{kg}$ per $24 \mathrm{~h}$ ). Third, to block the effects of the autonomic nervous system on the vasculature, SHR $(n=7)$ were infused with the $\alpha$, -adrenoceptor antagonist prazosin at a dose of $5 \mathrm{mg} / \mathrm{kg}$ per $24 \mathrm{~h}$. Fourth, to block the common efferent pathway of the autonomic nervous system, SHR $(\mathrm{n}=8)$ were infused with the ganglionblocking agent hexamethonium ( $600 \mathrm{mg} / \mathrm{kg}$ per $24 \mathrm{~h}$ ). Fifth, to stimulate the parasympathetic nervous system, SHR $(\mathrm{n}=8)$ were infused with a low dose of scopolamine. The infusion rate of scopolamine was detemined in a pilot experiment with four animals. The infusion rate in this pilot study was increased stepwise from 0.1 to $100 \mathrm{mg} / \mathrm{kg}$ per h every $20 \mathrm{~min}$. The optimal dose was considered the dose at which the heart rate decreased the most. This dose ( $5 \mathrm{mg} / \mathrm{kg}$ per h) was used in the $24 \mathrm{~h}$ experiments. After the $24 \mathrm{~h}$ infusions with hexamethonium and with metoprolol plus methyl-atropine the efficacy of pharmacological blockade was confirmed by the absence of heart rate changes $(<15$ beats $/ \mathrm{min}$ ) in response to injections of nitroprusside and phenylephrine that changed the blood pressure by -30 to $40 \mathrm{mmHg}$. The effectiveness of $\alpha_{\mathrm{f}}$-adrenergic blockade by $2.5 \mathrm{mg} / \mathrm{kg}$ per $24 \mathrm{~h}$ prazosin had been tested in our laboratory previously and found to result in a 160-fold shift towards the right-hand side of phenylephrine-induced increases in blood pressure ${ }^{2}$.

\section{Data analysis and statistics}

The BRS was detemined from spontaneous ramps in bllood pressure and pulse interval using a modified thmeseries method originally used by Bertinieri er al ${ }^{2.5}$ in cats. The validation and development of an algorithm to assess the cardiac baroreflex gain in rats continuously has been described in detail ${ }^{23}$. In essence, the new aspects of this algorithm, in contrast to that used for cats, are that it does not set thresholds for the mimimal amplitude of blood pressure or hearl rate changes, it does not select the direction of the change in pulse interval and it facilitates the triggering on slower changes occurring in blood pressure over time by low-pass filtering the signals. In short, first, moving averages over 10 beats were calculated both for the blood-pressure signal and for the pulse interval signal to filter out respiration-induced fluctuations. Second, the filtered signal was searched for ramps of decreasing or increasing blood pressure of four beats or more. Third, for each ramp found, the slopes between the blood-pressure ramp and the pulse-interval changes were determined at delays of three, four and five beats. The BRS was calculated as the average value of these three slopes. Average BRS values were stored every minute.

To describe the circadian thythm in the $24 \mathrm{~h}$ experiments, average blood pressure, heart rate and BRS values were calculated every hour. Differences between the averages of the $12 \mathrm{~h}$ dark and the $12 \mathrm{~h}$ light period were used to characterize the circadian thythmicity.

The magnitudes of the ultradian fluctuations in blood pressure, heart rate and BRS were analysed by fast Fourier transformation. These parameters were averaged every mimute both for the dark period and for the light period. From the 720 data points corresponding to each of these periods, a series of $512 \mathrm{~min}$ without missing data was chosen for determination of the power spectrum. The power spectra for the light and 

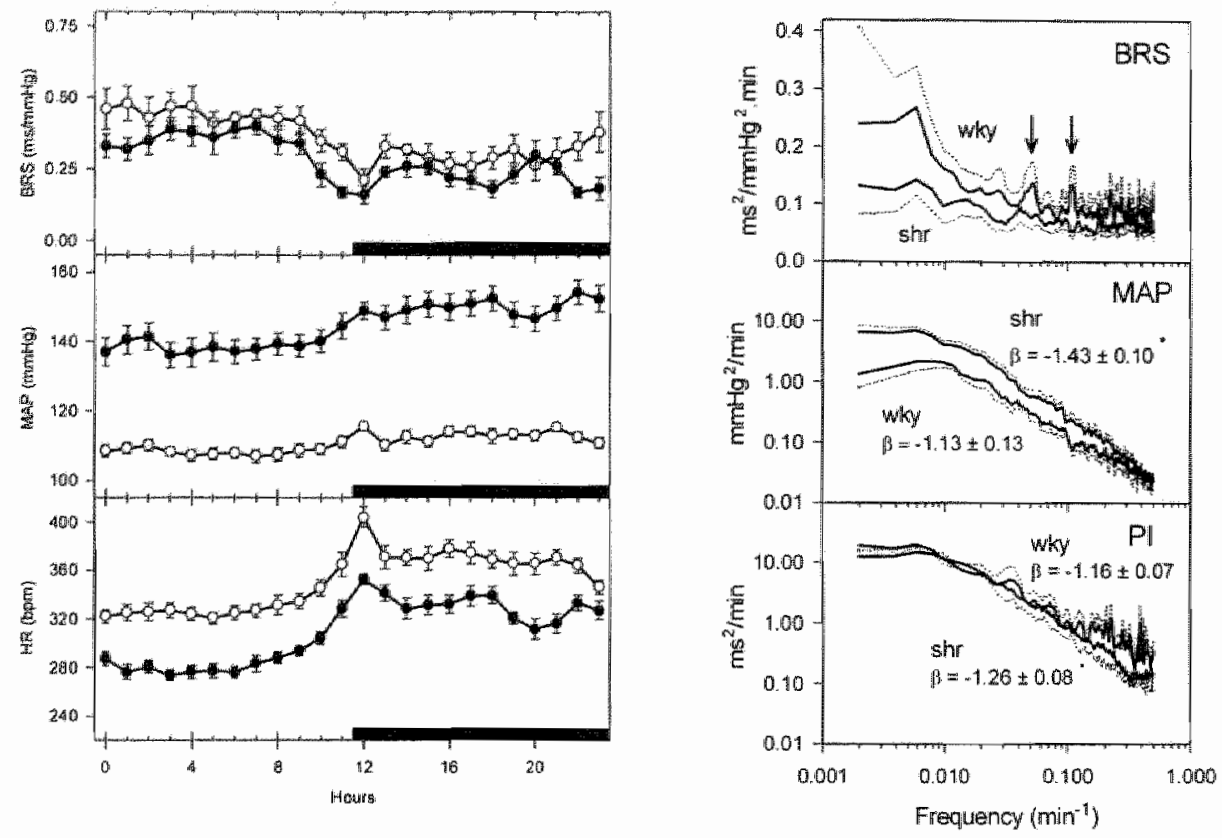

Figure 4.1. Circadian pattern of baroreflex sensitivity (BRS), mean arterial pressure (MAP), and heart rate (HR) in Wistar-Kyoto (O) and spontaneously hypertensive (-) rats. Note the trough in BRS at the transition from the light to dark period. Values are expressed as hourly means" \pm SEM. The dark period is indicated by the black bar at the base of each plot. Statistical differences are given in table 4.I

Figure 4.2. Averaged power spectra of minute-to-minute averages of the baroreflex sensitivity (BRS), mean arterial pressure (MAP), and pulse interval (PI) in WistarKyoto (WKY) and spontaneously hypertensive rats (SHR). Values are expressed as means + SEM for the upper curve and means - SEM for the lower curve. Note the a min and $\sim 20$ min oscillations of BRS in WKY $(\downarrow)$. Average slopes $(\beta \pm S D)$ of the linear regression lines of the MAP and HR spectra are compared between WKY and SHR within each plot. * $P<0.05$ versus WKY

dark periods for each recording were averaged, because in all cases the spectra for the dark, and light periods were very similar. After logarithmic transformation both of the frequency and of the power, linear correlation between the frequency and the power was used to describe the slope and intercept of the power spectrum in the range $0.01-0.5$ cycles/min $(0.00016-0.0083 \mathrm{~Hz})$.

Values are expressed as means \pm SEM unless indicated other-wise. Differences between WKY rats and SHR were assessed using one-way analysis of variance. Effects of pharmacological treatment versus saline control within groups of animals were compared with paired Student's t-tests. $\mathrm{P}<0.05$ was considered statistically significant. 
Table 4.1. Steady-state values in spowaneows hypertens we rats (SAR) and Wistar"Kyoro (WKW) rats.

WKY $(n=10) \quad \operatorname{SHR}(n=15)$

BRS $24 \mathrm{hr}(\mathrm{ms} / \mathrm{mm} \mathrm{Hg})$

BRS A Dark-Light (msimmHg)

MAP 24-h(mmH)

MAP A Dark-Light (mmHg)

HR 24-h (beats/min)

HR $\triangle$ Dark-Light (beats/min)
$0.36 \pm 0.03$

$-0.13 \pm 0.03$

$111 \pm 1$

$4.4 \pm 0.7^{* *}$

$351 \pm 6$

$40 \pm 4$
$0.28 \pm 0.02$

$-0.11 \pm 0.02$

$145 \pm 3^{4}$

$10.9 \pm 1.5^{*}$

$309+5$

$44 \pm 4$

Comparison of 24-haverage values of barareflex sensitivity (BRS), mean arterial pressure (MAP), and heart rate (HR) in SHR and WKY rats. ) Dark-Light the difference between average values of the $12 \mathrm{~h}$ dark and $12 \mathrm{~h} \mathrm{light} \mathrm{period.:} \mathrm{"P<}$ 0.05 , versus WKY rats; $P<0.01$, difference between light and dark periods

\section{Drugs}

Metoprolol tartrate (metoprolol), atropine methyl nitrate (methyl-atropine), hexamethonium bromide (hexamethonium), scopolamine hydrochloride (scopolamine) and phenylephrine hydrochloride (phenylephrine) were obtained from Sigma Chemical Company (St Louis, Missouri, USA). Prazosin hydrochloride (prazosin) was obtained from Plizer (Brussels, Belgium). Sodium nitroprusside (nitroprusside) was obtained from Janssen Chimica (Bearse, Belgium).

\section{Results}

\section{SHR versus $W K Y$ rats}

Figure 4.1 shows the circadian rhythms in blood pressure, heart rate and BRS for SHR and WKY rats. In both strains, the blood pressure and heart rate were higher during the dark (active) period, whereas the BRS was higher during the light (sleeping) period. Average $24 \mathrm{~h}$ heart rate and BRS values were lower in SHR than they were in WKY rats, whereas the blood pressure was higher. During the 24 h cycle, minimal BRS values were found at the transition from the light to the dark period. This period was accompanied by an increase in blood pressure and heart rate in both strains. The difference in blood pressure between the dark and the light period was smaller for WKY rats than it was for SHR (Table 4.1), whereas such differences in heart rate and BRS were similar. 
Table 4.2 Effects of treatment on the 24 h werage values and differences between averages for the 12 dark and 12 h light periods (A dark-light) of the baroreflex sensitivity (BRS), mean arterial pressune (MAP) and heart rate

\begin{tabular}{|c|c|c|c|c|c|c|c|c|}
\hline & \multicolumn{2}{|c|}{ 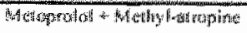 } & \multicolumn{2}{|c|}{ If } & \multicolumn{2}{|c|}{ Pratosing } & \multicolumn{2}{|c|}{ Stoprotaming } \\
\hline & 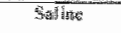 & Trustingerill & Salime & 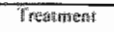 & S3line & 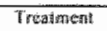 & Sulfink & Thearnety \\
\hline & $(x+2)$ & $(n=0)$ & $\left(\mathrm{n}=-\frac{\mathrm{g}}{\mathrm{s}}\right)$ & 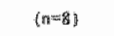 & $(\{)=7)$ & $(\mathrm{A}=\mathrm{A}=\mathrm{X})$ & $n=8$ & 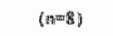 \\
\hline 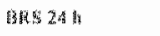 & $0.29+0.64$ & 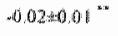 & 62800102 & $0.00 \mathrm{an0} 0 \mathrm{z}^{2+}$ & 6. 250.03 & $0.14=0.0 \%$ & 0.29 .20 .02 & $0.3200 .0 \%$ \\
\hline 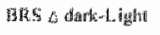 & 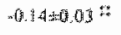 & $0,02,201,011^{-2}$ & $40,050004 y^{*}$ & -0.020 .0 .02 & $-8.13 \times 0.0 \%$ & $001+002$ & $-0,16 y=0,02$ & $-1,1300,02 \div$ \\
\hline$M A B Z 4$ & 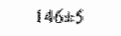 & $3444^{* 8}$ & 140x:14 & $197 \pm 6$ & 1450 & $\sin 4 x_{2} y$ & 3834 & $1,8 x+4$ \\
\hline 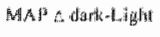 & $\mid 0.3 \times 2$. & $11.0 .2 .33^{\text {hin }}$ & $13.352 .0^{10}$ & $-0.9 \mathrm{y} y$ & $\mid 4.3 \pm 1.7 \%$ & $-1.2+1.5^{\cdots \cdot n}$ & $52230^{\circ}$ & $6.7 \times 1.6 \%$ \\
\hline HR $24 \mathrm{~h}$ & $30991+5$ & $2864+2$ & 30930 & $300+5$ & 300.5 & $390 \mathrm{~kg}$ & 3523 & $331,4^{+0}$ \\
\hline 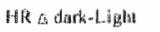 & 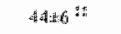 & $36 x^{2}=$ & $49 \pm 6=$ & $28 x+204$ & $51.3 \%$ & $23 \sqrt{3} 7^{\cdots+4:}$ & $43.53^{n:}$ & d9t5:* \\
\hline
\end{tabular}

" $P<0.05$, " $P<0.01$, versus saline; $P<0.05, " P<0.01$, difference berween light and dark periods

The magnitude of the ultradian rhythms was assessed by calculating the power spectra from minute averages. The blood pressure and heart rate spectra lacked predominant peaks. They showed an almost linear relationship in the frequency range $0.01-0.5$ cycles per minute (Fig. 4.2). The slope of the linear regression line ( $\beta$ ) of the spectrum for blood pressure was greater for SHR than it was for WKY rats [SHR $\beta=$ $1.43 \pm 0.10$ (mean \pm SD), WKY $\beta=-1.13 \pm 0.13 ; P<0.01$ ]. Also the slope of the pulse interval spectrum was higher for SHR than it was for WKY rats ( $S H R \beta=-1.26 \pm 0.08$, WKY $\beta=-1.16 \pm 0.07 ; P<0.05)$. The magnitude of the ultradian fluctuations in BRS was higher for WKY rats than it was for SHR; however, the difference did not attain statistical significance $(P=0.066)$. The BRS power spectra did not show a $/ / f$ relation. In the spectra for five of seven WKY rats and five of 12 SHR a small, well-defined peak could be seen with a period in the range $20-25 \mathrm{~min}$. Small peaks were visible at about $9 \mathrm{~min}$ in the spectra for two WKY rats and two SHR rats.

\section{Effects of cardiac autonomic blockade}

The BRS in SHR during cardiac autonomic blockade with metoprolol and methylatropine was close to zero throughout the $24 \mathrm{~h}$ period (Fig. 4.3). Under this condition the circadian rhythmicity in blood pressure and heart rate was not abolished. Blood pressure and heart rate differences between the dark and the light period were comparable to control differences (Table 4.2). Figure 4.4 shows the power spectra obtained during cardiac blockade with their matched controls. The power spectral density for the blood pressure did not change, but the slope of the power spectrum for the pulse interval became steeper and the value at the intercept decreased (Pulse interval $\beta_{\text {control }}=$ $-1.27 \pm 0.08, \beta_{\text {blockade }}=-1.84 \pm 0.30 ; P<0.05$ ). These changes were due mainly to the 

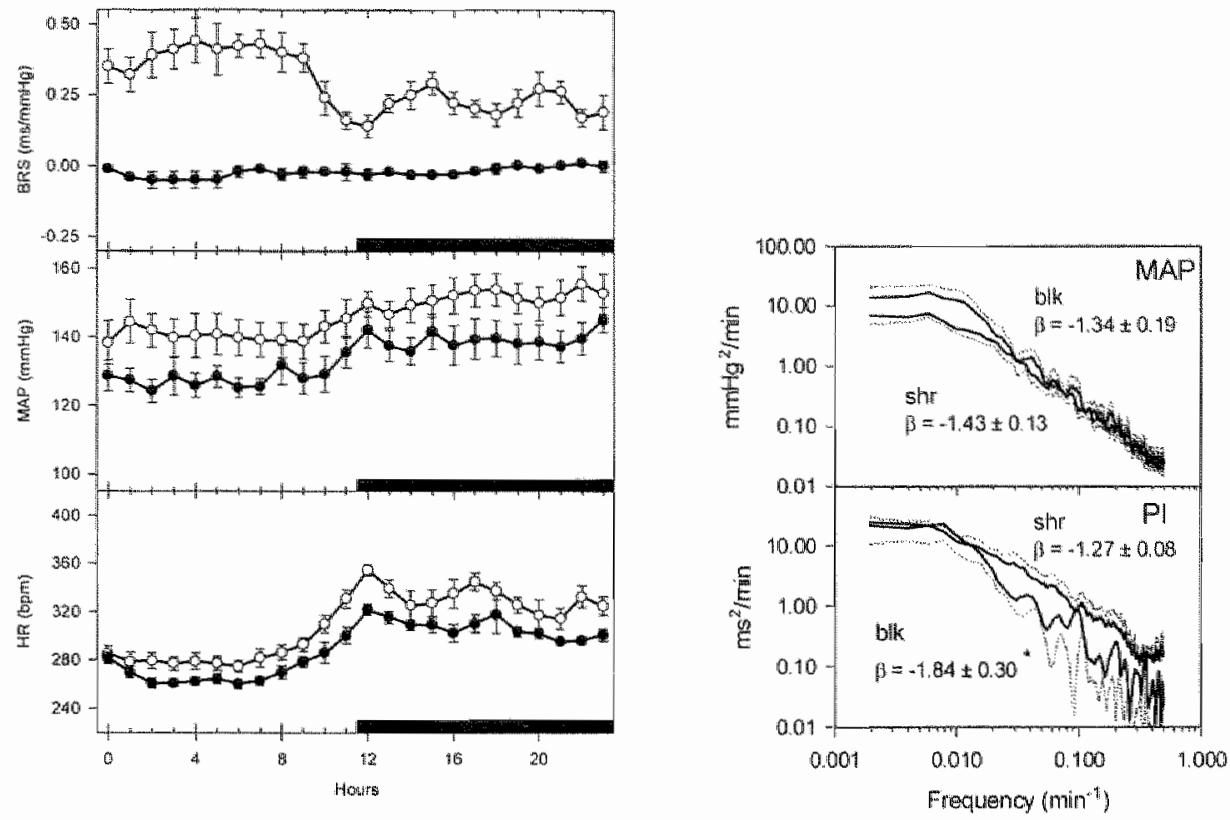

Figure 4.3. Circadian paterns of baroreflex sensitivity (BRS), mean arterial pressure (MAP), and heart rate (HR) in spontaneously hypertensive rats during saline infusion $(O$, control) and during cardiac autonomic blockade by an infitsion of metoprolol and methyl-atropine (-). Values are expressed as hourly means ISEM. The dark periad is indicated by the black bar at the base of each plot. Statistical differences are given in table 1.

Figure 4.4. Power spectra of minute-to-minute averages of mean arterial pressure $(M A P)$, and pulse interval (PI) in spontaneously hypertensive rats during saline infusion (SHR) and during cardiac automomic blockade by infision of metoprollol and methyl-atropine ( $B L K)$. Average slopes $(\beta \pm S D)$ of the linear regression lines of the MAP and PI spectra are compared within each plot. $\mathrm{P}<0.05$ versus SHR.

reduced magnitude of the pulse-interval fluctuations at the frequency range of a few minutes.

\section{Effects of ganglionic blockade}

Shortly after the infusion of hexamethonium into SHR had been started, the blood pressure fell considerably (data not shown), but it returned to near-control values within $4 \mathrm{~h}$. Thereafter, the $24 \mathrm{~h}$ blood pressure and heart rate averages did not differ from control values, but the baroreflex was blocked (Table 4.2, Fig. 4.5). In the absence of neurogenic tone, the circadian blood pressure rhythmicity was reduced significantly whereas that of the heart rate was maintained. Similarly, as was found during cardiac autonomic blockade, ganglionic blockade did not alter the power spectrum of the blood pressure. However, the spectral density power of the heart rate was reduced greatly. 

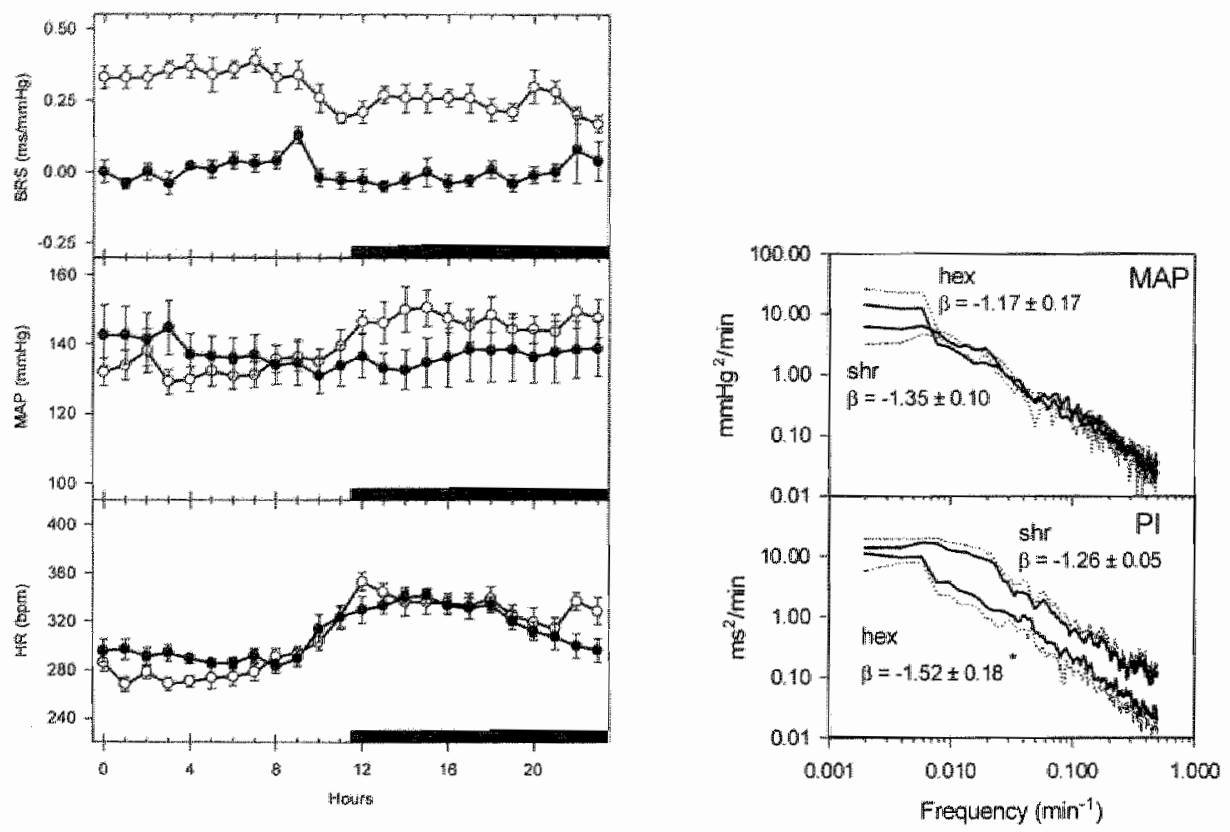

Figure 4.5. Circadian patterns of baroreflex sensitivity (BRS), mean arterial pressure (MAP), and heart rate (HR) in spontaneously hypertensive rats during saline infusion ( $O$, control) and during ganglionic biockade with hexamethonium (-). Values are expressed as hourly means \pm SEM. The dark period is indicated by the black bar at the base of each plot. Statistical differences are given in table 1 .

Figure 4.6. Power spectra of minute-io-mimute averages of mean arterial pressure (MAP), and pulse interval (PI) in spontaneousty hypertensive rats during saline infusion (SHR) and during infusion of hexamethonium (HEX). Average slopes $(\beta+S D)$ of the linear regression lines of the MAP and Pl spectra are compared within each plot. $* \mathrm{P}<0.05$ versus SHR.

This was associated with a slight but significant increase in the slope of the linear regression line of the heart rate $\left(\beta_{\text {cantrol }}=-1.26 \pm 0.05, \beta_{\text {buckate }}=-1.52 \pm 0.18 ; P<0.05\right)$ and a decrease in the intercept. These changes were due mainly 10 a decreased magnitude of the pulse interval fluctuations at the higher frequencies (Fig. 4.6).

\section{Effects of a-adrenergic blockade}

Prazosin treatment increased the average $24 \mathrm{~h}$ heart rate while the average $24 \mathrm{~h}$ blood pressure remained the same (Table 4.2, Fig. 4.7). The 24h BRS was reduced by $50 \%$ (Table 4,2). Prazosin treatment reduced the circadian heart rate and BRS rlyythmicities and even reversed the $24 \mathrm{~h}$ blood pressure pattern. The power spectrum of the BRS was not altered during prazosin treatment (Fig. 4.8). The spectral density power of the blood pressure was decreased throughout the frequency range and was associated with a slight fall in the linear regression coefficient $\left(\beta_{\text {control }} 1.44 \pm 0.08, \beta_{\text {primosina }}=-1.23 \pm 0.09 ; P\right.$ $<0.05)$. The spectral density power of the heart rate increased and the value at the 

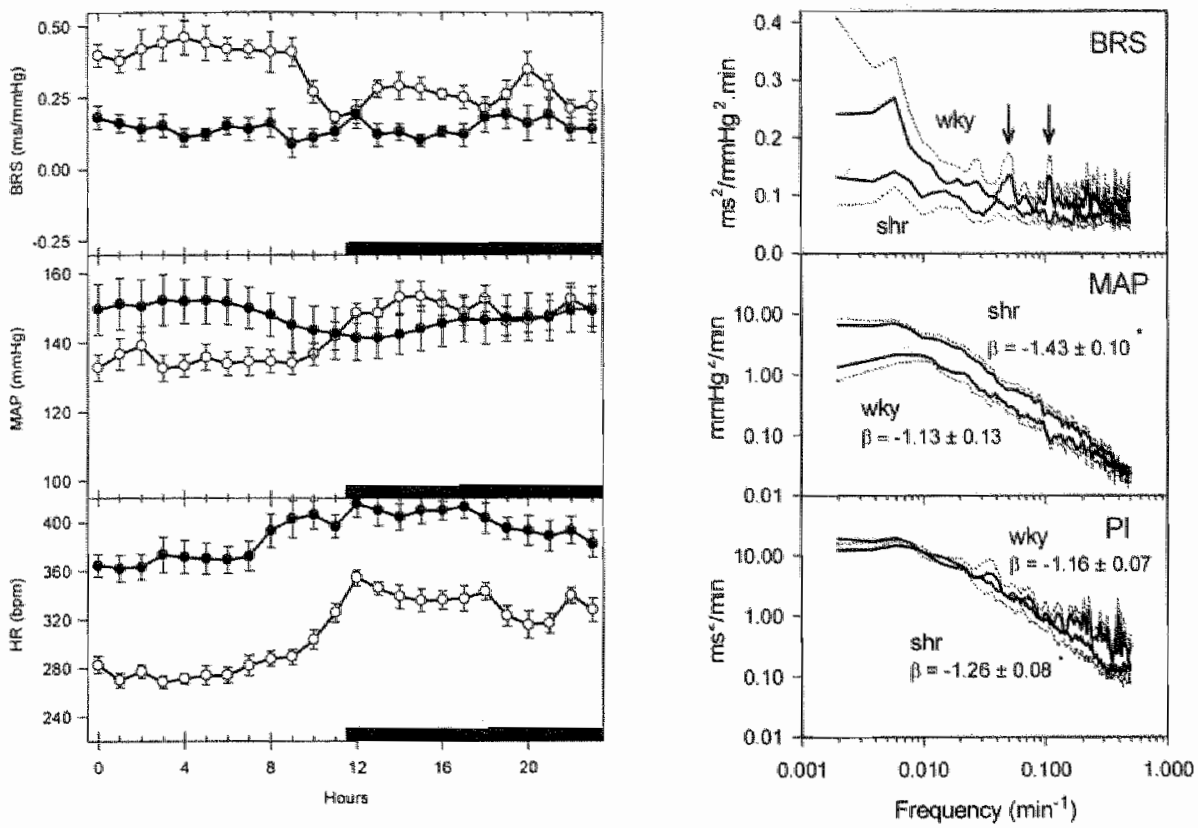

Figure 4.7. Circadian patterns of baroreflex sensitivity (BRS), mean arterial pressure (MAP), and heart rate (HR) in spontaneously hypertensive rats during saline infusion $(O$, control) and during infusion of prazosin (-). Values are expressed as hourly means $\pm S E M$. The dark period is indicated by the black bar at the base of each plot. Statistical differences are given in table 1 .

Figure 4.8. Power spectra of minute-to-minute averages of the baroreflex sensitivity (BRS), mean arterial pressure (MAP), and pulse interval (PI) in spontaneously hypertensive rats during saline infusion (SHR) and during infusion of prazosin (PRA). Average slopes ( $\beta \pm S D$ ) of the linear regression lines of the MAP and PI spectra are compared within each plot. ${ }^{*} P<0.05$ versus $S H R$.

intercept of the linear regression line increased without the slope altering (Fig. 4.8).

\section{Effects of vagal stimulation}

During the continuous, low-dose infusion of scopolamine the average $24 \mathrm{~h}$ heart rate fell by $20 \pm 4$ beats $/ \mathrm{min}$, proving that the vagal stimulation had been maintained throughout this period (Table 4.2). However, under this condition no effects on the blood pressure or BRS were observed. Also the circadian rhythmicities (Fig. 4.9) and ultradian (Fig. 4.10) fluctuations in blood pressure, heart rate and BRS were not altered. 

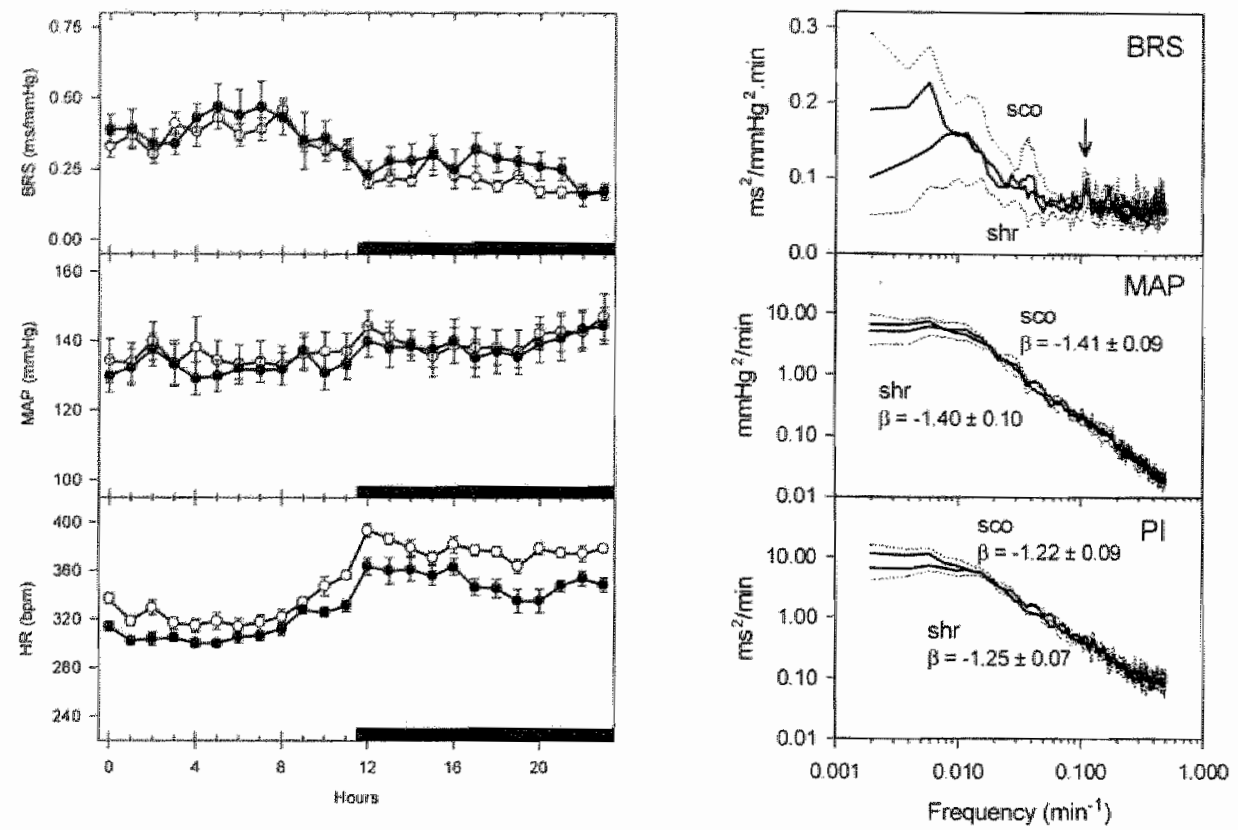

Figure 4.9. Circadian partern of baroreflex sensitivity (BRS), mean arrenal pressure (MAP), and heart rate (HR) in SHR during saline infusion (control) and during infusion of low-dose scopolamine. Values are shown as hourly means 1 SEM. The dark period is indicated by the black bar at the base of each plot. Statistical differences are given in table 4.1 .

Figure 4.10. Power spectrum of minute-to-minute averages of baroreflex sensitwity (BRS), mean arletial pressure (MAP), and heart rate (HR) in SHR during saline infinsion and during infusion of low-dose scopolamine (SCO). Note the $\sim 9 \mathrm{~min}$ oscillation of BRS ( $\downarrow)$. Average slopes ( $B \pm S D)$ of the linear regression lines of the MAP and HR spectra are compared withir each plot. * Indicates statistical differ. ences $(\mathrm{P}<0.05)$ between control and treated SHR.

\section{Discussion}

The autonomic nervous system had different, frequency-dependent effects on circadian and ultradian rhythms of the blood pressure, heart rate and BRS. These effects are discussed in detail in separate sections.

\section{Circadian blood pressure rhythms}

The circadian thythmicity of the blood pressure was found to depend upon the activity of the autonomic nervous system. The $24 \mathrm{~h}$ blood pressure rhythm was suppressed during the infusion of hexamethonium and even reversed by prazosin infusion, 
confirming our previous results with this agent ${ }^{20}$. An inversed blood pressure thythm also occurs in some forms of secondary hypertension and in renin-2 ransgente rats ${ }^{26}$. A possible explanation for these findings is that, under normal physiological conditions, the circadian rhythmicity in blood pressure is domimated by changes in the sympathetic activity of the vasculature. However, in the absence of neurogenic tone, the circadian rhythms of vasoactive hormones, like vasopressin and renin, which peak during the resting phase of the diumal eycle, become unmasked ${ }^{27-29}$. Altematively, prazosin might have dilated the muscle vascular beds selectively ${ }^{30}$, so that the blood pressure fell more during periods of activity than it did during the resting phase

\section{Circadian heart rate rhythms}

In contrast to that of the blood pressure, circadian rhythmicity of the heart rate was found to be largely independent from the autonomic nervous system. During cardiac autonomic blockade with metoprolol and methyl-atropine, the 24 h heart rate pattern was similar to control, although at a lower offset. One may argue that adrenaline mediated $\$ \$_{2}$-adrenoceptor stimulation might have determined the 24 h pattern. However, also during ganglionic blockade, the 24 h heart rate rhythm did not differ from the control thythm. Therefore, our data indicate that intrinsic heart rate is variable throughout the day. The present study, however, does not exclude the possibility that nonnicotinergic nerves ${ }^{3.1}$ play a role. Also in patients, after surgical denervation of the heart after transplantation, circadian thy thmicity of the heart rate is not abolished and parallels physical activity ${ }^{32}, 33$. We therefore suggest that the circadian heart rate rlyythm is predominantly caused by physical activity and that atrial filling, which increases as soon as cardiac output rises, plays a major role.

\section{Circadian rhythms of the BRS}

In this study we found that the $24 \mathrm{~h}$ average values of BRS were $23 \%$ lower in SHR than they were in WKY rats. Comparable reductions in the baroreflex gain in SHR have been documented before ( a reduction by $50 \%$ in SHR aged 9-12 weeks ${ }^{34}$; a reduction by $30 \%$ in SHR aged 14 weeks ${ }^{35}$ ). These earlier studies were performed at only one time point of the day. The current study shows that this difference in BRS persists throughout the day. This finding is ith accordance with data obtained in humans. Typically, the BRS in SHR showed a circadian thythm with its highest values occuring during the resting period and minimal values during the first hours of the active period, when blood pressure and heart rate were increasing. An explanation for the trough in BRS during this period could be that the baroreflex has not yet been reset to the increasing pressure and that the rise in heart rate induced by physical activity overnides its action. During the corresponding period in humans there is an increased incidence of cardiovascular incidents such as myocardial infarction ${ }^{37}$. This pattern suggests that the decreased baroreflex gain could be an independent risk factor for these cardiovascular incidents.

The reduction of the BRS in SHR seems to be due mainly to parasympathetic impairment ${ }^{35}$ and left ventricular hypertrophy ${ }^{38.3 \%}$. Therefore we expected that stimulation of the parasympathetic nervous system by infusion of a low dose of scopolanine would increase the BRS. The infusion of scopolamine decreased the average $24 \mathrm{~h}$ heart rate by $20 \pm 4$ beats/min. However, the BRS was increased only for a few hours during the dark period. This suggests that scopolamine could have altered the range, but not 
the gain, of the barorelles. Also, the presence of left ventricular hypertrophy per se $e^{38}$ could have been responsible for such minor effects of scopolamine in SHR. Alternatively, strong vagomimetic effects of scopolamine are possibly only exposed in severely hypersympathetic states, like in heart failure ${ }^{40}$, but not in spontaneous hypertension.

\section{Ultradian fluctuations in the blood pressure, pulse interval and BRS}

The low-frequency power spectra of the blood pressure and pulse interval showed an almost linear inverse relationship on a double-logarithmic scale within the frequency range 0.01-0.5 cycles/min, without predominant peaks. The slopes of the $1 / \mathrm{f}$ power spectra both of the blood pressure and of the heart rate were greater for SHR than they were for WKY rats. We have no physiological interpretation of this finding. Wagner et al. ${ }^{12}$ found that the slope of the l/f spectrum of the blood pressure in simo-aortic denervated dogs was higher than that of non-denervated dogs. The increase in the slope could indicate a decreased complexity of the non-linear interactions among the remaining control systems. Alternatively, the increased slope could be due to the enhanced activity of compensatory mechanisms at lower ultradian frequencies" . Indeed, after the hyperactivity of the sympathetic nerwous system in the sino-aortic denervated dogs had been suppressed with hexamethonium, the slope returned to control values ${ }^{12}$. In the present study in $\mathrm{SHR}$, hexamethonium did not cause such effects. This might indicate that the presumed sympathetic hyperactivity is rather low in adult SHR. In contrast, prazosin did reduce the magnitude of the ultradian fluctuations in blood pressure, without changing its averaged 24 h steady-state level. This suggests that $\alpha_{1}$-adrenergic receptors are involved in the generation of low-frequency fluctuations in blood pressure. Mayer waves in the blood pressure of conscious rats may stem from an intrinsic cyclical activity of resistance arteries with a period of about $10 \mathrm{~s}^{6,7,42}$. The amplitude of these vasomotor cycles is, amongst other factors, dependent on a-adrenergic stimulation ${ }^{6,42}$. At present the extent to which such relatively fast fuctuations contribute to the observed ultradian fluctuations in blood pressure is not known. Theoretically, deterministic chaotic control systems with scale invariant or $1 /$ foutput characteristics can evolve from the interaction of three non-linear equations ${ }^{15}$. Here, we specuWate that these non-nervous system-dependent spontaneous wasomotor fluctuations are among the factors contributing to long-term fluctuations in blood pressure.

In contrast to that which was found for blood pressure, the ultradian fluctuations in heart rate are under the predominant control of the autonomic nervous system, since cardiac autonomic blockade with metoprolol plus methyl-atropine and with hexamethonium reduced the spectral power throughout the frequency range. The different effects of the autonomic blocking agents on the blood pressure and heart rate suggest that, at these ultradian frequency ranges, in contrast to higher frequencies ${ }^{*}$, heart rate fluctuations and blood pressure fluctuations are coupled loosely. Whether this feature could result from a reduced baroreceptor feedback in SHR at these frequencies is not known. Wide-band blood pressure thuctuations with periods from $30 \mathrm{~s}$ to $30 \mathrm{~min}$ in cats were recently shown to be modulated at least partly by the baroreflex ${ }^{14}$. Clearly, more work is needed to unravel the haemodynamic mechanisms involved at these low frequencies.

Ultradian fluctuations in BRS were slightly more pronounced in WKY rats than they were in SHR. Also in WKY rats, rather than in SHR, cycles of $\sim 9$ and $\sim 20$ min period 
in BRS were found. The frequency of the slowest cycle corresponded to that found in blood pressure in dogs after they had been ummasked by cardiopumonary and sinom aortic denervation? The origin of these fuctuations is not known, but we speculate that they are caused by slow oscillations in vascular resistance since such oscillations were absent during prazosin infusion (Fig. 4.8).

One of the limitations of this study is that we cannot exclude the possibility that the administration of the agents to influence the autonomic nervous system might have caused central effects also and thus affected the behavioural activity of the rat. The infusions of hexamethonium and prazosin may have influenced the feeding and drinking behaviour of the rats and the observed cardiovascular effects may thus have been a consequence of these effects, too ${ }^{43.44}$. Furthermore, the pharmacological blockades by the agents may have varied during the $24 \mathrm{~h}$. Although we reconded the BRS to quantify the functional cardiac blockade with hexamethonium, we cannot exclude the possibility that vascular autonomic blockade was achieved throughout the 24 h period. Plasma sampling of sympathetic neurotransmitters or vasoactive hormones to monitor the autonomic blockade over time and the endocrine response to it was not possible in the present protocol, since the amount of plasma needed would have disturbed the haemodynamic measurements in the rats. For this reason we cannot estimate the extent to which changes in circulating neurotransmitters and vasoactive homones may have contributed to the present findings.

In conclusion, the influence of the autonomic nervous system on the blood pressure and heart rate in SHR is frequency-dependent. Circadian but not ultradian blood pressure rhythms are controlled by vascular autonomic activity. The circadian rhythmicity of the heart rate occurs in the absence of autonomic tone, whereas ultradian fluctuations in heart rate depend on it. A trough in BRS occurs for rats, just as it does for humans, after the sleeping period when locomotor activity is resumed.

\section{References}

1. Daniels FH, Leonard EF, Cortell S: Spectral analysis of arterial blood pressure in the rat. IEEE T Biomed Eng 1983; BME-30: 154-159.

2. Pomeranz B, Macaulay RJB, Caudil1 MA, et al: Assessment of autonomic function in humans by heart rate spectral analysis. Akn J Physiol 1985; 248: H151-11153.

3. Cerutti $C$, Barrès $C$, Paultre $C$ : Baroreflex modulation of blood pressure and heart rate variabilities in rats: assessment by spectral analysis. Am J P/wsiol 1994; 266: H1993$\mathrm{H} 2000$.

4. Daffonchio A, Franzelli C, Radaelli A, et al: Sympathectony and cardiovascular spectral components in conscious normotensive rats. Hypertension $1995 ; 25: 1287$. 1293.

5. Taylor JA, Eckberg DL: Fundamental relations between short-term $\mathbb{R} R$ interval and arterial pressure oscillations in humans. Circulation 1996:93:1527-1532.

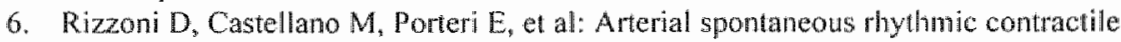
activity in humans and rats: spectral analysis and regulatory mechanisms. JHyperens $1995 ; 13: 1043-1052$.

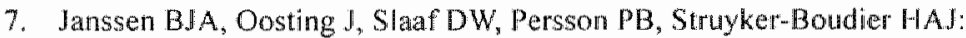
Hemodynamic basis of oscillations in systemic arterial pressure in conscious rats. Am IPhysiol 1995; 269: H62-H71. 
8. Ferrari $A \cup$, Daffonchio $A$, Albergati $F_{\text {, Mancia }} \mathrm{O}$ : Inverse relationship between heart rate and blood pressure variabilities in rats. Hypertension 1987; 10: $533-537$.

9. Persson PB, Ehnke H, Kohler WW, Kirchhem HR: Identification of major slow blood pressure 0scillaions in conscious dogs. Am I Physiol 1990; 259: H1050-H1055.

10. Broten IP. Zehr JE: Autonomic modutation of uttadian blood pressure and hean rate oscillations in dogs. Am J Plysiol 1989;256: R I127-R1137.

11. Blinowska K, Marsh DV: Ultra- and circadian fluctuations in arterial pressure and electronyogram in conscious dogs. Am J Physiol 1985; 249: R720-R725.

12. Wagner CD, Persson PB: Two ranges in blood pressure spectrum with different $1 / \mathrm{f}$ characteristics. Am / Physiol 1994; 267: H449-H454.

13. Marsh DJ, Osbom JL, Cowley Jf $A$ W: $1 / f$ fluctuations in arterial pressure and regulation of renal blood now in dogs. Am J Physiol 1990; 258: F1394-F/400.

14. Di Rienzo M, Castiglioni P, Pardi $G$, Mancia $G$, Pedotti $A$ : Effects of sinomartic denervation on spectral characteristics of blood pressure and pulse interval variability: a wide-band approach. Med Biol Eng Compun 1996; 34: 133-141.

15. Goldberger All, West BJ: Fractals in physiology and medicine. Yale J Biol Med 1987; 60: $421-435$.

16. Batungart P, Walger P, Fuchs $\mathrm{G}$, Dorst $\mathrm{KG}$, Vetter H, Rahn KH: Twenty-four-hour blood pressure is not dependent on endogenous circadian rhythm. $J$ Hypertens 1989 ; $7: 331-334$

17. Friberg P, Karlsson B, Nordlander M: Autonomic control of the diumal variation in arterial blood pressure and heart rate in spontaneously hypertensive and WistarKyoto rats. J Hypertens 1989; 7:799-807.

18. Van Den Buuse $M$ : Circadian thythms of blood pressure, heart rate, and locomotor activity in spontancously hypertensive rats as measured with radio-telemetry. Physiol Behov 1994; 55: 783-787.

19. Mancia G: Ambulatory blood pressure monitoring: research and clinical applications. J Hypertens 1990; 8(Suppl. 7): s1-s13.

20. Janssen BUA, Tyssen CM, Struyker-Boudier HAJ: Modification of circadian blood pressure and heart rate variability by five different anthypertensive agents in spontaneously hypertensive rats. J Cardiovasc Pharmacol 1991; 17: 494-503.

21. Takalo R, Korhonen I, Turjanmaa V, Majahalme $S$, Tuomisto M, Uusitalo A: Shortterm variability of blood pressure and heart rate in bordertine and milldy hypertensive subjects. Hypertension 1994; $23: 18-24$.

22. Lemmer B: "The Chronopharmacology of cardiowascular medications. An Rev Chonophamacol 1986:2:199-228.

23. Oosting J, Struijker-Boudier HAJ, Janssen BJA: Validation of a continuous baroreceptor teflex sensitivity index calculated from spontaneous thuctuations of blood pressure and pullse intervall in rats. J Hypertens 1997; 15:391-399.

24. van Kleef EM, Smits JFM. De Mey JGR, et al: "I-Adrenoceptor blockade reduces the angiotensin 11 -induced vascular smooth muscle cell DNA synthesis in the rat thoracic aorta and carotid artery. Cinc Res 1992; 70: 1122 1127.

25. Bertinieri $G$, Di Rienzo $M$, Cavallazzi A, Ferrari AU, Pedotti $A$, Mancia G: Evaluathon of baroreceptor retlex by blood pressure monitoring in unanesthetized cats. Am I Physiol 1988; 254: $1377-\mathrm{H} 383$.

26. Lemmer $B$, Mattes A, Bohm M, Ganten D: Circadian blood pressure variation in transgenic bypertensive rats. Hypertension 1993; 22:97-101.

27. Gordon RD, Wolfe LK, Island DP, Liddle GW: A diurnal thythm in plasma renin activity in mat. J Clin Inves $1966 ; 10: 1587-1592$.

28. Cugin $p$, Letizia $C$, Cerci $S$, et al: A chronobiological approach to circulating levels of renin, angiotensin-conwerting enzyme, aldosterone, $\mathrm{ACTH}$, and cortisol in Addison"s. disease. Chromobiol Int 1993; 10: 119-122. 
29. Kool MJ, Wijnen JA, Derkx FH, Struijker-Boudier HA. Wan-Bortel LM: Diurnal: variation in prorenin in relation to other humoral tactors and hemodynamics. $A$ w $J$ Hypertens 1994; 7: 723-730.

30. Gardiner SM, Bennet T: Regiona l hemodynamio responses to adrenoreceptor antagonism in conscious rats. An I P/msiol 1988; 255: H813-H824.

31. Corr L: Neuropeptides and the conduction system of the heart. In J Card 1992; 35 : $1-12$.

32. Van De Bome $P$, Leeman $M$, Primo $G$. Degaute JP. Reappearance of a nomal circadian rhythm of blood pressure after cardiac transplantation. Am J Cardiol 1992; 69: 794-801.

33. Idema RN, Van Den Meiracker AH, Balk AHMM, Bos E, Schalekamp ADH, Man in't Veld AJ: Abnormal diumal wariation of blood pressure, cardiac output, and vascular resistance in cardiac transp ant recipients. Circulotion 1994; 90: 2797-2803.

34. Struyker-Boudier HAJ, Evenwel RT, Smits JFM, Van Essen H: Baroreflex sensitivity during the development of spontaneous hypertension in rats. Clim Sci 1982; 56:163167.

35. Head GA, Adams MA: Time course of changes in baroreceptor reflex control of heat rate in conscious SHR and WKY: contribution of the cardiac vagus and sympathetic nerves. Clin Exp Pharmac Physiol 1988" 15:289.292.

36. Parati G, Di Rienzo M, Bertinieri G, et all: Evaluation of the baroteceptor-heart rate reflex by 24 -hour intra-arterial blood pressure monitoring in humans. Hypertension $1988 ; 12: 214-222$

37. Muller JE, Toffer $\mathrm{GH}$, Stone $\mathrm{PH}$ : circadian wariation and triggers of onset of acute cardiovascular disease. Circulation 1989; 4:733-743.

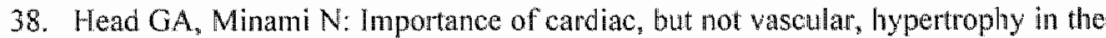
cardiac baroreflex deficit in spontaneously hypertensive and stroke-prone rats. $A \mathrm{~m} J$ Med 1992; 92: 54S-59S.

39. Minami N, Head GA: Relationship between cardiovascular hypertrophy and cardiac baroreflex function in spontaneously hypertensive and stroke-prone rats. I Hypertens 1993; 11: $523-533$.

40. La Rovere MT, Mortara A, Pantaleo Pi Maestri R, Cobelli F, Tavazzi L; Scopolamine improves autonomic balance in advanced congestive heart failure. Circulation 1994; 90: $838-843$.

41. Wagner CD, Nafz B, Persson PB: Very low frequent oscillations in blood pressure after ganglionic blockade. Hypertension 1996;28: 706, Abstract.

42. De Mey JGR, Boonen HCM, Struijker Boudier HAJ: Rhythmic contractile activity in resistance-sized arteries of spontaneously hypertensive rats. In Halpern $\mathrm{W}_{\text {, Pegram }} \mathbf{B}$, Brayden JE, McLaughlin MK, Osoll G (eds): Resistance Arteries Perinatology Press, New York, 1988: 336-341.

43. Levin ED, Ellison GD, Salem C, Jarvik M, Gritz E: Behavioral effects of acute hexamethonium in rats chronically intoxicated with nicotine. Physiol Behov 1988; 44 336-341.

44. Khan IM, Taylor P, Yaksh TL: Cardiovascular and behavioral responses to nicotinic agents administered intrathecally. J Pharmacol Exp Ther 1994;270:150-158. 
Chapter 4 


\section{Chapter 5 \\ Circadian and ultradian control of cardiac output in spontaneous hypertension in rats}

Jan Oosting

Harry A.J. Struijker-boudier

Ben J.A. Janssen

Published in American Journal of Physiology 1997: 273 (Heart circ. Physiol. 42):H66H75

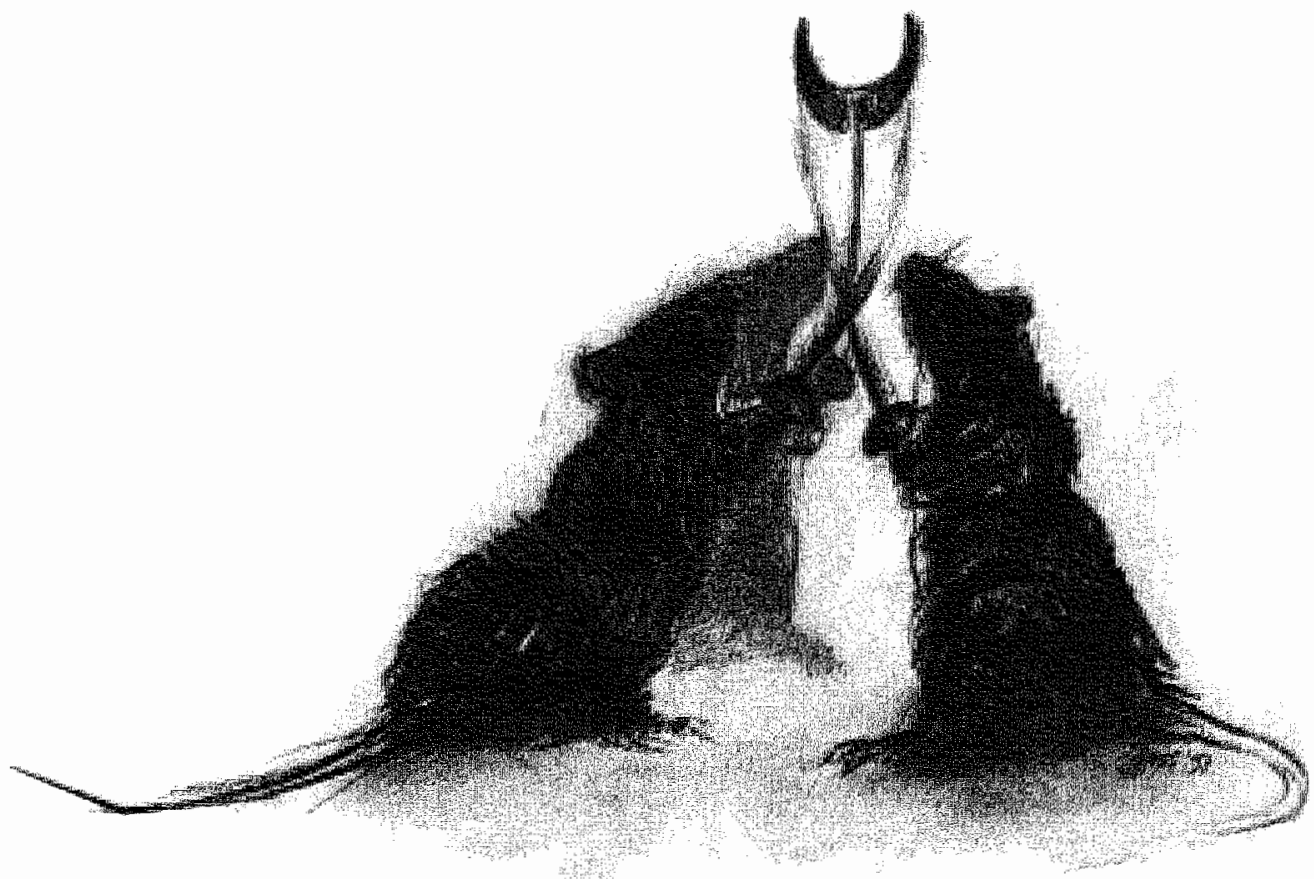




\begin{abstract}
The aim of the study was to test whether circadian and ultradian variations of cardiac output (CO) in spontaneously hypertensive rats (SHR) differ from those in normotensive Wistar Kyoto rats (WKY). Twenty-four-hour beat-to-beat recordings of $\mathrm{CO}$ (by electromagnetic flow probe) and mean arterial pressure (MAP) were performed in the absence and presence of cardiac autonomic blockade with metoprolol and atropine methylnitrate. Ultradian variability was analyzed by spectral analysis on beat-tobeat data series (high-frequency range) and on averaged minute-to-minute data series (low-frequency range). In general, circadian and ultradian rhythms of $\mathrm{CO}$ were similar in SHR $(n=10)$ and WKY $(n=9)$. Values of CO were high during the dark and low during the light period, whereas total peripheral resistance was highest during the light period. During cardiac autonomic blockade, relative differences between averaged values of $\mathrm{CO}$ over the dark and light periods were reduced. High-frequency spectral power of $\mathrm{CO}$ was mainly confined to fluctuations related to respiration and was not influenced by cardiac autonomic blockade. At low-frequency ranges, power spectra of $\mathrm{CO}$ lacked a dominant oscillator but showed $1 /$ f characteristics. During cardiac autonomic blockade, low-frequency spectral power of $\mathrm{CO}$ fell without changing the $1 / \mathrm{f}$ characteristics. These findings suggest that dynamic control of $\mathrm{CO}$ is not altered in SHR and that autonomic effects on $\mathrm{CO}$ are frequency dependent. In most frequency ranges, the relative variation of CO was higher than that of MAP. Thus, over $24 \mathrm{~h}$ in both adult SHR and WKY, MAP is controlled within a more narrow range than $\mathrm{CO}$.
\end{abstract}




\section{Introduction}

Arterial blood pressure fluctuates diumally with low values during periods of sleep and high values during periods of activity. The circadian patterns of cardiac output $(\mathrm{CO})$ and peripheral resistance, which are responsible for the diumal variation in arterial pressure, are less well known. Only in a few studies in humans ${ }^{1-4}$, nonhuman primates ${ }^{5.6}$, dogs $^{7}$, and rats ${ }^{8}$, has $\mathrm{CO}$, or indirect measures of it, been recorded over a full diumal cycle. In these studies, $\mathrm{CO}$ was low and peripheral resistance was high during periods of sleep, whereas the reverse pattern was observed during periods of activity. The evidence thus far suggests that the diurnal profile of $\mathrm{CO}$ is closely linked to the physical activity pattern. The diurnal changes in peripheral resistance, especially during periods of sleep, when metabolic demand and sympathetic tone are low, are probably governed by autoregulatory processes ${ }^{1.5}$. Except for one study in cardiac transplant recipients ${ }^{4}$, all aforementioned studies were confined to healthy volunteers and healthy animals.

In the established phase of spontaneous hypertension, both in humans and animal models, $\mathrm{CO}$ is normal, whereas peripheral resistance is elevated ${ }^{9.10}$. These results were obtained mainly from measurements performed over relatively short periods of time and mostly in resting conditions. However, circadian fluctuations in $\mathrm{CO}$ may be elevated in spontaneous hypertension and contribute to the increased diurnal fluctuations of blood pressure associated with this disease in humans "as well as in animal models ${ }^{12.13}$. In addition, ultradian ( $<24 \mathrm{~h}$ ) fluctuations in $\mathrm{CO}$ output could also be different in spontaneous hypertension. Indicative for this is the finding that short-term variability of heart rate (HR) is decreased ${ }^{14}$. Generally, this is explained as being caused by impaired vagal control of $\mathrm{HR}^{15}$. Whether this holds true for the regulation of $\mathrm{CO}$ in hypertension is not known.

The first aim of the present study was to investigate the circadian and ultradian profiles of systemic hemodynamic parameters in spontaneous hypertension. The second aim was to examine the dynamic interaction of $\mathrm{CO}$, arterial pressure, and peripheral resistance during a full circadian cycle. To this end, we recorded $\mathrm{CO}$ and mean arterial pressure (MAP) on a beat-to-beat basis for $24 \mathrm{~h}$ in spontaneously hypertensive rats (SHR) and Wistar-Kyoto rats (WKY). Experiments were performed under normal conditions as well as during cardiac autoriomic blockade with metoprolol and atropine methylnitrate. The dynamic relationship between blood pressure, $\mathrm{CO}$, and peripheral resistance was examined by spectral analysis.

\section{Methods}

\section{Animals}

Adult male WKY and SHR rats weighing $280-300 \mathrm{~g}$ were used. The rats were obtained from the Central Animal Facilities of the Universiteit Maastricht. Experiments were performed according to institutional guidelines and approved by the institutional ethics committee. The animals were kept on a 12:12-h light-dark cycle. After surgery, the animals were housed individually in cages and were allowed normal rat chow and drinking water ad libitum. 
Surgery

All rats were instrumented with an electromagnetic (EM) flow probe around the ascending aorta, an arterial catheter for measurement of blood pressure, and a venous catheter for administration of drugs. Surgery was performed in two stages, both under pentobarbital sodium ( $60 \mathrm{mg} / \mathrm{kg}$ ip) anesthesia and sterile conditions. In the first stage, the EM flow probe was placed. The trachea was intubated (PE-240). The skin and muscles overlying the third right intercostal spaces were separated and cut. After respiration was started with room air ( 60 strokes $/ \mathrm{min}$, tidal wolume $3 \mathrm{ml})$, the thorax was opened. The ribs were spread with a small retractor, and the aorta was dissected free. The EM flow probe ( $2.7 \mathrm{~mm}$; Skalar, Delft, The Netherlands) was placed around the ascending aorta just above the heart. The thorax was closed by pulling the ribs together with 3-0 silk, and the cable of the probe was fixed to the ribs. Muscles were sutured separately with 5-0 silk. The cable was guided to the neck, where the connector was fixed to the muscles and skin. The skin was sutured (3-0 silk), and subatmospheric intrathoracic pressure was restored by insertion of a Silastic drain through a stab wound between the sixth and seventh ribs and application of a negative pressure of $10 \mathrm{cmH} 2 \mathrm{O}$. The animals were allowed 2-3 days of recovery before the second stage of surgery. In this latter procedure, the abdominal aorta and the inferior vena cava were cannulated via the femoral vessels. The catheters were tunneled subcutaneously to the neck, where they were exteriorized. The catheters were filled with a heparinized saline solution $(5 \mathrm{U} / \mathrm{ml})$.

\section{Protocol and data acquisition}

The measurements were performed with the rats being kept in their home cage. Two to three days after implantation of the catheters, the rats were connected to the equipment. The cable of the flow probe and the arterial and venous catheters were guided through a rubber tube to protect them. The rubber tube was attached to a balanced, freely moving arm above the rat to allow the animal full movement. The EM flow probe was connected to a sine-wave EM flowmeter (Transflow 601 system, type MDL 1401, Skalar). The arterial catheter was connected to a low-volume displacement pressure transducer (microswitch, model 156PC I 56WL, Honeywell, Amsterdam, The Netherlands) that was connected to an amplifier that delivered a high-voltage signal to an analog-todigital converter board (model 2814, Data Translation, CN Rood, Rijswijk, The Netherlands) mounted in an IBM-compatible computer. Both the flow and pressure signals were sampled at $1,000 \mathrm{~Hz}$. A dedicated computer program was used to identify on-line the end-diastolic, flow of each beat, which was taken to be zero. Then, from beat to beat, the pulse interval (PI), HR, MAP, stroke volume (SV), CO, and total peripheral resistance (TPR) were calculated and stored on hard disk. At least $24 \mathrm{~h}$ were allowed to pass before measurements began, to accustom the animal to the experimental conditions.

Measurements were made for two consecutive days. An intravenous infusion of a $0.9 \%$ saline solution $(0.2 \mathrm{ml} / \mathrm{h})$ was given on the first day as vehicle. The total volume infused $(5 \mathrm{ml} / 24 \mathrm{~h})$ is low compared with average water intake $(-30 \mathrm{ml} / 24-\mathrm{h})$ in rats. On the second recording day, the cardiac autonomic system was blocked by an infusion of metoprolol ( $\left.1.65 \mathrm{mg} \cdot \mathrm{kg}^{-1} \cdot \mathrm{h}^{-1}\right)$ and atropine methylnitrate $\left(1.65 \mathrm{mg} \cdot \mathrm{kg}^{-1} \cdot \mathrm{h}^{-1}\right)$ dissolved in saline at a rate of $0.2 \mathrm{ml} / \mathrm{h}$. To obtain steady'state pharmacokinetics and to avoid acute 
drug effects, the recording was started 2 h after the infusion had started. The saline infusions were started in the second hour of the dark period. The recording during cardiac autonomic blockade was started in the fourth of fifth hour of the dark period. At the end of the 24-h infusion period, cardiac autonomic blockade was verified by recording HR changes after intravenous bolus injections of sodium nitroprusside and phenylephrine. After 24-h. infusion of metoprolol and atropine methylnitrate, the phenylephrine-induced changes were $\mathrm{MAP}+40+6 \mathrm{mmHg}$ and $\mathrm{HR}-6=1 \mathrm{~min}^{-1}$ in $\mathrm{SHR}$ $(\mathrm{n}=10)$ and $\mathrm{MAP}+40 \pm 2 \mathrm{mmHg}$ and $\mathrm{HR}-5 \pm 1 \mathrm{~min}^{-1}$ in WKY $(\mathrm{n}=9)$ Nitroprusside-induced changes were MAP-26 $2 \mathrm{mmHg}$ and $H R+9 \pm 1 \mathrm{~min}^{-1}$ in SHR and MAP $-28 \pm 2$ mmHg and HR $+11 \pm 2 \mathrm{~min}^{-1} \mathrm{~m}$ WKX. In intact WKY and SHR, such pressure changes evoke HR changes $>50 \mathrm{~min}^{-1} 15$, confirming a functional autonomic cardiac blockade. The fixed order of recording first velhicle and then treatment was chosen for a technical reason. In this particular setup, we found that when rats were tethered for longer periods of time the chance of dys function of the flow probe increased considerably. Therefore, when the reversed order would have been done, allowing for full recovery of the drug effects, the study would have been prolonged by 3 days.

\section{Data analysis}

Data were included for analysis only when both the 24-h recordings during saline and cardiac autonomic blockade were completed. To construct the circadian patterns, the beat-to-beat values of CO, MAP, HR, peripheral resistance, and SV were averaged over every hour of the recording. Coefficients of variation were calculated as 100 times the standard deviation of all 24 -h values divided by the 24 -h average value. As a measure of circadian rhythmicity, the relative circadian amplitude of each parameter was calculated as the difference between the maximum and minimum walues of the hourly averages in a $24-h$ period normalized by the average $24-h$ value. In addition, we calculated the relative difference between the average values over the $12-\mathrm{h}$ dark period and the 12-h. light period nomalized to the average 24-h values.

Spectral analysis in high-frequency range. The dynamic relationship between the systemic hemodynamic parameters was analyzed by spectral analyses as described previously ${ }^{\text {ix }}$. For the analysis in a high-frequency (HF) range, a stable period of 6,000 beats $(15-20 \mathrm{~min})$ was selected from the third hour of the dark period and the third hour of the light period. For spectral analysis, equidistantly sampled data are required. Therefore, from these two series of beat-to-beat data, equidistant data series were constructed using an algorithm that extracted from sequential $200-\mathrm{ms}$ time windows the maximum value of each parameter. Because PI was never $>200 \mathrm{~ms}$, the width of the time window was set at $200 \mathrm{~ms}$ to avoid aliasing. Spectral density was calculated by a fast Fourier transform on consecutive blocks of 1,024 values, and the results were averaged for all blocks in a recording. In this way we were able to explore the frequency range of $0.05-2.5$ Hz with a resolution of $0.005 \mathrm{~Hz}$. Data were averaged over a low-frequency (LF; ; $0.05-0.25$ $\mathrm{Hz}$ ), a midfrequency (MF; 0.25-0.55 Hz), and an $\mathrm{HF}(1.0-2.1 \mathrm{~Hz}$ ) band. In these selected frequency ranges, mechanisms related to autoregulation (LF), the autonomic nervous system (MF), and the respiratory cycle (HF) have been identified ${ }^{\text {it }}$.

Spectral analysis in LF range. For the analysis in the LF range, values of CO, blood pressure, and peripheral resistance were averaged every minute for both the dark and light periods. From the 720 data points in each of these periods, a series of $512 \mathrm{~min}$ 
was taken for the callculation of the power spectrum. Because for all rats power spectral density in the light and dark periods was similar, data were averaged over these periods. After logarithmic trans formation of both the frequency ( $)$ and the power, a linear correlation between $f$ and power was used to describe the slope $(\beta)$ and intercept of the linear part of the power spectrum between 0.01 and $0.5 \mathrm{cycles} / \mathrm{min}$. The inverse relation between $f$ and spectral density power reflects the operation of multiple processes with overlapping time scales 17 . The slope of the $1 / f$ spectrum is independent of total power and is an index of the complexity of the system controlling the parameter. This index has recently been useful in research describing changes in the labile behavior of HR and blood pressure ${ }^{18-21}$.

Transfer function analysis. In addition to spectral density power, the transfer function was calculated, with $\mathrm{CO}$ as the input signal and arterial pressure as the output signa $1^{16}$. The transfer gain was normalized by the average steady-state resistance. In this case, the normalized gain is the ratio of the fractional variation in pressure to $\mathrm{CO}$. A value of 1 for the gain indicates that, when the input $(\mathrm{CO})$ fluctuates by some fraction of the mean value, the output (arterial pressure) undergoes the same fractional variation, as would be the case in a rigid vaseular bed, without resistance variation. A value $<1$. signifies that the fractional variations in pressure are smaller than in $\mathrm{CO}$. A gain $>1$ indicates that relative fluctuations in pressure are greater than fluctuations in $\mathrm{CO}$. In physiological terms, the latter case means that the system prefers to control flow rather than pressure, which would be indicative of autoregulatory behavior. In addition, we computed the phase and coherence. The phase indicates the temporal relationship between the $\mathrm{CO}$ and blood pressure signals in the frequency domain. The coherence can have a value between 0 and 1 and is a frequency-domain estimate of the degree that the blood pressure variance can be explained by a linear operation of the $\mathrm{CO}$ variance.

Two-dimensional frequency distributions. Mutual interactions between systemic hemodynamic parameters were examined by contour plots. These plots, comparable to topographical altitude maps, were made by calculating two-dimensional frequency histograms and plotting lines through bins of 300 with equal numbers of occurrences. The scales of the axes were normalized to the average $24-\mathrm{h}$ value. The advantage of such plots over time-course graphics is that they 1) illustrate in more detail the range of the spontaneous variations of parameters and 2) reveal clusters of preferred combinations between parameters that are not visible in time-course graphics. We have used these techniques to illustrate our modified wiew on the concept of a set point and the concept of autoregulation ${ }^{22,23}$. Preferred combinations of parameters were identified and counted as such when the altitude lines enclosed a combination that occurred at least 600 times or more than surrounding combinations.

\section{Statistics}

Data are presented as means \pm SE. To compare effects of cardiac autonomic blockade versus saline in SHR and WKY, a two-way analysis of variance was used with SHR versus WKY as a between factor and saline versus autonomic blockade as a within factor. Statistical significance was accepted at $\mathrm{P}<0.05$. 
Table 5.1. Average 24-h walues and lability wices of systemic hemodnamion

\begin{tabular}{|c|c|c|c|c|}
\hline & \multicolumn{2}{|c|}{$W K Y(n=9)$} & \multicolumn{2}{|c|}{ SHR $(n=10)$} \\
\hline & Control & Blockade & Control & Blocksade \\
\hline \multicolumn{5}{|l|}{ A. Average $24-1 /$ values } \\
\hline MAP $(\mathrm{mmHg})$ & $111 \pm 3$ & $99 \pm 3 \&$ & $135 \pm 4 *$ & $121 \pm 45^{*}$ \\
\hline $\mathrm{CO}(\mathrm{ml} / \mathrm{min})$ & $77 \div 4$ & $71 \pm 35$ & $76 \pm 2$ & $66 \pm 2 \$$ \\
\hline TPR (mmHg/ml.min) & $1.51 \pm 0.09$ & $1.45 \pm 0.10$ & $1.83 \pm 0.10 *$ & $1.89 \pm 0.10^{*}$ \\
\hline MR (beats min) & $351 \geq 6$ & $333 \pm 7 \mathrm{~S}$ & $345 \pm 4$ & $317 \pm 4 \$$ \\
\hline$S V(\mu l)$ & $220 \pm 11$ & $213 \pm 11$ & $221+6$ & $207 \pm 7 \$$ \\
\hline \multicolumn{5}{|c|}{ AB: Coefficients of variation (of all $24-h$ beats) } \\
\hline MAP $(\%)$ & $8.7 \pm 0.6$ & $13.0 \pm 2.0 \$$ & $8.9 \pm 0.7$ & $12.1 \pm 1.1 \$$ \\
\hline $\mathrm{CO}(\%)$ & $14.1 \pm 0.7 \dagger$ & $\llbracket 2.1 \pm 1.0$ & $12.5 \pm 0.5+$ & $11.7 \pm 0.9$ \\
\hline $\operatorname{TPR}(\%)$ & $17.1 \pm 1.2 \pi$ & $19.5 \pm 2.4$ & $15.1 \pm 1.1+$ & $17.4 \pm 1.4$ \\
\hline HR $(\%)$ & $11.4 \pm 0.5$ & $5.6 \pm 0.3 \$$ & $11.5 \pm 0.5$ & $5.6 \pm 0.7 \$$ \\
\hline $\mathrm{SV}(\%)$ & $13.0 \pm 0.6$ & $11.7 \pm 0.8$ & $1 \| .5 \pm 0.4 *$ & $10.7 \pm 0.7$ \\
\hline \multicolumn{5}{|c|}{ 1C: Relative circadian amplinudes } \\
\hline MAP $\%)$ & $16.8 \pm 2.2$ & $34.1 \pm 8.7$ & $20.3 \pm 2.2$ & $26.8 \pm 2.9$ \\
\hline $\mathrm{CO}(\%)$ & $30.1 \pm 3.2+$ & $28.7 \pm 4.4$ & $28.0 \pm 1.8+$ & $26.4 \pm 3.7$ \\
\hline TPR $(\%)$ & $33.7 \pm 3.8 \uparrow$ & $45.4 \pm 8.2$ & $33.5 \pm 4.0 \uparrow$ & $38.9 \pm 6.9$ \\
\hline $\operatorname{HR}(\%)$ & $23.3 \pm 1.9$ & $16.8 \pm 1.4 \$$ & $26.9 \pm 2.7$ & $16.1 \pm 2.0 \$$ \\
\hline $\mathrm{SV}(\%)$ & $24.8 \pm 2.7$ & $21.4 \pm 2.1$ & $22.4 \pm 2.0$ & $18.7 \pm 2.7$ \\
\hline \multicolumn{5}{|c|}{ ID: Relative difference berween $12-h$ dark period and 12-h light period } \\
\hline MAP $(\%)$ & $\overline{0.1 \pm 1.7}$ & $7.6 \pm 4.8$ & $0.4 \pm=1.5$ & $4.0 \pm 2.5$ \\
\hline $\operatorname{CO}(\%)$ & $11.3+2.2+$ & $7.8 \pm 2.5 \$$ & $10.6 \pm 1.2+$ & $5.5 \pm 2.3 \$$ \\
\hline $\operatorname{TPR}(\%)$ & $-11.5 \pm 2.5+$ & $0.2 \pm 5.7$ & $-10.0 \pm 1.5+$ & $1.7 \pm 4.1 \$$ \\
\hline $\mathrm{HR}(\%)$ & $4.7 \pm 1.9$ & $6.1 \pm 1.3$ & $9.9 \pm 1.9$ & $4.7 \pm 1.68$ \\
\hline $5 V(\%)$ & $6.6 \pm 1.9$ & $1.6 \pm 2.3$ & $0.7 \pm 1.3 *$ & $0.8 \pm 1.8$ \\
\hline
\end{tabular}

Mean walues and 24-h lability indices of meam arterial pressure (MAP), cardiac ouph (CO), total peripheral resistance (TPR), heart rate (HR), and stroke volume (SV) in WKY and SHR during normal conditions (control) and during cardiac autonomic blockade with metoprolol t methylatropine (blockade). Statistical differences berween and within groups. (ANOVA) are

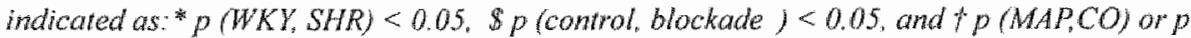
(MAP, TPR) $<0.05$ 

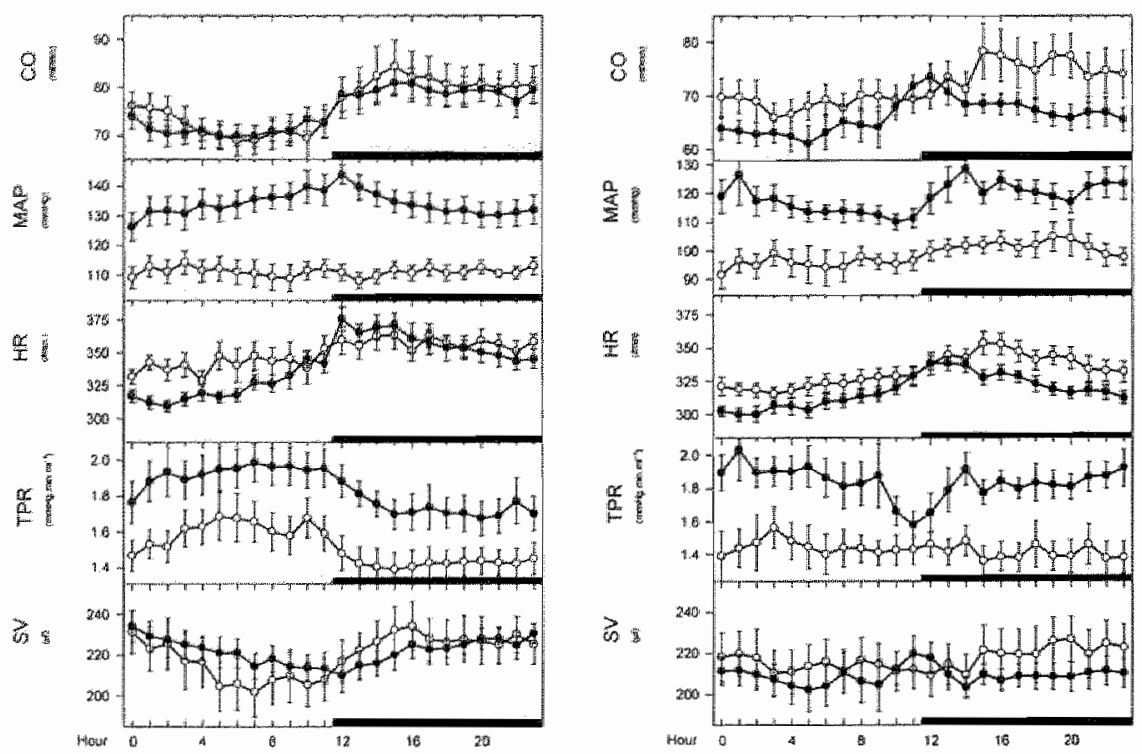

Figure 5.11. Average hourly hemodynamic pattern of 24-h recordings in WKY (n=9) and SHR $(n=10)$ during saline infusion. The saline infusion were started between $13-14 \mathrm{~h}$. Cardiac output (CO), mean arterial pressure (MAP), heart rate (HR), toral peripheral resistance (TPR), and stroke volume (SV) are shown. The dark period is indicated by the black bar on the time caxis. Staristical differences between SHR and WKY in terms of average values, coefficient of variation and relarive circadian amplitude are given in table 1.

Figure 5.2. Average hourly hemodynamic patlerm of 24-h recordings in the same animals as in figure I during cardiac autonomic blockade. The recordigs during the infusions of metoprolol t methyl-atropine were started between 16-18 h. Cardiac output (CO), mean arterial pressure (MAP), hean rate (HR), fotal peripheral resistance (TPR), and stroke volume (SV) are shown. The dark period is indicated by the black bar on the fime axis. Sratistical differences between SHR and WKY as well as between control and blockade are given in table 1 .

\section{Results}

\section{Steady state systemic hemodynamics}

In SHR, average 24-h MAP and peripheral resistance were higher than in WKY (Fig. 5.1, table 5.1). No difference was found in average 24- $\mathrm{HLR}, \mathrm{CO}$, and SV In both SHR and WKY, CO and HR exhibited higher values during the dark, active period, whereas peripheral resistance showed higher values during the light, resting period. This was quantified by calculating the relative difference between the average values over the dark and light periods (see Table 5.1).

The 24-h coefficients of variation of the systemic hemodynamic parameters were similar for SHR and WKY (see Table 5.1). In both strains, the coefficient of variation of 
Table 52 : Relaive spectral density power of systentic hemodynowics in 3 frequency mongess

\begin{tabular}{|c|c|c|c|c|c|}
\hline & \multirow[b]{2}{*}{$\begin{array}{l}\text { Prequency } \\
\text { range }\end{array}$} & \multicolumn{2}{|c|}{ WKY $(n=9)$} & \multicolumn{2}{|c|}{ SHR $(n=10)$} \\
\hline & & Comtrol & Blockade & Contral & Blockade \\
\hline \multirow[t]{3}{*}{$\overline{\mathrm{MAP}}(\%)$} & $\mathrm{LF}$ & $35.9 \pm 2.0$ & $34.5 \pm 8.9$ & $30.3 \pm 2.0$ & 30.942 .5 \\
\hline & $M F$ & $7.2 \pm 1.0$ & $5.9 \pm 1.0$ & $13.3 \pm 1.75$ & $11.0+2.1 \$$ \\
\hline & $\mathrm{HF}$ & $1.5 \pm 0.2$ & $2.5 \pm 0.7$ & $3.8 \pm 0.65$ & $2.7 \pm 0.7$ \\
\hline \multirow[t]{3}{*}{$\mathrm{CO}(\%)$} & $\mathrm{LF}$ & $9.8 \pm 0.6$ & $8.9 \pm 0.3$ & $12.7 \pm 1.5$ & $14.2 \pm 11.7 \$$ \\
\hline & $\mathrm{MF}$ & $8.6 \pm 0.5$ & $8.1 \pm 0.3$ & $8.6 \pm 0.8$ & $10.0 \pm 0.6$ \\
\hline & HF & $40.9 \pm 1.4$ & $47.2 \pm 1.5^{*}$ & $37.4 \pm 2.9$ & $41.4 \pm 2.7$ \\
\hline \multirow[t]{3}{*}{ TPR $(\%)$} & $\mathrm{LF}$ & $11.5 \pm 0.6$ & $13.4 \pm 0.8$ & $14.7 \pm 1.5$ & $14.8 \pm 1.3$ \\
\hline & $\mathrm{MF}$ & $8.6 \pm 0.7$ & $8.4 \pm 0.4$ & $9.9 \pm 0.9$ & $9.6 \pm 0.6$ \\
\hline & $\mathrm{HF}$ & $34.8 \pm 1.6$ & $39.4 \pm 1.7$ & $35.1 \pm 2.5$ & $34.5 \pm 3.0$ \\
\hline
\end{tabular}

Relative spectral density power of wean arterial pressure (MAP), cardiac ourput (CO), and rotal peripheral resistance (TPR), in 3 frequency ranges: Low frequency $(L F)=0.05-0.25$ $\mathrm{Hz}$; Mid Frequency $(\mathrm{MF})=0.25-0.55 \mathrm{~Hz} ; \mathrm{High} \mathrm{Frequency}(\mathrm{HF})=1.0-2.1 \mathrm{~Hz}$. Siatistical differences benween and within groups (ANOVA) are indicated as: $p(W K Y, S H R)<0.05$ \& $p$ (control, blockade) $<0.0 .5$

blood pressure was significantly smaller than those of $\mathrm{CO}$ and peripheral resistance. The relative circadian amplitudes of the systenic hemodynamic parameters (summarized in Table 5.1 ) were, in general, $20-30 \%$ of the average $24-\mathrm{h}$ mean value. These values did not differ between SHR and WKY. However, in both groups, the relative circadian amplitude of blood pressure was significantly smaller than the relative amplitudes of $\mathrm{CO}$ and peripheral resistance.

Cardiac autonomic blockade produced comparable systemic hemodynamic effects in WKY and SHR (Fig. 5.2, Table 5.1). Average 24-h values for CO, MAP, and HR decreased significantlly, whereas peripheral resistance did not change. In SHR, the average $24-\mathrm{h}$ vallue for $\mathrm{SV}$ fell slightly but significantly, whereas $\mathrm{SV}$ remained unchanged in WKY (Table 5.1). On autonomic blockade, the coefficient of variation for HR decreased, whereas that for blood pressure increased (Table 5.1). The coefficients of variation for $\mathrm{CO}$, peripheral resistance, and $\mathrm{SV}$ remained unaltered. The effects of cardiac autonomic blockade on the 24-h rhythmicity of the systemic hemodynamic parameters are indicated in Table 5.1. In both SHR and WKY, the relative circadian amplitude of HR fell during cardiac autonomic blockade, whereas the 24-h rhythmicity of all other parameters was unchanged. In terms of relative dark-light differences, 24-h rhythmicity of CO fell significantly in both WKY and SHR during cardiac autonomic blockade. In addition, in SHR but not in WKY, the relative differences between the dark and light period averages of HR and TPR were reduced.

Figures 5.1 and 5.2 show that during control as well as during cardiac autonomic blockade $\mathrm{CO}$, arterial pressure, and $\mathrm{HR}$ rose in the beginning of the dark, active period. At the start of the light period CO decreased, which was due to a fall in HR. SV declined 

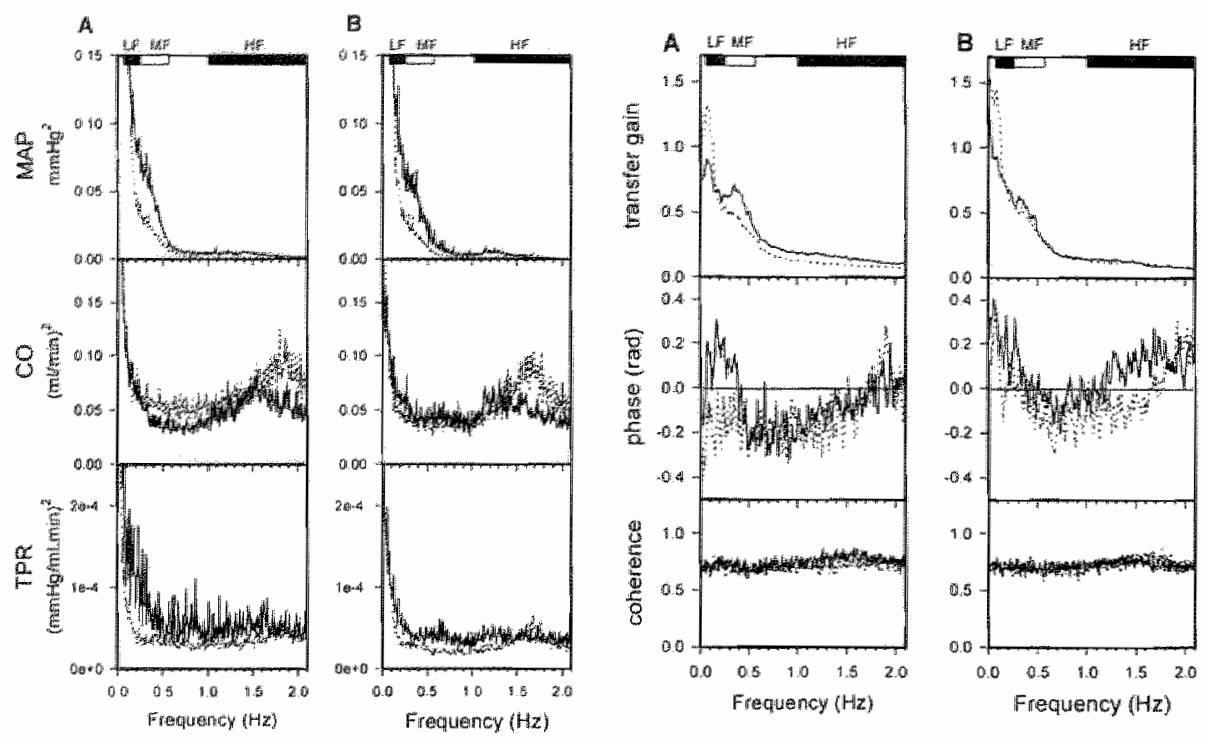

Figure 5.3. Averaged power spectra of systemic hemodwnamics at high frequency ranges. Mean arterial pressure (MAP), cardiac outpu (CO), and total peripheral resistance (TPR) are shown. The left panels show WKY $(n=9$, dotted lines) and $S H R(n=10$, comtinuows lines) during saline infusion. The right panels show the results obtained in the same animals during cardiac autorom ic blockade. Statistical differences in selected frequency bands are presented in table 2. The ramge of the low $(L F)$, mid $(M F)$, and high (HF) frequency bands is indicated by bars at the top of the figure: (LF: 0.05-0.25 Hz. MF:0.25-0.55 Hz, and HF:1.0-2.1 Hz)

Figure 5.4. Aweraged transfer gain phase, and coherence between cardiac output and blood pressure at high frequency ranges. The left panels show WKY ( $n=9$, dotted lines) and $S H R$ $(n=10$, continuows lines) during saline infusion. The right panels show the results obtained in the same animals during cardiac autonomic blockade. The range of the low (LF), mid (MF). and high (HF) frequency bands is indicated by bars at the top of the figure: (LF:0.05\%0.25 Hz, $M F: 0.25-0.55 H Z_{\text {ond }} H F: 1.0-2.1 \mathrm{~Hz}$

progressively during the light period. Peripheral resistance was highest during the sleeping period and fell during the transition from the light to the dark period.

\section{HF dynamics}

Average $H F$ spectral density power of $\mathrm{CO}$, arterial pressure, and peripheral resistance is presented in Fig. 5.3. In both SHR and WKY, fluctuations of CO were mainly found at the respiratory-related peaks, which were located at slightly lower frequencies in SHR than in WKY. In contrast to the spectra ofCO and peripheral resistance, spectral density power of arterial pressure lacked clear respiratory-related peaks and was mostly confined to frequencies $<0.5 \mathrm{~Hz}$. The relative powers of $\mathrm{CO}$, arterial pressure, and peripheral resistance are compared between SHR and WK $Y$ in three selected frequency bands in Table 5.2. During control conditions as well as cardiac autonomic blockade, the $\mathrm{MF}$ power of arteriall pressure, but not of $\mathrm{CO}$ and peripheral resistance, was significantly greater (factor of $\sim 2$ ) in SHR than in WKY. The phase relationship between CO and arterial pressure showed a transition from positive to negative values at $0.4 \mathrm{~Hz}$, 

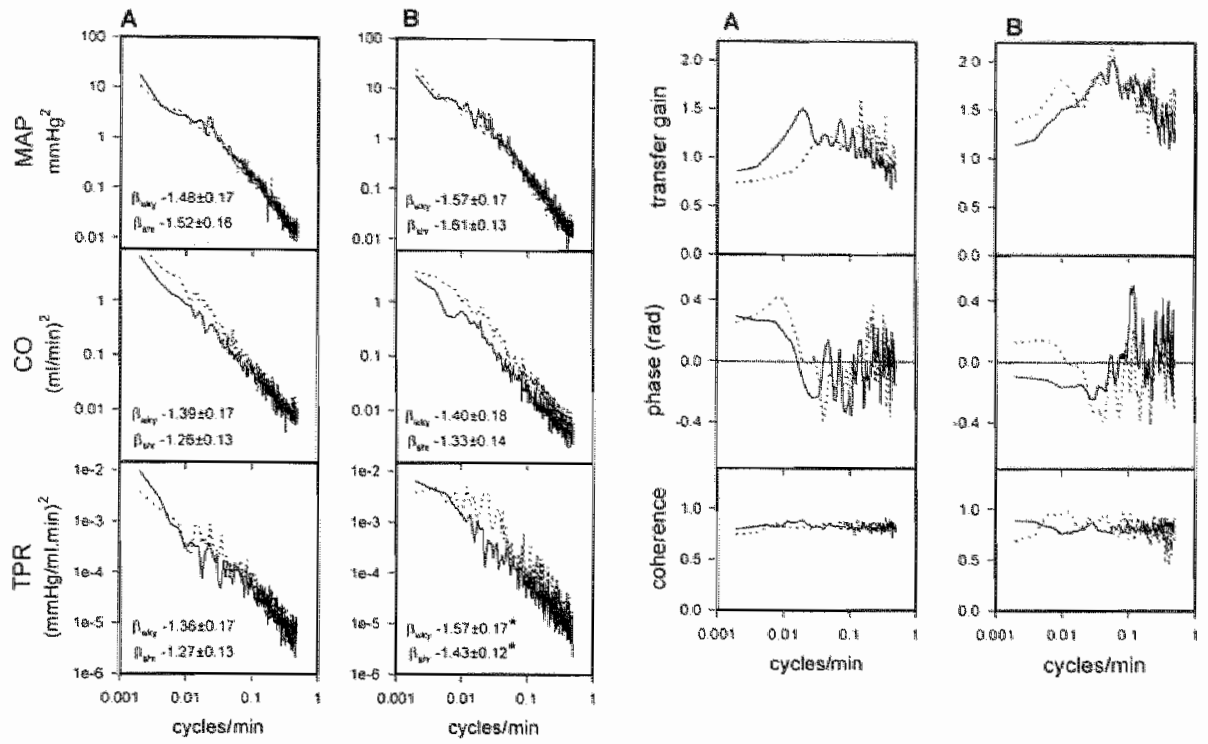

Figure 5.5. Averaged dowble logarithmic power spectra of systemic hemodynamics at low frequency ranges. Mean artertal pressure (MAP), cardiac output (CO), and lotal peripheral resistance (TPR) are shown. The lef panels stow $W K Y(n=9$, dotred lines, and $S H R(n=10$. contimuous linesl durng saline infusion. The right panels show the results obtaned in the sane animals during cardiac atutonomic blockade. The slopes of the tinear regression lines of the power spectra, which were calculated between 0.5 and $0.01 \mathrm{cycles} / \mathrm{min}$, are indicated as 3 . Values are means SD. *indicates a significant difference $(p<0.05)$ between control and Blockade. Differences between SHR and WKY were not statistically significant.

Figure 5.6. Averaged transfer gain, phase, and coherence between cardiac outpur and blood pressure at low frequency ranges. The left parels show $W K Y(n=9$, dotred lines) and SHR $(n=10$. contimows lines) during saline infusion. The right panels show the results obrained in the same animals during cardiac autonomic blockade. Differences between SHR and WKY were not statistically significant.

indicating that $\mathrm{MF}$ fluctuations in pressure were leading those in $\mathrm{CO}$ beyond $0.4 \mathrm{~Hz}$ (Fig. 5.4). The nomalized transfer gain between $\mathrm{CO}$ and arterial pressure was $<1$ over the frequency range from 0.1 to $2.5 \mathrm{~Hz}$ (Fig. 5.4). Thus, in this frequency range, fluctuations of $\mathrm{CO}$ were relatively greater than those of blood pressure.

\section{LF dynamics}

The spectra of blood pressure, $\mathrm{CO}$, and peripheral resistance in the $L F$ range lacked predominant peaks, and total power was not different between SHR and WKY. When both frequency and power were logarithmically transformed, $C O$ and arterial pressure showed an almost linear relationship with frequency in the range from 0.01 to $0.5 \mathrm{cycles} / \mathrm{min}$ (Fig. 5.5). The slopes of these linear regression lines are indicated in Fig. 5.5 and were not different between SHR and WKY Cardiac autonomic blockade reduced spectral density power of $\mathrm{CO}$ but not of arterial pressure and peripheral resistance. Under this condition, the slope of the regression lines of peripheral resistance spectra increased in both SHR and WKY. Under control conditions, the normalized transfer 
A

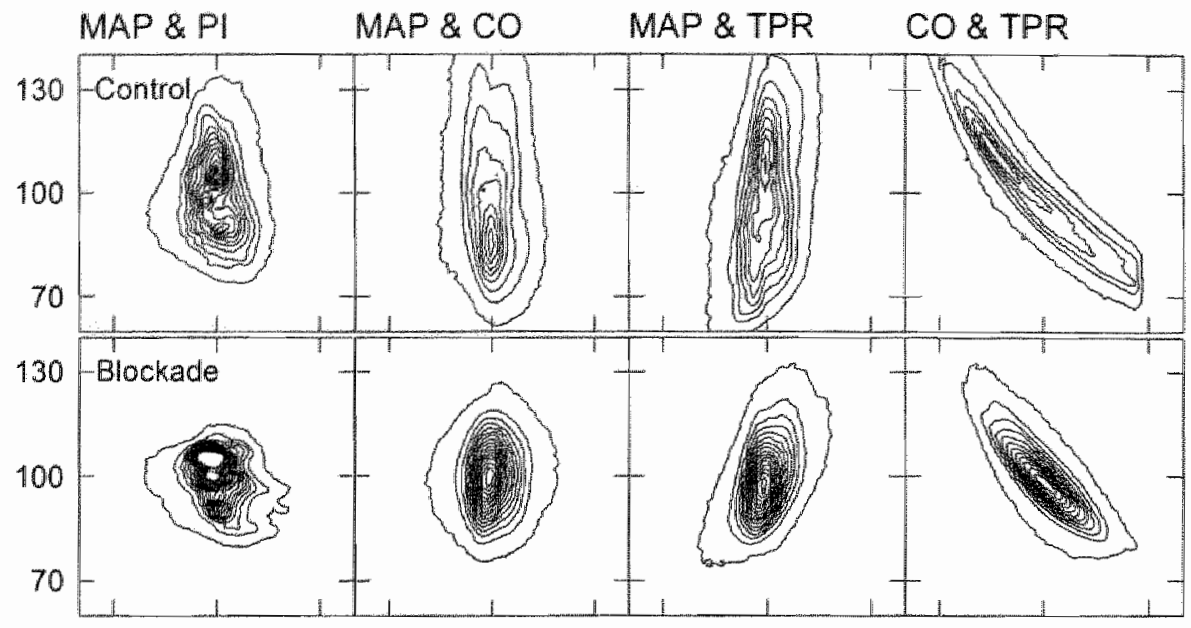

B

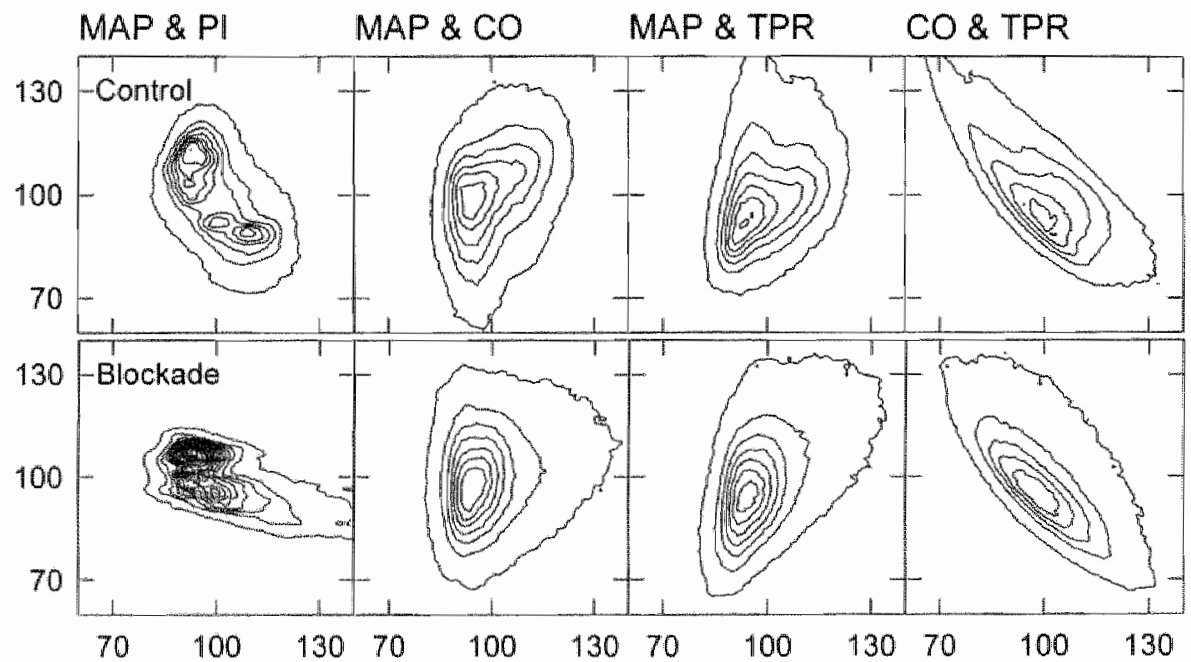

Figure 5.7. Contow plots showing the 24-h range of interaction of beat-fo-beat recorded systemic hemodynamics during intravenous infusion of saline and metoprolol thethylatropine (blockade) in a representative WKY and SHR. For each animal the contourplots (birdseye view of 2-dimensional frequency distribution) between mean arterial pressure (MAP) and pulse interval (PI), MAP and cardiac outpu (CO), MAP and rotal peripheral resisfance (TPR), and CO and TPR are given. Each plor contains about 500.000 data points. All paramerers are plotted relatively to their 24 -h average value, with the first-mentioned parameter on the abscissa and the second on the ordinate. Altitude lines are plotted with intervals of 300 . In the MAP \& PI plots combinations mostly showed 2 or more preferred states. The MAP \& $C O$. MAP \& TPR, and CO\&TPR plots show only a single preferred state. Note the relative difference in variaton of $C O$ and $M A P$ and the inverse relationship between $C O \& T P R$. 
gain between CO and blood pressure was close to 1 in both SHR and WKY (Fig. 5.6), and the phase was close to 0 . Thus, in this frequency range, the magnitude of the variations in $\mathrm{CO}$ were comparable to those in blood pressure and occurred concomitantly. During cardiac autonomic blockade the transfer gain between $\mathrm{CO}$ and blood pressure increased to $\sim 1.5$ in both rat strains, which was due to the decreased fluctuations in $\mathrm{CO}$. The phase relation did not change.

\section{Two-dimensional frequency distributions}

Contour plots of the two-dimensional frequency distributions of the systemic hemodynamics are presented for a representative WKY and a respresentative SHR in Fig. 5.7. Under control conditions, the contour plots of MAP and PI showed multiple peaks in 8 of 10 SHR and 7 of 9 WKY. The average number of peaks in these plots was $2.5 \pm 0.3$ in SHR and $1.9 \pm 0.2$ in WKY. In two SHR and one WKY, the peaks seemed to be located around a center of relatively few occurrences.

The contour plots of MAP and CO, MAP and TPR, and CO and TPR displayed, in general, a single peak. In 3 of $10 \mathrm{SHR}$ and 2 of 9 WKY a second peak was found. The average number of peaks in these three plots was $1.4 \pm 0.2$ in SHR and $1.2 \pm 0.1$ in WKY. The blood pressure value found at the most frequent combination in such plots generally coincided with the blood pressure value at the highest peak in the MAP and PI plots. The elongated shape of the MAP and CO plots indicates that over the 24-h period, the relative variability of $\mathrm{CO}$ was higher than the relative variability of blood pressure. A similar pattern occurred when arterial pressure was plotted versus peripheral resistance. In contrast, the frequency distributions of $\mathrm{CO}$ and TPR appeared to be inversely related.

After cardiac autonomic blockade, multiple peaks appeared in all contour plots between MAP and PI. The average number of preferred combinations increased significantly to $3.6 \pm 0.3 \mathrm{in}$ SHR and $3 . \Downarrow \pm 0.3 \mathrm{in}$ WKY. It was apparent that the overall relative variability of PI was decreased (see also Table 5.1). The most frequent value of blood pressure was often lower than its average 24-h mean value. During cardiac autonomic blockade, the contour plots relating MAP and CO, MAP and TPR, and CO and TPR exhibited multiple peaks in 3 of $10 \mathrm{WKY}$ and 2 of $10 \mathrm{SHR}$. The average value was not different from control and was $1.1 \pm 0.1$ in SHR and $1.3 \pm 0.2$ in WKY In comparison with the control plots, the figures show that the range of the variation in $\mathrm{CO}$ was hardly changed, whereas the range in arterial pressure was greater. This is in agreement with Table 5.1, which shows that the 24 -h coefficient of variation of blood pressure is increased during blockade.

\section{Discussion}

The main new findings of this study are: 1) circadian rhythmicity of $\mathrm{CO}$ is similar in adult SHR and WKY; 2) the magnitude of the circadian rhythmicity of $\mathrm{CO}$ is reduced by blockade of the cardiac autonomic nervous system; 3) short-term dynamic behavior of CO consists mainly of mechanically induced fluctuations related to respiration; 4) at LF ranges, power spectra of CO lack a dominant oscillator but show $1 / \mathrm{f} \mathrm{characteristics;}$ and 5) over 24-h periods in both SHR and WKY, variability of CO is relatively greater 
than variabilty of blood pressure. In these time frames, control of blood pressure is preferted over control of $\mathrm{CO}$.

\section{Circadian rhythmicity of systemic hemodynamics}

In agreement with previous studies ${ }^{13} 22$, at least in absolute values, the circadian rhythm of MAP was more pronounced in SHR than in WKY. However, coefficients of variation and relative circadian amplitudes of blood pressure were not different beween the strains. This suggests that the systems involved in the regulation of the circadian blood pressure rhythm are not different between strains but that the difference is merely a consequence of the elevated pressure. It was shown previously in SHR that the elevated pressure is not a result of increased $\mathrm{CO}{ }^{10.24}$. We now also demonstrate that the circadian fuctuations of $\mathrm{CO}$, in both absolute and relative terms, are similar in adult WKY and SHR. CO was highest during the dark, active period of these nocturnal animals and lowest during the light, sleeping period. Thus, over the whole 24 -h cycle, increased peripheral resistance is responsible for the high blood pressure. In SHR and WKY, the diumal patterns of $\mathrm{CO}$ and peripheral resistance are inversely related. Peripheral resistance was low during the dark, active period and high during the light, sleeping period.

The hemodynamic mechanisms underlying the inverse relationship of the diumal patterns of $\mathrm{CO}$ and peripheral resistance are not fully clear. In the present study, the fail of $\mathrm{CO}$ during the light phase was mediated by reductions of $\mathrm{HR}$ as well as $\mathrm{SV}$ in both SHR and WKY. During cardiac autonomic blockade, values of CO were also higher during the dark period than during the light period, although the relative differences between these periods were significantly attenuated. This suggests that both nervous and nonnervous factors are involved in the generation of the 24-h. thythm of $\mathrm{CO}$. However, as indicated by Table 5.1 and the contour plots in Fig. 5.7, the range of the variation of $\mathrm{CO}$ with circadian period is not diminished by cardiac autonomic blackade. Cardiac autonomic blockade reduced specifically the amplitude of the 24-h cycle of CO but mot cycles of shorter periods. As depicted in Figs. 5.1 and 5.2, at the beginming of the light period, $\mathrm{CO}$ fell because of an abrupt fall in HR. $\mathrm{SV}$ declined progressively in this period and was lowest at the end of the light period, when HR was rising again. Similar observations were obtained by Smith et al. "in normotensive Wistar rats. In humans and nonhuman primates, a reduction in HR seems the dominant factor involved in the fall of $\mathrm{CO}$ at sleep, with only minor changes in $\mathrm{SV}^{4.3-5}$. Such species differences could be due to differences in posture. Rats remain in the same position, whereas humans and nonhuman primates assume a recumbent position at sleep. However, there is redundancy in this control system. When HR was prevented from falling overnight by atrial demand pacing, $\mathrm{CO}$ fell in monhuman primates by a reduction in $\mathrm{SV}^{6}$. The reduction in $\mathrm{CO}$ during sleep may be due to venous pooling of the blood or to a reduction in plasma volume. The slow, progressive fall of SV during the light period in rats could be indicative of the latter mechanism. Rats do not drink during the light period, and water volume may decline with ongoing urine formation, expiration of air, or perspiration. Interestingly , these diurnal changes in hemodynamics and plasma volume could be governed by increased levels of atrial natriuretic peptides, which are generally increased in the sleeping period. At the beginning of the lights-off period, HR also rises during cardiac autonomic blockade. The mechanisms of this increase of $H R$ are 
unclear but may depend upon behaworally and sympathetically induced changes in cardiac filling.

Several mechanisms could be responsible for the rise in peripheral resistance during sleep. The most favored explanation is that due to decreased metabolic denand, autoregulatory mechanisms reduce blood flow, especially through skeletal muscle $1,3,25$. Alternatively, the diurnal variation in epineplune, which in rats runs in parallel with the rhythm of $\mathrm{HR}^{26}$, may have a role in the rhy thm of peripheral resistance via $\beta_{2}$-adrenergic vasodilatation ${ }^{27}$. The matter becomes even more complicated, because cardiac autonomic blockade attenuated the rise in peripheral resistance at the onset of the inactive period and abolished the relative dark-light difference, especially in SHR (Table 5.1). Thus, under these conditions, the relative changes in TPR are not in phase any more with the dark-light cycle. However, in cardiac autonomic-blocked SHR, peripheral resistance fell during the period when $C O$ was highest, which was at the transition from the light to the dark phase (see Fig. 5.2). The infusion of the drugs may have altered the entrainment to the dark-light cycle and phase advanced the activity pattern of the SHR. Mechanistic studies are needed to resolve to what extent flow and autonomic-dependent mechanisms contribute to control of 24-h peripheral resistance.

\section{$\mathrm{HF}$ oscillations of $\mathrm{CO}$}

Similar to findings in humans ${ }^{23}$, HF oscillations of $C O$ were mainly confined to the respiratory frequency band. As indicated by the normalized transter function, the rela tive amplitude of $\mathrm{CO}$ was a factor of $7-10$ greater than that of blood pressure and not different between SHR and WKY. Furthermore, the phase angle between CO and blood pressure, being close to zero at these frequencies, indicates that the oscillations occured simultaneously. Blockade of the cardiac autononic nervous system did not alter this. These findings indicate that the respiratory-related oscillations in $\mathrm{CO}$ are not related to reflex-induced changes in sympathetic or vagal nerve activity. Thus, these fluctuations are probably induced by a direct mechanical coupling of respiration and $C O$. The oscillations in $\mathrm{CO}$ are then further transmitted into blood pressure and thus certainly not the result of baroreceptor activation.

In the MF, spectral density power of blood pressure, but not of $\mathrm{CO}$, was significantly greater in SHR than in WKY. Similar results were found during cardiac autonomic blockade. These findings suggests that enhanced MF oscillations in the vasculature of SHR may have been responsible for the increased MF power of blood pressure. Indeed, the MF fluctuations in peripherall resistance were higher in SHR than in WKY; however the difference was not statistically significant. This may be due to an artiact. By calculating peripheral resistarce as the quotient of arterial pressure and $\mathrm{CO}$, one transters the HF oscillations existing in $\mathrm{CO}$ to peripheral resistance, where they may not actually exist. Whether the enhanced MF fluctuations in blood pressure in SHR are due to elevated sympathetic nerve activity or exaggerated postsynaptic mechanisms can not be decided from this study. We favor the latter explanation, because MF oscillations of sympathetic nerve activity do not differ between SHR and WK Y ${ }^{29}$.

\section{LF Oscillations of $\mathrm{CO}$}

Dominant LF oscillations in CO were not found in SHR or WKY either during control conditions or during cardiac autonomic blockade. In all cases, the double loga- 
rithmic power spectrum was linear in the frequency band from 0.01 to $0.5 \mathrm{cycles} / \mathrm{min}$. Similar spectra were found for arterial blood pressure and peripheral resistance. These $1 / f$ characteristics are typical for systems that are controlled in a nonlinear, chaotic fashion. This means that the system is controlled by multiple processes, acting at overlapping time scales ${ }^{17} .30$. The slope of the $1 / \mathrm{f}^{3}$ regression line is an index for the complexity of the dynamic process. In the present study, the 1/f slopes of the time series of $\mathrm{CO}$, blood pressure, and peripheral resistance did not differ either among themselves or between SHR and WKY.This suggests that, in this LF range, the complexity of the regulation of the systemic hemodynamics is comparable and not dependent on the pressure level. A similar conclusion was reached by Holstein-Rathlou et al. ${ }^{21}$ using telemetry to record blood pressure in normotensive and two-kidney, one-clip hypertensive Sprague-Dawley rats as well as in SHR.In addition, the absolute values of the slope of the logarithmic regression line between frequency and spectral power of blood pressure were very similar to those reported by that group. During cardiac autonomic blockade, the slope of the $1 / \mathrm{f}$ time series of peripheral resistance rose significantly in both WKY and SHR. This may be a reflection of the increased impact of baroreceptor-mediated changes on vascular resistance when the autonomic input to the heart is blocked. Evidence is accumulating that the baroreflex buffers low-frequency variations in arterial pressure ${ }^{18}$. In SHR after cardiac autonomic blockade, the slope of the $1 /$ spectrum of arterial pressure increased slightly but not significantly. This finding is consistent with a recent study in sinoaortic-denervated, dogs, in which the $1 / f$ slope of the blood pressure spectrum was higher than in nondenervated animals ${ }^{18}$. Cardiac autonomic blockade decreased total power of $\mathrm{CO}$, but the $1 / \mathrm{f}$ slope did not change. "This suggests that factors other than the cardiac autonomic nervous system are an important determinant of the LF dynamics of CO.

In contrast to what was found at the high frequencies, the normalized transfer gain between $\mathrm{CO}$ and arterial pressure was close to 1 over the whole frequency range. Thus, at these low frequencies, fluctuations of $\mathrm{CO}$ and arterial pressure were relatively of the same magnitude. During cardiac autonomic blockade, the relative fluctuations of $\mathrm{CO}$ fell whereas those of blood pressure remained unaltered. This reduction was largely due to decreased variability of HR (spectra not shown). The LF oscillations of CO and arterial pressure occurred simultaneously whether or not the cardiac autonomic nervous system was blocked. To our knowledge, dynamic characteristics of cardiac output have been investigated over periods up to $9 \mathrm{~h}$ only in one study in dogs ${ }^{31}$. In this report, dominant oscillations with periods near $1.5 \mathrm{~h}$ were found in $\mathrm{CO}$ and arterial pressure, but the oscillator was not identified. In the present study in rats, such slow rhythms were never observed. However, in both species at these low frequencies, the phase angle between $\mathrm{CO}$ and blood pressure was not different from zero. Thus LF fluctuations of $\mathrm{CO}$ most likely drive those of arterial pressure.

\section{4-h frequency distributions of systemic hemodynamics}

The combined frequency distributions of MAP and $\mathrm{CO}$ can be regarded as plots of normalized pressure versus normalized flow using the spontaneous variations of these two parameters. In such a plot, complete autoregulation of systemic blood flow would be found when the flow variation remained close to the average value over the whole pressure range ${ }^{32}$.In our plots, however, the relative variation of $\mathrm{CO}$ was always greater than that of arterial pressure. This indicates that, over 24 -h periods in rats, 
arterial pressure was controlled more tightly than $\mathrm{CO}$. In the majority of the rats, the contour plots of MAP and CO and MAP and TPR exhibited a singlo peak. This could mean that there is one single set point for the combination of these parameters. Altematively, one may argue that these parameters are fairly unrelated throughout the day and that the contour plot is the result of two gaussian distributions. The contour plots of CO and TPR showed a clear negative correlation, as would have been expected fiom the diumal pattem. The width of the distribution was relatively narrow, especially compared with the width of the histograms relating the other combinations. This is another indication that control of pressure is relatively tighter than control of $C O$ or peripheral resistance over $24 \mathrm{~h}$. During cardiac autonomic blockade, coefficients of variation of arterial pressure variations became significantly greater, whereas those of Co decreased slightly. Thus CO fluctuations do stabilize to a certain extent those in arterial pressure. However, in all cases, it was never observed that fluctuations in CO were smaller than those in arterial pressure. This finding seems in contrast with theories that long-term control over CO prevalis over control of blood pressure. Over long periods of time, $C O$ is linked to metabolic demand for axygen and should be independent of neurat control. However, in the present study, average CO fell during autonomic blockade, and coefficients of variation were not lower than those of arterial pressure. Possibly large 24-14 differences in the metabolic needs of the different tissues may underlie the considerable 24 h labile behavior of $\mathrm{CO}^{25}$. Cleatly, the present data indicate that 24 in is not enough time for autoregulation of $\mathrm{CO}$ to occur.

The existence of multiple states in the contour plots of MAP and PI confirms our earlier findings that multiple preference states exist of combinations of blood pressure and $\mathrm{PI}$. The absence of multiple states in the plots relating the mutual interactions of $\mathrm{CO}$, arterial pressure, and peripheral resistance and the absence of multiple states in the plots relating $\mathrm{CO}$ and $\mathrm{SV}$ (data not shown) indicate that these preferred combinations are introduced by the variation of PI only. These preference states of PI are not caused by variations in autonomic tone to the heart. In contrast, after cardiac autonomic blockade the number of such preference states in PI even increased. Thus autonomic activity seems to mask the existence of such preferred states. The origin of the preferred states of PI may be related to an intrinsic property of the heart or of the cardiac pacemaker cells in reaction to the opposed work load over 24 t. The preference for a limited number of different frequencies could be a reflection of the existence of subpopulations of pacemaker cells within the sinus node ${ }^{33}$, which have the highest firing frequency, depending on factors such as atrial stretch or humoral factors. On the other hand it may be energetically more effective to switch between such states than to have a continuous range of HR. A switch between such states is typical for chatic control systems". Thus the rat heart works in gears rather than on the basis of an automatic transmission.

In summary, using different approaches in examining beat-to-beat recordings of systemic hemodynamics, we found that, over 24 -h periods in WKY and SHR, blood pressure seems to be controlled within a more narrow range than $\mathrm{CO}$. Short-term oscillations of $\mathrm{CO}$ were, even in the absence of cardiac autonomic lone, coupled to the respiratory cycle. The diumal variation of $\mathrm{CO}$ was reduced but not abolished by blockade of the cardiac autonomic nervous system. This suggests that factors other than the autonomic nervous system control the 24-h. fuctuations of CO. A remarkable finding 
wass that the rat hear seems to beat at a himited number of preferential HR. The origin of this property of the heart will need further clucidation.

\section{References}

1. Veerman DP, Imholz BPM, Wheling W, Wesseling KH, Van Montfans $G A$ : Circadian profie of systemic hemodynamics. Hyperfension 1995; $26: 55-59$.

2. Cugini $P$, Di Palma L, Di Simone $S$, et al: Circadian rhythm of cardiac output, peripheral vascular resistance, and related variables by a beat-to-beat monitoring. Chronobiol In $1993 ; 10: 73-78$.

3. Kool MJ, Wijnen JA, Detkx FH, Struijker-Boudier HA, Van-Bortel LM: Diurnal variation in prorenin in relation to other humoral factors and hemodynamics. Am $J$ Hypertens $1994 ; 7 ; 723-730$.

4. Idema RN, Van Den Meiracker A.H, Balk AHMM, Bos E, Schalekamp ADH, Man in 't Veld Al: Abnomal diumal variation of blood pressure, cardjac output, and vascular resistance in cardiac transplant recipients. Circulation 1994; 90:2797-2803.

5. Enge: BT, Talan MI: Diumal patterns of hemodynamic performance in nonhuman primates. Am I Physiol 1987; 253: R779-R785.

6. Engel BT, Talan MI, Chew PH: Effect of nocumal atrial demand cardiac pacing on diumat hemodynamic patterns. J Appl Physiol 1992; 72: 1798-1802.

7. Montani J-P, Leliand Mizelle H, Van Vliet BN, Adair TH: Advantages of continuous measurements of cardiac output $24 \mathrm{~h}$ a day. Am J Physiol 1995; 269: H696-H703.

8. Smith TL, Coleman TG, Stanek KA, Murphy WR: Hemodynamic monitoring for 24h in unanesthetized rats. Am I Physiol 1987; 253: H1335-H1341.

9. Conway J: Hemodynamic aspects of essential hypertension in humans. Phys Rev 1984: 64(Suppl. 2): 617-660.

10. Trippodo NC, Frohlich ED: Similarities of Genetic (Spontaneous) Hypertension. Circ Res 1981; 48:309-319.

11. Mancia G: Ambulatory blood pressure monitoring: research and clinical applications. J Hypertens 1990; 8(Suppl. 7): s1-s13.

12. Janssen BJA, Tyssen CM, Struyker-Boudier HAJ: Modification of circadian blood pressure and heart rate variability by five different antihypertensive agents in spontaneously hypertensive rats. I Cardiovasc Pharmacol 1991; 17: 494-503.

13. Friberg $P$, Karlsson $B$, Nordlander $M$ : Autonomic control of the diurnal variation in arterial blood pressure and heart rate in spontaneously hypertensive and WistarKyoto rats. J Hyperters 1989; 7: 799-807.

14. Ferrari AU, Daffonchio A, Albergati F, Mancia G: Inverse relationship between heart rate and blood pressure wariabilities in rats. Hypertension 1987; 10:533-537.

15. Head GA. Adams MA: Time course of changes in baroreceptor reflex control of heart rate in conscious SHR and WKY, contribution of the cardiac vagus and sympathetic nerves. Cin Exp Phownoc Physiol 1988; 15:289-292.

16. Janssen BIA, Oosting I, Slaa DW, Persson PB, Struyker-Boudier HAJ:

Hemodynamic basis of oscillations in systemic arterial pressure in conscious rats. Am JPhysiol 1995; 269: H62-H71.

17. Goldberger AL, West BI: Fractals in physiology and medicine. Yale J Biol Med 1987; $60: 421-435$.

18. Wagner $\mathrm{CD}$, Persson $\mathrm{PB}$ : Two ranges in blood pressure spectrum with different $1 / \mathrm{f}$ characteristics. Am J Physiol 1994; 267: H449-H454.

19. Parati G, Saul JP, Di Rienzo M, Mancia G: Spectral analysis of blood pressure and heart rate variability in evaluating cardiovascullar regulation. Hypertension 1995; 25: $1276 \cdots 1286$. 


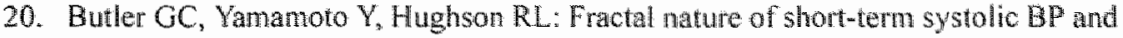
HR variability during lower body negative pressure. Am J Phpsiol $1994,267: 126$. R33.

21. Holstein-Rathlou N-H, He J, Wagner AJ, Marsh DJ: Patterns of blood pressure variability in nomotensive and hypertensive rats. Am I Physiol 1995; 269: R 1230R1239.

22. Janssen BJA, Tyssen CM, Struijker Boudier HAJ, Hutchins PM: 24-Hour homeodynamic states of arterial blood pressure and pulse interval in conscious rats. $J$ Appl Plysiol 1992; 73: 754-761.

23. Persson PB, Ehmke H, Kircheim HR, et al: Autoregulation and non-homeostatic behaviour of renal blood flow in conscious rats. I Physio $1993 ; 462: 261-273$.

24. Smith TL. Hutchins PM: Central hemodynamics in the developmental stage of spontaneous hypertension in the unanesthetized rat. Hypertension 1979; 1:508-517.

25. Delp MD, Manning O, Bruckner JV, Armstrong RB: Distribution of cardiac output during diurnal changes of activity in rats. Am J Physiol $1991 ; 261: H 1487-H 1493$.

26. De Boer SF, van der Gugten J: Daily variations in plasma noradrenaline, adrenaline and corticosterone concentrations in rats. Physiol and Behav 1987; 40:323-328.

27. Gardiner SM, Bennett T: Adrenoceptors and cardiovaseular regulation in conscious, unrestrained, Long Evans and Brattleboro rats. J Aufon Nerw Syst 1988; 24: 193-203.

28. Toska K. Eriksen M: Respiration-synchronous fluctuations in stroke volume, heart rate and arterial pressure in humans. J Physiol Lond 1993; 472:501-512.

29. Persson $P B$, Stauss $H$, Chung $O$, Wittmann $U$, Unger $T$ : Spectrum analysis of sympathetic nerve activity and blood pressure in conscious rats. Am J Physiol 1992; 263: H1348-H1355.

30. Marsh DJ, Osborn JL, Cowley Jr AW: I/f fuctuations in arterial pressine and regulation of renal blood flow in dogs. Am s Physiol 1990; 258; F1 394-F1400.

31. Shimada SG, Marst DJ: Oscillations in mean arterial blood pressure in conscious dogs. Circ Res 1979; 44:692-700.

32. Cowley Jr. AW, Hinojosja-Laborde C, Barber BI, Harder DR, Lombard $₫ H$, Greene AS: Short-term autoregulation of systemic blood flow and cardiac output. Nips 1989; 4: 219-225.

33. Bromberg BI, Hand DE, Schuessler DP: Primary negativity does not predict dominant pacemaker location: implication for sinoatrial conduction. Am f Physiol 1995; 269 : H877-H887. 
Chaprer 5

100 


\section{Chapter 6}

\section{Time-Dependent Efficacy of Antihypertensive Agents in Spontaneously Hypertensive Rats}

Ben J. A. Janssen

Jan Oosting

Caroline M. Tyssen,

Harrie A. J. Struyker-Boudier

Published in Chronobiology International $1993 ; 10,420-434$

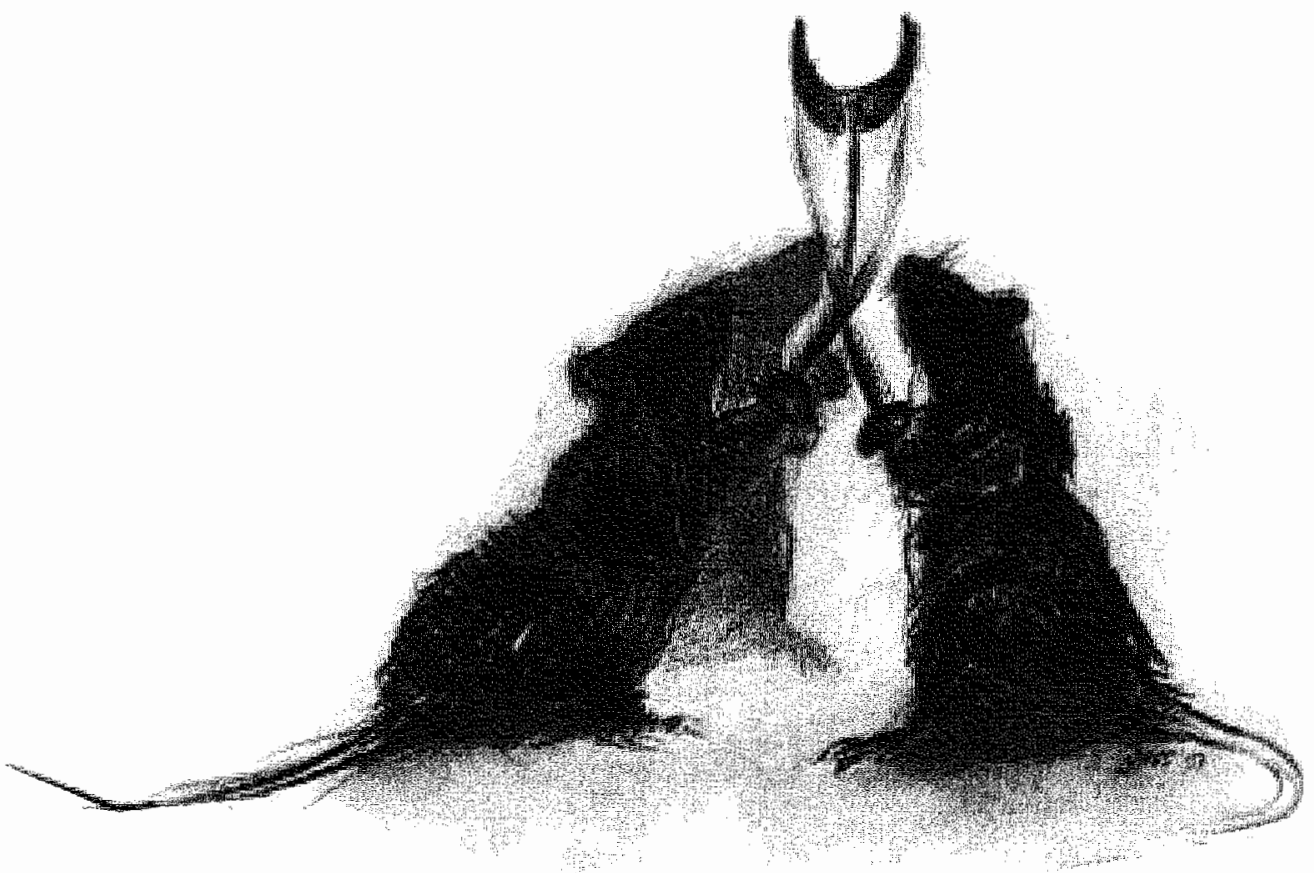




\section{Abstract}

The efficacy of antihypertensive agents was compared when given at different time points in the circadian rhythm. Spontaneously hypertensive rats (SHRs) were kept on a 12/12-h cycle with lights on/off at 07:00/19:00 h. A computerized system was used to measure intraarterial blood pressure and heart rate continuously. Agents or vehicle were intravenously injected at two time points. One at the beginning of the sleeping period, at which low efficacy was expected $(T=10)$, and one at $T=16$, which is $3 \mathrm{~h}$ before the circadian peaks in blood pressure (BP) and heart rate (HR), aimed at reducing the rise in BP and HR at awakening. The hypotensive effect of propranolol, metoprolol, labetalol, prazosin, clonidine, and rilmenidine was greater when injected at $T=16$ than at $T=10$ ( $\mathrm{p}<0.05$ for propranolol, metoprolol, and rilmenidine). In contrast, the renal vasodilators captopril and tertatolol were more potent after injection at $\mathrm{T}=10$. Felodipine was equally effective at both time points. Thus, the effects of antihypertensive agents are related to the phase of the circadian rhythm. The data on the sympatholytic agents in general and $\beta$-blockers and centrally acting agents in particular support antihypertensive regimens with timed administrations. 


\section{Introduction}

The concept of chronopharmacological treatment of hypertension is not new? Its application has regained interest $t^{2-6}$ after epidemiological data showed that cardiovascular pathophysiological events (such as sudden cardiac death, myocardial infarction, and ischemia) exhibit circadian rhythmicity too ${ }^{7.8}$, showing a peak incidence during the early morning hours when blood pressure increases rapidly. Furthermore, meta-analyses of major clinical trials on the benefits of antihypertensive therapy revealed that the reductions in numbers of deaths due to cerebrovascular diseases is about twice that due to cardiovascular diseases?. It has been suggested that one of the reasons for this disparity may be that patients are vulnerable to unsuppressed peak morning blood pressure 5 . On the basis of these studies, one may assume that most benefit could be gained by optimizing antihypertensive treatment during the early moming hours when most life-threatening cardiovascular events take place. On the other hand, because most antihypertensive agents lower blood pressure throughout the $24 \mathrm{~h}$ period without changing the circadian pattern ${ }^{2}, 6$, improving benefit may depend more on the tonic level of blood pressure or on the choice of the drugs. Prospective studies, however, are necessary for proving the beneficial effects of both therapies.

In the present study in spontaneously hypertensive rats (SHRs) we compared the antihypertensive efficacy of agents when administered at different time points in the circadian rhythm. Agents of different classes of antitypertensives were used; sympatholytic agents were investigated in particular. In a previous study in SHR ${ }^{10}$ we have shown that these latter agents were more effective in modulating circadian rhythmicity of blood pressure (BP) and heart rate (HR) than nonsympatholytic antihypertensives. Two time points were chosen: one at which low efficacy was expected (i.e., during the beginning of the sleeping phase of the rat) and one at which high efficacy was expected for blocking the spontaneous rise in BP and HR during the awakening period. To avoid chronopharmacokinetic differences in absorption, we administered agents as intravenous bolus injections.

\section{Materials and Methods}

\section{Amimals}

Male adult SHRs (14-16 weeks old) were obtained from the mbred colonies of rats of the central animal facilties of our university. Originally, these rats were derved from the Okamoto-Wistar stratins. Before the experiments, rats were housed in groups of four. Rats were maintained on a 12/2-h hight/dak cycle flights on from 07:00 19:00 h, $>200$ lux) in a quet room at $21 \pm 2 E C$. Food and water were avalable ad libitum.

\section{Surgery}

Arterial catheters were constructed from a 5 -cm PE- 10 tubing, heat-sealed to a 80-cn $P E-60$ twbing. Venous catheters were nade from an 80 -cm piece of $P E-10$ twing, heat-seated to a 5 -cm piece of PE-20 tubing. The PE- 10 section of tubing was bent into a ${ }_{\text {-shape }} 4 \mathrm{~cm}$ from its tip to provide proper angulation of the catheters during implantation. Under aseptic conditions, surgery was performed during light ether anesthesid. 
A longitudinal incision was made in the grom of the leg as well as on the back of the rat $5 \mathrm{~cm}$ above the tail. The arterial and venous catheters were implanted via the femoral vessels. The canmulate were advanced $4 \mathrm{~cm}$ into these vessels so that the tips were $\sim 1$ cm above the bifurcation. The catheters were secured to the leg muscle and tunnelled to the back of the animal. The arterial and venous catheters were guided through a stainless steel spring $(60-70 \mathrm{~cm}$ long) that was fixed to a piece of silicone rubber, which was tightly sutured to the back of the rat with the aid of mersilene gauze. In this way the watheters were protected from damage. The wounds were closed with fine intracutaneous stitches, and the rats were given $150 \mathrm{mg}$ of chloramphenicol per $\mathrm{kg}$. The catheters were filled with heparinized ( $5 \mathrm{U} / \mathrm{ml}$ ) saline and together with the spring connected to the equipment as described below.

\section{Measurements}

During the experiments, rats were housed individually in their home cages. The arterial catheter was connected via a hydraulic swivel (model $375 / 20$, Instech Labs, Plymouth Meeting, PA, U.S.A.) to a low-volume displacement pressure transducer (micro-Switch, model 156PC156WL, Honeywell, Amsterdam, The Netherlands). A constant perfusion of the atterial line with heparinized saline $(30 \mathrm{IU} / \mathrm{ml} ; 2.4 \mathrm{ml} / 24 \mathrm{~h})$ was maintained by a syringe pump (Razel model A, Razel Scientific Instruments, Stamford, CT, U.S.A.) to prevent clotting in the catheter. The arterial pressure transducer was connected to an amplifier that delivered a high-level woltage signal to an analog-to-digital converter board (model 2814, Data Translation, CN Rood, Rijswijk, The Netherlands) housed in an IBM AT-compatible microcomputer. Electrical drift in the arterial pressure monitoring system was acceptably low and smaller than $1 \mathrm{~mm} \mathrm{Hg/week} \mathrm{as} \mathrm{revealed} \mathrm{by}$ periodic calibrations. The system allowed simultaneous recording of eight rats. The arterial pressure signal was sampled continuously at $\sim 60$ samples/beat. Software was developed for calculating beat-by-beat mean arterial pressure (MAP) and pulse interval (PI). These beat-to-beat values for MAP and HR $(60,000 / \mathrm{PI})$ were averaged each min. Hourly values for MAP and HR were calculated by averaging 60 1-min values and stored on disk.

\section{Protocols}

Experiments were started after rats had recovered at least 72 h from surgery. From then on reproducible circadian rhythms in BP and HR can be obtained ${ }^{\prime \prime}$ ". Drugs were given as slow bolus injections $(0.1-0.3 \mathrm{ml})$ via the venous catheter that was extended outside the cage, followed by $0.25 \mathrm{~m}$ saline for washing the cannula. In this way injections can be given without disturbing the rats. Injections were given at two different time points in the circadian cycle. Vehicle (saline) or chug solutions were injected either at 10:00-10:15 h $(\mathrm{T}=10)$ or at 16:00-16:15 h $(\mathrm{T}=16)$, and effects on MAP and HR were studied for 24 H. At least $48 \mathrm{~h}$ were allowed to pass before another injection was given. Drugs were given in random order. The time of injection was also randomized. The following antihypertensive agents were used: metoprolol ( $1.5 \mathrm{mg} / \mathrm{kg}$ ), propranolol $(5 \mathrm{mg} / \mathrm{kg}$ ), prazosin $(0.6 \mathrm{mg} / \mathrm{kg}$ ), and labetalol $(10 \mathrm{mg} / \mathrm{kg}$ ), respectively, as a $\beta$ - 1 selective, a $\beta$-nonselective, an $\alpha-1$ selective, and combined $\beta$-and $\alpha$-adrenoceptor antagonist; the centrally acting agents clonidine $(10 \mu \mathrm{g} / \mathrm{kg}$ ) and rilmenidine ( $1 \mathrm{mg} / \mathrm{kg}$ ) [rilmenidine was chosen because this agent is less sedative than clonidine ${ }^{12}$; the angiotensin I converting enzyme inhibitor captopril ( $10 \mathrm{mg} / \mathrm{kg})$; tertatolol $(0.5 \mathrm{mg} / \mathrm{kg}$ ) as a $\beta$-blocker 

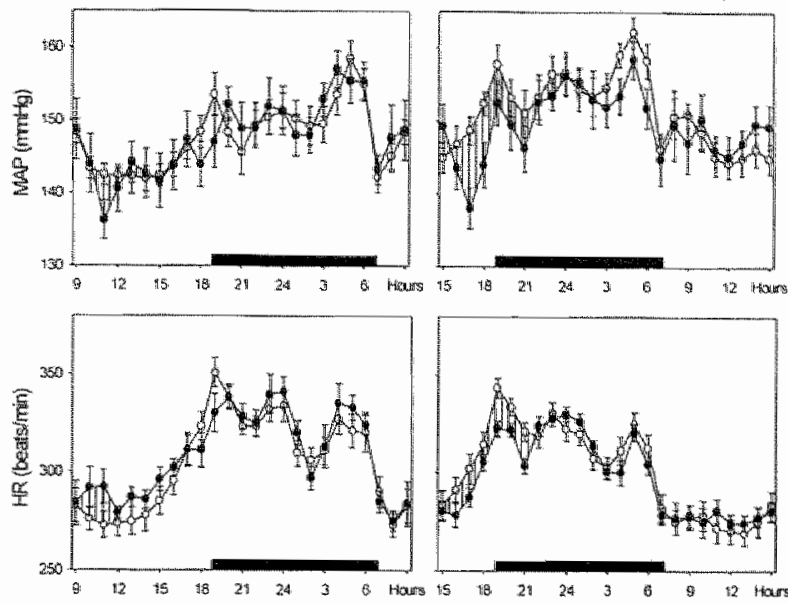

Figure 6.1. Compromison of the efecrs of velicle (open cirches) and metoprolal (Filled circles) on circadion rhy th in mean arterial pressure (MAP) and hear rate (HR) when injected af $10 \mathrm{~h} T \mathrm{~T}=10: \mathrm{m}=10 ; \mathrm{lef}$ panel) or at $16 \mathrm{~h}(\mathrm{~T}=16$ : now 10: right panel). Data are depicred oner a 24 hariod following injection at $T=10$ and $T=16$.

with $5-\mathrm{HTl}_{\mathrm{a}}$, antagonistic properties; and the calcium antagonist felodipine $(0.3 \mathrm{mg} / \mathrm{kg})$. As an effective dose, onethird was taken of the amount used in a previous experiment while studying the efficacy of continuous infusions ${ }^{10}$. Agents were dissolved in saline or, in the case of propranolol, prazosin, and captopril, in water.

\section{Calculations and Statistics}

Because 24-h MAP and HR rhythms vary from day to day, for each individual rat a 24-h reference curve was calculated by averaging MAP and HR over at least three, but in most cases four, different 24 -h periods during which only saline was injected. The effects of drugs on MAP and HR are then related to this reference curve. The duration of the effect of each single injection could not be determined accurately because of the individual spontaneous variability in MAP and HR. Therefore, the averaged (over all rats) time curves of MAP and HR were used in determining the mean duration of an effect (TdurMap and TdurHr respectively). These averaged time curves as well as the averaged reference curves were subjected to a cumulative summation technique, to construct a so-called "cusumplot," from which time points of change (end of effect) can be identified ${ }^{13}$.

Then for each single injection, a summation was made of the differences in MAP and HR with the reference curve over TdurMap and TdurHr. These latter values of summated differences in MAP and HR can be regarded as a measure of the pharmacodynamic response and were defined as $\Sigma \Delta M$ ap and $\Sigma \Delta H r$. They are visualized as the shaded area in Figs. 1-9. Furthermore for each injection the maximal effect ( $\triangle M A P_{\text {Max }}$ and $\Delta \mathrm{HR}_{\mathrm{Max}}$ imaximal differnce wiith the reference curve) was determined. As a last parameter of drug efficacy, the difference (with the reference curve) in the summated rate pressure product $(\mathrm{RPP}=$ MAP. FR) over TdurMap was calculated ( $\triangle 2 \mathrm{RPP})$. Then, the above named parameters were averaged per agent and per injection time.

For each agent, differences between these parameters at injection time $\mathrm{T}=10 \mathrm{or}$ $T=16$ were compared with a paired t-test in the event paired recordings could be completed for all rats of one group. Otherwise an unpaired t-test was applied. Because 
Table 6.1. Comparison of the effoacy of antihyperensive agents.

\begin{tabular}{|c|c|c|c|c|c|c|c|c|c|c|}
\hline & 7 & Melestrest & $\begin{array}{l}\text { Fyorstario } \\
\text { Was? }\end{array}$ & Pratosin & Labetol a! & Clomiditue & $\begin{array}{l}\text { Fiturin: } \\
\text { sfing }\end{array}$ & Capreqperi & Teriatislel & Prithodipine \\
\hline 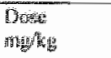 & & 1.5 & 5 & 6.6 & 3 & 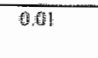 & 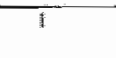 & 10 & 0.5 & 0.3 \\
\hline 时 & & 10 & 7 & 9 & 10 & 8 & $\$$ & 9 & 6 & 11 \\
\hline 畔 sili & & 10 & $y$ & 10 & 12 & 8 & 8 & 8 & 6 & 11 \\
\hline 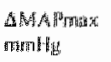 & $16)$ & $-4 x_{3}^{*}$ & .30 & 49) 2 ? & -244 & -1042 & - 16 Gat 1 & (9): & $-8 x^{4}+4$ & $-25 \pm 2$ \\
\hline 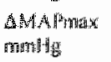 & 16 & $-11+4$ & $-11 \pm 2$ & -16 要近 & $-3 y+24$ & $-12 \pm 2$ & $-1 x+3$ & .1444 & $12+2$ & -32 \\
\hline $\begin{array}{l}\text { AHhmax } \\
\text { byon }\end{array}$ & 19 & +2014 & $18 \mathrm{~s}$ & $67 \%$ & $30+5$ & $-20=5$ & .37 ing & 24⿻3 & $.7 \pm 9$ & $40 \div 7$ \\
\hline $\begin{array}{l}\Delta H_{1} R_{\text {max }} \\
\text { bpm }\end{array}$ & 66 & $-15 \geq 6^{*}$ & $-114: 4 *$ & $51: 15$ & 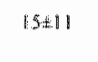 & $-18 x 5$ & $-40+16$ & $33 \pm 9$ & $-18 \div 6$ & $60) \pm 9$ \\
\hline $\begin{array}{l}\text { EAMAP } \\
\text { MmBHy }\end{array}$ & 10 & $-8 \operatorname{sen} 4$ & $47 \pm 7$ & $\times 7+21$ & $+1060 \pm 118$ & -364212 & $-40 \pm 11$ & $-113 \pm 377$ & $-80 \pm-47$ & -7446 \\
\hline 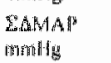 & It & $-36 \div 16^{*}$ & $.91 \pm 24^{\circ}$ & $.109 \pm 16$ & $.113 \pm 10$ & $-51+12$ & -790 & $-67 \pm 24$ & $-25 \div 25$ & $-75 \pm 8$ \\
\hline 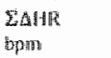 & 10 & 78439 & $+2+28$ & $36 \%+59$ & $114+23$ & $-59+28$ & -30015 & $53+19$ & $-15 \leq 1 \mid$ & 80415 \\
\hline 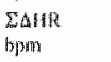 & 16 & $-76 \pm 21 \%$ &.$|2| \approx 55$ & 248454 & $43 \pm 18 *$ & $x, 3 \pm 11$ & $-139277^{*}$ & $45 \times 13$ & -2340 & $66 x+10$ \\
\hline ¿ARP \% & 10 & 41829 & 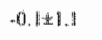 & $+4.3 \pm 2,6$ & $4.6 \pm 2.6$ & -5.518 & $-6 \cos 28$ & $-1.6 \pm 29$ & $-3.3 \times 1.8$ & $-6.4 \pm 1.7$ \\
\hline XARHP & 16 & -3.712 .6 & $-9.5 .11 .4 *$ & $.0 .1+26$ & 9.918 & $-4.7+1.5$ & $-40.2 \pm 222^{2}$ & -19412 . & $-50 \times 29$ & $-85 \pm 2.1$ \\
\hline 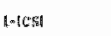 & & mappined & piaticed & tantained & 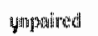 & pasired & prired & unpaired & Mirspaired & pained \\
\hline
\end{tabular}

Agents were injected at $T=10$ or $T=16$. Effects are expressed by maximal and summated changes in mean arterial pressure ( $\triangle M A P$ max. $\triangle \triangle M A P)$ and heart rate (AHRnar, $\triangle \triangle H R$ ) and differences in rate pressure product ( $\triangle A R P P$ ) over the duration of the effect. ${ }^{*} \mathrm{P}<0.05$ significantly differen between effects at $T=10$ and $T=16$.

no dose response curves were constructed, differences between agents were not subjected to quantitative analyses, but described only qualitatively. Data are presented as means \pm SE unless indicated otherwise. Differences were regarded significant at $P<$ 0.05 .

\section{Results}

As depicted by the reference curves in Figs. 6.1-6.9, MAP and HR vary considerably in SHRs throughout a 24 -h period. However, there is a consistent pattern. MAP and HR are low during the lights-on period with a small peak at $\sim 10: 00 \mathrm{~A}$.M. Then, from $-16: 00 \mathrm{~h}, \mathrm{MAP}$ and HR start to rise, exhibiting a first peak at 20:00 $\mathrm{h}$ followed by two other peaks at 1:00 and 6:00 A.M. during the lights-off period. Maximal MAP and HR values were usually found during the third and first peak of the dark period, respectively. Figures 6. $1-6.9$ compare for each agent the effects of a single injection on MAP and $\mathrm{HR}$ when given either at $\mathrm{T}=10$ or $\mathrm{T}=16$. Table 6.1 summarizes the results for the deducted parameters such as maximal and summated difference in MAP and MR as well as differences in RPP caused by the injections. The duration of the averaged response to each drug is indicated in the figures by the shaded area.

The anthypertensive effect of metoprolol (Fig. 6.1) was significantly greater when 

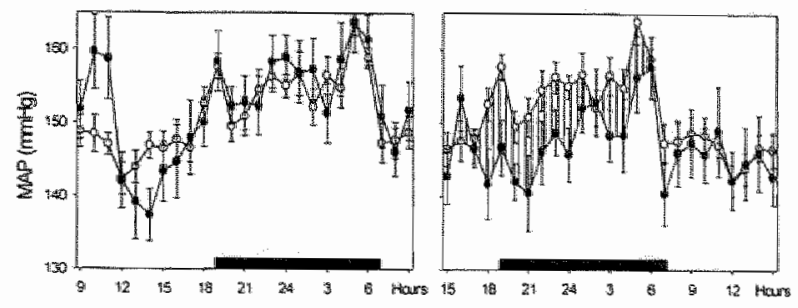

Figure 6.2. Comparison of the effects of velucle (Open circles) and propranolol (Filled cheles, on circadhan rhythm in MAP and HR when injected at $T=10(n=7)$ or at $T=16(n=7)$, Abbreviations are explanned in
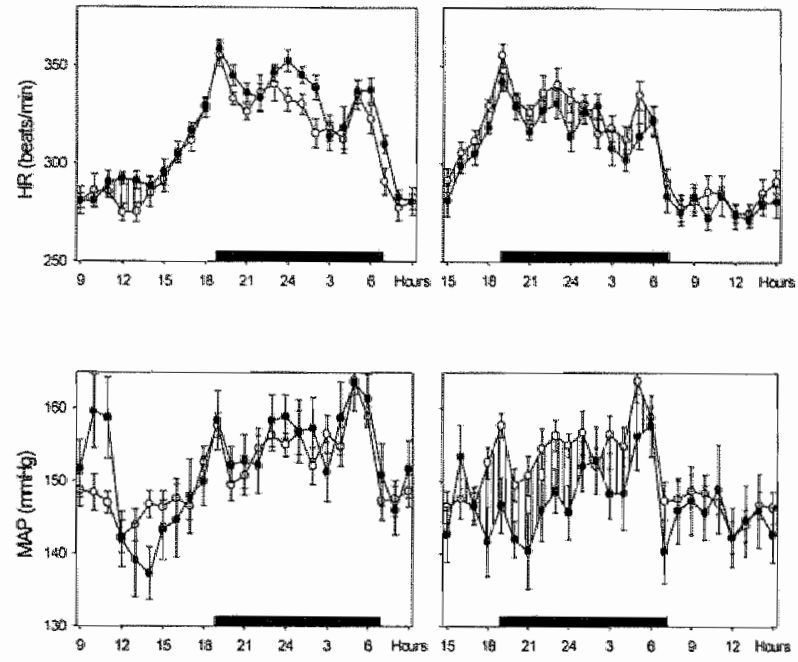

Figure 6.3. Comparison of the effects of vehicle (Open circles) and prazosin $0.6 \mathrm{mg} / \mathrm{kg}$ (Filled circles) on circadian whythm in MAP and HR when injected at $T=10(n=9)$ or at $T=16(n=$ 10). Abbreviations are explained in the legends to Fig.
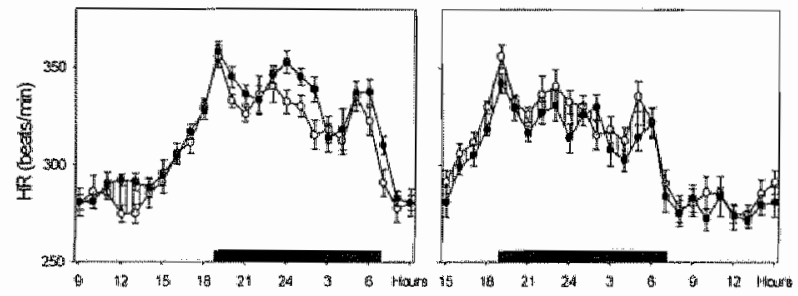

6.1 .

the agent was injected at $T=16$ than at $T=10$. At $T=10$ there was even a slight increase in HR, whereas at $\mathrm{T}=16 \mathrm{HR}$ was lower than the reference curve, but increasing in a similar way as the reference curve.

When injected at $\mathrm{T}=10$ propranolol (Fig, 6.2) first increased MAP for $2 \mathrm{~h}$ and then decreased it for $4 \mathrm{~h}$, accompanied by a small increase in HR. At $T=16$ the initial increase in MAP was smaller than after $T=10$ and was followed by a greater and much longer-lasting reduction in MAP. Reductions in HR after injection of propranolol at $\mathrm{T}=$ 16 were small but significantly different from those at $T=10$. For both propranolol and metoprolol the reduction in $\triangle \Sigma R P P$ was significantly greater after injection at $T=16$ than $\mathrm{T}=10$.

Prazosin (Fig. 6.3) reduced MAP effectively when injected either at $T=10$ or $T=$ 16. $\triangle M_{M A P} \quad \Sigma \Delta M a p$, and $\triangle \Sigma R P P$ were greater at $T=16$ than at $T=10$, although differences were not statistically significant. The parameters describing the degree of tachycardia following administration of prazosin were greater at $\mathrm{T}=10$ than at $\mathrm{T}=16$. 

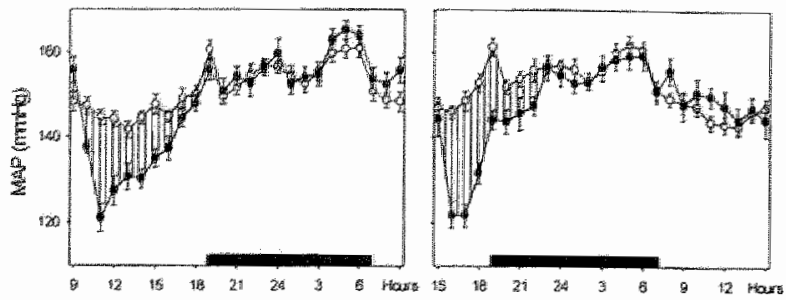

Fugure 6.4. Comparison of the effects of vehicle (Open circles) and labetolol $3 \mathrm{mg} / \mathrm{kg}$ (Filled circles, on circadian rhythm in MAP and HR when injected at $T=10(n=10)$ or at $T=16(\mathrm{n}$ 12). Abbreviations are

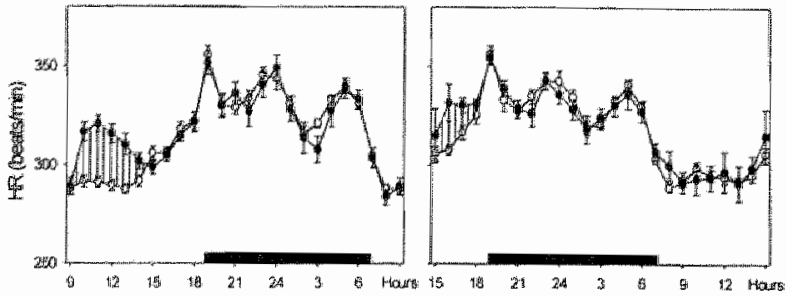
explawed in the legends to Fig. 6.1.
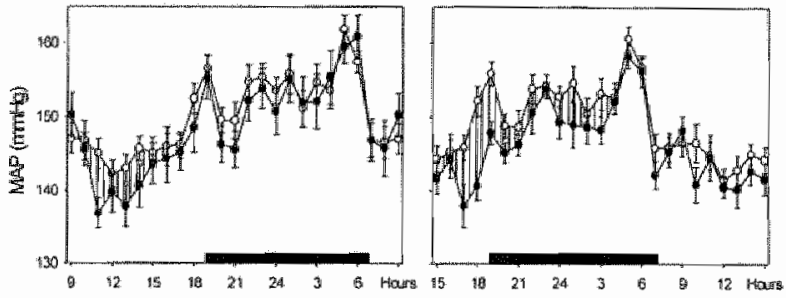

Fugure 6.5. Comparison of the effects of velvicle (Open circles) and clonidine $10 \mathrm{\mu g} / \mathrm{kg}$ (Filled circles, on circadian rhym in MAP and HR when injecled at $T=10(n=8)$ or at $T=16(n=$ 8). Abbreviations are ex-
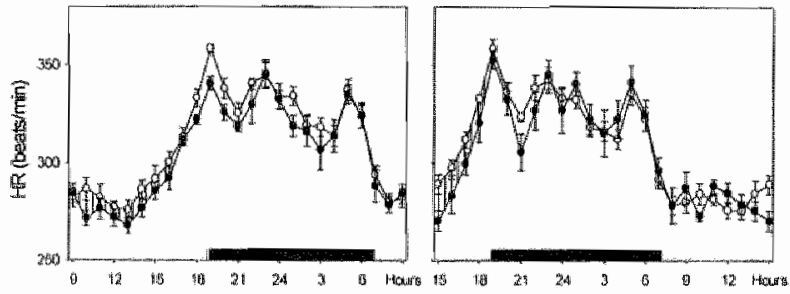
plained in the legends to Fig. 6.1.

These differences, however, also did not reach significance.

After injection of labetalol at $\mathrm{T}=16, \Sigma \Delta \mathrm{Map}$ and $\triangle \mathrm{MAP} \mathrm{P}_{\mathrm{Max}}$ were greater than at $\mathrm{T}$ $=16$, but differences were not statistically significant. At both injection times HR increased following administration of labetalol. Maximal changes in HR were not different, but the degree of tachycardia $(\Sigma \Delta H R$ ) was significantly greater at $T=10$ than at $T$ $= \pm 6$.

The BP lowering effect of clonidine (Fig. 6.5) was greater when injected at $\mathrm{T}=16$ than at $T=10$. The differences in $\Sigma \Delta$ Map $(-36 \pm 12$ vs. $-51 \pm 12 \mathrm{~mm} \mathrm{Hg})$ were almost significant $(p<0.08)$. The decreases in HR and $\triangle R P P$ following clonidine administration were similar at $\mathrm{T}=10$ and $\mathrm{T}=16$.

Rilmenidine (Fig. 6.6) decreased MAP and HR effectively in SHRs. Maximal reductions in MAP and HR that were achieved after injection at $T=10$ or $T=16$ were comparable. The summation of MAP and HR reductions as well as the reduction in 

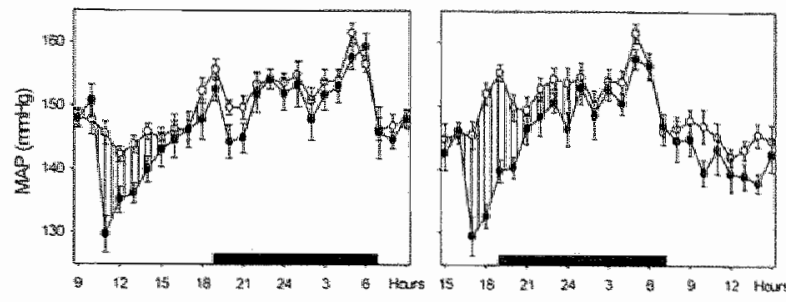

Figure 6.6. Comparison of the affects of wehcle (Opencirctes) and wheniane / $\mathrm{mg} / \mathrm{hg}$ (Filled circlesy on circadion rhym in MAP and HR when miected at $T=10(n=8)$ or $a t$ $T=16(\mathrm{~h}=8)$. Abbroviations
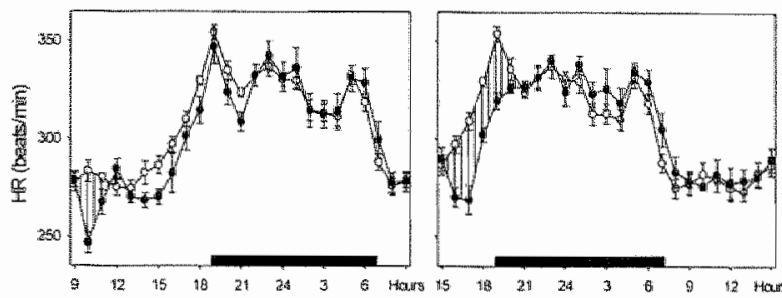
are explained in the legends to Fig. 6.1.
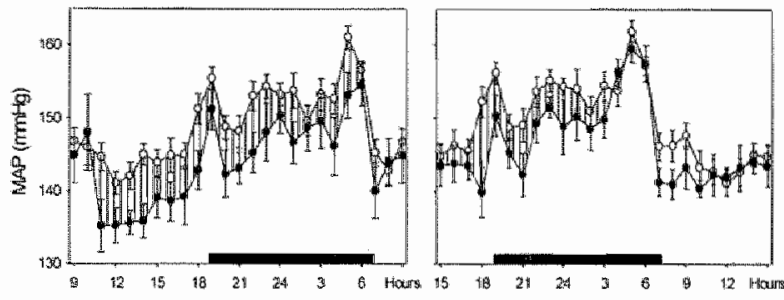

Figure 6.7. Comparison of the effects of vehicle (Open circles) and captopril $10 \mathrm{mg} / \mathrm{kg}$ (Filled circles) on circadian rhyth in MAP and HR when injecred at $T=10(n=9)$ or at $T=16(n=$ 8). Abbreviations are ex-

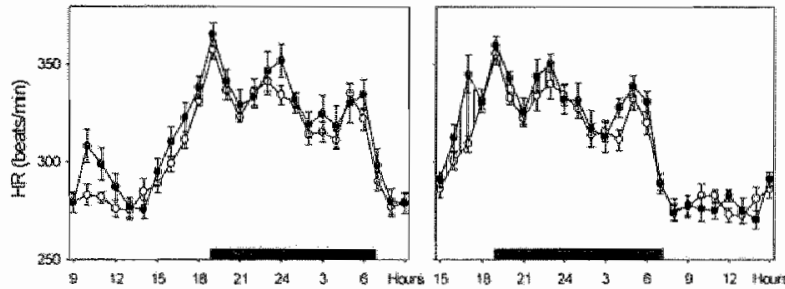
plained in the legends to Fig.

$\triangle \Sigma R P P$ was significantly greater after $T=16$.

In contrast to the above-mentioned sympatholytic agents, captopril (Fig. 6.7) was longer effective in lowering MAP when given at $\mathrm{T}=10$ rather than at $\mathrm{T}=16$. However, values of $\Sigma \Delta M a p$ at $T=10$ and $T=16$ were not significantly different. In both cases the effects on MAP were accompanied by a small degree of tachycardia.

A similar pattern was found when tertatolol (Fig. 6.8) was given. Reductions in $\Sigma \Delta$ Map were approximately three times greater when given at $\mathrm{T}=10$ than at $\mathrm{T}=16$. However, the variability in this response was quite large, and differences between mean values were not statistically significant. Remarkably, tertatolol was without effect on HR.

The antihypertensive effects of felodipine (Fig. 6.9) were similar when given at either $T=10$ or $T=16$, although the duration of the response seems to be greater after injection at $\mathrm{T}=10$. At both times, the agent caused a profound reduction in $M \mathrm{AP}^{\mathrm{P}}$ 

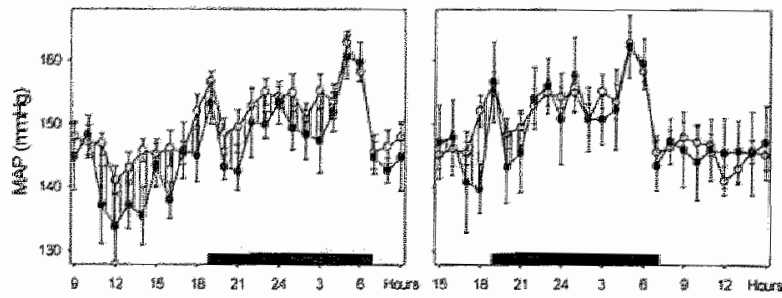

Figure 6.8. Comparison of the effects of vehicle (Open circles) and tertatolol $0.5 \mathrm{mg} / \mathrm{kg}$

(Filled circles) on circadian whyhm in MAP and HR when injected ar $T=10(n=6)$ or at $T=16(n=6)$. Abbreviations
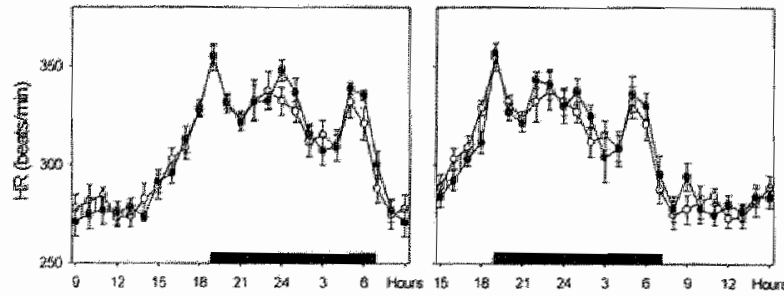
are exploined in the legends to Fig. 6.\%.
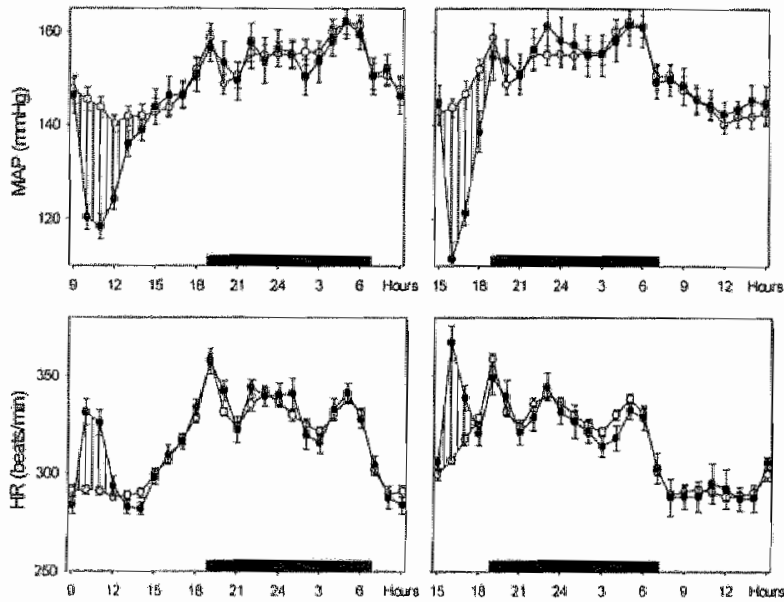

Figure 6.9. Comparison of the effects of vehicle (Open circles) and felodipine $0.3 \mathrm{mg} / \mathrm{kg}$ (Filled circles) on circadiam Hyyhm in MAP and HR when injected at $T=10(n=11)$ or at $T=16(n=11)$. Abbreviations are explained in the legends to Fig. 6.1.

associated with tachycardia. After the maximum effect was reached, MAP returned rapidly to control levels.

\section{Discussion}

The present study shows that the cardiovascular effects of a number of antihypertensive agents in SHRs are dependent on the time of administration in the 24-h cycle. Sympatholytic agents, in particular, were consistently more effective when administered at the beginning of the rise in BP at awakening than during the first hours of the sleeping pertiod.

Both, circadian phase-dependent changes in pharmacokinetics and pharmacodynamics tnay underlie the temporal differences in efficacy of the agents. Chronokinetic differences in reabsorption were avoided by giving intravenous bolus injections. How- 
ever, temporal differences in binding capacity of plasma proteins, netabolic clearance rate, or excretion may influence the avalability of agents. Yet, the present data on the $\beta$-blockers propramolol and metoprolol suggest that chronokinetic factors are of minor importance as compared with chronopharmacodynamic factors. Whereas the antilypertensive efficacies of propranolol and metoprolol were greater when injected at $T=16$ than at $T=10$, the elimination half-lives of these $\beta$-blockers in plasma and organs of rats are known to be shorter during the dark period than during the light period". Similar conclusions were reached when the phamacokinetics and cardiovascular effects of propranolol in healthy subjects were compared ${ }^{15}$. It has been suggested that increased liver blood flow and hereased metabolic activity during the active period, on the one hand, and increased susceptibility due to enhanced sympathetic activity, on the other hand, underlie the discrepancy between pharmacokinetic and pharmacodymamic behavior of these $\beta$-blockers ${ }^{1-16}$.

Although no dose-response studies were performed and no quantitative comparison of the differences in efficacies of the agents can be made, certain aspects of the present findings require specific discussion. The most clear-cut circadian tempora! differences in efficacy were found with the $\beta$-blockers metoprolol and propranolol. The antihypertensive response was much greater and longer lasting when these agents were injected at $T=16$ than at $T=10$. In contrast to that of metoprolol, the antihypertensive effect of propranolol at $\mathrm{T}=10$ and $\mathrm{T}=16$ was preceded by a $2-\mathrm{h}$ and a $1-\mathrm{h}$ lasting increase in blood pressure, respectively, which is probably caused by baroreceptor-mediated peripheral vasoconstriction ${ }^{13}$.

The injection of the $\beta$-blockers at $T=16$ did not cause a profound bradycardia. The maximal average reduction in $H R$ in $1 \mathrm{~h}$ was only 11 beats/min for both the $\beta$-blockers. The rate of rise in HR during that period was also not different from the nontreated situation. This finding suggests that the increase in HR during the awakening rise in rats is probably more the result of a fall in parasympathetic activity rather than sympathetic activation. When these $\beta$-blockers were injected during the first hours of the sleeping period, during which basal HR is very low and vagal activity prevails, even small, but reproducible, average increases in $H R$ were found. Since both agents lack intrinsic sympathicomimetic activity, the nechanism of this response is unclear. However, we speculate that a $\beta$-blocker-induced fall in stroke volume may underlic this small increase in HR. On the other hand, injection of propranolol at $\mathrm{T}=10$ may have unmasked a vagal cardioaccelatory system in these rats ${ }^{18}$.

The effects caused by the $\alpha$-blocker prazosin and labetalol, an agent with combined $\alpha$-and $\beta$-blocking properties were comparable and for a major part determined by baroreceptor reflex activation. Labetalol was used since in human studies this agent was most effective in reducing the moning rise in $\mathrm{BP}^{3.6}$. In SWRs prazosin and labetalol caused a pronounced fall in MAP, and the hypotensive response was greater when the agent was injected at $T=16$ than at $T=10$. Differences in these effects at $T=10$ and $T$ $=16$ were not statistically significant and may be due to the fact that the administered dose was quite large for both agents. After injection of labetalol, the amount of reflex tachycardia was greater at $T=10$ than at $T=16$. Not only maximal changes in HR were larger, but the duration of the reflex tachycardia was also enhanced after injection at T $=10$. Differences in the central processing of baroreceptor reflex arch as well as differ"ences in pharmacokinetics may explain this finding. Baroreceptor sensitivity has been 
reported to be enhanced during sleeping hours "whis w corroborated by the fact that BP lability indexes are generally lower during these thours ${ }^{\text {in }}$. On the other hand the rate of elimination of labetalol may have been increased due to the enhanced metabolic activity during the dark hours. Further studies should clarify whether and how prazosin and labetalol can be administered for an optimal chronopharmacological profile.

The cardiovascular ffects of the centrally acting agents clonidine and rimenidine were also more pronounced at $T=16$ than at $T=10$. These data are in agreement with those of Sannajust et al. ${ }^{20}$, who showed that the BP lowering effect of these agents in SHrS is related to the preexisting sympathetic tone. In addition, the hypotensive effect of clonidine and rilmenidine at $T=16$ may also be related to their inhibitory effect on vasopressin and adrenocorticotropic hormone $(\mathrm{ACTH})$ release.". These latter effects may be more pronounced at $T=16$, since this is the time point at which plasma corticosteroid levels are supposed to peak ${ }^{22}$. In contrast with the $\beta$-blockers, the effects of clonidine and rilmenidine were accompanied by bradycardia, even when injected at $\mathrm{T}=$ 10, when sympathetic activity is supposed to be minimal. This reduction in HR may be explained by baroreceptor loading caused by an initial rise in pressure as a result of vascular $\alpha$-adrenoceptor stimulation. The $\beta$-blockers, in contrast, lead to baroreceptor unloading. Thus, the effects of clonidine and rilmenidine seem to be governed by vagal activation as well as sympathetic inhibition.

The temporally dependent cardiovascular effects of the angiotensin-converting enzyme (ACE) inhibitor captopril were opposite to those found after injection with the above-mentioned sympatholytic drugs. Although $\Sigma \Delta \mathrm{MAP}$ at $\mathrm{T}=10$ was wice the value found at $T=16$, these differences in efficacy did not reach significance because of considerable intraanimal variation. Part of this variability may be explained by the fact, as was found in humans ${ }^{23}$, that plasma renin activity (PRA) shows a burst-like mode of appearance over $24 \mathrm{~h}$. Especially during the sleeping period, oscillations in the behavior of PRA councides with episodes of rapid eye movement (REM) and non-REM ${ }^{24}$. Remarkably, the duration of the BP lowering effect of captopril when injected at $T=10$ was much longer than that observed after injection at $\mathrm{T}=16$. Similar findings were observed after injection of tertatolol, a $\beta$-blocker with 5-HT1, receptor-blocking properties ${ }^{25}$. The in vivo cardiovascular effects of captopri ${ }^{26}$ and tertatolol ${ }^{27}$ have been reported to last considerably longer than can be expected on the basis of their half--lives. The underlying hemodynamic mechanisms of this prolonged eardiovascular activity may depend on the specilic renal vasodilatory properties of captopril and tertato ${ }^{28.2 \%}$. Thus, especially during the sleeping period, when urine production and glomerular filtration rate are lower than during the activity period ${ }^{30}$, the kidney may be, as has been shown for furosemide." and a preparation of captopril and hydrochlorothiazide ${ }^{32}$, highly sensitive to renal vasodilators. Further studies are necessary for supporting this hypothesis, which may lead to a timed regimen of administration of $A C E$ inhibitors.

The antihy pertensive efficacy of felodipine in SHRs was not dependent on circadian phase. Recently, similar results ware obtained in SHRs for amlodipine by Lemmer et al. "On the other hand, this group reported that the effects of amlodipine in normotensive rats were dependent on circadian phase ${ }^{34}$. Thus, strain differences seem to influence the circadian efficacy of calcium antagonists.

In summary, the cardiovascular effects of antihypertensive agents in SHRs are dependent on the"r time of administration. Especially, $\beta$-adrenergic blockers and cen- 
trally active agents showed greater anthypertensiwe efficacy when given at a time point to attenuate the early moming rise (in rats, early night) in BP. This finding suggests that agents that lower BP, among other mechanisms, by a reduction of cardiac output, may be suitable tools for the chronophamacological treatment of hypertension.

\section{References}

1. Smolensky MH, Tatat SE, Bergman SA, et al: Circadian blythmic aspects of thuman cardiovascular function: a review by chronobiologic statistical methods. Chronobiologia 1976;3:337-371.

2. Lemmer B: The Chronopharmacology of cardiovascular medications. Anm Rev Chronopharmacol 1986; $2: 199-228$.

3. Sirgo MA, Mills RJ, DeQuattro V: Effects of antihypertensive agents on circadian blood pressure and heart rate patterns. Arch Intern Med 1988; 148: 2547-2552.

4. Pepine Cl: Therapeutic implications of circadian variations in myocardial ischemia and related physiologic functions. An J Hyperfers 1991; 4:442S-448S.

5. Materson BJ, Preston RA: Classic therapentic trials in hypertension. Am J Hypertens $1991 ; 4: 4495-4535$.

6. Gould BA, Raftery EB: Twenty-four-hour blood pressune contiol: an intraarterial review. Chronobiol Int 1991; 8:495-505.

7. Muller JE, Stone PH, Turi $Z \mathrm{G}$, et al: Circadian wariation in the frequency and onset of acute myacardial infarction. New Engl J Med 1985; 313:1315-1322.

8. Gottlieb SO: Circadian patterns of myocardial ischemia: pathophysiologic and therapeutic considerations. J Cardiovasc Phamacol 1988; 12(suppl 7): 18-21.

9. MacMahon SW, Cutler JA, Furberg CD, Payne GH: The effects of drug treatment for hypertension on morbidity and mortality from cardiovascular disease: a review of randomized trials. Prog Cardiovaso Dis 1986; 29(suppl 1): 99-1 118.

10. Janssen BJA, Tyssen CM, Struyker-Boudier HAJ: Modification of circadian blood pressure and heart rate variability by five different antihypertensive agents in spontaneously hypertensive rats. J Cardiovasc Pharmacol 1991; 17: 494-503.

11. Janssen BJA, Tyssen CM, Struijker Boudier HAJ, Hutchins PM: 24-Hour homeodynamic states of arterial blood pressure and pulse interval in conscious rats. $J$

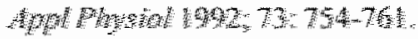

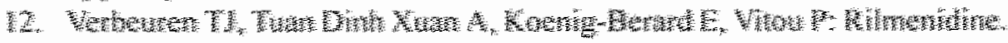

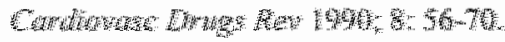

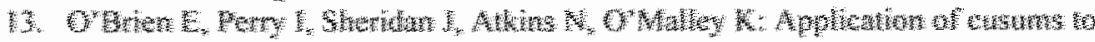

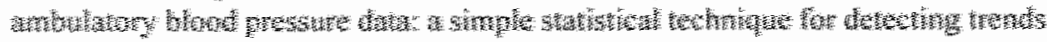

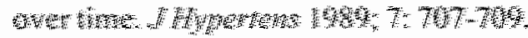

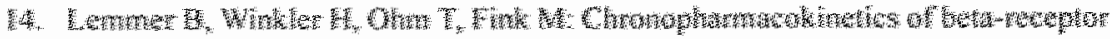

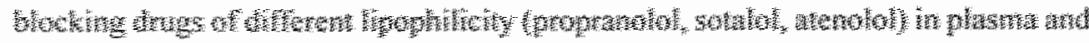

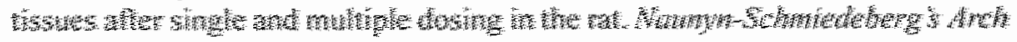

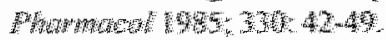

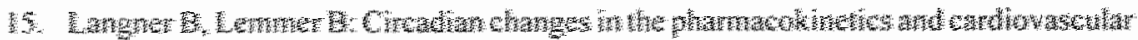

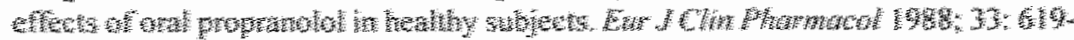
स.2.

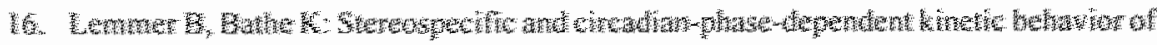

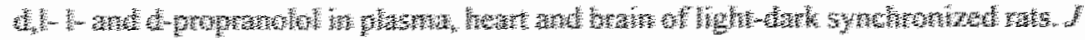

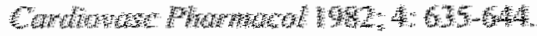

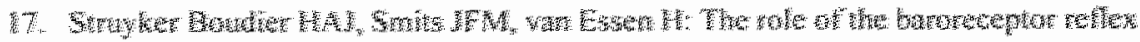


in the cardiovascular effects of propranolol in the conscious spontaneously hypertensive rat. Clin Sch Mol Med 1979; 56: 163-167.

18. Com L: Neuropeptides and the conduction system of the heart. In $J$ Card 1992; 35: $1-12$

19. Hossmann V, Fitzgerald GA, Dollery CT: Circadian thythm of baroreflex reactivity and adrenergic vascular response. Cardiovasc Res 1980; 14:125-129.

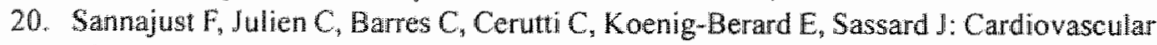
effects of riminidine, a new a2-adrenoceptor agonist, and clonidine in conscious spontaneously hypertensive rats. Cin Exp Pharmac Physiol 1989; 16:837-848.

21. Reid IA. Ahn JN, Trinh $T$, Shackelford $R$, Weintraub M, Keil LC: Mechanism of suppression of vasopressin and adrenocorticotropic hormone secretion by clonidine in anesthetized dogs. J Pharmacol Exp Ther 1983;229:1-8.

22. De Boer $\mathrm{SF}$, wan der Gugten $\mathrm{J}$ : Daily variations in plasma moradrenaline, adrenaline and corticosterone concentrations in rats. Physiol and Behav 1987; 40:323-328.

23. Vieweg WVR, Veldhuis JD, Carey RM: Temporal pattern of renin and aldosterone secretion in men: effects of sodium ballance. Am J Physiol 1992; 262: F871-F877.

24. Brandenberger G, Follenius M, Simon C, Ehrhart J, Libert JP: Nocturnal oscillations in plasma renin acrivity and REM-NREM sleep cycles in humans: a common regulatory mechanusm? Sleep 1989, 11:242-250.

25. Struyker Boudier HAJ, Abbott A: Novel antihypertensive drug reveals unexpected complexities in betamadrenoceptor pharmacology. TIPS 1989; 10:469-471.

26. Wenting GJ, de Bruyn JHB, Man in "t Veld AJ, Woittiez AJJ, Derkx FHM, Schalekamp MADH: Hemodynamic effects of captopril in essential hypertension, renovascular hypertension and cardiac failure: correlations with short-and long-term effects on plasma renin. Am J Cardiol 1982; 49:1453-1459.

27. De Blasi A, Lipartiti M, Pirone F, Rochat C, Prost JF, Garattini S: Reduction of betaadrenergic receptors by tertatolol: an additional mechanism for beta-adrenergic blockade. Clin Pharmacol Ther 1986; 39:245-254.

28. Smits JFM, Struyker Boudier HAJ: Systemic and regional hernodynamics following acute inhibition of angiotensin I converting enzyme in the conscious spontaneously hypertensive rat. Prog Pharmacol 1984; 5: 39-49.

29. Nievelstein HNMW, Tyssen CM, Smits JFM, Struyker Boudier HAJ: Long-term renal vasodilator effect of the beta-adrenoceptor blocker tertatolol in conscious spontaneously hypertensive rats. I Cardiovasc Pharmacal 1988; 12: 252-254.

30. Koopman MG, Minors DS, Waterhouse JM: Urinary and renal circadian rhythms. In Arendt $\mathrm{J}$, Waterhouse JM, Minors MG (eds): Biological thythms in clinical practice John Wright, London, 1989:83m98.

31. Tateishi T, Fujimura A, Miura T, Ebihara A: Chronopharmacological study of furosemide in hunan subjects. In J Clin Pham Res 1988; 8: 401-407.

32. Fogari R, Tettamanti F, Zoppi A, Poletti L, Botta GF: Evaluation of the efficacy of once-daily administration of captopril plus hydrochlorothiazide by 24 -hour ambulatory blood pressure monitoring. Curr Ther Res 1988; 44: 1050-1057.

33. Lemmer B, Mattes A, Boese S: Dose-dependent effects of amlodipin on 24-hour thythm in blood pressure and heart rate in the nomotensive and hypertensive rat. $A m$ J Hypertens 1992; $5: 110 \mathrm{~A}$.

34. Mattes A, Lemmer B: Effects of amlodipine on circadian thythms in blood pressure, heart rate and motility: a velemetric study in rats. Chronobiol Int 1991; 8: 526-538. 


\section{Chapter 7}

Circadian-phase dependent

pharmacodynamics of

angiotensin converting enzyme

inhibitors in spontaneously

hypertensive rats

Jan Oosting

Harry A. Struijker-Boudier

Ben J. Janssen

Submitted for publication

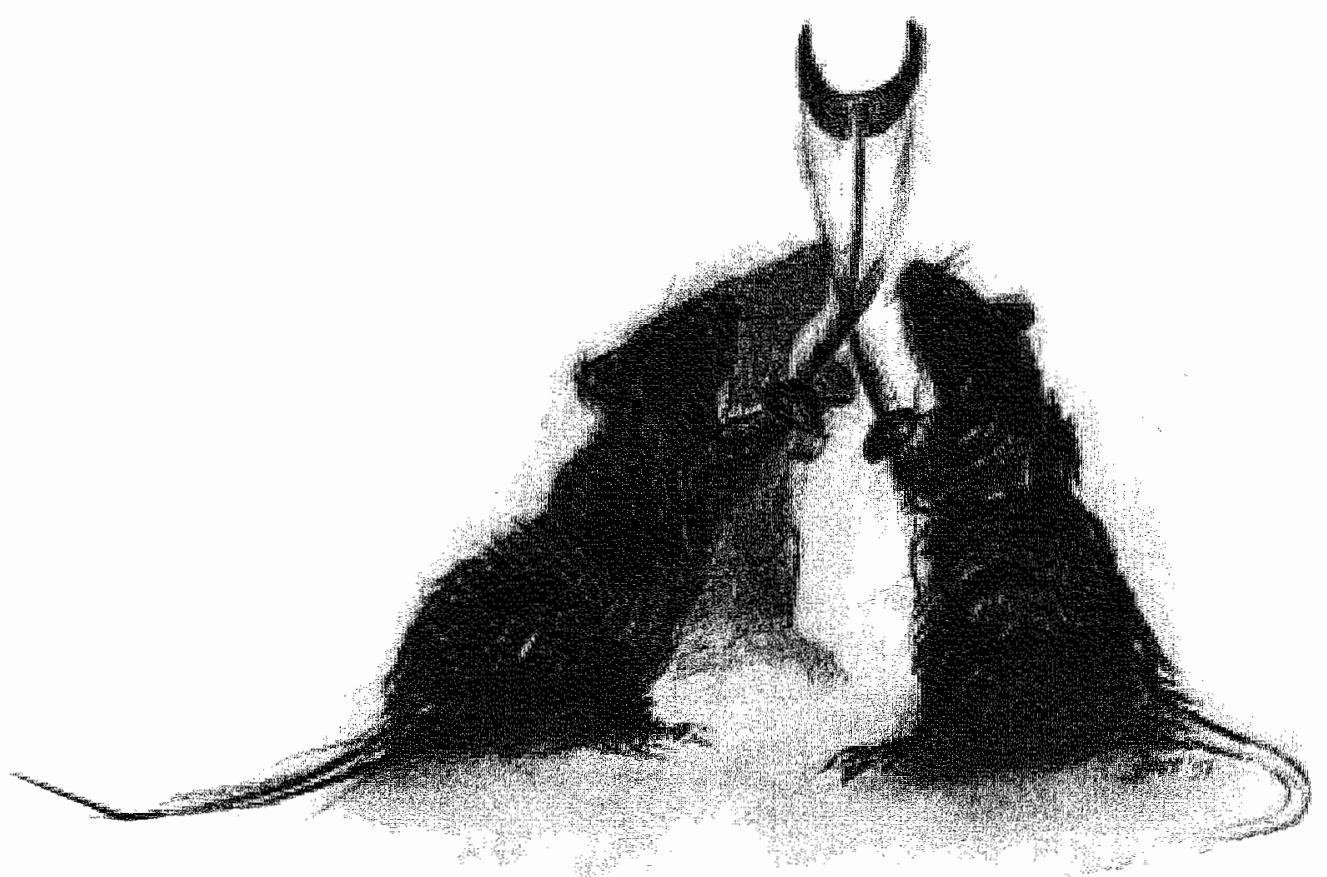




\section{Abstract}

Objective To study the antihypertensive efficacy of drugs that inhibit the renin angiotensin system when administered at different time points of the day.

Methods Adult spontaneously hypertensive rats, were treated on 5 consecutive days with infusions of the ACE-inhibitors captopril $\left(3,10\right.$, and $\left.30 \mathrm{mg}^{-1} \mathrm{~kg}^{-1} \cdot 6 \mathrm{~h}^{-1}\right)$, enalaprilat $\left(0.3 \mathrm{mg} . \mathrm{kg}^{-1} .6 \mathrm{~h} \mathrm{~h}^{-1}\right)$, lisinopril $\left(0.1 \mathrm{mg} . \mathrm{kg}^{-1} .6 \mathrm{~h}^{-1}\right)$, or the $\mathrm{AT}$,-receptor antagonist losartan (10 mg. $\left.\mathrm{kg}^{-1} .6 \mathrm{~h}^{-1}\right)$, either during the transition from the lights-off to the lights-on, resting period (evening dose), or during the transition from the lights-on to the lights-off, active period (morning dose).

Results The effects of all agents on the circadian blood pressure pattern were comparable. In general, the average reduction of blood pressure over 24 hours was not different following a morning or evening dose. However, the blood pressure pattens were markedly different during specific periods of the day for the two treatment regimens. The diflerence in blood pressure between the lights-off and lights-on period was smaller following the morning than the evening treatment regimen. Reflex tachycardia was more pronounced when drugs were given as the evening dose, whereas the rate pressure product, an index of cardiac oxygen consumption, was more decreased following the morning dose.

Conclusions In spontaneously hypertensive rats, circadian thythms of blood pressure can be modulated by timed administration of agents that inhibit the renin angiotensin system. Especially when given during the transition from the resting to active period of the day, these agents reduce effectively the surge in blood pressure normally observed in this period. 


\section{Introduction}

Morbid events related to hypertension, such as myocardial imfarction, angina pectoris, and nonembolic strokes strike more often in the early monning hours than at other time points of the day ${ }^{\prime}$. This has raised the question whether protection against such events can be enhanced by targeting the anti-hypertensive therapy towards this early morning period, which is characterized by a sharp nise in blood pressure and heart rate ${ }^{3.4}$. Prospective clinical studies in support of this hypothesis are not available. Nowadays one special delivery system has been developed for the calcium antagonist verapamil. The drug preparation is designed to control the onset and to extend the release of the agent to achieve maximal levels of the drug during the early morning surge in blood pressure

For angiotensin converting enzyme (ACE) inhibitors, such special formulations do not exist. Obviously, this can be explained by the fact that recently developed ACE inhibitors have a long pharmacological half life and are applicable as a once a day preparation aimed at controlling blood pressure over the whole 24 -h period. However, when therapy once a day is used, the drugs are usually ingested in the moming. Hence, one may expect that the lowest plasma levels and the least pharmacological effect will occur during the last hours of the dosing interval, which coincides with the early morning blood pressure rise. Thus, there may be insufticient control during the time at which hypertensive patients are at greatest risk for the development of cardiovascular events. Indeed, studies on once a day B-blockers ${ }^{6}$ and ACE inhibitors ${ }^{7-10}$ have indicated that blood pressure control may not be adequate during the last hours of the 24h dosing interval, particularly when the drug is ingested as a morning dose.

To obtain a significant fall in blood pressure at the end of the dosing interval, the United States Food and Drug Administration (FDA) introduced the concept of the trough-to-peak ratio. New antihypertensive agents should meet the requirement that $50-66 \%$ of their maxinal blood pressure lowering effect (peak) persists until the next dose (trough)"1.12. Dose titration of antihypertensives is complicated, also when drugs have a relatively linear relation between their pharmacokinetic and pharmacodynamic behaviour ${ }^{13}$. This process may become even more complex when a direct relation between these parameters is lacking. This applies particularly for many $\mathrm{ACE}$ inhibitor's, since their antihypertensive effect depends partly on the amount of inhibition of tissue $\mathrm{ACE}^{14.15}$ and does not coincide with the time wher peak plasma levels are achieved ${ }^{7}$.

Many mechanisms have been brought forward to explain the pharmacodynamic behaviour of ACE inhibitors. Relevant to this study, is the circadian variation in the components of the renin-angiotensin system. In normal and hypertensive humans ${ }^{17}$, is and in animals ${ }^{19.20}$ plasma renin levels are low at the beginning of the sleeping period but increase steadily to be highest at the time of awakening. However, little to none information is available about the circadian variability in plasma and tissue of other components of this humoral system ${ }^{2}$. Despite the lack of such basic data a few recent studies in patients have demonstrated that the timing of dosing is important in the 24 . h protection by $A C E$ inhibitors ${ }^{710}$. The results of these studies are not very consistent, which nay be one of the reasons why a chronotherapeutic approach of hypertension has received little attention. 
To generate more conclusive information about the time-dependent efficacy of ACE-inhibitors in the treatment of hypertension, we investigated the circadian-phase dependent efficacy of several ACE inhibitors in spontaneously hypertensive rats (SHR). This animal model was chosen because the circadian blood pressure rhythm in this species is comparable to the one in essential hypertensive patients ${ }^{22.23}$. One should, however, account for a 12-h phase difference in the haemodynamic patterns in these nocturnally active animals. In $\mathrm{SHR}$, blood pressure and heart rate rise slowly during the last two hours of the lights-on period and increase rapidly when the rats become fully active when the lights are off. At the beginning of the lights-on period blood pressure and heart rate fall steeply. A second reason to use this model was that, comparably to findings in patients ${ }^{3 .}{ }^{24}$, the circadian pattern of blood pressure is preserved, when antihypertensive agents are continuously infused ${ }^{22}$. For instance, during a constant intravenous infusion with captoprill, we found that the circadian variation in blood pressure was not altered despite $20-30 \mathrm{mmHg}$ reduction in arterial pressure. Assuming that under these circumstances steady state inhibition of ACE was achieved, this suggests that the pharmacodynamic reaction to an $\mathrm{ACE}$ inhibitor is more important than its pharmacokinetic profile. Lastly, in two studies in SHR, the antihypertensive effect following single bolus injections of captopri ${ }^{25}$ and enalaprilat ${ }^{26}$, were circadian phasedepended too.

In the present study, we have compared the antihypertensive efficacy and troughto-peak ratio's of the ACE-inhibitors, captopril, enalaprilat and lisinopril, and the AT,receptor antagonist losartan when infused intravenously in SHR during the transition from the dark to light period or during the transition from the light to dark period. All agents were infused at either time period repeatedly for a period of five consecutive days. We chose to administer the agents intravenously to minimize acute counter regulatory effects associated with bolus injections as well as to obtain comparable bioavailability at both periods of the day. When agents are administered orally, circadianphase dependent differences in absorption may determine importantly the effect. Captopril was used as a reference drug at three different dosages. To investigate whether central nervous effects of $\mathrm{ACE}$-inhibition could be involved we compared the timerelated effects of captopril to those of enalaprilat, which does not cross the blood brain barrier as readily as captopri ${ }^{27}$. The ACE-inhibitor lisinopril was compared with captopril to estimate the influence of its longer half life on the time-related effects on the circadian blood pressure patterns. Lastly " Losartan, was used to discriminate between effects of ACE inhibition and $\mathrm{AT}$, -receptor blockade.

\section{Methods}

\section{Animals}

Adult SHR rats weighing $280-300 \mathrm{~g}$ were used. The rats were obtained from the breeding colonies of the central Animal Facilities of the Universiteit Maastricht. Experiments were performed according to the institutional guidelines, and were approved by the institutional animal ethics committee. After surgery, the animals were housed individually in cages, and were allowed normal rat chow and drinking water ad libitum. The animals were kept on a 12-hour lights-on/12-hour lights-off circadian rhythm in a climati- 


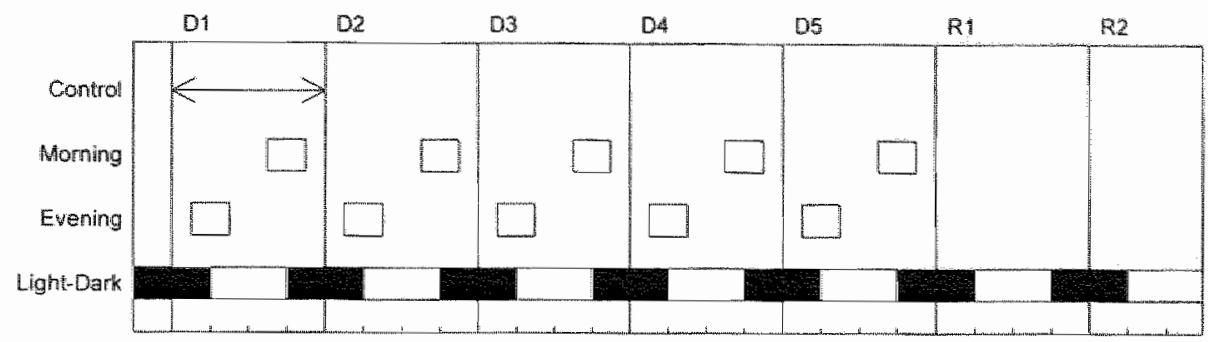

Time (h) $\quad 0 \quad 6 \quad 12 \quad 18 \quad 24$

Figure 7.1. Time line of the experimental protocol. The graph shows $l$ week of recording: 5 days of either saline or drug infusion (DI-DS) and 2 days of recovery (RI and R2). The synchonization in time with the lights-off (black bars) and lights-on (white bars) period is given by the light-daxk row. The bars in the row of Morning/Evening indicate the actual 6 hours periods at which the rats recened saline or the arug as a morning or evening dose. respectively.

sed room with constant temperature $\left(22^{\circ} \mathrm{C}\right)$ and humidity $(70 \%)$. Before the measurements, rats were accustomed to the light-dark cycle for at least one week.

\section{Surgery}

All rats were instrumented with an arterial catheter for measuring blood pressure and a venous catheter for administration of drugs as described in detail previously ${ }^{22}$. In short, the catheters were implanted via the femoral vessels and then tumnelled to the lower back of the animal under pentobarbital anaesthesia. The catheters were exteriorized through a $40 \mathrm{~cm}$ long steel spring which was fixed to the back muscles with a piece of silicone rubber. The venous catheter was filled with a heparinised saline solution ( 5 $U / \mathrm{ml}$ ). The steel spring was led to the outside of the cage, where the arterial catheter was connected via a hy draulic swivel (Model 375/20, Instech Labs, Plymouth Meeting, PA, USA) to a low-volume displacement pressure transducer (micro-switch, model 156PC 156WL, Honeywell, Inc, Amsterdam, the Netherlands). The arterial canula was kept patent by a continuous arterial infusion of heparinised saline solution ( $30 \mathrm{U} / \mathrm{ml}$ ) at a rate of $2.4 \mathrm{ml}$ per day. This setup allowed us to measure blood pressure continuously and to administer drugs whthout disturbing the rats, for periods lasting 5 weeks in general.

\section{Data acquisition}

After surgery, the animals were allowed at least 3 days of recovery to restore the circadian rhythmicity of haemodynamics. The measurements were done in the home cage of the animal. The arterial pressure transducer was connected to an amplifier that delivered a high-voltage signall to an analog-to-digital converter board (model 2814 , Data Translation, CN Rood, Rijswij, the Netherlands) mounted in an IBM compatible computer. The blood pressure signall was sampled at $512 \mathrm{~Hz}$. Beat-to-beat vallues of mean arterial pressure (MAP), heart rate (HR), and rate pressure product (RPP) as an index of oxygen consumption by the heart, were calculated on-line. All data were averaged every half hour and stored on computer disk for later analysis. 
Table 7.1 Baseline walues of wean arterial pressure, heari nate and rate pressure product

\begin{tabular}{|c|c|c|c|c|c|c|c|c|}
\hline & \multicolumn{3}{|c|}{ Evening Dose } & \multicolumn{5}{|c|}{ Morning Dose } \\
\hline & $n$ & $\begin{array}{l}\text { MAP } \\
(\mathrm{mmHg})\end{array}$ & $\begin{array}{l}\text { Mre } \\
\left(\mathrm{minn}^{-1}\right)\end{array}$ & $\begin{array}{l}\operatorname{RPP}\left(10^{3}\right. \\
\text { mmHgrmin }\end{array}$ & $n$ & $\begin{array}{l}\text { MAP } \\
\text { (mmHg) }\end{array}$ & $\begin{array}{l}H R \\
\left(\min ^{-1}\right)\end{array}$ & $\begin{array}{l}\operatorname{RPP}\left(10^{3}\right. \\
\left.\mathrm{mmHg} \min ^{-1}\right)\end{array}$ \\
\hline Captopril 3 & 9 & 14944 & $314 \pm 9$ & $46.7 \pm 1.3$ & 8 & $149 \pm$ & $338 \pm 7$ & $50.6 \pm 1.1$ \\
\hline Captopril 10 & 8 & 15042 & $312 \pm 7$ & $47.1 \pm 1.1$ & 10 & $151 \pm 4$ & $318 \div 7$ & $48.2 \pm 1.0$ \\
\hline Captopril 30 & 9 & $1.51+4$ & $313 \pm 8$ & $47.5 \pm 1.1$ & 8 & $145 \pm 3$ & $318 \pm 7$ & $46.4 \pm 1.3$ \\
\hline Enalaprilat & 8 & $142 \pm 5$ & $341 \pm 7$ & $49.0 \pm 2.5$ & 8 & $144 \pm 3$ & $319 \pm 7 *$ & $46.3 \pm 1.4$ \\
\hline Lostartan & 8 & $141 \pm 4$ & $344 \pm 5$ & $48.7 \pm 1.6$ & 8 & $141 \pm 3$ & $317 \pm 6^{*}$ & $44.8 \pm 1.3$ \\
\hline Lisinopri & 6 & $154 \pm 5$ & $32 \| \pm 4$ & $49.5+1.2$ & 7 & $152 \pm 5$ & $322 \pm 3$ & $49.0 \pm 1.1$ \\
\hline
\end{tabular}

Walues are 24-h averages over the first control day. Values are expressed as means $\pm S E M$. $M A P$, mean arterial pressure; $H R$, heart rate; $R P P$, rate pressure product. * $P<0.05$ morning ws evening dose.

\section{Protocols}

Each experiment lasted one full week, during which MAP, HR, and RPP were continuously measured. The design of the protocol is summarized in Figure 7.1. One group of SHR was treated on five consecutive days during the transition from the light to dark period. The infusion of the drug was started 3 hours before the lights went off and was maintained for 6 hours. In parallel with the human situation, this period was defined as the morning dose, since the agents were given during the transition from sleep to activity in the rats. In the other group of SHR the agents were infused five days for 6 hours during the transition from the light to dark period, starting 3 hours before lights on. This infusion period was defined as the evening dose. After a five days treatment period, measurements of MAP, HR, and RPP were continued for 2 days to record the effects of withdrawal of the agent. In each animal a time control experiment was per formed consisting of a 5 day repeated infusion of $0.9 \% \mathrm{NaCl}$ at a rate of $2.4 \mathrm{ml}$ 6 hours either during the morning or evening period followed by 2 days of recovery, The volume of the infused fluid ( $2.4 \mathrm{ml} / \mathrm{day})$ is not likely to influence haemodynamics regarding the fact that adult rats crink about $30 \mathrm{ml}$ of water daily. The order of such a 7 days experiment with an antihypertensive agent or with saline was randomized in each rat.

Using this protocol, the following sets of experiments were conducted. Captopril infusions were performed as a moming and evening dose at $3 \mathrm{mg} \cdot \mathrm{kg}^{-4} .6 \mathrm{~h}^{-1}, 10 \mathrm{mg} \cdot \mathrm{kg}^{-1} \cdot 6$ $\mathrm{h}^{-4}$, and $30 \mathrm{mg} \cdot \mathrm{kg}^{-1} .6 \mathrm{~h}^{-1}$. Enalaprilat was infused as a morning and evening dose at 0.3 $\mathrm{mg} \cdot \mathrm{kg}^{-1} \cdot 6 \mathrm{~h}^{-1}$. Lisinopril was infused as a moming dose at $0.1 \mathrm{mg} \cdot \mathrm{kg}^{-1} \cdot 6 \mathrm{~h}^{-1}$ given at the morning period. In addition, lisinopril was administered as an equivalent dose dissolved in the drinking water. Losartan was infused as a moming and evening dose at 10 mg. $\mathrm{kg}^{-1}$. If possible multiple agents were infused in one rat. Treatment was however not commenced before the blood pressure level had returned to control values. 


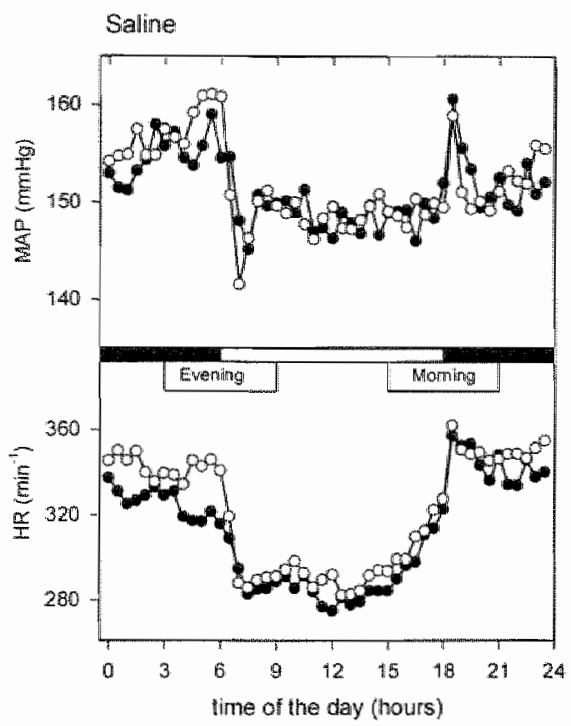

Figure 7.2. Comparison of average paterns of nean arterial presswe (MAP) and heart rate (HR) in SHR during a 6 ll infision of salme $\left(0.9 \% \mathrm{NaCl}_{2} 2.4 \mathrm{ml}\right.$ ) durimg the morming ( $m=33$, open circles) and evening $(n=31$, closed circles) period. The dart bars denote the lights-of period of the day.

\section{Data analysis}

Recordings were made for 7 full days. The beginning of day 1 was defined at halfway the lights-off or dark period at which the first infusion was given (Figure 1). For each day of treatment averages of MAP, MR and RPP were calculated every 30 minutes. The antihypertensive efficacy was calculated as the absolute difference of MAP, HR, and RPP in each 30 minute period with the values obtained during the saline infusion in the same rat. The average blood pressure lowering effect over a complete day was calculated as the average value of 48 half-hour differences in each day. To obtain a measure for the duration and stability of the antihypertensive efficacy, three parameters were calculated additionally. As a first parameter we calculated the maximal amplitude of the circadian rhythm of MAP by subtracting the lhalf-hour minimum value in each day from the half-hour maximal value in each day. As a second parameter the MAP difference between the light and dark period was calculated by subtracting the average 12-h value of MAP during the light period from the average 12-h value during whe datk period. For each infusion day a trough-to-peak ratio of MAP was calculated as the quotient of the average MAP value in the hour preceding the next infusion (trough) and the maxinum reduction of MAP on 3 consecutive half hour valtues in the $24-$ h period after the start of the infusion (peak). The within animal variability of this parameter was determined as the coefficient of variation over the trough-to-peak values obtained on days 3,4 and 5 of treatment. Since the latter was very high, the trough-to-peak value was also computed from group averages of the trough and peak effects in blood pressure.

\section{Drugs}

Captopril was purchased from Sigma Chemicals, Axel, The Netherlands. Enalaprilat and lisinopril and losartan were kindly donated by Merck Sharp and Dohme, Haarlem, The Netherlands. All agents were dissolved in saline and frozen in small aliquots before use. 

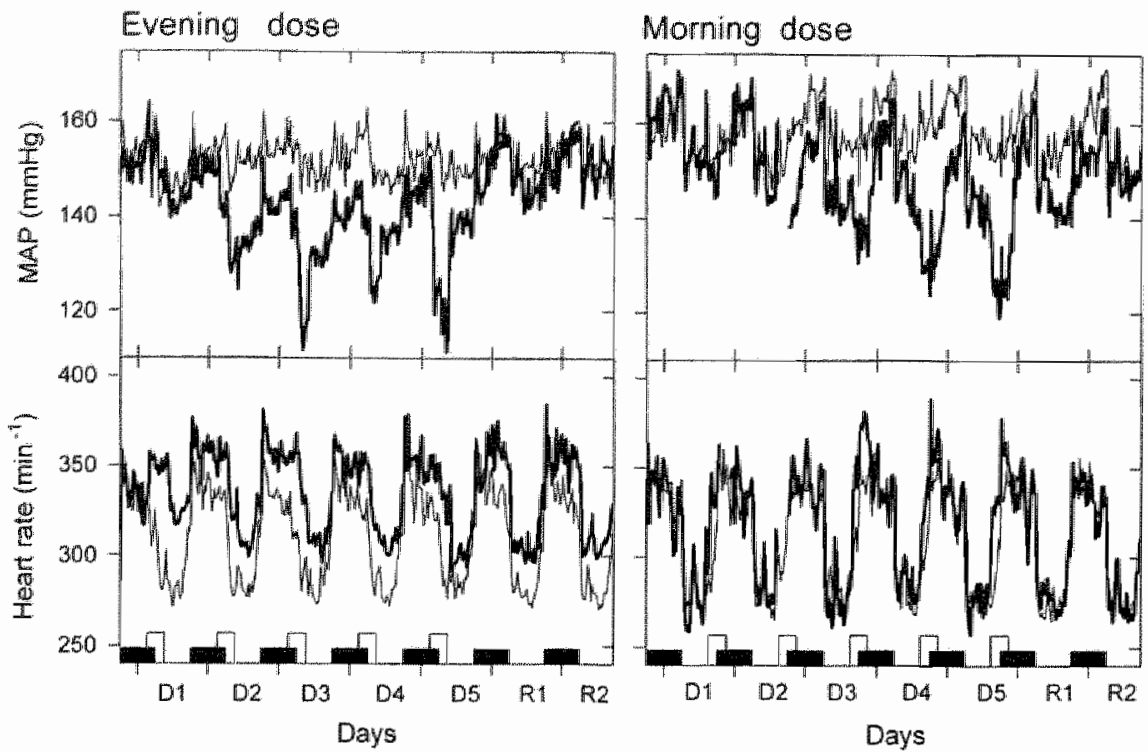

Fignare 7.3. Patterns of mean arterial pressure (MAP) and heart rate (HR) during the 5 days of treatment (D 1-D5) with captopril $10 \mathrm{mg} \cdot \mathrm{kg}^{\prime} .6 \mathrm{~h}^{-4}$ as an evening dose (lef panel) and as a morning dose (right panel). The effects upon withdrawal of capropril are also shown ( $R$ I and R2). Values are group averages obtained dwing the infusions of saline (thin line) and during captopril (thick lime). The number of animals in each grotp is given in Table 7.1. For reasons of clarity the SEM is not shown. The closed bars denote the lights-aff period of the day. The 6 th infusions were given during the periods denoted by the open bars.

\section{Statistics}

Statistical evaluation was performed by analysis of variance (ANOVA). Haemodynamic effects occurring over time during saline or drug infusion in each rat were defined as a within factor. Differences between the effects caused by a morning dose and an evening dose as well as differences in effects between agents were compared as between factors. Data obtained during the first two days of treatment were not included into the analysis because of possible run-in effects of the drugs. Only average values found at days 3, 4, and 5 of treatment were included in the evaluation. Differences between drugs were tested by ANOVA followed by a post-hoc Scheffe" 's T-test. Statistical significance was accepted at $\mathrm{P}<0.05$.

\section{Results}

\section{Baseline haemodynamics}

Baseline haemodynamic values of MAP, HR, and RPP are compared between groups of rats in Table 7.1. The baseline values were defined as the average $24-\mathrm{h}$ values of MAP, HR, and RPP during the first day of intravenous saline infusion. The table shows that these values of MAP, HR and RPP were not different between the group of rats which received saline during the moming period and the groups of rats which 


\section{Captopril $10 \mathrm{mg} \cdot \mathrm{kg}^{* 11}$}

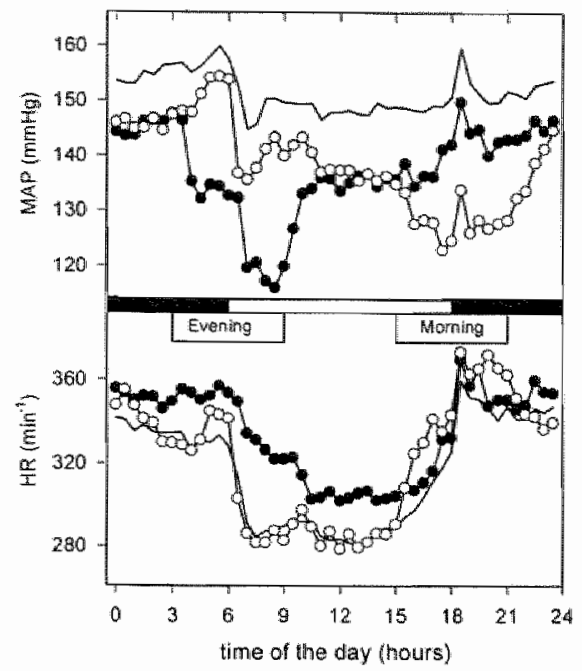

Figure 7.4. Effects of tratment with copotopril $\left(10 \mathrm{mg} \cdot \mathrm{kg}^{-1}\right)$ on mean arrerial pressire (MAP) and heart rate (HR) over a fill 24 -hour perad. SHR were infused either during the mornting (open circles) or evening period (closed circles). Values are means over doy 3.5 of treatment. The values abrained dwing the saline infusions were averaged over the morming and evering groups (srraght limes) The number of animals in ench group is given in Table 7.1. The closed bars denote the lights-of peniod of the doy.

received saline during the evening period. Only between the groups of rats which were treated with $3 \mathrm{mg} \cdot \mathrm{kg}^{\circ} .6 \mathrm{~h}^{-4}$ captopril a slight but significant difference in the baseline values of HR was found.

In all groups, the five-day repeated infusion of $2.4 \mathrm{ml}$ saline solution in 6 hours did not alter the 24-h pattern of blood and heart rate. As shown in Figures 7.2 and 7.3, the circadian profile of MAP and HR remained unaltered for the 7 clay control period when saline was infused during the morning or evening period. Stability of the haemodynamics during the week of saline infusions was assessed in all groups by ANOVA with time as a within factor. The analysis revealed that in none of the groups MAP and HR were significantly different between the days of the week.

For better understanding of the 24-h blood pressure patterns during timed antihypertensive treatment it is necessary to describe in detail the 24-h MAP and HR profiles during saline infusion. As shown in Figure 7.2 the 24h HR pattern shows a bimodal distribution with high values during the dark period, and low values during the light period. Highest values of HR are found during the transition from the light to the dark period, when the rats become active. The 24-h MAP pattern shows a more gradual increase in blood pressure throughout the day, starting in the light period and showing the highest blood pressure at the end of the dark period (Figure 7.2). During the transition from the light to dark period mostly a sharp peak occurs. During antihypertensive treatment, these 24-h patterns of MAP and HR are generally preserved and visible on top of the effects induced by the agents.

\section{Time-related effects of treatment with captopril}

The time-related effects during the five-day treatment with captopril $10 \mathrm{mg} \cdot \mathrm{kg}^{-1} \cdot 6$ $\mathrm{h}^{-3}$ are summarized in Figure 7.3. In both experiments the antihypertensive properties of captopril showed increasing efficacy over the ensuing days of treatment with only a small reduction in blood pressure occurring during the first infusion, and more than 30 $\mathrm{mmHg}$ during the infusion of captopril at day 5 . This effect was more pronounced when 


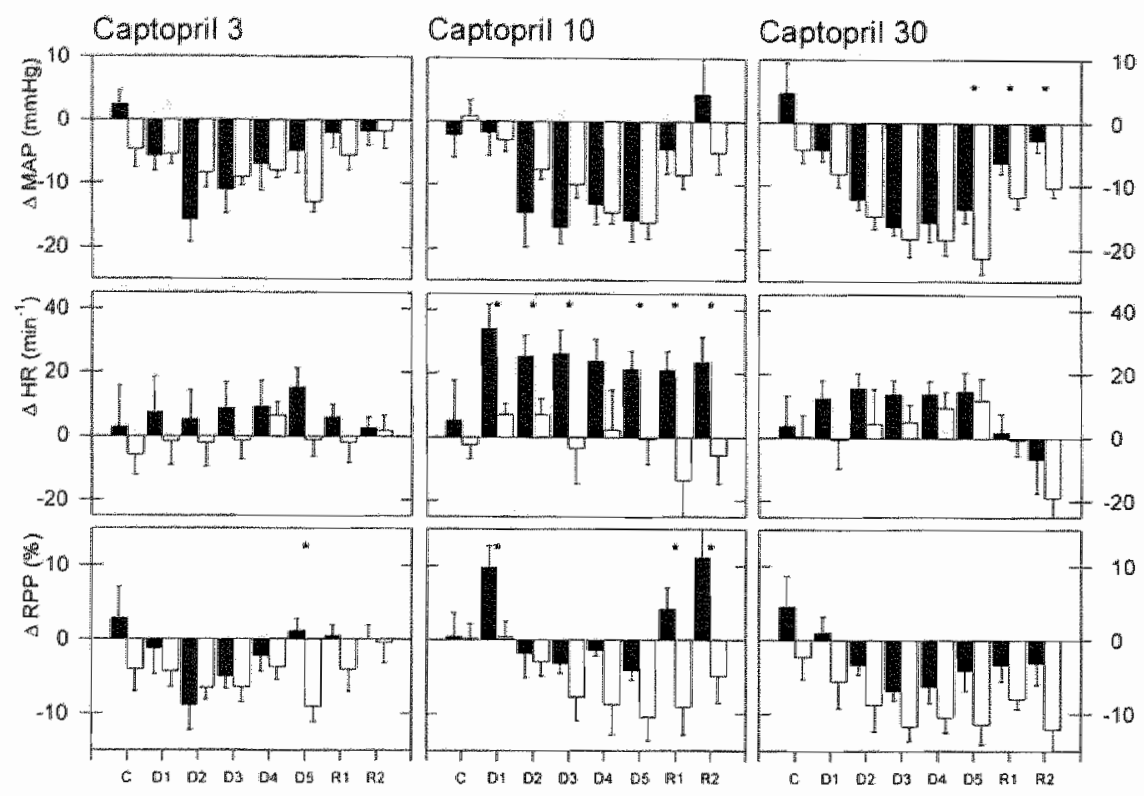

Figure 7.5. Comparisan of $24-1$ differences (drug versus saline) in mean arterial pressure (MAP), heart rate (HR) and rafe pressure product (RPP) durimg the five day treament (DI-

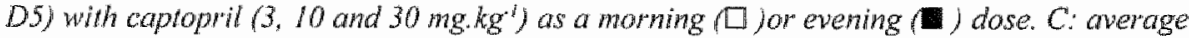
walues during the 6 h before the start of day I. RI, R2. values during the wo days of recovery (see figure 7. 1). Values are means \pm SEM.* $P<0.05$ morning versus evening dose.

captopril was given as a morning close than as an evening dose, in which case a full antihypertensive effect was obtained at the third day of infusion. As summarized in Figures 7.4 and 7.5 , the average reduction in blood pressure over day 3 to 5 of infusion was not different when the $10 \mathrm{mg}$ dose of captopril was infused in the evening or in the moming period. However, the 12-h phase difference between the infusion periods had a pronounced differential effects on the circadian profiles of MAP. As shown in the Figures 7.3 and 7.4, the evening dose of captopril lowered the peak of MAP which normally occurred at the end of the dark period, and when the lights went on, MAP declined further. The morning dose of captopril blunted the rise of blood pressure in the transition from the light to dark period. After cessation of the $6 \mathrm{~h}$ infusion with captopril, MAP revurned rapidly to levels not far from control. Reflex tachycardia was significantly greater when captopril $10 \mathrm{mg} \mathrm{kg}^{-1}$ was given as the evening dose than when given as the morning dose (Figure 7.4 and 7.5). Consequently, also the fall in RPP was signiticantly greater for the morning dose than evening dose of captopril $10 \mathrm{mg}$ (Figure $7.5)$.

The result of this pharmacodynamic behaviour of captopril is that the 24-h maximal amplitude of MAP significantly increased from about $32 \mathrm{mmHg}$ during the saline infusion to $44 \mathrm{mmHg}$ during the captopril $10 \mathrm{mg} \cdot \mathrm{kg}^{-1} .6 \mathrm{~h}^{-1}$ infusions (Table 7.2). The increase in circadian amplitude was comparable for the evening and moming dose of captopril $10 \mathrm{mg} \cdot \mathrm{kg}^{-1} .6 \mathrm{~h}^{-1}$. Secondly, because of the 12 -h phase shift between the infusion periods the differences between the averages of MAP during the 12-h dark and 12- 
Table 7.2. Maximal amplinde of the 24 -h blood pressure wariation

\begin{tabular}{|c|c|c|c|c|c|c|}
\hline & \multicolumn{3}{|c|}{ Evening Dose } & \multicolumn{3}{|c|}{ Morning Dose } \\
\hline & $\mathrm{n}$ & $\begin{array}{l}\text { Control } \\
(\mathrm{min} H \mathrm{H})\end{array}$ & $\begin{array}{l}\text { Treatment } \\
\text { (mmHg) }\end{array}$ & in & $\begin{array}{l}\text { Controt } \\
\text { (mmHg) }\end{array}$ & $\begin{array}{l}\text { Treament } \\
(\mathrm{mmH})\end{array}$ \\
\hline Captopril 3 & 9 & $34 \pm 2.9$ & $35 \pm 3.0$ & 8 & $31 \pm 1.1$ & $39 \pm 1.9^{4}$ \\
\hline Capiopril 10 & 8 & $31 \pm 2.3$ & $44 \pm 3.4 *$ & 10 & $33 \pm 2.0$ & $45 \pm 3.0^{*}$ \\
\hline Captopril 30 & 9 & $33 \pm 2.6$ & $42 \pm 2.4^{*}$ & 8 & $38 \pm 2.2$ & $48 \pm 1.9^{*}$ \\
\hline Enalaprilat & 8 & $32 \pm 1.6$ & $35 \pm 1.8$ & 8 & $37 \pm 2.5$ & $39+2.8$ \\
\hline $\begin{array}{l}\text { Losartan } \\
\text { Lisinopril }\end{array}$ & $\begin{array}{l}8 \\
6 \\
\end{array}$ & $\begin{array}{l}33 \pm 2.1 \\
37 \pm 1.3 \\
\end{array}$ & $\begin{array}{l}34 \pm 2.7 \\
36 \pm 2.2^{4}\end{array}$ & $\begin{array}{r}8 \\
7 \\
\end{array}$ & $\begin{array}{l}37 \pm 2.8 \\
35 \pm 1.9 \\
\end{array}$ & $\begin{array}{l}35 \pm 1.3 \\
47 \pm 3.3 * 1 \\
\end{array}$ \\
\hline
\end{tabular}

Walues are the average (over days 3-5) difference between the minimam and maximum 30 min value of MAP occurring during 24 hours. Recordings were nade daring saline infusions (control) and dwing treament. Vahes are expressed as means s. SEM. ": lisinopril in ariwhing water; *. $P<0.05$ trearment ws combol: $t: P<0.05$ moming ws. evening dase.

Table 7.3. Blood pressure difference between 12-h lights-off and 12-h lights-on period.

\begin{tabular}{|c|c|c|c|c|c|c|}
\hline & \multicolumn{3}{|c|}{ Evening Dose } & \multicolumn{3}{|c|}{ Morning dose } \\
\hline & $n$ & $\begin{array}{l}\text { Control } \\
(\mathrm{mmHg})\end{array}$ & $\begin{array}{l}\text { Treatment } \\
(\mathrm{mmHg})\end{array}$ & n & $\begin{array}{l}\text { Control } \\
(1 \mathrm{~m} m \mathrm{Hg})\end{array}$ & $\begin{array}{l}\text { Treatment } \\
(\mathrm{mm} H \mathrm{~g})\end{array}$ \\
\hline Captopril 3 & 9 & $3.2 \pm 1.3$ & $6.0 \pm 0.8^{*}$ & 8 & $5.0 \pm 0.8$ & $3.3 \pm 0.7 *$ \\
\hline Captopril 10 & 8 & $4.9 \neq 0.7$ & $10.3 \pm 1.0^{*}$ & 10 & $5.3 \pm 1.0$ & $2.8 \pm 1.1 t$ \\
\hline Captopril 30 & 9 & $4.5 \pm 0.5$ & $9.9 \pm 0.8^{*}$ & 8 & $1.6 \pm 1.0$ & $-3.1 \pm 0.6^{*}+$ \\
\hline Enalaprilat & 8 & $5.5 \pm 1.2$ & $6.9=0.9$ & 8 & $1.5 \pm 1.0$ & $-0.5 \pm 1.5$ \\
\hline Losartan & 8 & $4.2 \pm 1.4$ & $8.9 \pm 0.9 *$ & 8 & $3.1 \pm 1.1$ & $1.6+1.5^{n+1}$ \\
\hline Lisinopril & 6 & $6.0 \pm 0.6$ & $6.7 \pm 1.0^{12}$ & 7 & $5.8 \pm 0.5$ & $-1.6 \pm 1.1 *$ \\
\hline
\end{tabular}

Values are the average difference (over day -5) of the 12-h lights-of and $12-h$ lights-on period. Values are expressed as means $5 E M$. "Visinopril in drinking water: * $P<0.05$ treamen ws control: $\gamma: P<0.05$ marning vs evening dose.

Table 7.4. Average walses and Between day variability of thowgh-fo-peak raijos.

\begin{tabular}{|c|c|c|c|c|c|c|c|c|}
\hline \multirow{3}{*}{ Captopril 3} & \multicolumn{4}{|c|}{ Evening Dose } & \multicolumn{4}{|c|}{ Morning Dose } \\
\hline & \multicolumn{3}{|c|}{ ind ividually } & \multicolumn{2}{|l|}{ group } & \multicolumn{2}{|c|}{ individually } & $\begin{array}{l}\text { Tip (\%) } \\
\text { group }\end{array}$ \\
\hline & 9 & $27+13$ & $131 \pm$ & 70 & 8 & $29 \pm 11$ & 87 & 44 \\
\hline Captopril 10 & 8 & $18 \pm 7$ & $126 \pm 47$ & 28 & 10 & $48 \pm 5 t$ & & 52 \\
\hline Captopril 30 & 9 & $30 \pm 3$ & $110 \pm 37$ & 40 & 8 & $34 \pm 7$ & 85 & 37 \\
\hline Enalapriat & 8 & $20 \pm 13$ & $89 \pm 19$ & 37 & 8 & $24 \pm 11$ & $264 \pm 97$ & 43 \\
\hline Losartan & 8 & $27 \pm 7$ & $142 \pm 77$ & 30 & 8 & $53 \pm 8+$ & $62 \pm 18$ & 88 \\
\hline Lisinopril & & not appli & cable. & & 7 & $35 \pm 3$ & $101 \pm 27$ & 45 \\
\hline
\end{tabular}

The trowgh-ro-peak (T/P) ratio was calculated in 2 was. First it was calculated as the anerage value over day 3-5 of treatment in each individual rat. The variability in thits measure is show as the coefficient of variation ( $C W$ ). For a comparison $T / P$ ratio s were calculated from the group averages of peak and trough effects over days 3 to 5 . Values are expressed as meantSEM. $\rightarrow: P<0.05$ morning vs evening dose. For the evening dose of lisinoprit no TP peak ratio was calculated since the drug was administered via the drinking water: 


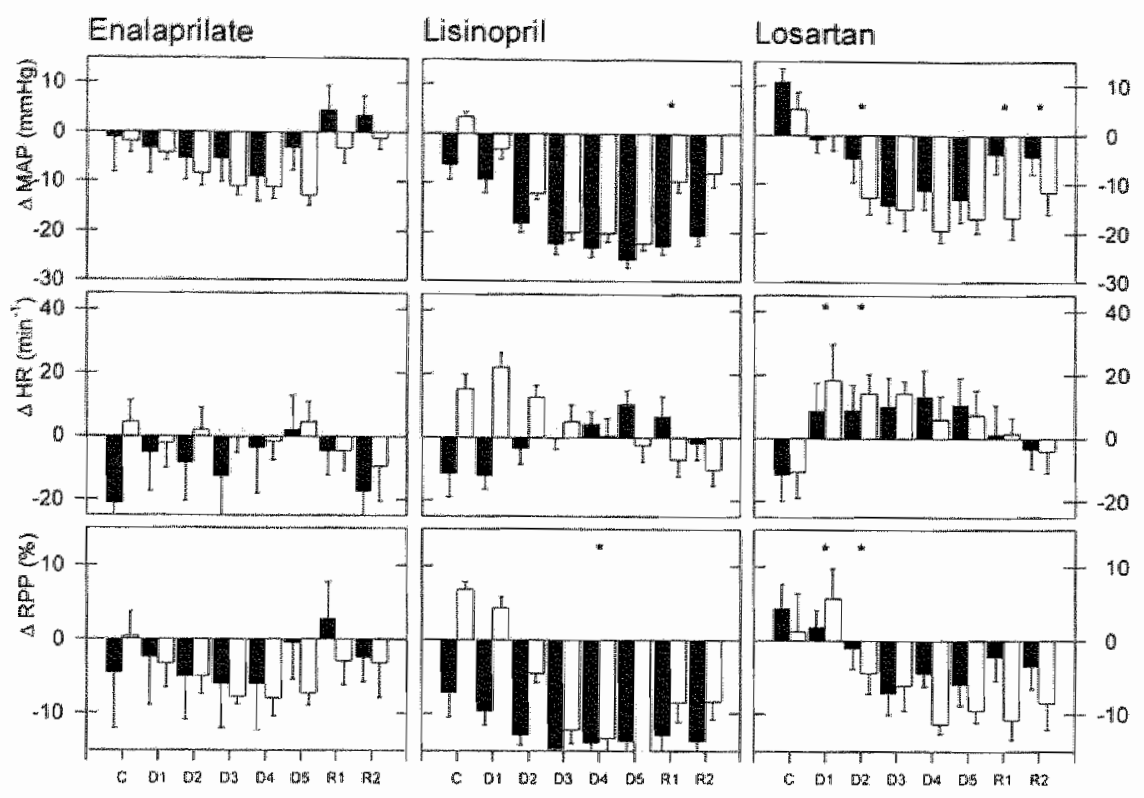

Figure 7.6. Comparison of 24 -h differences (drug versus saline) in mean arterial pressure (MAP), hear rate (HR) and rate pressure product (RPP) during the five day treatment (DID5) with enalaprilat $\left(0.3 \mathrm{mg} \cdot \mathrm{kg}^{-1}\right)$, lisinopril $\left(0.1 \mathrm{mg} / \mathrm{kg}^{-1}\right)$, and losartan $\left(10 \mathrm{mg} \mathrm{kg}^{-1}\right)$ as a morning ( $\square$ jor evening ( ) dose. $C$ : average values during the 6 h before the start of day 1 . $R I, R 2$ : values during the two days of recovery (see figure 7.1). Values are means \pm SEM. $P$ $<0.05$ morning versus evering dose.

$\mathrm{h}$ light period vary too. As shown in Table 7.3, the mean dark-light difference during saline was about $5 \mathrm{mmHg}$. During captopril treatment this difference increased to 10 $\mathrm{mmHg}$ when the infusions were given during the evening period, but fell to $3 \mathrm{mmHg}$ when the infusions were given in the morning period.

The above described effects of captopril $10 \mathrm{mg} \cdot \mathrm{kg}^{-1} .6 \mathrm{~h}^{-1}$ were dose-dependent, being smaller and greater when the dose of captopril was $3 \mathrm{mg} \cdot \mathrm{kg}^{-1} .6 \mathrm{~h}^{-1}$ and $30 \mathrm{mg} \cdot \mathrm{kg}$ $1.6 \mathrm{~h}^{-1}$, respectively. The data obtained with these doses are summarized in the Tables 7.2-7.4 and Figure 7.5.

After cessation of the last infusion of captopril, MAP returned to near control values during the dark period on day 6 . Then, when the lights went on MAP fell again below control on day 6 although no drug was infused. This effect was absent on day 7 , the second day of withdrawal.

\section{Time-related effects of enalaprilate}

Following treatment with enalaprilate, there was a progressive lowering of MAP over the days, reaching stability after 3 days of infusion (Figure 7.6). The average circadian patterns obtained during the evening and morning infusion with enalaprilat are given in Figure 7.7. The average reductions of blood pressure and increments of heart rate over days 3-5 of treatment were not different for the evening and moming regimen, although there was a tendency for blood pressures being lower during the 

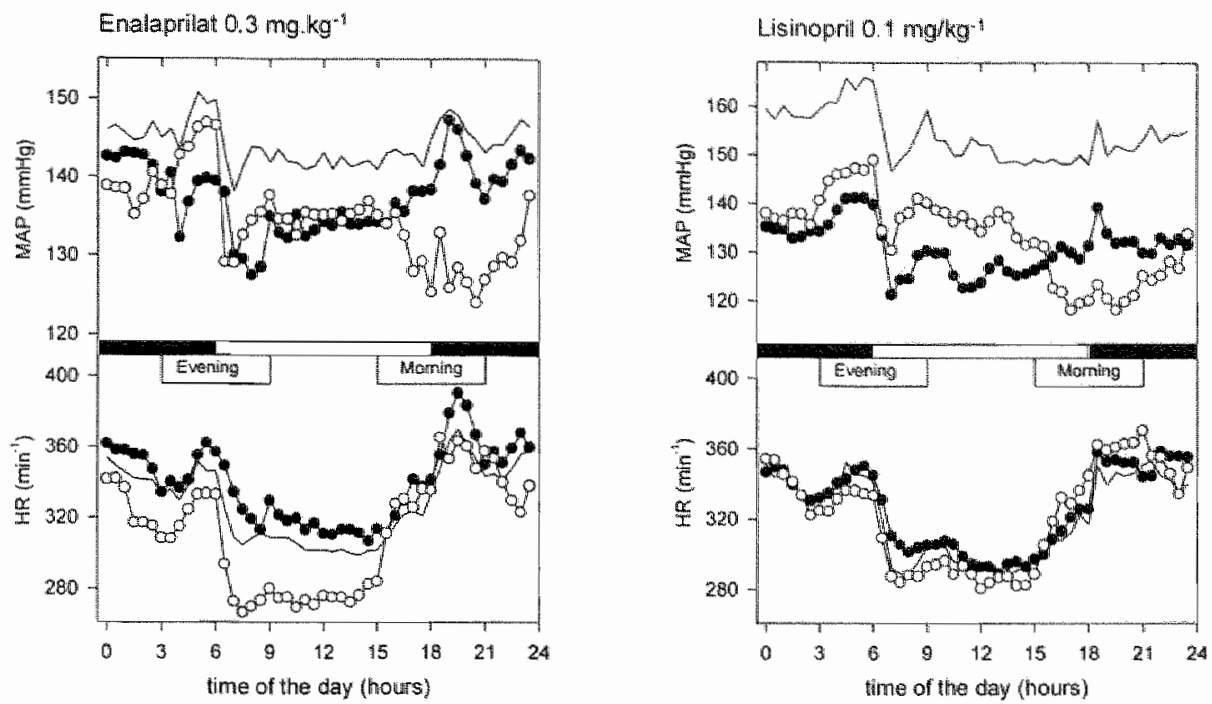

Figure 7.7. Effects of treatment with enalaprilat $\left(0.3 \mathrm{mg} . \mathrm{kg}^{\prime}\right)$ on mean arterial pressure (MAP) and heart rate (HR) over a full 24-hour period. SHR were infused either during the morning (open circles) or evening period (closed circles). Valves are means over day 3 -5 of treatment. The values obtained during the saline infusions were averaged over the morning and evening groups (stroight lines). The muber of animals in each group is given in Toble 7.1 . The closed bars denote the lights-aff period of the day.

Figure 7.8. Effects of treatment with lisinopril ( $\left.0.1 \mathrm{ng} \cdot \mathrm{kg}^{-1}\right)$ on mean arrerial pressure (MAP) and heart rate (HR) over a full 24 -hour period. SHR were infused either during the morning (open circles) or lisinopril was given in equivalent doses in the drinking water (closed circles). Values are means over day 3-5 of treatment. The values oblained during the saline infusions (respectively, water drinking) were averaged over the morning and evening groups fstraight lines) The number of amimals in each group is given in Table 7.I. The closed bars denote the lights-off period of the day.

morning regimen and reflex tachycardia being greater when the evening dose was applied. The circadian amplitude of MAP did not change during treatment with enalaprilate (Table 7.2). Differences between the 12 -h dark and 12-h light period were smaller (nearly significantly $P<0.1$ ) when enalaprilate was given as a morning than when it was given as an evening dose (table 7.3 ).

\section{Time-related effects of lisinopril}

In one group of SHR, lisinopril was infused for 5 days in the morning period and in the other it was given in the drinking water for 5 days. During both treatment schedules blood pressure reductions reached a plateau on day 3 of the experiment. The average decrease of $24 \mathrm{~h}$ blood pressure values during days 3 to 5 was not different between these two groups (Figure 7.6). However, as shown in Figure 8, the greatest protection during the early moming hours in the rat was obtained with the moming infusion rather than when lisinoprill was taken via the drinking water. Heart rate was not significantly altered cluring both treatment regimens (Figure 7.8). With the morning dose of lisinopril, the maximal amplitude increased (Table 7.2), whereas the difference 


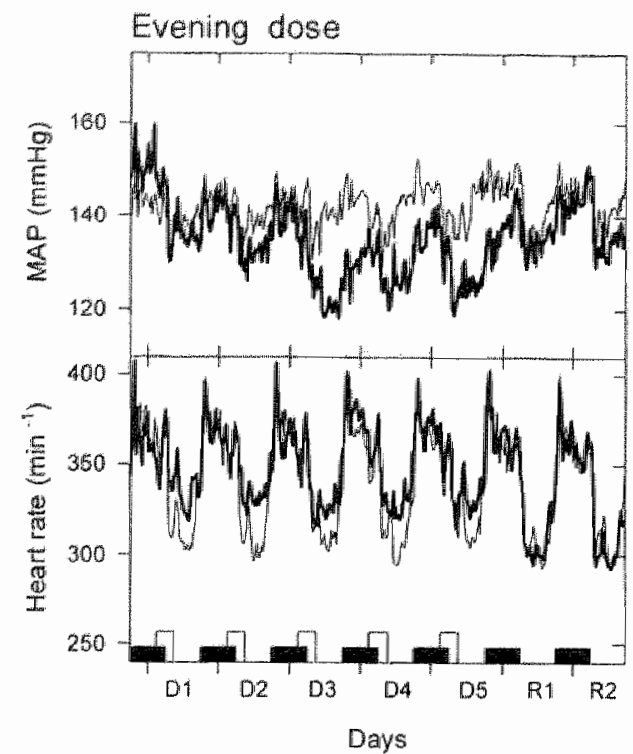

Morning dose

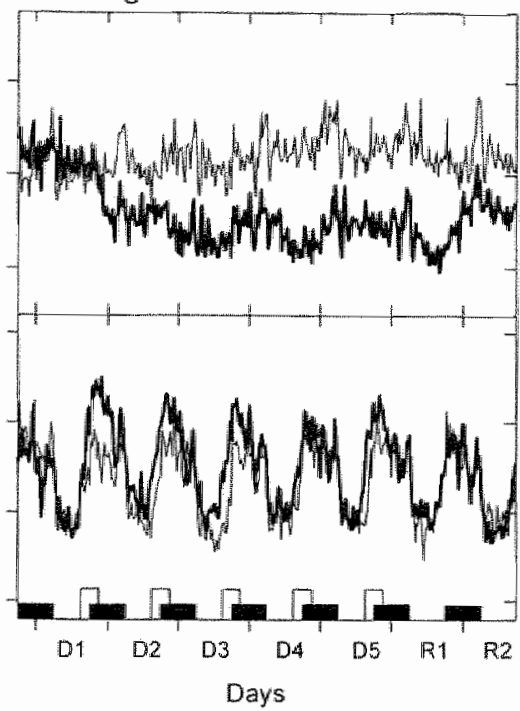

Figure 7.9. Patterns of mean arierial pressure (MAP) and hear rate (HR) dwring the 5 days of treament (Di-D5) with losartan $10 \mathrm{mg} \cdot \mathrm{kg}^{-1} .6 \mathrm{~h}$ as an evening dose (left panel) and as a morning dowe (right panel). The effects upon whthdrowal of losartan are also shown (RI and R2). Vatues are group averages obrained during the infusions of saline (thin line) and during losartan (hick line). The mumber of animals in each group is given in Table 7.l. For reasons of clarity the SEM is not shown. The closed bats denote the lights-off period of the day. The $6 \mathrm{~h}$ infusions were given during the periods denoted by the open bors.

between the dark and light period became significantly smaller (Table 7.3). These parameters remained unchanged when lisinopri] was given in the drinking water.

\section{Time-related effects of losartan}

As with captopril, enalaprilate, and lisinopril the blood pressure lowering effect of this agent increased during the days of treatment reaching stability at day 3 (Figures 7.6 and 7.9). During both treatment regimens the average daily reduction in MAP was about $15 \mathrm{mmHg}$. As shown in Figure 7.9 and 7.10 , the main antihypertensive effect of losattan was not confined to the infusion period as with captopril and enalaprilate, but lasted much longen: Especially with the morning dose the 24-h blood pressure patterns remained relatively flat and the rise in blood pressure was blunted during the transition from the light to dark period. Table 7.3 indicates that the average difference of MAP between the dark and light period was signilicantly smaller for the morning than for the evening dose. The circadian anplitude of MAP was not significantly altered from the values obtained during saline (Table 7.2).

Losartan did not influence heart rate significantly. The higher values of HR following the evening dose are the consequence of thigher baseline values of $H R$ in this group (Table 7.1). The average reduction in RPP tended to be greater for the morning than for the evening dose (Figure 7.6). 


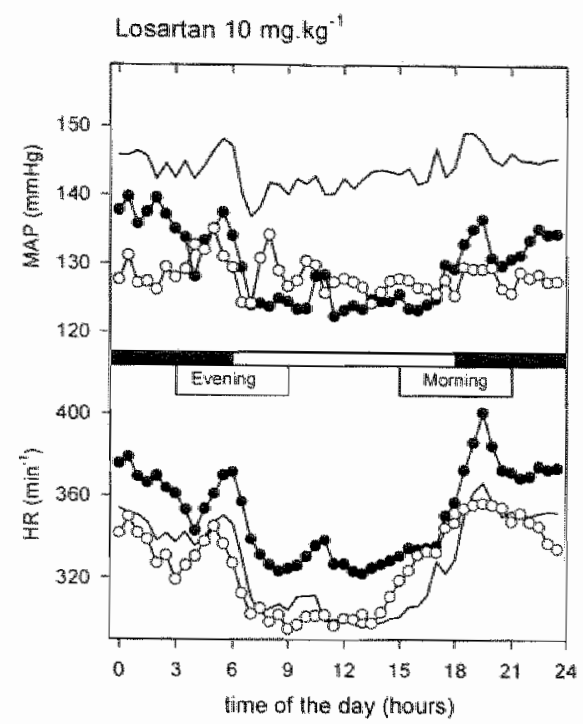

Figure 7 . 10. Effects of treatment wh losarian $\left(10 \mathrm{mg} \mathrm{kg}^{\prime}\right.$ ) an mean arterial pressme (MAP) and hearl rate (HR) over of full 24 -how pertod. SHR weve infused either during the worning (open cincles) or evening period (closed cincles). Values are means over doy $3-5$ of irectment. The values obtained dwing the saline infustons were averaged over the morning and evening groups (straigh lines). The number of animals in each growp is given in Table 7.1. The closed bars devote the lights-off period of the doy.

\section{Comparison of averaged effects over all treatment groups}

We compared the overall efficacy of treatment during the morning period with treatment during the evening period by averaging the data over each subgroup. Following the analysis of variance, the decrease in RPP was significantly more pronounced when agents were given in the morning period $(-8.7 \pm 0.9 \%)$ than in the evening period $(-4.1 \pm 1.2 \%, P=0.003$, Figures 7.5 and 7.7$)$. Averaged 24 -h reductions in MAP and averaged changes in HR were not different between the morning and evening dosing regimens. Through-to-peak ratio's are compared in Table 7.4. These ratio's were significantly higher when captopril $10 \mathrm{mg} . \mathrm{kg}^{\prime}$ and losartan were given as a morning than evening dose. In general the values were not higher than $50 \%$. The within animal variability in the trough-to-peak ratio, expressed as the coefficient of variation, was in all groups about $100 \%$. To reduce the variability we calculated the trough-to-peak ratio also from the average trough and peak values of blood pressure in each group. In this case, the trough-to-peak ratio's were about $15 \%$ higher. Upon withdrawal of all agents rebound hypertension was never observed.

\section{Discussion}

The main finding of this study is that with timed administration of inlribitors of the renin-angiotensin system the circadian blood pressure rhythm of SHR can be modulated to reduce the early morning blood pressure surge. Although, in general, the average reduction over 24 hours was not different between the morning or evening treatment regimen, the blood pressure patterns were different between the two regimens during specific periods of the day. With the morning dose differences between day-night blood pressures were smaller than with the evening dose, whereas with the latter regimen often reflex tachycardia occurred during the sleeping period. The rate pressure product, an index of cardiac oxygen consumption, was lower following the 
morning than evening dose. With the short-term acting agents captopril and enalaprilat, blood pressure returned at the end of the daily dosing interval to control levels, whereas this effect was less pronounced following the long-term acting agents lisinopril and losartan. Upon withdrawal of all agents, blood pressure retumed gradually to control Rebound hypertension was never observed.

\section{Run-in effects, pharmacokinetic and pharmacodynamic mechanisms.}

One of the remarkable findings of the present study is that the blood pressure lowering effect increased when the ACE inhibitors and losartan were administered repeatedly over 5 days. It may be common knowledge that upon starting antihypertensive treatment so-called run-in effects occur. Especially in the design of clinical studies one accounts for such effects, however, this is the first time that they are shown to occur in rats. In general, in SHR, stable blood pressure reductions were obtained after the third dosing interval. The only exception to this was the repeated morning infusion of $10 \mathrm{mg} \cdot \mathrm{kg}^{-1}$ of captopril. In this case, the antihypertensive effect increased over all days of treatment (Figure 7.3). The latter effect was not drug or dose-dependent since stable effects were reached after 3 days with the 3 and $30 \mathrm{mg} . \mathrm{kg}^{-1}$ dose of captopril. Several mechanism may account for the increasing efficacy over days of treatment. For the agents with a longer half life, such as lisinopril and losartan, it is reasonable to assume that the degree of $\mathrm{ACE}$ inhibition and $\mathrm{AT}$,-receptor blockade, respectively, increases over the days due to accumulation of the drug or its active metabolites. For a short-acting agent like captopril, it seems rather unlikely that this occurs because then the average reduction in blood pressure on the first day of infusion should be much greater for the $30 \mathrm{mg} \cdot \mathrm{kg}^{-8}$ than for the $3 \mathrm{mg} \cdot \mathrm{kg}^{-1}$ dose. The plasma half life of captopril and the terminal half life of the enzyme inhibitor complex are shorter than 2 hours ${ }^{28}$. Consequently the amount of plasma ACE inhibition after 24 hours is probably minimal, which could be the explanation that blood pressure returned to near control values at the end of each dose interval. For both enalaprilat and lisinopril the terminal half tife of the enzyme inhibitor complex is much longer (about $30 \mathrm{~h}$ ). Nonetheless, also for enalaprilat blood pressure returned close to control values at the end of each dose interval. Other factors such as differences in tissue penetration and deposition or differences in paracrine or autocrine actions, may explain this between drug variability.

Irrespective of such variable pharmacokinetics, it is likely that a common additional mechanisms is involved because the dynamic changes on blood pressure were very similar for all ACE inhibitors. From the blood pressure patterns one may deduce that the repeated infusion of ACE-inhibitors has sensitized the cardiovascular system for $\mathrm{ACE}$ inhibition. ACE inhibitors have natriuretic properties and the loss of salt may have increased the extent to which blood pressure becomes dependent upon renin or angiotensin II (AII). This dependency is likely to be highest at the end of each dose interval and consequently, the next dose of the antihypertensive agents leads to greater fall in blood pressure. The fact that $\mathrm{ACE}$ inhibitors do have greater antihypertensive properties during low salt intake corroborates this hypothesis.

Also with losartan similar run-in effects occurred. At peak concentrations the dose of losartan $\left(10 \mathrm{mg}^{-\mathrm{kg}^{-1}}\right)$ is supposed to block about $90 \%$ of all $\mathrm{AT}$, -receptors ${ }^{29}$ and shifts the AII pressor response curve about a factor $35 \mathrm{in} \mathrm{rats}^{30}$. With this dose, the degree of AT, -receptor blockade is probably not very different between day 1 and day 
5 of treatment. Thus, in an unchanged system the antihypertensive effect of losartan on day 1 should not be far from the fall occurring on day 3-5. Because this was not the case - the antihypertensive effect was greater on day $3-5$ than on day 1 - blood pressure is likely to be become more dependent upon All during losartan treatment. This explanation is supported by the finding that losartan is more effective in (mRen)27 transgenic hypertensive rats (TGR) than in SHR ${ }^{3 !}$.

\section{Circadian-phase dependent mechanisms}

Mechanisms responsible for differences in the blood pressure patterns between the morning and evening treatment regimen with the ACE inhibitors and losartan must be related to a circadian variation in one or more of the components of the reninangiotensin system. Both circadian phase-dependent differences in pharmacokinetics as well as pharmacodynamics may be involved. In the present study we have not examined pharmacokinetic data concomitantly with the blood pressure measurements. Because of the limited amount of blood in rats, it is impossible to obtain blood samples repeatedly, without interfering with the blood pressure measurements. Moreover, as discussed below, several findings disprove an important role for circadian phase-dependency of pharmacokinetics.

\section{Role of AII}

The difference in the blood pressure patterns between the morning and evening dose must be related to time-dependency of the production of AII, since comparable time-dependent patterns were observed with the $\mathrm{AT}_{1}$-receptor antagonist losartan and ACE inhibitors. Furthermore this finding excludes an important role for kinins in causing these time dependent effects. This latter aspect is supported by a recent study in TGR in which blood pressure reductions following enalaprilat and losartan were comparable ${ }^{31}$. A specific effect of brain All can be ruled out too. The time-dependent antihypertensive patterns of captopril were not different from those of enalaprilat, an agent which does not readily cross the blood brain barrier ${ }^{27}$. To which extent AII fluctuates over $24-h$ periods in non-treated SHR is unknown. In one study in rats, peak values were found in the early morning, coinciding with those of aldosterone ${ }^{19}$. Following the same way of reasoning as above, throughout the 24 -h cycle, blood pressure may be most dependent upon All when sodium intake is lowest, i.e. at the end of the resting period just before resuming feeding and activity. This could be one of the major reasons to explain the efficacy of losartan during this period of the day, i.e. the early morning period (see Figure 7.10).

\section{Role of $A C E$}

The circadian variation in the amount of circulating $A C E$ is probably not responsible for the time-dependent efficacy of the present antihypertensive. In SHR, plasma ACE concentrations were relatively constant throughout the $24-\mathrm{h}$ period ${ }^{12}$. Also tissue ACE did not vary markedly over 24 hours ${ }^{22}$. However, in the latter case only data about ACE concentrations in the lungs were studied. Therefore, circadian variations in tissue ACE of organs, which play a major role in systemic resistance to blood flow, can not be excluded. Also in healthy subjects pharmacokinetics of enalapril were not different after an evening or morning dose ${ }^{7.33}$. 


\section{Role of renin}

The most Itkely rate limiting factor responsible for the time-dependent effects of these drugs is renin. Under normal conditions, in rats, plasma tenin levels increase from a trough value at the onset of the resting period to reach maximal values at the time of awakening ${ }^{19,20}$. This pattern mirrors the circadian variation in blood pressure, which suggests that, especially during the resting period, renin release may be largely dependent on the renal perfusion pressure ${ }^{3}$. On the other hand, the circadian rhythm of renin may depend on the sympathetic nervous activity to the kidney because peak levels of noradrenaline and renin coincide in the early moming hours. This view is supported by the observation that the circadian periodicity in plasma renin levels disappears during chronic 9 -blockade in patients as well as after bilateral nephrectomy ${ }^{2 !}$. Furthermore, kidney-derived renin is known to be rate-limiting in the production of AII by tissues ${ }^{35}$. According to this, the antihypertensive effect of the early moming infusion of the ACE inhibitors may have been caused by blunting the peak values of renin either via renal vasodilation or sympathetic inhibition. Clearly, the latter mechanism is involved because following the morning doses of the ACE inhibitors, the degree of reflex tachycardia was less than following the evening dose.

An implication of renin being possibly the rate-limiting factor is that the effect of ACE inhibition on blood pressure is low or absent when the production of renin is low". In rats, this is most-likely to occur at the end of the active period, when they ingest a significant amount of food to bridge the resting period. At this time point plasma renin is lowest ${ }^{19}$ and we found least antihypertensive efficacy. Also the blood pressure pattern obtained during the 2 days of recovery support that the circadian variation in one of the endogenous components is rate limiting for the action of the ACE inhibitors and losartan. Upon withdrawal of the last morning dose of captopril, blood pressure returned to control values. However, then during the progression of the resting period, blood pressure fell again below control levels. A similar secondary fall in blood pressure in the resting period effect was observed after the last morning dose of losartan (Figure 7.10). This pattern was absent after the last evening dose. Similar delayed effects have been reported to occur in patients too. Smith at all. ${ }^{36}$ showed that after withdrawal of trandolapril when blood pressure had returned to control values between 14.00 and $24.00 \mathrm{~h}$, it fell again below control in the ensuing night between 0 and $08 \mathrm{~h}$. Based on these data we suggest that the physiological production of renin is determining the circadian variation in the antihypertensive efficacy of the ACE inlibitors and losartan.

\section{Trough-to-peak ratio}

In the curtent study we have examined the effect of the dosing time on the trough-to-peak ratio of the ACE inhibitors and losartan. For captopril (10 $\mathrm{mg}_{\mathrm{kg}} \mathrm{kg}^{-1}$ ) and losartan the trough-to-peak ratio was significantly higher when the drugs were infused during the moming. However, only for the morning dose of losartan the trough-to-peak ratio was above $50 \%$ and in the range $(50 \%-66 \%)$ required for FDA approval ${ }^{11.12}$. The other drugs failled to meet this criterium. Obviously species differences may explain why these values are lower in rats than in humans. Because of a high metabolic rate in rats, the half-lives of the present agents are probably shorter than in humans. However, it is of our concern that even in our controlled experimental setup with continuous 
monitoring of blood pressure, the within animal variability of the trough-to peak values was very high (about 100\%). A clear explantation for the trough-to-penk values being so inconstant is lacking. Factors involved are probably the day-to-day variations in blood pressure associated with the activity/sleep pattern and the day-to-day variation in renin release which occurs burst like especially during sleep ${ }^{\prime 7}$. Our present data in rats add to the concerns formulated by others on the employment of this index ${ }^{12.37}$.

\section{Therapeutic implications}

In the current study we have shown that blood pressure pattems in hypertensive animals can be modulated with timed dosing of drugs that antagonize the renin angiotensin system. So far 4 studies in patients have been conducted ${ }^{7-1}$. Although they disagree to a certain extent about the optimal time period of administration, all these studies showed that the timing of the administration of ACE inhibitors was important for the ensung circadian blood pressure pattern. Which $24-h$ blood pressure pattern has an optimal protection for the morbid events related to hypertension has to be established in clinical trials. Our data in SHR, foster the development of ACE pteparations or $\mathrm{AT}$, -receptor antagonist which also have a controlled onset to anticipate upon the circadian variations in components of the renin-angiotensin system.

In conclusion, circadian blood pressure rhythms in SHR were differentially modu* lated by a circadian-phase dependent administration of $\mathrm{ACE}$ inhibitors and the $\mathrm{AT}$ receptor antagonist losartan. The differential effects were more likely due to circadian variations in components of the renin angiotensin system than circadian differences in the pharmacokinetics of these agents.

\section{References}

1. Muller JE, Tof Jer $\mathrm{GH}$, Stone $\mathrm{PH}$ : circadian variation and triggers of onset of acute cardiovascular disease. Circulation 1989; 4: 733-743.

2. Marler JR, Price TR, Clark GL, et al: Morning increases in onset of ischemic stroke. Stroke 1989; 20:473-476.

3. Gould BA, Raftery EB: Twenty-four-hour blood pressure controll: an intraarterial review. Chronobiol Int 1991; 8: 495-505.

4. Materson BJ, Preston $\mathbb{R A}$ : Classic therapeutic trials in hypertension. Am I Hypertems $1991 ; 4: 449 \mathrm{~S}-453 \mathrm{~S}$.

5. Neutel JM, Alderman M, Anders RI, Wever MA: Nowel delivery systen for verapamil designed to achieve maximal blood pressure control during the early moming. period Am Heart J 1997; 132: 1202-1206.

6. Myers MG: Twenty- four-hour blood pressure control: a brief rewew of aspects of target-organ portection. J Hyperiens 1996; 14: Supp S7-S10.

7. Witte $K$, Weisser $K$, Neubeck $M$, et al: Cardiovascular effects, phamacokinetics, and converting enzyme inhibition of enalapril after morning wersus evening administration. Clin Pharmacol Ther 1993;54:177-186.

8. Palatini P, Racioppa A, Raule G, Zaminotto M, Penzo M. Pessina AC. Effect of timing of administration on the plasma $A C E$ inhibitory activity and the antihypertensive effect of quitrapril. Clin Phamacol Ther 1992; 52 : 378-383.

9. Morgan T, Anderson A, Jones $\mathrm{E}$ : The effect on $24 \mathrm{~h}$ blood pressure control of an angiotensin converting enzyme inhibitor (perindopril) administered in the morning or at night. J Hyperters 1997; 15:205-2》1. 
10. Palatin P, Mos L, Motolese M, et al: Effect of evening versus moming benazepril on 24-hour blood pressure: a comparative study with continuous intraarterial monitoring. Int J Cin Pharmacol Ther Toxicol 1993; 6:295-300.

11. Myers MG: Trough-to-peak ratio and 24-hour blood pressure control. Methodologic issues. Am J Hypertens 1995; 8:214-219.

12. Elliott HL, Meredith PA: Trough:peak ratio: clinically useful or practically irrelevan? J Hypertens 1995; 13:279-283.

13. Brunner HR, Menard $J$, Weber $B$, et al: Treating the individual hypertensive patien: considerations on dose, sequentiall monotherapy and drug combinations. J Hypertens. $1990 ; 8: 3-11$.

14. Smits JPM, Nelissen-Vrancken HJMG, Strujiker Boudier HAJ: ACE Inhibitors, hypertension and cardiovascular structure. In Schachter M(ed): ACE Inhibitors: current use and future prospects, Ist ed. Dunitz, $\mathrm{M}_{\mathrm{s}}$ London, UK, 1995: 161-194.

15. Nicolau OY, Haus E, Popescu M, Sacket-Lundeen L, Petrescu E: Circadian, weekly, and seasonal variations in cardiac mortality, blood pressure, and catecholamine excretion. Chronobiol int 1991; 8: $149-159$.

16. Mullins J J, Peters $J_{\star}$ Ganten D: Fulminant hypertension in transgenic rats harbouring the mouse Ren-2 gene. Narure 1990; 334:541-544.

17. Veweg WVR, Veldhuis JD, Carey RM: Temporal pattern of remin and aldosterone secretion in men: effects of sodium balance. Am J Physiol 1992; 262: F871-F877.

18. Modlinger RS, Scharif-Zadeh K, Ertel NH, et al: The circadian thythn of renin. JCln Endacrinol Metab 1976; 43: 1276-1282.

19. Hilfenhaus $M$ : Circadian thythm of the renin-angiotensin-aldosterone system in the rat. Arch Toxicol 1976; 36: 305-316.

20. DeForrest JM, Davis JO, Freeman RH, Stephgens GA, Watkins BE: Circadian changes in plasma renin activity and plasma aldosterone concentration in two-kidney lypertensive uats. Hypertension 1979; : 142-149.

21. Derkx FHM, Admiraal PJ), Kool MJ, Van Bortel LM, Van Acker BAC: Chronobiology of the renim-angiotensin system. Blood Presswe Monitoring 1996; S7-SI1.

22. Janssen BJA, Tyssen CM, Struyker-Boudier HAJ: Modification of circadian blood pressure and heart rate variability by fiwe different antihypertensive agents in spontaneously hypertensive rats. J Cardiovasc Pharmacol 1991; 17: 494-503.

23. Lemmer $B$, Mattes A, Bohn $M$, Ganten D: Circadian blood pressure variation in transgenic hypertensive rats. Hypertension 1993; 22: 97-101.

24. Sirgo MA, Mills RJ, DeQuattro $\mathrm{V}$ : Effects of antihypertensive agents on circadian blood pressure and heart rate patterns. Arch Infern Med 1988, 148: 2547-2552.

25. Ianssen BJA, Oosting I, Tyssen CM, Struyker-Boudier HAJ: Time-dependent efficacy of antihypertensive agents in spontaneously hypertensive rats. Chronobiol Int 1993:10:420-434.

26. Lemmer B, Witte K, Makabe T, Ganten D, Mattes A: Effects of enalaprilat on circadian profiles in blood pressure and heart rate of spontaneously and transgenic hypertensive rats. I Cardiovase Pharmacol 1994; $23: 311-314$.

27. Golhke $P$, Urbach H, Schölknes BA, Unger T: Inhibition of converting enzyme in the cerebrospinal fluid of rats after oral treatment with converting enzyme inhibitors. J Pharmacol Exp Ther 1989;249:609-616.

28. Bunning $\mathrm{P}$ : Kinetic properties of the angiotensin converting enzyme inhibitor ramiprilat. J Cardiowasc Phamacol 1987; 10 (Suppl, 7): s31.-535.

29. Kario K, Matsuo T, Kobayashi H, Imiya M, Matsuo M, Shimada K: Nocturnal fall of blood pressure and silent cerebrovascular damage in elderly hypentensive patients. Hypertension 1996;27:130-135. 
30. Kario K, Shimada K: Differential effects of amlodipine on ambulatory blood pressure in elderly hypertensive patients with different nocturnal reductions in blood pressure. Am J Hypertens 1997; 10: 261-268.

31. Schnecko A, Witte K, Lemmer B: Effects of the angiotensin II receptor antagonist losartan on 24-hour blood pressure profiles of primary and secondary hypertensive rats. J Cardiovasc Pharmacol 1995; 26: 214-221.

32. Stepien $M$, Witte $K$, Lemmer $B$ : Chronobiologic evaluation of angiotensin-converting enzyme activity in serum and lung tissue from nomotensiwe and spontaneously hypertensive rats. Chronobiol Int 1993; 10:331-337.

33. Weisser $\mathrm{K}$, Schloos J, Lehmann $\mathrm{K}$, Düsing R, Vetter H, Mutschler E: Pharmacokinetics and converting enzyme inhibition after moming and evening administration of oral enalapril to healthy subjects. Eur J Clin Pharnocol 1991; 40:95-99.

34. Nafz B, Berthold H, Ehmke H, Hackenthal E, Kirchheim HR, Persson PB: Flow versus pressure in the control of renin release in conscious dogs. Am JPhysiol 1997 273: F200-F205.

35. Al-Yusuf AR, Kolar J, Bhatnagar SK, Hudak A, Smid J: Seasonal variation in the incidence of unstable angina and myocardial infarction: effect of dry hot climate on the occurence of complications following acute myocardial infarction. I Trop Med Hyg $1986 ; 89: 157-161$.

36. Smith $\mathbb{D H G}$, Neutel JM, Black $H \mathbb{R}$, Schoenberger JA, Weber MA: Once-daily monotherapy with trandolapril in the treatment of hypertension. $J$ Hum Hyperters $1996 ; 10: 129-134$.

37. Law CM, Barker DJP, Bull AR, Osmond C: Matemal and fetal influences on blood pressure. Arch Dis Child 1991; 66:1291-1295. 
Chaprer 7

136 


\section{Chapter 8 \\ General discussion}

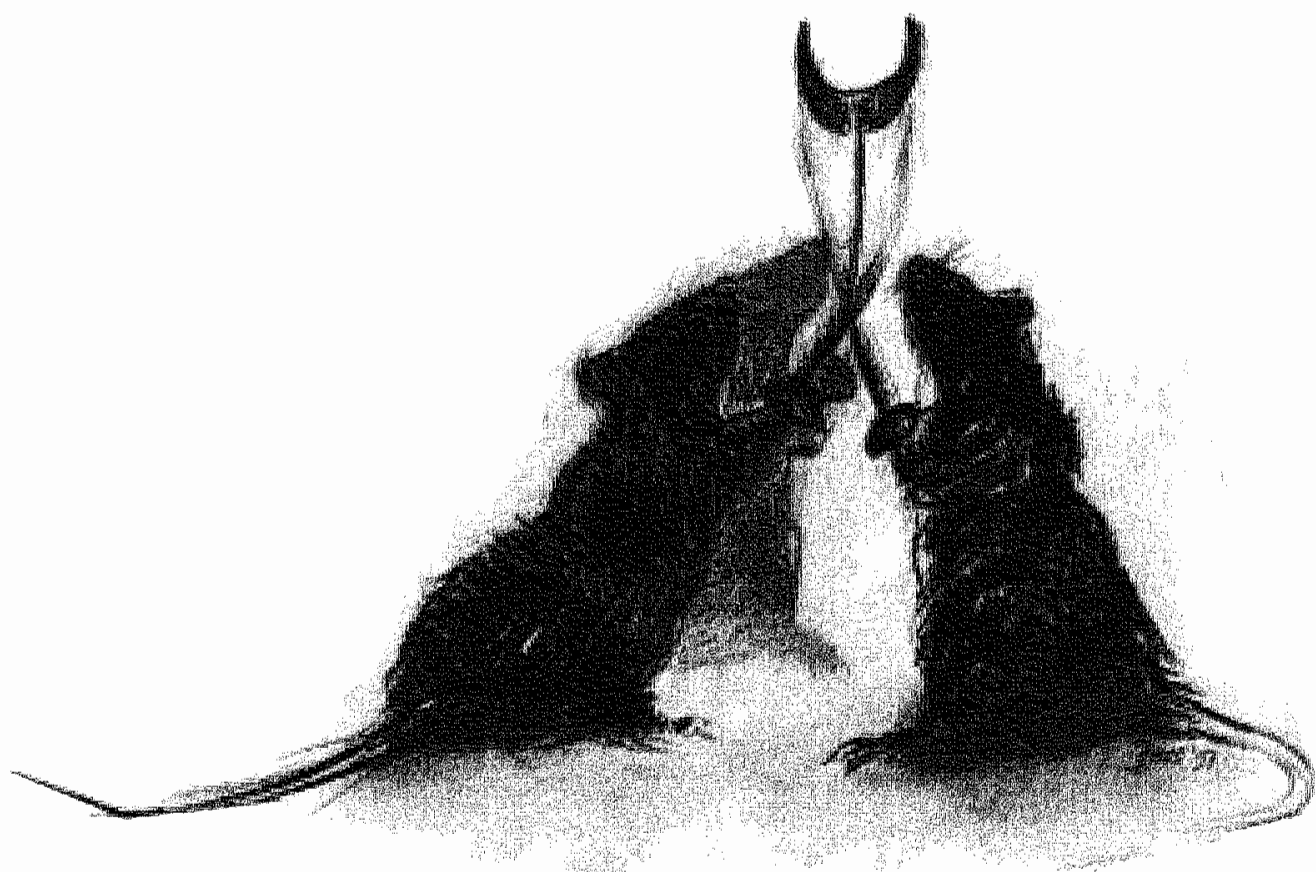


Chapter 8 
In this thesis we have investigated cardiovascular reguatory nechanisms in hypertension, and the effect of anti-hypertensive treatment in relation to the time of day. For this reason we focussed in detail on the short-tem and long-tem variabilty of time-series of cardiowascular parameters. The am of this final chapter is to place the present findings in perspective, emphasizing on the pathophysiological consequences of the circadian patterns of hemodynamics in hypertension. Finally, the implications for therapy are discussed.

\section{Time-series analysis}

Rhythmic variability can be used as a non-destructive probe of regulatory mechanisms. Spectral analysis of heart rate and, to a lesser extent, of blood pressure have been used to quantify autonomic function in a number of pathophysiological states'. Fast fluctuations in heart rate related to respiration are mainly associated with parasympathetic activity, whereas slower oscillations (the so-called Mayer waves around $0.1 \mathrm{~Hz}$ ) are mostly attributed to sympathetic activity ${ }^{2-4}$.

In order to make judgements on the activity of a regulatory mechanism based on spectral analysis one should be sure that there is only one mechanism that has the ability to cause oscillations in that particular frequency range. In chapter 2 we have measured beat-to-beat variabillity of regional blood flows and cardiac output to determine the hemodynamic origin of oscillations in blood pressure. Spectral analysis showed that high frequency, respiratory related, fluctuations of blood pressure were mechanically coupled to variability of cardiac output, i.e mainly stroke volume. Blood pressure oscillations in the lower frequency ranges resulted mainly from myogenic-like oscillations in regional blood flows and not from autonomic nervous activity. In addition, it has recently been demonstrated that also endothelial derived factors 5 contribute to fluctuations of blood pressure in the low frequency range. Thus, in the low frequency area at $0.1 \mathrm{~Hz}$ blood pressure variability is influenced by many factors. In contrast, heart rate fluctuations in this frequency range seem to follow the blood pressure variations and may mainly reflect baroreflex activity. In chapter 3 we have used spectral analysis in our search for a on-line method to derive baroreflex sensitivity from beat-to-beat changes in blood pressure and heart rate. In our rat strains, however, the values obtained from these calculations showed only little correlation with baroteflex gains measured with the classic pharmacological method. For testing the autonomic state in patients, classic tests like deep breathing and Valsalva's manoeuvre usually suffice?. When autonomic function must be monitored for longer periods, spectral analysis of heart rate signals and blood pressure can be considered. However, these data should be interpreted with care. Up to now, there are no data bases with values of spectral measures obtained in a normal healthy population. On the other hand, there are striking similarities in spectral measures of blood pressure between SHR and essential hypertensive patients over 24 -h periods. In both species, low frequency oscillations in blood pressure are increased and higln and low oscillations of heart rate are decreased. Also baroreflex gains over 24 hour periods as calculated by sequential methods revealed similar results in SHR and essential hypertensive patients. Thus, whereas these tools seem to have their diagnostic value, the underlying pathophysiological mechanisms are not fully clear.

The present thesis stresses the importance of measuring cardiovascular function 
throughou the day. In chapter 4 we found an intriguing inverse effect between the chroadian and ultradian effects of total autonomic blockade on variability of blood pressure and heart rate. Total autonomic blockade produced the expected decrease of shorterm variablity of heart rate and a slight increase in short-tern variability of blood pressure. The opposite was true for the circadian variability of these parameters. The 24 $\mathrm{h}$ heart rate thythm remained unaltered, whereas the 24 h rhythm of blood pressure was abolished. A comparable phenomenon was seen in humans after cardiac transplantation". Thus long-term variations in heart rate seem to be rather independent of automomic tone and may be more related to intrinsic mechanisms such as atrial filling.

Hemodynamic monitoring over prolonged periods of time poses the question. how the data must be gathered. Rats have almost half a million heart beats every day, and data reduction is necessary to perform statistical analyses on the results. However, this process carries the risk of losing important information or interesting phenomena hidden in short-term sequences of these parameters. Modern computers are fast enough to compute on-line measures of the dynamics of the cardiovascullar system (see chapter 3). We believe, that the application of such techniques will lead to new diagnostic tools and add to our understanding and of the cardiovascular system in many pathologies.

In addition to these time-related methods we have used 2 -dimensional frequency distributions of beat-to-beat values of complete 24 hour periods. This was done to gain an insight into the distribution of hemodynamic parameters, together with the beat-tobeat interactions between 2 parameters. Using this technique we could show (chapter 5) that on a circadian time-scale variations of cardiac output were greater than variations of blood pressure. This suggests that even on such a long-term time-scale blood pressure is controlled tighter than cardiac output. In our view there is no such thing as a set-point for cardiac output. The adaptive processes that control cardiac output over extended periods, such as Guyton"s whole-body autoregulation ${ }^{10.11}$ occur in our view at organ level. Over long-term periods, every vascular bed regulates its own flow as a function of its requirements. Because these requirement vary throughout the day, relatively large variations are observed. The application of the 2-dimensional frequency distribution also showed that, unlike values of other systennic hemodynamic parameters, heart rate values were clustered at certain preferred levels. It seens that, at least in rats, the heart likes to work in certain gears. The underlying mechanism of this phenomenon is unknown. Certain heart rates could be energetically more effective, or preferred by internal properties of the pacemaker cells in the sinus node. In conclusion, the calculation of measures derived from beat-to-beat values gives us an unique insight into the dynamics of cardiovascular function over prolonged periods of time, although more work is needed to validate such probes clinically.

\section{Circadian cardiovascular function and pathophysiology}

Epidemiological studies have shown that the onset of several cardiovascular morbid events occurs more often in the early morning. The circadian pattern of several physiological functions may explain the striking of such events at this time-point of the day. First it must be stated that the vascular system in these patients is already vulnerable, mostly by the occurrence of atherosclerosis in cononary arteries or arteries providing the brain with blood. The physical stress that eventually causes the injury to the vessel wall is not evenly distributed throughout the day. It has already been well 
established that blood pressure and heart rate are higher during the active period of the day ${ }^{2.13}$. The increase in blood pressure in the morning causes an increase in the passive strain on the arterial system, while the increase in heart rate causes an addifional increase of the dynamic strain. The concomitant increase of rate pressure prod uet augments the workload of the heart, and increases oxygen consumption. Cardiac output is also higher during the active period, but the data on the circadian patten of total peripheral resistance are inconsistent ${ }^{14-16}$. This may be due to methodological problems. In chapter 5 we have made direct measurements of cardiac ouput with electromagnetic flowprobes in unanesthetized rats over 24 hours. In that study we have shown that total peripheral resistance is higher durung the passive phase of the day, because the relative circadian variation in cardiac output is higher than the relative circadian variation in blood pressure. Until recently it has been difficult to measure cardiac output in humans without arousing the subject under study. The pulse contour and Modelflow method have been developed to measure an indirect index of cardiac output from peripheral blood pressure recordings in humans ${ }^{12}, 13$. These methods assure the undisturbed continuous measurement of cardiac output. Through these methods it has been assessed that also in humans total peripheral resistance is higher in the passive period $^{19.20}$. We have also shown that total peripheral resistance is still high at the transition from the sleeping to the active stage, and only starts to decrease when the animals become active. This imposes an increased afterload in the morning. The heart has to pump harder in order to ensure sufficient flow against a high resistance. An extra factor in keeping resistance high in the morning could be the impaiment of flowinduced vasodilatation in hypertension ${ }^{21.22}$. In chapter 4 we have shown that baroreflex function is decreased at this time point, causing an increase in short-term blood pressure variabillity. In short, heart rate, arterial pressure, blood pressure variability, and peripheral resistance all contribute to the high stress on the arterial wall during the early morning. The increase in stress on the wall could lead to damage of predisposed or fragile sites like atherosclerotic plaques. In particular, the rupture of these plaques is now recognized as a major pathogenic mechanism for myocardial or brain infarcts. Other factors like an increased susceptibility for the generation of blood clots $^{23.25}$ at this time-point even increase the chance that an atherosclerotic rupture leads to a life threatening infarction.

The incidence of myocardial infarction also shows a weekly pattern, with the highest incidence on Mondays ${ }^{26}$. This phenomenon can be explaned by the tendency of humans to sleep out during the weekend. This causes a plase-delay in the endogenous regulatory systems controlling blood pressure. When the activity pattem of workdays is resumed on Monday moming, a phase-advance is required, whereas the regulatory systems are still geared for inactivity, with high peripheral resistance. Blood pressure and heart rate will have to increase mote than nomally to guarantee sufficient blood flow. This can be viewed as an exaggerated form of the nomal adaptations to the circulation in the early moming.

\section{Circadian considerations for therapy}

Much has been done in the last 40 years to improve anti-hypertensive therapy. From the early sympaticolytic agents to modern drugs like $A C E$-inhibitors and calcium antagonists, ant-hypertensive agents have become safer and more devoid of adverse 
effect. Yet ant-hypertensive reatment is not yet optimal. People treated for hypertension still have a thigher risk for diseases associated with hypertension than people with nomal blood pressure ${ }^{27.36}$. A number of factors can be held responsible for this failure of anti hypertensive treatment [see Introduction]. One of these factors is the observation that current anti-hypertensive therapy does not take the circadian rhythmicity of cardiovascular events into account.

To understand the time-telated effects of anti-hypertensive treatment it is important to know the major determinants of circadian patterns of hemodynamics. Physical activity is the most important factor for the level of blood pressure and heart rate ${ }^{31}$, but it is likely that there is also an endogenous blood pressure rhythm ${ }^{20}$. Of the regulatory mechanismins if seems that the autonomic nervous system has a causal role in the generation of the circadian pattern of blood pressure ${ }^{32}$. The balance between parasympathetic and sympathetic nervous system is shifted towards the sympathetic side during the active period and towards the parasympathetic side during the passive period ${ }^{3-26}$. In contrast to the autonomic nervous system, other regulatory mechanisms, like the renin angiotensin system and vasopressin show adaptive or counter regulatory behaviour on the circadian timescale, witth higher activity during the passive period. ${ }^{13.37}{ }^{40}$. This phenomenon is further illustrated by the reversal of the circadian pattern of blood pressure in certain (renin-dependent) secondary forms of hypertension and in Renin-2 transgenic rats ${ }^{41}$. The circadian patterns of these hormones can explain the increase in total peripheral resistance during the passive period. These differences in regulatory mechanisms, may imply that drugs targeted at the sympathetic nervous system, like "i. and $\$$-blockers blunt the circadian variability of blood pressure, whereas drugs targeted at the renin angiotensin system can increase circadian variability of blood pressure, and may be used to restore the decrease of the circadian blood pressure variability in non-dippers..

Current anti-hypertensive treatment is primarily aimed at providing an even blood pressure reduction throughout the day ${ }^{42}$. Many studies have examined the 24 -hour efficacy of anti-hypertensive agents (for reviews see ${ }^{43-45}$ ). A general finding of these studies is that, although anti-hypertensive treatment reduces the average blood pressure level, the circadian pattern of blood pressure is preserved and that treatment does not attenuate the early moming rise in blood pressure.4. It is yet unclear what the goal shotuld be in a circadian approach towards anti-hypertensive treatment. Sirgo et al.4 have stressed the importance of anti-hypertensive efficacy of drugs all through the day with an emphasis on the early morning, which is often situated at the end of a dosing inerval. This evenly distributed effect throughout the day is also part of the recommendations of the FDA for new drugs, and is generally achieved with long-acting agents. In hypertensive subjects where the normal difference between the active and the resting period is diminished, or even reversed, an increased incidence of end organ damage is $\sec ^{46.47}$, and anti-hypertensive treatment fails to restore the normal difference between nightime, and daytime blood pressure. Here the timing of dosing could be used to restore the normal day-night pattern of blood pressure.

The FDA has published guidelines for the registration of new anti-hypertensive drugs ${ }^{48}$. One of the most controversial of these guidelines was the requirement to have a trough to peak ratio of at least $50 \%$ when using the recommended dosing scheme 49 54. The trough to peak ratio was designed to ensure efficacy at the end of the dosing 
interval, without having to resort to inappropriately high doses. In the chapter 7 we have examined the effect of the dosing time on trough to peak ratio. In general the trough to peak ratio of blood pressure was higher when the drugs were infused duning the morning. Only in one case (losartan morning dose) the trough to peak ratio was above $50 \%$. The other drugs failed to meet the cut-of point. The high metabolic rate of rats, and therefore shorter half-life of drugs, could play a role here, as well as the fact that blood pressure was recorded continuously in contrast to most clinical studies where blood pressure is measured in intervals. However, it is of our concern that even in our highly controlled experimental setup with continuous momitoring of blood pressure, we were not confident of the obtained values. The inter individual variability of trough to peak ratio was unacceptably high, with a coefficient of variation of about 100 $\%$ in most groups, and large differences were found between two ways to calculate trough to peak ratio. These factors should lead to reconsidering the value of this parameter.

We believe that restoring the circadian blood pressure pattern to normal may not be sufficient in this group of patients with an increased risk for cardiovascular illness. We hypothesize that it could be beneficial to desynchronize the circadian patterns of the processes that now all show their peak stress in the early morning. One way of doing this is by delaying the rise in blood pressure at this moment by treating the patient with short-acting drugs in the early morning. In chapter 7 we have shown that it is possible to manipulate blood pressure patterns in this way. In humans the exact timing at this period is difficult because the patients are still asleep at the moment the drugs should have their peak effect. However, release preparations have been devised in the meantime, that are specifically targeted at this period ${ }^{55.56}$. The approach of changing the pattern of blood pressure will require treatment with the use of short-acting drugs ${ }^{57}$. This is in contrast with the current tendency to prolong the half life of antihypertensive drugs, thus obtaining a flat anti-hypertensive profile.

A serious drawback of therapy aimed at changing the pattem of blood pressure is that it requires the patient to take medication at the same time every day. Compliance is low for anti-hypertensive medication ${ }^{58,59}$, whereas strict adherance to the dosing schedule is important for chronopharmacology. Also in order to monitor the treatment it will be necessary to carry out regular 24 hour anbulatory blood pressure measurements. This can lead to therapy besed on risk-stratification. People at a higher risk for morbid cardiovascular events, with other risk factors like old age, end organ damage, left ventricular hypertrophy, obesity, and/or smoking, will require more aggressive therapy of hypertension, whereas low-risk patients probably will be sufficiently treated with current anti-hypertensive therapeutic strategies.

Currently most attention is given to blood pressure levels, whereas other - hemodynamic parameters are more or less neglected. Our study in chapter 7 showed that when the dose was targeted at different time points of the day, not so much the blood pressure reduction was different between time points, but the heart rate. This can be an important consideration for treatment, because the workload of the heart is rate dependent. At the moment there is insufficient data to interpret circadian patterns of peripheral resistance and cardiac output during treatment, although it is conceivable that especially drugs targeted at the renin angiotensin system can be beneficial in lowering total peripheral resistance in the moming. 


\section{Concluding remarks}

Despite the reduction of blood pressure the incidence of cardiac life threatening events is still higher in treated hypertensive subjects than one would expect on the basis of the achieved reduction of blood pressure ${ }^{29}, 30$.

We have shown that with a chronotherapeutic approach to anti-hypertensive treatment it is possible to change the pattern of blood pressure throughout the day, thereby desynchronizing the circadian patterns that exert a physical stress on the arterial wall. Prospective trials in humans will be necessary to elucidate if a chronotherapeutic approach to hypertension is beneficial in preventing cardiovascular disease, compared to current anti-hypertensive treatment.

\section{References}

1. Mancia $G$, Ferrari $A$, Gregorini $L$, et al: Blood pressure and heart rate variabilities in nomotensive and hypertensive human beings. Cire Res 1983;53:96-104.

2. Pagani $M$, Lombardi $F$, Guzzetti $S$, et al: Power spectral analysis of heart rate and arterial pressure variabilities as a marker of sympatho-vagal interaction in man and conscious dog Cimc Res 1986; 59: 178-193.

3. Malliani A, Pagani M, Lombardi F, Cerutti S: Cardiovascular Neural Regulation Explored in the Frequency Domain. Cinculation 1991; 84: 482-492.

4. Akselrod S, Gondon D, Madwed JB, Snidman NC, Shannon DC, Cohen RJ: Hemodynamic regulation; investigation by spectral analysis. Am J Physiol 1985; 249: H867 H875.

5. Just A, Witmann U, Nafz B, et al: The blood pressure buffering capacity of nitric oxide by comparison to the baroreceptor reflex. Am J Physiol 1994; 267: H521-H527.

6. Brown TE, Beightol LA, Koh J, Eckberg DL: Important influence of respiration on human $\mathrm{R}-\mathrm{R}$ interval power spectra is largely ignored. $J$ Appl Physiol 1993; 75:2310. 2317 .

7. Karemaker IM: Heart rate variability: why do spectral analysis? Heant 1997; 77: 99101.

8. Parati G, Castiglioni P, Di Rienzo M, Omboni S, Pedotti A, Mancia G: Sequential spectral analysis of 24-hour blood pressure and pulse interval in humans. Hypertension $1990 ; 16: 414-421$.

9. Idema RN, van-den-Meiracker AH, Balk AH, Bos E, Schalekamp MA, Man-in"t-Veld AJ: Decreased circadian blood pressure variation up to three years after heart transplantation. Am J Cardiol 1994; 73: 1006-1009.

10. Coleman TG, Granger $\mathrm{H} J$, Guyton $\mathrm{AC}$ : Whole-body circulatory autoregulation and hypertension Circ Res 1971; 28:Suppl 2:76-87.

11. Guyton $\mathrm{AC}$, Granger H., Coleman TG: Autoregulation of the total systemic circulation and its relation to control of cardiac output and arterial pressure Circ Res 1971; $28 *$ Suppl 1:93-97

12. Lemmer B: Circadian rhythms in the cardiovascular system. In Arendt J, Waterhouse J. Minors D (eds): Biological rhythms in the cardiovasucular system John Wright, Bristol, England, $1990: 51-70$.

13. Millar-Craig MW, Bishop CN, Raferty EB: Circadian variation of blood pressure. Lance 1978; 1: 795-797.

14. Engel BT, Talan MI: Diurnal patterns of hemodynamic performance in nonhuman primates. An of Physiol 1987;253: R779-R785.

15. Kool MI, Wijnen JA, Derkx FH, Struijker-Boudier HA, Van-Bortel LM: Ditmal 
variation in proremin in relation to other humoral factors and henodynamics. $A m b$ Hypertens 1994; $7: 723 \div 730$.

16. Kawano $\mathrm{Y}$, Tochikubo $\mathrm{O}$, Miamisawa $\mathrm{K}$, Miyajuma $\mathrm{E}$, shini $\mathrm{M}$ : Circadian variation of haemodynamics in patients with essential hypertension: comparison between early moming and evening. J Hypertens 1994; 12: 1405*1412.

17. Wesseling KH, Jansen JRC, Settels JI, Scheuder J3. Computation of aortic fow fiom pressure in humans using a nonlinear, three-element model. J Appl Physiol 1993; 74: 2566-2573.

18. Voogel A.J. Montfrans GA: Reproducibility of twenty-four-hour finger arterial blood pressure, variability and systemic hemodynamics. I Hypertens 1997 ; 15 (12 pl 2): $1761-1765$.

19. Veerman DP, Imholz BPM, Wieling W, Wesseling $\mathrm{KH}$, Van Montrans GA: Circadian profile of systemic hemodynamics. Hypertension $1995 ; 26: 55-59$.

20. Voogel AJ, Stok WJ, Pretorius PJ, Van Montrans GA, Langewouters GJ, Karemaker JM: Circadian blood pressure and systemic haemodynamics during 42 days of 6 degrees head-down tilt. Acta Physiol Scand 1997; 161:71-80.

21. Smiesko $V$, Johnson $P C$ : The arterial lumen is controlled by flow related shent stress. NPS $1993 ; 8: 34-38$.

22. Bevan $J A$, Laher I: Pressure and flow-dependent vasculat tone. Faseb J 1991; 5:22672273.

23. Tofler GH, Brezinski D, Schaefer Al, et al: Concurrent moming increase in platelet aggregability and the risk of myocardial infarction and sudden cardiac death. Now Engl J Med 1987; 316: 1514-1518.

24. Rosing DR, Brakman P, Redwood DR, et al: Blood fibrinolytic activity in man.

Diurnal variation and the response to varying intesities of exercise. Circ Res $1970 ; 27$. $171-184$

25. Andreotti F, Davies GJ, Hacket DR, et al: Major cincadian fluctuations in fibrinolytic factors and possible relevance to time of onset of myocardial infarction, sudden deeth and stroke. Am J Cardiol 1988; 62;635-637.

26. Wilich SN, Löwel H, Lewis M, Hörmann A, Arntz HR, Keil U: Weekly variation of acute myocardial infarction. Increased monday risk in the working population. Circularion 1994; 90: 87-93.

27. Hansson $\mathbb{L}$ : Shortcomings of current antihypertensive therapy. Am J Hypertens 1991; $4: 84 \mathrm{~s}-87 \mathrm{~s}$.

28. Cruickshank JM, Thorp JM, Zacharias FJ: Benefits and potenstial harn of lowering blood pressure. Lancet $1987 ;$ i: $581-584$.

29. Lindholm L, Ejlertsson $G$, Schersten $B$. High risk of cerebro-cardiovaseular morbidity in well treated male lypertension. Acta Med Scand 1984;216:251-259.

30. Istes $\mathrm{CG}$, Walker $\mathrm{LM}$, Beevers $\mathrm{GD}$, et al: Mortality in patients of the Glaggow blood pressure clinic. J Hypertens 1986; 4:141-156.

31. Chau NP, Mallion M, De Gaudenaris $R$, ef al: Twenty-four hour ambulatory blood pressure in shift workers. Comculation 1989;80:341-347.

32. Janssen BJA, Tyssen CM, Dundam H, Riatveld WJ: Suprachiasmatic lesions eliminate 24 -h blood pressure variability in rats. Physiol Behow 1994; $55: 307-311$.

33. Hartikanen J, Tarkiainen 1, Tahvanainen K, Manysaari M, Lansimies E, Pyorala $K$ : Circadian variation of cardiac autonomic regulation during 24 h bed rest. Clin Physio $1993 ; 13: 185-196$

34. De Boer SF, van der Gugten J: Daily variations in plasma noradrenaline, adrenaline and corticosterone concentrations in rats. Physial and Behov 1987; 40:323-328.

35. Linsell CR, Lightman SL, Mullen PE, Brown MJ, Causon RC: Circadian rhythms of epinephrine and norepinephrine in man. JClin Endocrinol Metab 1985; 60:12101215. 
36. Tuck ML, Stern N, Sowers JR: Enhanced 24-Hour Norepinephrine and Renin Secretion in Young Patients with Essential Hypertension: Relation with the Circadian Pattern of Arterial Blood Pressure. Am J Cardiol1985; 55 : 112-115.

37. George CPL, Messerli $\mathrm{CH}$, Genest d, et al: Diumal variation of plasma vasopressin in man. I Clin Endocinol Metab 1975, 41:332-338.

38. Modlinger RS, Scharif-Zadeh K, Ettell NH, et al: The circadian mythm of renin. I CHin Endocrinol Metab $1976 ; 43: 1276-1282$.

39. Gordon RD, Wolfe LK, Island DP, Liddle GW: A diurnal thythm in plasma renin activity in man. I Clin Invesi 1966; 10: 1587-1592.

40. Cugini P, Letizia $C$, Cerci $S_{*}$ et all: A chronobiological approach to circulating levels of renin, angiotensin-converting enzyme, aldosterone, ACTH, and cortisol in Addison's discase. Chronobiol lat 1993; 10: 119-122.

41. Lemmer B, Mattes A, Bohm M, Ganten D: Circadian blood pressure variation in transgenic hypertensive rats. Hypertension 1993;22: 97-101.

42. Guidelines Subcommittee of the WHO/ISH Mild Hypentension Liaison Committee: 1993 Guidelines for the management of mild hypertension. Hypertension 1993; 22 : 392-403.

43. Voogel AJ, Van Der Meulen JHP, Van Montfans GA: effects of antihypertensive drugs on the circadian blood pressure profille. J Cardiovasc Pharmacol 1996; 28; 463469.

44. Sirgo MA, Mills. RU, DeQuattro V: Effects of antihypertensive agents on circadian blood pressure and theart rate patterns. Anch Intern Med 1988; 148: 2547-2552.

45. Materson BJ, Preston RA; Classic therapeutic trials in hypertension. Am J Hypertens $1991 ; 4: 449 S-4535$.

46. Parati G, Pomidossi G, Albini F, Malaspina D, Mancia G: Relationship of 24-hour blood pressure mean and variability to severity of target-organ damage in hypertension. J Hyertens 1987; 5: 93-98.

47. Parati $\mathrm{G}$, Ravogli A, Frattola $\mathrm{A}$, et al: Blood pressure variability: clinical implications and effects of antihypertensive treatment. $J$ Hypertens 1994; 12: $\mathrm{S} 35-\mathrm{S} 40$.

48. Rose M, McMahon FG: Some problems with antihypertensive drug studies in the context of the new guidelines. Am I Hypertens 1990; 3: 151-155.

49. Myers MG: Trough-to-peak ratio and 24-hour blood pressure control. Methodologic issues. Am J Hypertens 1995; 8: 21:4-219.

50. Meredith PA, Elliott HL: Antihypertensive treatment and trough: peak ratio: general considerations, J Hypertens 1994; 12 : S79-\$83.

51. Mancia G, Parati G, Pomidossi G, et al: Evaluation of the antilypertensive effect of of once-a-day captopril by 24 -hour anbulatory blood pressure monitoring. $f$ Hypertens 1987(Suppl. 5): $591-593$.

52. Smits JFM, Struker-Boudier HAJ: Regional hemodynamic effects of rülmenidine and clonidine in the conscious spontaneouslly hypertensive rat. Fundam Clin Pharmacol $1991 ; 5: 651-661$.

53. Lipicky RJ: Trough : peak ratio: the rationale behind the united states food and drug administration recommendations. J Hypertens 1994; 12 : s17-519.

54. Meredith PA. Elliott HL: FDA guidelines on trough : peak ratios in the evaluation of antihypertensive agents. J Cardiovasc Pharmacol 1994; $23: \mathrm{S26-530.}$

55. Neutel JM, Alderman M, Anders R.I, Wever MA: Novel delivery system for verapamil designed to achieve maximal blood pressure control during the early morning period. Am Heart J 1997; 132: 1202-1206.

56. White WB, Mehrotra DV, Black HR, Fakouhi TD, COER-Verapamil Study Group: Effects of controlled-onset extended-release verapamil on nocturnal blood pressure (dippers versus nondippers). Am J Cardiol 1997; 80:469-474. 
57. Levy G: Phamacokinetic constraints and opportumities. Anw NY Acad Sci 1991; 618: 116-122.

58. Unquhart $\mathrm{J}$ : Real-time compliance data to help define optimal drug regimens. Amn $N Y$ Acad Sci 1991; 618:522-532.

59. Urquhart J: Role of patient compliance in clinical pharmacokinetics. A review of recent research. Clin Pharmacokinet 1994; 27: 202-215. 
Chopter 8

148 


\section{Chapter 9 \\ Nederlandse samenvatting}

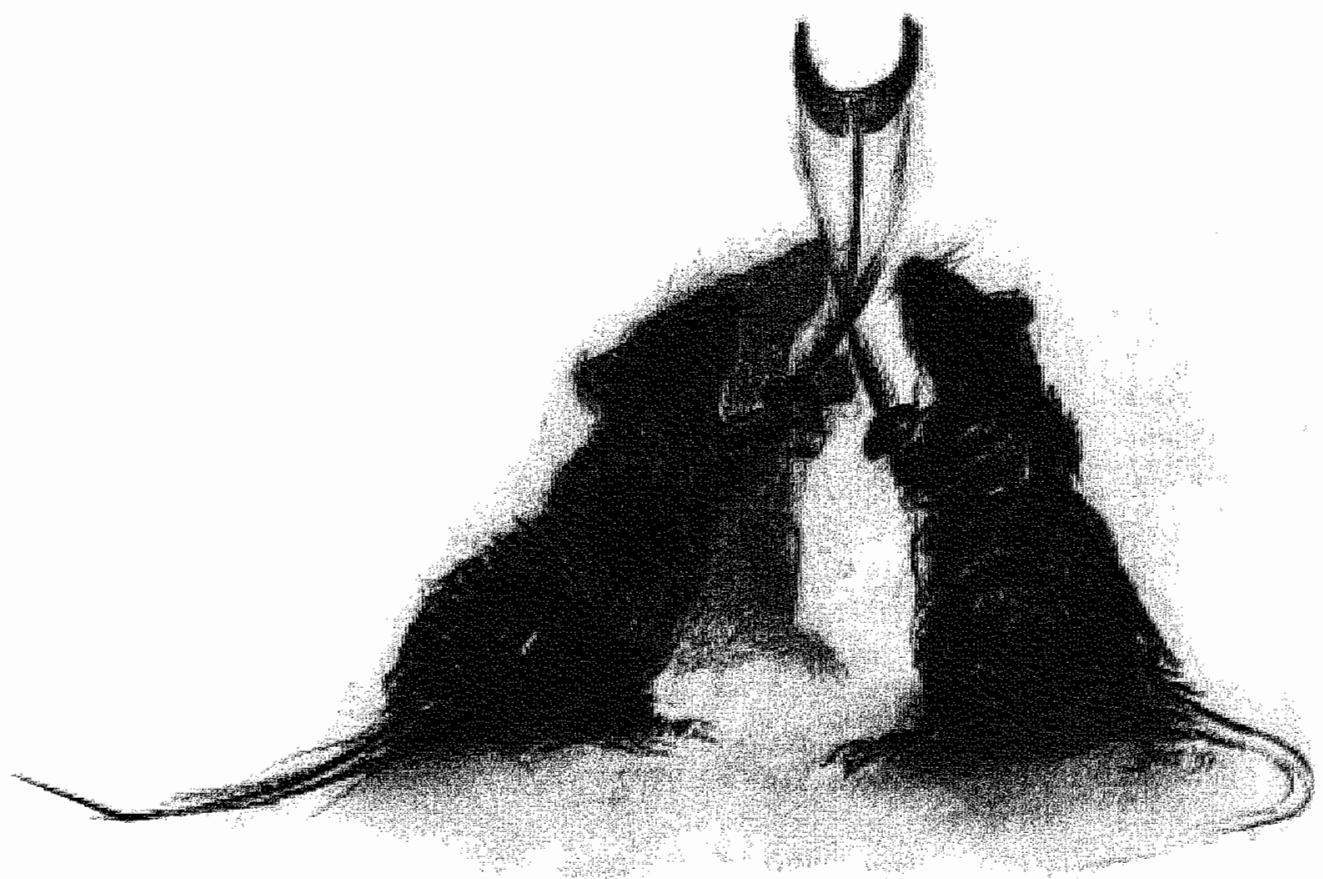


Het blijkt dat cardiovasculaine incidenten zods myocardinfarct, herseninfarct of plotselinge dood vooral vótkomen in de vroege ochtend. Het doel van dit proefschrif is een studie naar de mechanismen die aan dit feromeen ten grondslag liggen.

Hypertensie is de belangrijkste risicofactor woor hef ontstam van atherosclerose, en daamee voor het ontstaan van hartinfarcten. In $90 \%$ van de patienten met hypetensie wordt bij onderzoek geen oorzaak woor het ontstaan van hypertensie gevonden. Deze vorm heet primaire of essentiele hypertensie. In de resterende $10 \%$ worden afwijkingen van nieren, bijnieren of de nierarterieěn gezlen. Deze vormen worden secundaire hypertensie genoemd. Het blijkt dat bij primaire iypertensie het dag nacht ritme van de bloeddruk in het algemeen aanwezig is, tervijl bij secondaire vormen van hypertensie vaak een klein verschil of zelfs een negatief verschil tussen dag-en nachtwaarden van de bloeddruk wordt gezien. Patiènten met een klein verschil in bloeddruk tussen dag en nacht (non-dippers) hebben een vergootte kans op complicaties van hypertensie, zoals linker ventrikel hypertrofie of retinopathie.

De huidige behandelings richtlijnen woor hypertensie zijn erop gericht de diastolische bloeddruk onder de $95 \mathrm{mmHg}$ te krijgen. De laatste jaren gaan er echter ook stemmen op om patiënten te behandelen afhankelijk van de aanwezigheid van andere risicofactoren als cholesterol plasma spiegels, lichaamsmassa, en al aanwezige schade tengevolge van hypertensie. Gezien de hoge incidentie tijdens de ochtend van het vóorkomen van myocardinfarct zou het wenseljk zijn dat anti-hypertensieve therapie ook gericht is op de vroege ochtend.

Het onderzoek in dit proefschrilt beschrijft in de hootdstukken 1 tot 5 een aantal fysiologische processen die op de korte en lange termijn een rol spelen bij de regulatie van het cardiovasculaire systeem. In do hoofdstukken 6 en 7 wordt de invloed van een aantal antihypertensieve farmaca op het dag-nacht ritne van cardiovasculaire paraneters onderzocht

In de algemene introductie wordt de fysiologie beschreven van het systeem dat dag-nacht verschillen kan veroorzaken van allerlei processen in het lichaam. Hiverbij worden 2 verschillende vormen onderscheiden: 1) Endogeen ritme: processen die afhankelijk zijn van een innerlijke klok. Deze processen vertonen ook een dag-nachi ritme als er geen dag-nacht verschillen meer zijn in de omgeving. 2) Exogeen ritme: processen die dag-nacht verschillen vertonen als reactie op dag nacht verschillen in de omgeving. Het voordeel van een endogeen ritme is dat een proces zich kan instellen op veranderingen die nog gaan komen. De meeste fysiologische processen an parameters vertonen dag-nacht verschillen, maar in het grootste gedeelte daarvan is niet bekend of dit door een endogeen of exogeen ritme bepaald wordt.

Ook binnen het cardiovasculaire systeem volgen de meeste parameters een dagnacht ritme. Van de bloeddruk en de hartfrequentie is bekend dat zij hogere waarden vertonen gedurende de dag ten opzichte van de nacht. Hartminuutvolume en totale perifere weerstand zijn minder goed onderzocht. Voor het hartminuutvolume zijn er aanwijzingen dat het overdag hogere waarden vertoont dan "s nachts. De relatieve verschillen in hartminuutwolume zijn groter dan die van de bloeddruk. Daarom is "s nachts de totale perifere weerstand hoger dan overdag. De invloed van cardiovasculaire regelmechanismen vertoont ook een dag-nacht ritme, waarbij opvalt dat behalve (nor)adrenaline de meeste hormonen met een wasoconstrictieve werking een ritme hebben met hogere plasmaspiegels tijdens de nacht. 
Er is een aantal fysiologische processen die aanleiding kunnen geven to een werhoogd risico op cardiovasculaire incidenten tijdens de vroege ochtend. De bloeddruk en de hartfrequentie stijgen gedurende deze periode. Tesamen met een verhoogde bloeddruk variabiliteit zorgt dit voor een verhoogde fysische belasting van de valuwanden het hart. Bloed stolt makkelijker tijdens deze periode terwijl bloedstolsels minder snel worden afgebroken. Tenslotte vertaont het homoon cortisol in deze periode zijn hoogste warden waardoor coronaire arterieen extra gevoelig zijn voor catecholamines.

In hoofdstuk 2 zijn de korte termijn schommelingen van de bloeddruk vergeleken met schommelingen in het harminuutvolume en de doorstroming van nieren, darmen en het achterlijf van niet-geanestheseerde rustende ratten. Hierbij zijn drie frequentie gebieden onderzocht. 1) Hoog frequent ( $\mathrm{HF}$; rond $1.6 \mathrm{~Hz}$ ): schommelingen rond deze frequentie worden meestal in verband gebracht met de invloed wan het parasympatische autonome zenuwstelsel en de ademhaling. In het HF gebied wordt gezien dat de variabiliteit van het slagvolume de variabiliteit van het hartminuutvolume bepaalt, en dat er een directe, mechanische, koppeling is tussen het hartminuutvolume signaal en het bloeddruk signaal. De HF schommelingen worden gedempt voortgeleid naar de perifere vaatbedden van nieren, darmen en achterliff. 2) Midden frequent (MF; rond 0.4 Hz): deze schommelingen zijn meestal afhankelijk van het functioneren van het autonome zenuwstelsel. MF schommelingen in de bloeddruk worden vooral veroorzakt door doorstromingsschommelingen in het achterlijf terwijl de doorstroming van de nieren en de darmen de schonmelingen in de bloeddruk passief volgen. 3) Laag frequent (LF; rond $0.12 \mathrm{~Hz}$ ): de oorsprong van deze schommelingen dient gezocht te worden in myogene luctuaties van arterieèn in lokale vaatbedden. De LF schommelingen van bloeddruk lijken te worden veroorzaakt door myogene reacties in de vaatbedden van de nieren en de damen. Het feit dat de myogene reactie een ritme vertoont in de bloeddruk toont aan dat de spieractiviteit van de arterieèn tijdens deze reactie gecoordineerd wordt.

In hoofdstuk 3 is een methode ontwikkeld on de baroreceptor reflex gevoeligheid (BRS) bij ratten te meten met behulp van spontane fluctuaties van bloeddruk en hartperiode. Bij vergelijking van de nieuwe methode met een standaard methode bij verschillende onstandigheden blijkt dat de meuwe methode een goede overeenkomst geeft met de standaard methode.

Het grote voordeel van de in hoofdstuk 3 ontwikkelde methode is dat de BRS continu in vrij bewegende dieren kan worden bepaald. Deze methode is in hoofdstuk 4 gebruikt on te bepalen of de BRS een dag-nacht rime vertoont. Daaruaast zijn schommelingen in BRS, bloeddruk en hartfrequentie onderzocht met een periode tussen 5 minuten en uren (ultradiane ritmen). Deze onderzoeken zijn gedaan bij normotensieve en hypertensieve ratten. Tevens is de invloed van verschillende middelen onderzocht die het autonone zenuwstelsel beinvloeden. Met betrekking tot de BRS werd gevonden dat deze gedurende de gehele dag lager is in hypertensieve ratten, vergeleken met normotensieve ratten. Opvallend is dat de BRS zijn minimale waarde bereikt tijdens de overgang van de slaap naar de actieve periode, de periode waarin bij mensen het vóorkomen van myocardinfarcten is verhoogd. Het dag-rnacht ritme van de bloeddruk is sterk afhankelijk van de beinvloeding van het autonome zenuwstelsel. Na uitschakeling van het perifere autonome zenuwstelsel op farmacologische wijze is er geen dag-nacht verschil meer in de bloeddruk. Remming van het sympatisch autonoom zenuwstelsel 
van de bloedvaten leidt zelfs tot een lagere waarde van de bloeddruk tijdens de actieve periode. Spectrum analyse laat een zogenaamd $1 / f$ verband zien hussen spectrale vermogen en de frequentie. In het algemeen duidt een dergelijk $1 /$ f verband op het ontbreken van een dominant regelmechanisme en de aanwezigheid wan meerdere regelmechanismen met invloed in het onderzochtte frequentie gebied. Manipulatie van het autonome zenuwstelsel heeft relatief weinig effect op deze relatie. De hartfrequentie reageert zowel voor wat betreft het dag-nacht ritme als de ultradiane ritmes anders dan de bloeddruk. Het dag-nacht ritme van de hartfrequentie is weinig gevoelig voor remming van het autonome zenuwstelsel, en lijkt daamee voomamelijk athankelijk van intrinsieke cardiale mechanismen.

In hoofdstuk 5 is het dag-nacht ritme van het hartminuutvolume onderzocht, en de invloed die het autonoom zenuwstelsel en de aamwezigheid van hypertensie erop heeft. Ook zijn ritmen met een kortere periode en de slag-op-slag relatie lussen verschillende cardiovasculaire parameters onderzocht. Het blijkt dat het hartminuutvolume tijdens de actieve periode een hogere waarde heeft dan tijdens de slaap periode, en dat de waarden en het dag-nacht patroon bij de normotensieve en hypertensieve ratten vrijwel identiek zijn. Het grote verschil tussen normotensieve en hypertensieve ratten is de totale perifere weerstand die bij hypertensie verhoogd is. Het patroon is echter vergelijkbaar. Na blokkade van het cardiale autonome zenuwstelsel is het hartminuutvolume gedaald, en is het verschil tussen dag en nacht sterk verminderd. Het relatieve vermogen van het hartminuutvolume is ongeveer 2 keer zo groot als die van de bloeddruk in het onderzochtte frequentiebereik. Net als de bloeddruk en hartfrequentie in hoofdstuk 4, laten het hartminuutvolume en de totale perifere weerstand een $1 / f$ relatie zien tussen vermogen en frequentie in het periodebereik tussen enkele minuten en uren. Er zijn geen verschillen tussen normotensieve en hypertensieve ratten. De steilheid van de $1 / f$ relatie van de weerstand is verhoogd na autonome blokkade, waarschijnlijk als gevolg van het ontbreken wan de bufferende werking van de baroreflex. Uit de directe slag-op-slag vergelijking over 24 uur tussen bloeddruk en hartminuutvolume blijkt dat over deze periode het hartminuutvolume meer variabel is dan de bloeddruk, en ook dat er geen rechtsstreeks verband is tussen deze twee paramelers. Tussen totalle perifere weerstand en hartminutrolume bestaat wel een rechtstreekse relatie. Ondat de variabiliteit wan hartminuutvolume in het hele bereik van hoogfrequente schommelingen tot het dag-nacht ritme hoger is als die van de blocddruk lijkt het waarschijnlijk dat dit niet een centraal geregelde parameter is. De figuren van 24 uurs slag-op-slag relaties tussen hartfrequentie en andere parameters laten regelmatig meerdere pieken gezien. Aangezien deze pieken in aantal toenemen na cardiale blokkade is het waarschijnlijk dat deze door een intrinsiek mechanisme van het hart veroorzakit worden.

In hoofdstuk 6 is het effect van verschillende tijden van toediening bekeken van een aantal klassen van anti-hypertensiewe stoffen. Er zijn duidelijke verschillen in effectiviteit en werkingsduur gevonden. De sympaticolytische stoffen zijn het meest effectief in de periode dat de bloeddruk stijgt terwijl renale vaatverwijders als de $A C E$. remmer captopril en de beta-blokkeerder tertatolol meer effectief zijn bij toediening tijdens het begin van de slaap.

In hoofdstuk 7 is een aantal stoffen die het renine-angiotensine systeen beinvloeden met elkaar vergeleken. De stoffen zijn in deze studie op 5 achtereenvolgende 
dagen als infuus gegeven op twee verschillende tijdstippen. De gemiddelde bloeddrukdaling gedurende 24 uur is niet verschillend tussen een ochtend of een avond dosering, maar er zijn wel duidelijke verschillen in het patroon van de bloeddruk gedurende 24 uur. Het rate-pressure product, een maat voor de zuurstofconsumptie wan het hart, daalt tijdens de ochtend dosering sterker dan tijdens de avond dosering. Dit lijkt vooral bepaald door een sterkere hartfrequentie verhoging bij de avond dosering. Een interessant fenomeen tijdens deze studie is dat het anti-hypertensieve effect van deze middelen in de loop van een aantal dagen toenam, zonder dat dit te wijten kon zijn aan ophoping van de stoffen in het lichaam. Het lijkt erop dat de bloeddruk na enkele dagen van behandeling afhankelijk wordt van het angiotensine II, het hormoon dat onderdrukt wordt door deze middelen. De veranderingen in het patroon van de bloeddruk en hartfrequentie geven aan dat de tijdsafhankelijke toediening van ACE-remmers een bijdrage kunnen leveren aan de behandeling van hypertensie.

In dit proefschrift hebben we laten zien dat het mogelijk is om het patroon van de bloeddruk zodanig te veranderen dat de piekbelasting van risicofactoren die belangrijk zijn voor het ontstaan van myocardinfarct niet meer allen op hetzelfde tijdstip van de dag plaatsvinden. In het slothoofdstuk wordt de betekenis van deze observaties besproken in het kader van risicofactoren en behandelstrategieën bij hypertensieve patiënten. 


\section{Dankwoord}

Het maken wan een proefschrift doe je niet alleen. Daarom wil ik op deze plek graag een aantal mensen bedanken die een bijdrage hebben geleverd aan de totstandkoming ervan.

Allereerst Ben Janssen. Beste Ben, zonder jou was dit proefschrift niet af gekomen. Jouw ideeen zijn de uitgangspunten geweest voor de studies, en dit proefschrift laat ook duidelijk zien dat het onderzoek aan vrij bewegende, niet verdoofde dieren essentieel is in het onderzoek van de circulatie. Je bent steeds in staat geweest om de twijfels weg te nemen die ik had bij het schrijven van de verschillende hoofdstukken. Ik hoop dan ook dat je net zo blij bent als ik, dat het project na al deze jaren toch dit resultaat heeft opgeleverd.

Harry Struijker Boudier. Beste Harry, ik wil je graag bedanken voor je taak als promotor bij dit proefschrift. Jouw steun en begeleiding hebben een belangrijke rol gespeeld bij het gereed komen van het boekje.

Caroline Eerdmans. Beste Caroline, bedankt voor je hulp op het operatie lab. Je hebt er altijd voor gezorgd dat de dieren voor mijn experimenten perfect voorbereid waren.

Verder wil ik de rest van de wakgroep farmacologie bedanken voor de prettige samenwerking en de goede sfeer.

De medewerkers van de proefdiervoorzieningen, bedankt voor alle inspanningen voor het leveren van de ratten, en de hulp tijdens de verhuizing naar de nieuwbouw, waardoor het mogelijk was mijn experimenten te vervolgen in de kelder.

De instrumentele dienst. Bedankt voor alle snelte hulp bij problemen met het meet programma en het ontwikkelen van de nieuwe meetopstelling.

Ook wil ik graag iedereen bedanken die mijn verblijf in Maastricht zo aangenaam hebben gemaakt. De leden van de schermvereniging MAS in Contro, die doordrongen zijn van de prioriteit die een evaluatie van een training moet hebben. De zwemclub, die Elsbeth en mij bij elkaar gebracht heeft. De inwoners van \#descent en $\# w-e$, waar ik mijn eersie schreden op IRC deed.

Frits Knol en Jessica Jetten. Beste Jessica en Frits, bedankt voor de hulp bij de vormgeving en opmaak van dit proefschrift.

Als laatste mijn ouders. Pap, mam, ik wil jullie bedanken voor de wijze waarop jullie me altijd hebben gesteund in mijn keuzes. 


\section{Curriculum Vitae}

1975-1981 Atheneum B te Groningen

1981-1989 Studie Geneeskunde te Groningen

1989-1991 Dienstplicht, vervuld in het militair revalidatie centrum te Doorn

1991 Tijdelijk werk in verpleeghuizen te Almen, Deventer en Lelystad

1991-1996 Assistent in Opleiding bij afdeling farmacologie Liniversiteit

Maastricht. Project 'Circadiane variabiliteit van bloeddruk regulatie mechanismen bij hypertensie"

1997-heden Arts-onderzoeker bij afdeling Pathologie LUMC Leiden. Project 'Blob Informatie en Presentatie Systeem.

\section{Publicaties}

\section{Full papers}

- Janssen BJA, Oosting J, Tyssen CM, Stuyker-Boudier HAJ: Time-dependent efficacy of antihypertensive agents in spontaneously hypertensive rats. Chronobiol Int 1993; 10: 420-434.

-. Janssen B.JA, Oosting I, Slaaf DW, Persson PB, Struyker-Boudier HA J: Hemodynamic basis of ascillations in systemic arterial pressure in conscious rats. Am J Physio 1 1995; 269: H62-H71.

- Oosting J, Struijker-Boudier HAJ, Janssen BJA: Validation of a continuous baroneceptor reflex sensitiwity index calculated from spontaneous fluctuations of blood pressure and pulse interval in rats. J Hypertens 1997; 15:391-399.

- Oosting J, Struijker-Boudier HAJ, Janssen BJA: Autonomic control of ultradian and circadian rhythms of blood pressure, heart rate, and baroreflex sensitivity in spontaneously hypertensive rats. $J$ Hypertens 1997; 15: 401-410.

- Oosting J, Strijker-Boudier HAJ, Janssen BJA: Circadian and ultradian control of cardiac output in spontaneous hypertension in rats. Am J Physiol 1997; 273: H66$\mathrm{H} 75$.

\section{Abstracts}

* Oosting J, Tyssen $\mathrm{CM}_{\text {, }}$ Struijker-Boudier HAJ, Janssen BJA; Effects of angiotensin converting enzyme imhibitors on the early morning rise in blood pressure in rats; Pharm Whbl Sci Ed 1992: $14 ; \mathrm{H} 10$

- Oosting J, Eerdmans Tyssen CM, Janssen BJA: Baroreflex sensitivity in rats: validation of methods using spontaneous blood pressure changes. Elw J Phystol (Pflugers Arch) 1993; 424: R6.

- Oosting I, Struijker-Boudier HAJ, Janssen BJA; Role of the batoreflex in the hypotensive response following short-term phenylephrine-induced pressor effects. I Hypertens: 1996; 14: S112, abstract $\mathrm{P} 470$.

- Oosting J, Eerdmans-Tyssen CM, Janssen BJA; Chronophamacology of Propranolol and Captopril in Spontaneously hypertensive rats; Phar Tox 1993; 72: Suppl II 453

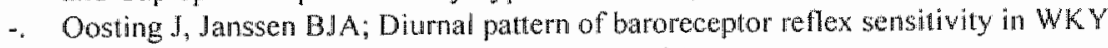
and SHR rats; Phor Wrld Scno 1993: 15:6 Suppl I

- Janssen BJA, Oosting J, Struijker-Boudier HAJ; Chronopharmacology of antihypertensives in spontaneously hypertensive rats; Canj Phys Phas 1994 : 72:Supp 1;137 
- Oosting I, Janssen BJA, Struijker-Boudier HAJ; 24 hour baroneceptor reflex controll in WKY and SHR rats;Canj Phys Phar 1994: 72:Suppl 1;608

- Oosting $J_{\text {s }}$ Struijker-Boudier HAJ, Janssen BJA; Intermittent infusions of wasoconstrictive agents cause hypotension in the drug-free period in SHR; Phar Wrld Scne $199416: 6$ Suppl $J ; 12$ 

